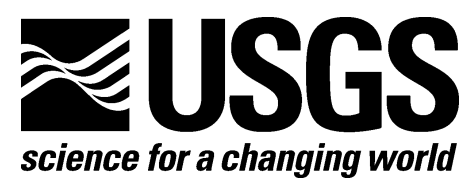

\title{
Assessment of Effectiveness and Limitations of Habitat Suitability Models for Wetland Restoration
}

By Rassa O. Draugelis-Dale

Open-File Report 2007-1254

U.S. Department of the Interior

U.S. Geological Survey 


\section{U.S. Department of the Interior DIRK KEMPTHORNE, Secretary}

\section{U.S. Geological Survey Mark D. Myers, Director}

U.S. Geological Survey, Reston, Virginia 2008

For product and ordering information:

World Wide Web: http://www.usgs.gov/pubprod

Telephone: 1-888-ASK-USGS

For more information on the USGS - the Federal source for science about the Earth, its natural and living resources, natural hazards, and the environment:

World Wide Web: http://www.usgs.gov

Telephone: 1-888-ASK-USGS

Suggested citation:

Draugelis-Dale, Rassa, 2008, Assessment of effectiveness and limitations of habitat suitability models for wetland restoration: U.S. Geological Survey Open-File Report 2007-1254, 136 p.

Any use of trade, product, or firm names is for descriptive purposes only and does not imply endorsement by the U.S. Government.

Although this report is in the public domain, permission must be secured from the individual copyright owners to reproduce any copyrighted material contained within this report. 
The habitat suitability index models presented in this report are hypotheses of associations between species and habitat suitability and not assertions of any proven cause-andeffect relationships. Many of the models have not been tested in the field. Preexisting models from Florida and Louisiana have been critically examined, and any corrections or clarifications are incorporated in the model presentations throughout this report, with author or developer consultation or approval. Synchronization of mathematical/scientific nomenclature or notation is emphasized. Any additional variables and theory expansion or alternatives are included where deemed necessary (see footnote indications). Proposed models for the Louisiana Coastal Area Study are presented in detail as well as in a condensed format (appendixes 1 and 2) and are subject to change with improved field observations and information. Please direct any comments or correspondence as well as any intent of usage of part or all of the proposed models to Rassa Dale, U.S. Geological Survey, National Wetlands Research Center, 700 Cajundome Blvd., Lafayette, LA 70506. 
Table of Contents

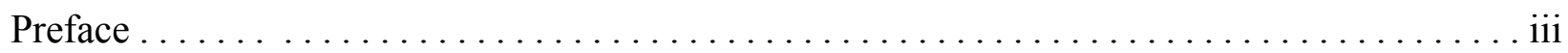

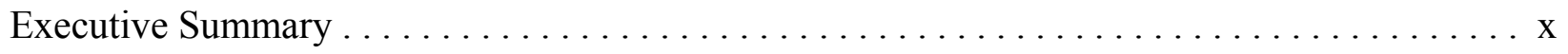

Chapter 1 Assessing Effectiveness and Limitations of Habitat Suitability Models for

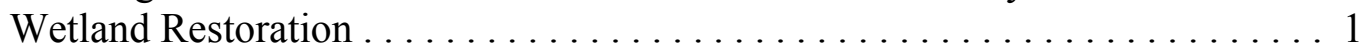

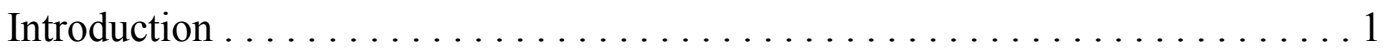

Louisiana Ecosystem Model . . . . . . . . . . . . . . . . . . 4

Summary of Subprovince Hydrodynamic Models . . . . . . . . . . . . 6

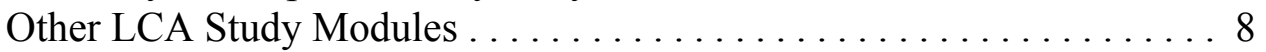

Benefits Assessment Protocols . . . . . . . . . . . . . . . . 9

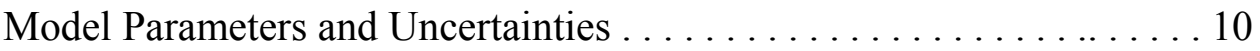

Chapter $2 \quad$ Habitat Suitability Index (HSI) Models $\ldots \ldots \ldots \ldots \ldots \ldots \ldots \ldots \ldots \ldots \ldots 13$

Chapter $3 \quad$ Spatially Explicit Species Index (SESI) Models . . . . . . . . . . . . . . . . 15

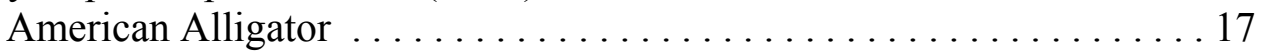

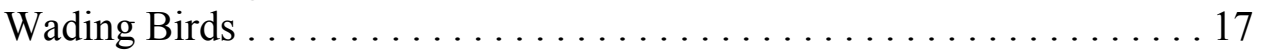

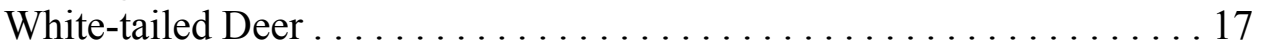

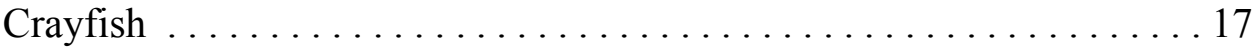

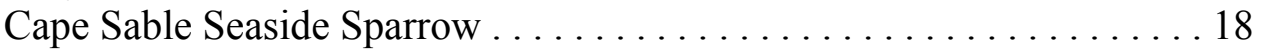

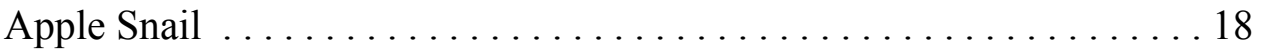

Snail Kite . . . . . . . . . . . . . . . . . . . . . . 18

Chapter $4 \quad$ The American Alligator Models . . . . . . . . . . . . . . . . . . . . . 19

American Alligator . . . . . . . . . . . . . . . . . . . . . 19

Alligator Habitat Suitability Index of Louisiana . . . . . . . . . . . . . 19

Alligator Habitat Suitability Index (HSI) of Florida . . . . . . . . . . . . 22

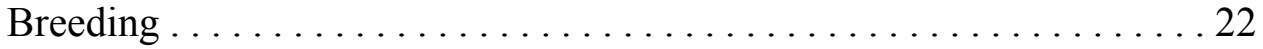

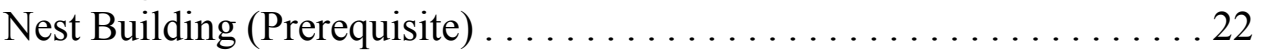

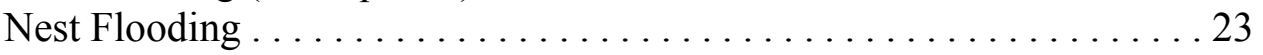

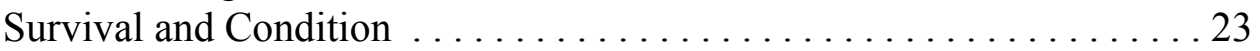

Habitat Suitability Index . . . . . . . . . . . . . . . . . 24

Evaluation of Alligator HSI Performance in Florida . . . . . . . . . . . . . . 24

Alligator Spatially Explicit Species Index (SESI) of Florida . . . . . . . . . . 26

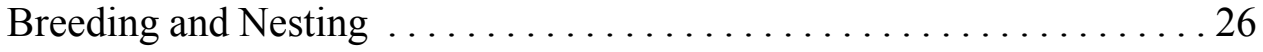

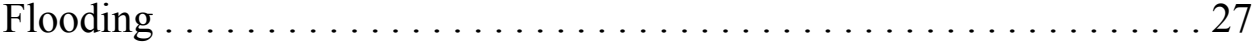

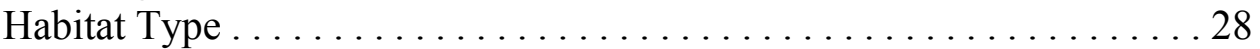

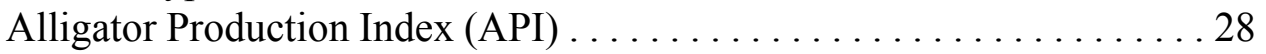

Comparison of Florida Alligator HSI and SESI Models . . . . . . . . . . . . . 29

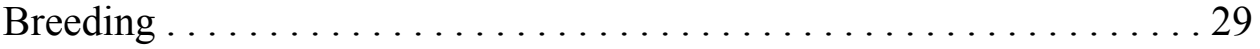

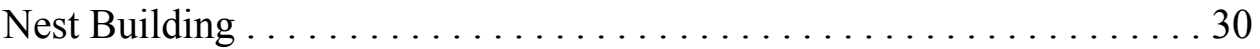

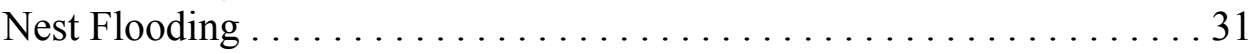

Total Suitability Index . . . . . . . . . . . . . . . . . 33

Comparison of All Alligator Models . . . . . . . . . . . . . . . . . 34

Statistical Analyses . . . . . . . . . . . . . . . . . . . . . . . . 39 
General Evaluation of All Alligator Models . . . . . . . . . . . . . . . . 40

Florida Models . . . . . . . . . . . . . . . . . . . . . . . 40

Scoring All Models by Factor Categories . . . . . . . . . . . . . . . 41

Assessment of the Alligator Models . . . . . . . . . . . . . . . . 43

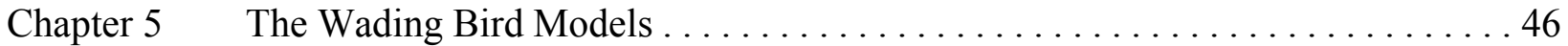

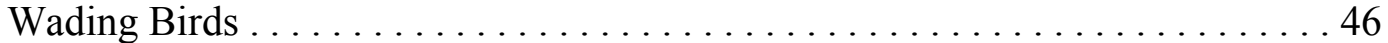

Great Blue Heron . . . . . . . . . . . . . . . . . . . . . . . . . 46

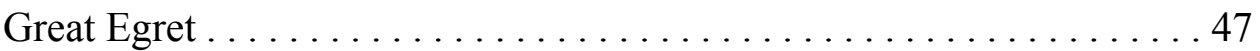

White Ibis . . . . . . . . . . . . . . . . . . 47

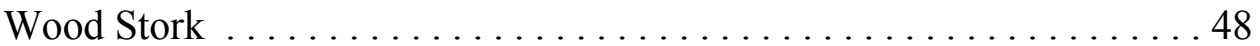

General Wading Bird Habitat Suitability Indices (Louisiana) . . . . . . . . . . . . 49

Great Blue Heron . . . . . . . . . . . . . . . . . . . . . . . . . . . . 49

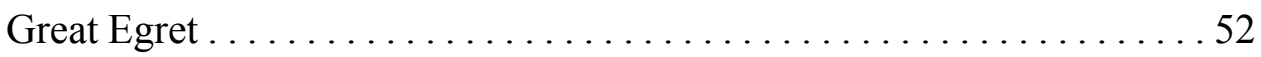

White Ibis . . . . . . . . . . . . . . . . . . . . . 55

Comparison of General HSI Models for Great Blue Heron, Great Egret, and

White Ibis . . . . . . . . . . . . . . . . . . . . . . . . . 57

Recommendations ........................664

Florida Wading Bird Habitat Suitability Models . . . . . . . . . . . . . . . . . 65

Wading Bird Habitat Suitability Index (HSI) of Florida . . . . . . . . . . . . 65

Water Depth . . . . . . . . . . . . . . . . . . . . . . . 65

Water Recession Rate ... . . . . . . . . . . . . . . . . 66

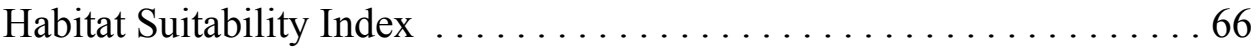

Evaluation of Wading Bird HSI Performance in Florida . . . . . . . . . . . . 67

Wading Bird Spatially Explicit Species Index (SESI) of Florida . . . . . . . . 70

Parameters . . . . . . . . . . . . . . . . . . . . . . . 70

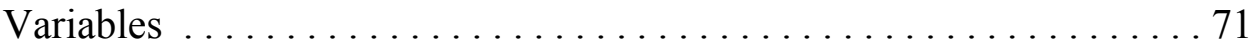

Total Wading Bird Suitability Index $\ldots \ldots \ldots \ldots \ldots \ldots \ldots \ldots . \ldots \ldots$

Comments Concerning SESI Model Definitions . . . . . . . . . . . . . . . 75

Comparison of Florida Wading Bird SESI and HSI Models . . . . . . . . . . 76

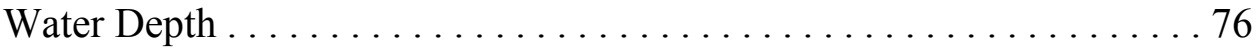

Water Recession . . . . . . . . . . . . . . . . . . 76

Total Suitability Index . . . . . . . . . . . . . . . . . . . . . . . . 77

Comparison of Florida Models with General HSI Models . . . . . . . . . . 78

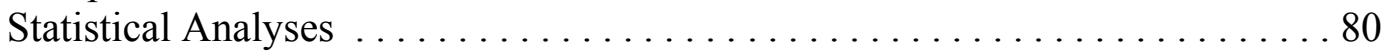

General Evaluation of All Wading Bird Models . . . . . . . . . . . . . . 80

Scoring All Models by Factor Categories . . . . . . . . . . . . . . . . 81

Assessment of the Wading Bird Models . . . . . . . . . . . . . 85

Chapter 6 Assessment and Recommendations for Louisiana and Florida Models . . . . . . 87

General Assessment . . . . . . . . . . . . . . . . . . . . . . . . . 87

Recommendations for the Alligator LCA Study Model $\ldots \ldots \ldots \ldots \ldots \ldots . . \ldots 9$ 
Proposed LCA Study Model for Alligators . . . . . . . . . . . . . . . . 91

Water Depth Component and Final Index .................... 93

Evaluation of Proposed Alligator LCA Study Model ................. 93

Recommendations for the Wading Bird LCA Study Model . . . . . . . . . . 101

Proposed LCA Study Model for Wading Birds . . . . . . . . . . . . . . . . 101

Foraging Information ............................ 103

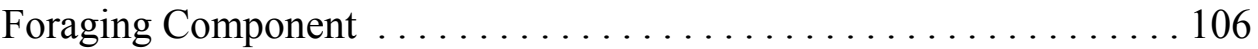

Nesting Colony Information . . . . . . . . . . . . . . . . . 107

Nesting Component ................................... 109

Final Index ...................................... 109

Evaluation of Proposed Wading Bird LCA Study Model . . . . . . . . . . . 111

Conclusion . . . . . . . . . . . . . . . . . . . . . . . . . . . 127

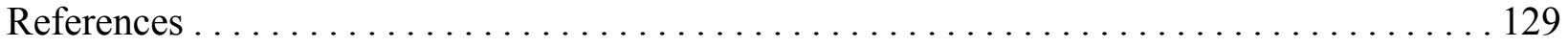

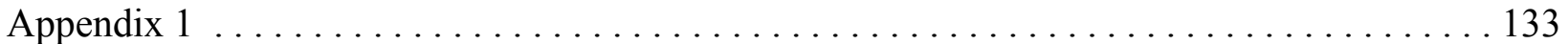

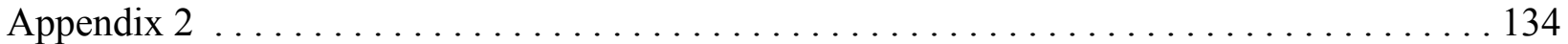

\section{Figures}

1. Marsh zones of coastal Louisiana, modified with permission from Chabrek, $1970 \ldots \ldots \ldots 3$

2. The five modules with their appropriate linkages (U.S. Army Corps of Engineers, 2004) . .4

3. LCA study area subprovinces 1-4 (U.S. Army Corps of Engineers, 2004) . . . . . . . . 5

4. Suitability for breeding. The HSI model is the solid line; the SESI model is the dotted line. Modified with permission from Rice and others (2004) . . . . . . . . . . . . . . . . 29

5. Suitability for nest building. The HSI model is the solid line; the SESI model is the dotted line. The horizontal solid line shows the suitability threshold at index value of 0.5 . Modified with permission from Rice and others (2004) ..................30

6. Suitability for nest nonflooding. The HSI model is the solid line; the SESI model is the dotted line. Modified with permission from Rice and others (2004) .............. 31

7. Wetland habitat types of coastal Louisiana. $A$, Swamp and three marsh types (adapted from Portnoy, 1977). B, All four marsh types with acreages (including intermediate marsh), adapted with permission from Chabrek (1972) ....................... 45

8. Water depth. The HSI model is the solid line; the SESI long-legged model is the long dotted line; and the SESI short-legged model is the short dotted line. Modified with permission

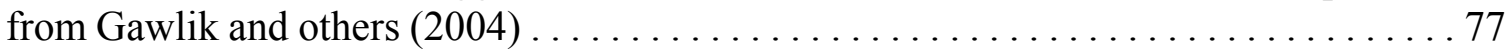

\section{Tables}

1. Comparison of all habitat suitability index (HSI) models for the American alligator (Alligator mississippiensis). Setting 1. Florida models are denoted as SESI (F) and HSI (F), general HSI model as HSI (G), and LCA study HSI model as HSI (L). Final index

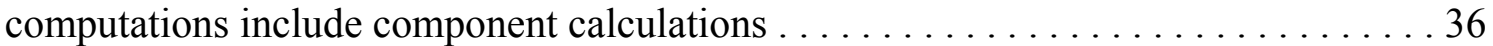

2. Comparison of all habitat suitability index (HSI) models for the American alligator (Alligator mississippiensis). Setting 2. Florida models are denoted as SESI (F) and HSI (F), general HSI model as HSI (G), and LCA study HSI model as HSI (L). Final index 
computations include component calculations . ................... 37

3. Comparison of all habitat suitability index (HSI) models for the American alligator (Alligator mississippiensis). Setting 3. Florida models are denoted as SESI (F) and HSI (F), general HSI model as HSI (G), and LCA study HSI model as HSI (L). Final index

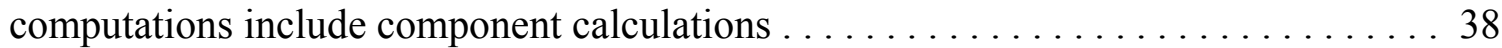

4. Scoring of the American alligator (Alligator mississippiensis) models by factor categories. Florida models are denoted as SESI (F) and HSI (F), general HSI model as HSI (G), and LCA study HSI model as HSI (L). Scoring of categories: high (well represented or defined), mod (moderately represented), or low (lacking or poorly defined) . . . . . . . . . . . . . . . . . . . . . . . . . . . . 42

5. Comparison of all general habitat suitability index (HSI) models for the wading birds: great blue heron (Ardea herodias), great egret (Ardea alba), and white ibis (Eudocimus albus). Setting 1. Final index computations include component calculations ....... 59

6. Comparison of all general habitat suitability index (HSI) models for the wading birds: great blue heron (Ardea herodias), great egret (Ardea alba), and white ibis (Eudocimus albus). Setting 2. Final index computations include component calculations . . . . . 60

7. Comparison of all general habitat suitability index (HSI) models for the wading birds: great blue heron (Ardea herodias), great egret (Ardea alba), and white ibis (Eudocimus albus). Setting 3. Final index computations include component calculations .......61 61

8. Comparison of all general habitat suitability index (HSI) models for the wading birds: great blue heron (Ardea herodias), great egret (Ardea alba), and white ibis (Eudocimus albus). Setting 4. Final index computations include component calculations .......62 62

9. Comparison of foraging water depths in all habitat suitability index (HSI) models for the wading birds: great blue heron (Ardea herodias), little blue heron (Egretta caerulea), great egret (Ardea alba), white ibis (Eudocimus albus), and wood stork (Mycteria americana), separated by short- and long-legged groups. Setting 1. Florida models are

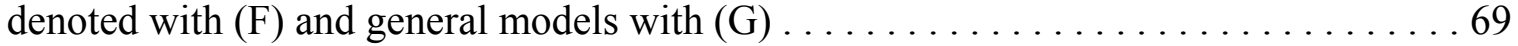

10. Comparison of foraging water depths in all habitat suitability index (HSI) models for the wading birds: great blue heron (Ardea herodias), little blue heron (Egretta caerulea), great egret (Ardea alba), white ibis (Eudocimus albus), and wood stork (Mycteria americana), separated by short- and long-legged groups. Setting 2. Florida models are denoted with $(\mathrm{F})$ and general models with $(\mathrm{G}) \ldots \ldots \ldots \ldots \ldots \ldots \ldots$

11. Comparison of water depth, percent of area and foraging radius in Spatially Explicit Species Index (SESI) models for the wading birds: great blue heron (Ardea herodias), great egret (Ardea alba), snowy egret (Egretta thula), and wood stork (Mycteria americana) as long-legged birds; white ibis (Eudocimus albus) and little blue heron (Egretta caerulea) as short-legged birds. Setting $1 \ldots \ldots \ldots \ldots \ldots \ldots \ldots . \ldots . \ldots . \ldots 79$

12. Comparison of water depth, percent of area and foraging radius in Spatially Explicit Species Index (SESI) models for the wading birds: great blue heron (Ardea herodias), great egret (Ardea alba), snowy egret (Egretta thula), and wood stork (Mycteria americana) as long-legged birds; white ibis (Eudocimus albus) and little blue heron (Egretta caerulea) as short-legged birds. Setting $2 \ldots \ldots \ldots \ldots \ldots \ldots \ldots . \ldots . \ldots . \ldots 79$

13. Scoring of the wading bird models by factor categories, separated by short- and longlegged groups. Florida models are denoted as SESI (F) and HSI (F), and general HSI 
models as HSI (G) for the great blue heron (Ardea herodias), great egret (Ardea alba), wood stork (Mycteria americana), and white ibis (Eudocimus albus). Scoring of categories: high (well represented or defined), mod (moderately represented), or low

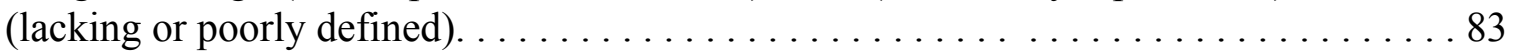

14. Comparison of all habitat suitability index (HSI) models for the American alligator (Alligator mississippiensis) with the proposed LCA study model. Setting 1. The Florida model is denoted as HSI (F), the LCA study HSI model as HSI (L), and the proposed model (geometric mean with water component) as HSI (new L). An alternate HSI formula (arithmetic mean) for the proposed model is denoted as Alt HSI. Included at the bottom is the value of the general HSI model denoted as HSI (G) with no intermediate computations.

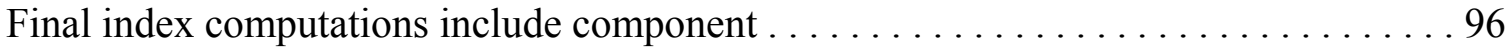

15. Comparison of all habitat suitability index (HSI) models for the American alligator (Alligator mississippiensis) with the proposed LCA study model. Setting 2. The Florida model is denoted as HSI (F), the LCA study HSI model as HSI (L), and the proposed model (geometric mean with water component) as HSI (new L). An alternate HSI formula (arithmetic mean) for the proposed model is denoted as Alt HSI. Included at the bottom is the value of the general HSI model denoted as HSI $(\mathrm{G})$ with no intermediate computations.

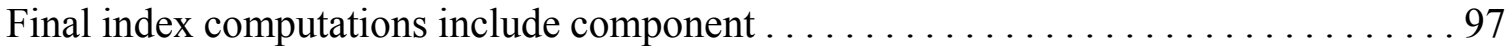

16. Comparison of all habitat suitability index (HSI) models for the American alligator (Alligator mississippiensis) with the proposed LCA study model. Setting 3. The Florida model is denoted as HSI (F), the LCA study HSI model as HSI (L), and the proposed model (geometric mean with water component) as HSI (new L). An alternate HSI formula (arithmetic mean) for the proposed model is denoted as Alt HSI. Included at the bottom is the value of the general HSI model denoted as HSI (G) with no intermediate computations.

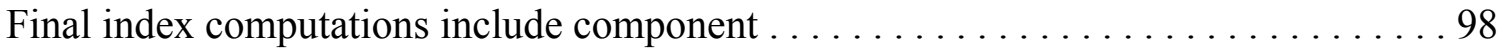

17. Comparison of all habitat suitability index (HSI) models for the American alligator (Alligator mississippiensis) with the proposed LCA study model. Setting 4. The Florida model is denoted as HSI (F), the LCA study HSI model as HSI (L), and the proposed model (geometric mean with water component) as HSI (new L). An alternate HSI formula (arithmetic mean) for the proposed model is denoted as Alt HSI. Included at the bottom is the value of the general HSI model denoted as HSI (G) with no intermediate computations.

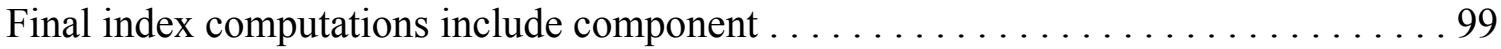

18. Comparison of all habitat suitability index (HSI) models for the American alligator (Alligator mississippiensis) with the proposed LCA study model. Setting 5. The Florida model is denoted as HSI (F), the LCA study HSI model as HSI (L), and the proposed model (geometric mean with water component) as HSI (new L). An alternate HSI formula (arithmetic mean) for the proposed model is denoted as Alt HSI. Included at the bottom is the value of the general HSI model denoted as HSI $(\mathrm{G})$ with no intermediate computations. Final index computations include component . . . . . . . . . . . . . . . . 100

19. Abundance values as percentage of total breeding adults for wading birds: great blue heron (Ardea herodias), great egret (Ardea alba), and white ibis (Eudocimus albus). . 102

20. Comparison of general habitat suitability index (HSI) models for wading birds with the proposed LCA study models, separated by short- and long-legged groups. Setting 1 
(versions 1 (v. 1) and 2 (v. 2)). Wading birds include: great blue heron (Ardea herodias), great egret (Ardea alba), and white ibis (Eudocimus albus). General HSI models are denoted as HSI (G) and the proposed model as HSI (new L). Final index computations include

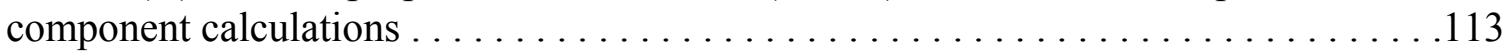

21. Comparison of general habitat suitability index (HSI) models for wading birds with the proposed LCA study models, separated by short- and long-legged groups. Setting 2 (versions 1 (v. 1) and 2 (v. 2)). Wading birds include: great blue heron (Ardea herodias), great egret (Ardea alba), and white ibis (Eudocimus albus). General HSI models are denoted as HSI (G) and the proposed model as HSI (new L). Final index computations include component calculations .................................... 115

22. Comparison of general habitat suitability index (HSI) models for wading birds with the proposed LCA study models, separated by short- and long-legged groups. Setting 3 (versions 1 (v. 1) and 2 (v. 2)). Wading birds include: great blue heron (Ardea herodias), great egret (Ardea alba), and white ibis (Eudocimus albus). General HSI models are denoted as HSI (G) and the proposed model as HSI (new L). Final index computations include component calculations . .................................. 117

23. Comparison of general habitat suitability index (HSI) models for wading birds with the proposed LCA study models, separated by short- and long-legged groups. Setting 1 (versions 3 (v. 3) and 4 (v. 4)). Wading birds include: great blue heron (Ardea herodias), great egret (Ardea alba), and white ibis (Eudocimus albus). General HSI models are denoted as HSI (G) and the proposed model as HSI (new L). Final index computations include component calculations ..................................... 121

24. Comparison of general habitat suitability index (HSI) models for wading birds with the proposed LCA study models, separated by short- and long-legged groups. Setting 2 (versions 3 (v. 3) and 4 (v. 4)). Wading birds include: great blue heron (Ardea herodias), great egret (Ardea alba), and white ibis (Eudocimus albus). General HSI models are denoted as HSI (G) and the proposed model as HSI (new L). Final index computations include

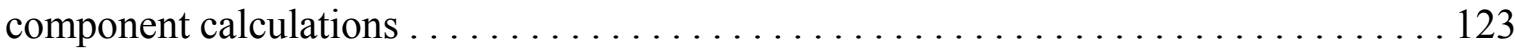

25. Comparison of general habitat suitability index (HSI) models for wading birds with the proposed LCA study models, separated by short- and long-legged groups. Setting 3 (versions 3 (v. 3 ) and 4 (v. 4)). Wading birds include: great blue heron (Ardea herodias), great egret (Ardea alba), and white ibis (Eudocimus albus). General HSI models are denoted as HSI (G) and the proposed model as HSI (new L). Final index computations include component calculations ..................................... 125

\section{Conversion Factors}

\begin{tabular}{lll} 
Multiply & By & To obtain \\
\hline feet $(\mathrm{ft})$ & 0.3048 & meter $(\mathrm{m})$
\end{tabular}




\section{Executive Summary}

Habitat suitability index (HSI) models developed for wildlife in the Louisiana Coastal Area Comprehensive Ecosystem Restoration Plan (LCA study) have been evaluated for parameter and overall model quality. Parameter uncertainties and oversimplification of HSI models were noted. The success of the HSI models from the South Florida Water Management District for The Everglades restoration project and from the Spatially Explicit Species Index Models (SESI) from the Across Trophic Level System Simulation (ATLSS) Program of Florida warranted investigation with possible application of modeling theory to the current LCA study. Since the grid scales were highly incompatible across certain models, any spatial or geostatistical comparisons were not feasible. Instead, examinations of theoretical formulae and comparisons of the models made by using diverse hypothetical settings of hydrological or biological ecosystems were used to highlight weaknesses as well as strengths among the models. These were assessed, and recommendations were made for the LCA study.

An enhanced HSI model for the LCA study is proposed for alligators. A new HSI model for wading birds, separated for long- and short-legged groups, is introduced for the LCA study. These proposed models are summarized in a condensed format in appendixes 1 and 2. Both HSI models are compatible with the current structure of the models used in the LCA study and are based on data from the LCA study, the Florida models (HSI and SESI), and the general HSI models developed by the U.S. Fish and Wildlife Service (USFWS). Performance comparisons of the proposed models with other suitability models are made by using the hypothetical settings.

Florida SESI and HSI models are region-specific for The Everglades and introduce certain features that cannot be readily implemented in the current model framework of the LCA study. The general HSI models, however, are more broadly defined for all coastal wetlands throughout the United States but also include additional features. Thus, a scoring system is employed to measure the effectiveness of all features across the models, from which a subset is selected that represents the best-applicable features for the current design of the LCA study models. The intention of the subset selection is to simplify or eliminate extensive data measurements of some models but to retain important basic information that uses accessible data.

The development process for the HSI models proposed for the LCA study involves synchronization of the selected features across all relevant models. A compromise is usually reached for optimal suitability ranges, often by averaging several limit values and/or tapering to extended limits, frequently resulting in wider ranges. Furthermore, the proposed models conglomerate more features from all models and contain more information than individual models. Also, different formula options are considered (arithmetic versus geometric means). Consequently, the proposed suitability index value is usually higher than in other models. This may be biologically inferred as an increase of acceptable sites, since wildlife could instinctively adapt to hydrological or biological ecosystem variations and be found in uncommon sites in the coastal regions. The HSI models proposed for the LCA study have not been field tested and are subject to modifications of variable definitions and calibrations of specific limit values. 


\section{Chapter 1 \\ Assessing Effectiveness and Limitations \\ of Habitat Suitability Models for Wetland Restoration}

\section{$\underline{\text { Introduction }}$}

Worldwide, there is a constant conflict between maintaining economic development and minimizing ecological damage to natural systems (Houghton, 1994). Many industries depend on the input and sustenance of natural resources; therefore, a critical balance needs to be preserved throughout time (Constanza and Daly, 1991). Over the past several years, there have been increased efforts for ecological restoration that involve physical compensations of altered land use, as well as development of strategies for improved ecosystem management policies.

Historically, the coastal regions have supported greater human development, such as recreational and commercial industries (fishing and hunting sport activities, fisheries, transport or navigation, and natural energy extractions of oil and gas). These activities, however, are associated with observed, significant coastal wetland loss and degradation, which are identified as major national critical problems affecting mainly the Mississippi River Delta Plain and central gulf coast regions (U.S. Army Corps of Engineers [USACE], 2004). The Mississippi delta is composed of over 4 million hectares of wetlands, lakes, and bays, formed by the deposition of sediments from the Mississippi River (Roberts, 1977). Two distinct geomorphic regions (fig. 1) have developed over the progression of 7,000 years: an eastern deltaic plain and southwestern chenier plain (Boesch and others, 1994; Chabreck, 1972; Fisk and others, 1954; Gould and McFarlan, 1959). Changes in the course of the river over time have affected and altered the formation of both the deltaic (a continuous subsidence process directly associated with the river) and the chenier plains (formed from river sediment carried by long-shore currents in the Gulf of Mexico). These two regions have major disparities in hydrology and marsh formation, in part because of the difference in subsidence rates, where the deltaic plain's rate $(1 \mathrm{~cm} / \mathrm{yr})$ is twice that of the chenier plain $(0.57 \mathrm{~cm} / \mathrm{yr})$. The rate dissimilarities are related to the erosion of Pleistocene surfaces followed by deposition of silts to depths of $200 \mathrm{~m}$ in the deltaic plain and to $15 \mathrm{~m}$ in the chenier plain (Penland and Suter, 1989). Apparently, less erosion occurred in the chenier plain since the river never actually flowed directly through the region. The marshes also show contrasting patterns of development. In the deltaic plain, initially freshwater marshes at the mouths transformed to saline, whereas the reverse occurred in the chenier plain, where saline marshes in the gulf converted to freshwater marshes when formation of new marshes and cheniers isolated them inward from the gulf. 
The Louisiana coastal regions have the highest wetland loss rate in the Nation. This loss is mainly attributed to reductions in freshwater and sediment inputs, where rises in salinity or sea level have resulted from land subsidence, as well as to reductions in river sediment delivery and deposition caused by levees, canals, and impoundments (Kesel, 1988; Templet and MeyerArendt, 1988; Day and others, 1997; Swenson and Turner, 1987; Turner and Cahoon, 1987; Reed and Fuller, 1995; Craig and others, 1979; Connor and Day, 1987). Wetland ecosystems are thereby destabilized, converting marsh to open water. Furthermore, wetland loss is not only observed in the marsh edges but also in the submergence of interior marshes. Other environmental factors contributing to wetland loss include global warming, climate, precipitation, hydroperiods, and regional (geomorphological) and local (topographical) features. For coastal Louisiana, the most important stress factors are sediment and nutrient deprivation due to river diversions, increased salinity, and fluctuating flooding levels (USACE, 2004).

The biological diversity and productivity of the Mississippi River Delta Plain define the most vast wetland landscape, together with the largest fishery and migratory bird habitats, in the United States. Consequently, the preservation of this biodiversity of plant, fish, and wildlife habitats is monumentally threatened by wetland alterations.

In response, the Louisiana Coastal Area (LCA) Comprehensive Ecosystem Restoration Plan (LCA study) is being developed to investigate the acceleration in wetland loss and to recommend ecological restoration strategies and policies for ecosystem management (USACE, 2004) based on the Comprehensive Everglades Restoration Plan of Florida. Specifically, the LCA study will establish the guidelines for designing and evaluation processes by generating conceptual ecological models; that is, by associating theoretical modeling concepts with ecological assessment and rehabilitation to assist in defining ecological needs and restoration benefits. Modeling offers an effective, inexpensive, and easily-implemental procedure to help understand how certain ecological mechanisms regulate the community structure and ecosystem function. Outcomes generated by modeling restoration alternatives or manipulations, based on geomorphic and hydrodynamic processes, include: (1) determination, prediction, monitoring, and validation of rates of wetland loss; (2) land to water ratio computations; (3) nutrient content modifications; and (4) biological ecosystem responses provided as habitat suitability index (HSI) models.

Similarly, the South Florida Water Management District has already constructed HSI models for The Everglades restoration (Tarboton and others, 2004). In addition, the U.S. Geological Survey has developed the Across Trophic Level System Simulation (ATLSS) program (The Institute for Environmental Monitoring [TIEM], 2004b; Curnutt and others, 2000). This set of spatially explicit species index (SESI) models has been utilized in The Everglades/Big Cypress regions of Florida to likewise predict biological responses of selected species to diverse scenarios of projected alterations in the hydrologic regimes.

In addition, there are also general HSI models developed by the U.S. Fish and Wildlife Service (USFWS). These species-specific models offer universalized methodologies to assess broader spectrums of habitat throughout the United States. 
In the hierarchical approach to restoration efforts, the decisive level of success is ultimately determined by the biological ecosystem response. A biological response is measured by a species productivity and population dynamics. For a given species, the index value of habitat capacity, generated by any of the above models, is usually computed by combining hydrodynamic factors (for example, water depths or land to water ratios), habitat type, and specific breeding or nesting characteristics of the species.

The objective of this report is to evaluate different habitat suitability models for selected species and to consider plausible adaptations to the LCA study:

1. Compare the SESI with HSI models of Florida or provide a methodology. Compare both Florida models (SESI and HSI) with the LCA study models.

2. Compare the species-specific general HSI models by the USFWS with HSI models of Florida and the LCA study.

3. Propose recommendations for improvements in the LCA study models.

Because of the size and scope of this report, the comparisons were limited to only the American alligator (Alligator mississippiensis) and several species of wading birds (great blue heron (Ardea herodias L.), great egret (Ardea alba L.), and white ibises (Eudocimus albus)).

The remainder of this chapter is devoted to the extensive assessment of the LCA study (USACE, 2004). General features of multiple HSI models and the Florida SESI model are presented in chapters 2 and 3. Detailed theoretical and performance comparisons in various hypothetical settings for the American alligator and several species of wading birds are provided in chapters 4 and 5, respectively. Limitations on the nature of comparisons between models are explicitly given. Chapter 6 closes with a final assessment and recommendations based on all model theoretical and performance comparisons. Two models are proposed for the LCA study, an enhanced American alligator HSI model and a newly developed HSI model for wading birds.

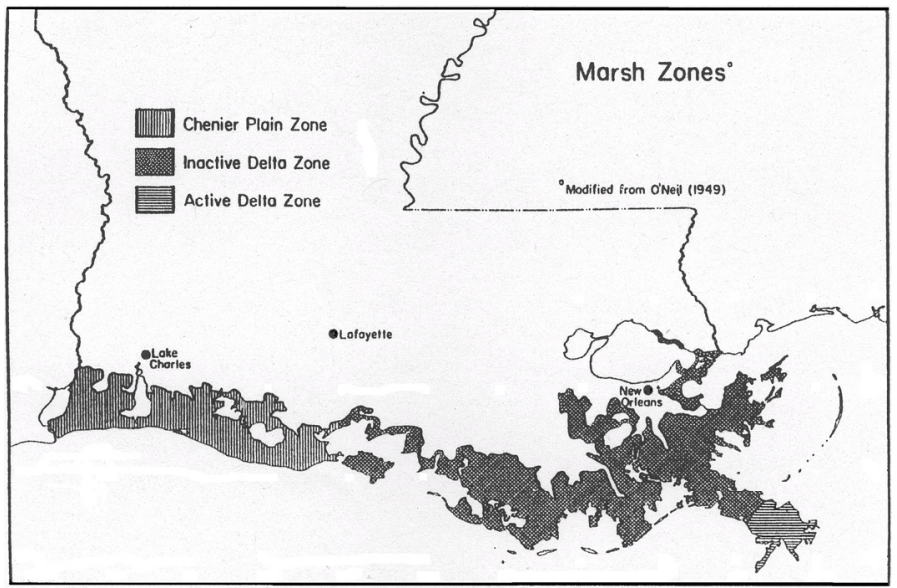

Figure 1. Marsh zones of coastal Louisiana, modified with permission from Chabrek, 1970. 


\section{$\underline{\text { Louisiana Ecosystem Model }}$}

The goals of LCA over the next 50 years are to reduce the rate of wetland loss by at least one-half, as well as to conserve the current total wetland area or build the area by one-half of its present level (USACE, 2004). The conceptual models developed, known collectively as the LCA Ecosystem Model, should predict all processes on spatial and temporal scales in order to recommend adjustments that will promote natural processes to restore the wetlands. The productivity of the wetland ecosystem is a weighted balance along gradients of resources (nutrients), regulators (salinity), and hydroperiod. Through modeling, the objective of the LCA study is to search for an optimum balance to reduce the stress and increase productivity. This, in turn, influences the habitat use by fauna and subsequently defines and delimits the nature of modeling for habitat suitability in wetlands.

Modeling procedures construct algorithms and calculate benefits for specific input manipulations. The LCA Ecosystem Model consists of five stages: (1) define the alternatives that cause a specific amount of environmental change; (2) using these alternatives, estimate the change in the five modules of "hydrodynamics," "land-building," "habitat switching," "habitat use," and "water quality"; (3) use the output produced from some modules as input to other modules, where appropriate; (4) combine the module outputs in a series of calculations that determine the benefit response; and (5) evaluate the original alternatives by using these benefits in comparison to the initial objectives. The linkages between the different modules are presented in figure 2 .

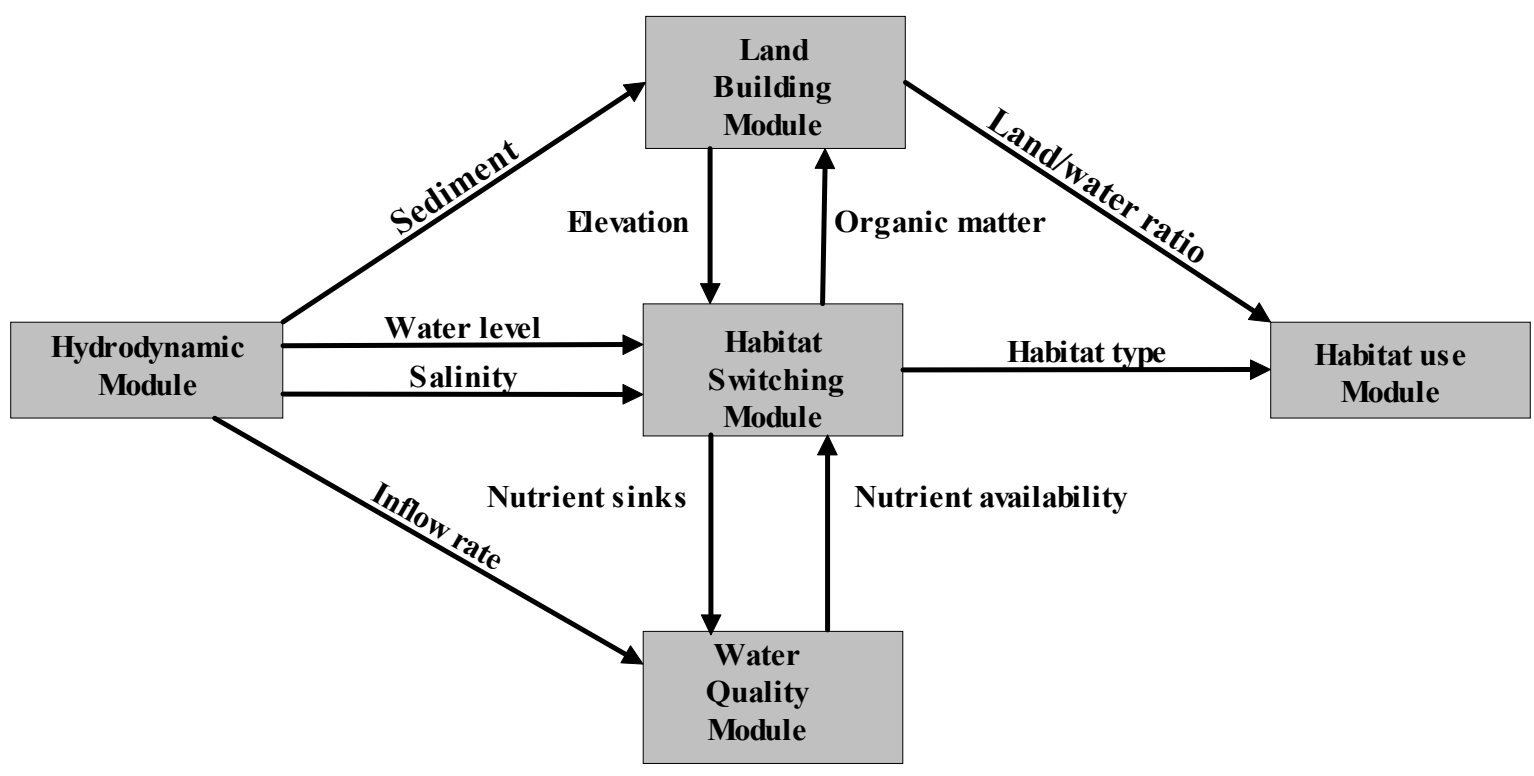

Figure 2. The five modules with their appropriate linkages (USACE, 2004). 
Future model design improvements are envisioned in efforts to reduce the scientific uncertainty in making predictions. The initial hypotheses and assumptions of casual mechanisms are to be continually reassessed and modified throughout project development (benefits evaluated every 10 years). Thus, the framework for the LCA Ecosystem Model was contrived in such a manner so as to be able to evolve when additional modules and information become available.

The current status of the success of the LCA Ecosystem Model is unfavorable. The major criticism is the general failure of modeling efforts to effectively integrate available environmental factors and produce plausible predictions (USACE, 2004). Over 25 different hydrodynamic and water quality models have been examined. Lacking is the development of more consistent spatial designs in the landscape models. Furthermore, it is recommended that numerous additional biological and species-specific models be incorporated within the landscape models. Future developments should include more accurate feedback processes in order for the models to predict ecosystem response of not only geophysical, hydrodynamic, and chemical, but also biological effects as well. Geophysical models, based on exact processes, generate the highest level of precision in simulation. This is followed by hydrodynamic models, which give coarser spatial resolution and estimation of ecosystem responses. Both types of models are herein referred to as "simulation modeling." "Desktop modeling," such as monitoring and feasibility studies, provides empirical information to evaluate responses, contributing statistical assessments of relationships instead of computational algorithms. Moreover, the desktop statistical approach may be also applied to hydrodynamic, ecological, and water quality models.

The LCA Ecosystem Model was initially designed to use all 34 alternatives specified in the restoration plan in simulation modeling; however, because of the size of the study area and time constraints, a full, comprehensive ecosystem model was compromised with a hybrid of simulation modeling for certain alternatives and desktop modeling for the remaining alternatives. In the future, less sophisticated desktop modeling will be replaced with more sophisticated simulation modeling as funds become available and the need arises to run models at finer resolutions. Furthermore, to handle the complexity of the diverse ecosystems, the large study area was divided into four subprovinces (fig. 3): (1) Pontchartrain Estuary/Breton Sound, (2) Barataria Basin, (3) Acadiana/Terrebonne Basin, and (4) Chenier Plain.

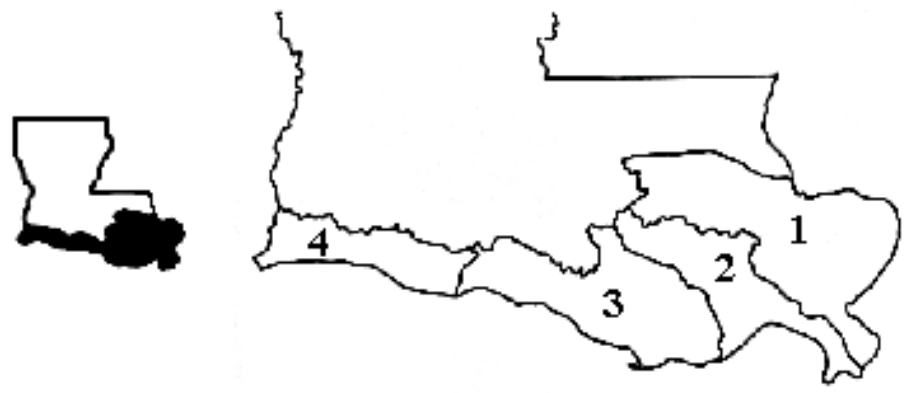

Figure 3. The LCA study area subprovinces 1-4 (adapted from USACE, 2004). 
A spatial framework (a polygon grid of 43,000+ cells) was developed for the LCA Ecosystem Model by using the geographic information system (GIS), where a common explicit spatial reference system was defined as a means of consolidating all five modules. Data could be entered and processed in $1-\mathrm{km}^{2}$ units using a variety of data formats and easily exchanged among scientists. The flexibility of the grid design allowed independent development of various models, requiring only that the output be appropriately spatially referenced.

Eight key spatial datasets in vector and raster formats were initially included (overlaid) in the framework: (1) "LCA cell grid," (2) "cell index," (3) “desktop habitat base," (4) "subsidence information," (5) "hydrologic box information," (6) "predicted land loss or gain," (7) "scenario infrastructure (subprovince-specific data)," and (8) "elevation" for one of the subprovinces. Combined attribute information from the above datasets constituted input material for the various models. The model outputs could be spatially displayed as thematic maps.

Four scenarios depicting different wetland land loss targets are defined for the simulations over the next 50 years: "base" (natural land loss at existing $\mathrm{km}^{2} / \mathrm{yr}$ with no restoration actions, specific for each subprovince), "reduced" (decrease the land loss by half as many $\mathrm{km}^{2} / \mathrm{yr}$ ), "maintain" (offset the expected loss to zero net land loss), and "enhanced" (offset the loss and increase land area by half).

\section{Summary of Subprovince Hydrodymamic Models}

Various shortcomings in the subprovince models have been noted (USACE, 2004). One major criticism is the nonsynchronization of model types across the subprovinces; that is, the models are too localized, in part due to the different geographical features in each subprovince. Some of the subprovince models completely failed to address all four target scenarios, making comparisons among them difficult. An overall model that uses more generalizations is needed.

For LCA subprovince 1 (Pontchartrain Estuary), the hydrodynamic model was adopted from the well-defined Princeton Ocean Model (POM). The POM results generally were in agreement with observations, slightly underpredicting tidal elevation but closely predicting surface currents. For each target scenario, diversion hydrographs are presented, as well as spatial maps of surface salinity distributions. One model limitation is that data indicating large flows through channels to Lake Pontchartrain are not available and are thereby not accommodated in the model. This drawback is being evaluated, and the model is currently under revision. Also, the model is not fully validated. Other limitations were discussed addressing the sigma coordinate system requirements, orthogonal grid structure restrictions, lack of an explicit wetting/drying algorithm, unrealistic model behavior or instability problems, as well as residual errors based on initial assumptions.

Salinity was predicted by using the multidimensional hydrodynamic numerical TABSMD model developed by D. Elmore of the U.S. Army Corps of Engineers (USACE) for LCA subprovince 2 (Barataria basin). The model is in two versions, "no marsh" and "with marsh." 
The "no marsh" model was found to be very stable. The "with marsh" model, however, runs very slowly and requires many assumptions and was consequently put on hold. Sensitivity analyses on the "no marsh" model were conducted to attempt to answer many questions: (1) does the model conserve mass (flow) and thus salt; (2) how is salinity at target locations sensitive to tidal forcing and salinity levels at the seaward boundary; (3) does the model reproduce phase lags at tidal passes, and (4) how is salinity sensitive to wind forcing? The "no marsh" model was found to be stable for all aforementioned issues and was therefore validated. A further comparison of the "no marsh" and "with marsh" models was performed by using salinity reduction factor (SRF) curves generated from the "with marsh" model run in static mode. The SRF curves predicted slightly higher salinity reductions when water diversions were in use than those predicted from the "no marsh" models, but within the standard error of the model.

Furthermore, in the dynamic mode, the response of the "no marsh" model was found to be out of phase with changes at the seaward boundary and half of that at the boundary. The emphasis in this study was on short-term manipulations in the sensitivity analyses, and it appeared to lack general simulations for the four scenarios.

The Acadiana Basin Model (ABM) was developed as a version of the hydrodynamic Coastal Ecological Landscape Spatial Simulation (CELSS) model for LCA subprovince 3 (Acadiana Bay/Terrebonne basin). It contains a soil-building module that simulates marsh changes to rise in sea level. Unique to this model is the Atchafalaya River, which provides a large-scale freshwater diversion component not available in the other subprovinces. Hence, this model predicted a deltaic land growth in the first 50 years, and then a state of equilibrium to be reached whereby land would be lost as quickly as gained. These results were generalized to the other LCA subprovinces. The model, however, lacked sufficient data for certain parameters, such as accurate elevation measurements for marsh survival and nutrient information necessary to measure vegetation productivity.

The LCA subprovince 4 (chenier plain) used two different hydrodynamic models, H3D and MIKE11, for two distinct areas. The H3D model was adapted to the Calcasieu/Sabine basin. Tidal and wind patterns have strong effects on this area and were emphasized in the model to simulate water level and salinity distributions. Only the "base," "maintain," and "enhance" scenarios were applied. Because of the geography, the models considered for the Rockefeller State Wildlife Refuge were reduced to a one-dimensional river model, MIKE11. This area is characterized predominantly by channels and canals. The shallow water depths restricted the measurements for proper stratification of salinity, and the insufficient amount of open water areas inhibited adequate observation of circulation of water currents, so that using two- or threedimensional models was not justified. Here, target scenarios were redefined into two types: "base" (untouched) and a specific "conceptual design," which idealistically makes certain modifications (water control structures) for culverts and canals in the area. Both models were fully validated, and root mean square errors were reasonably small, indicating adequate and well-calibrated modeling. 


\section{Other LCA Study Modules}

The results of the hydrodynamic simulations given in the previous section are to be scaled down to the basin level. They are the inputs for desktop modeling of the water quality, habitat use, and habitat switching modules (fig. 2). This involves the characterization of the order of magnitude in index models, where index values are computed for present and projected scenarios. The model responses (index value) should be within comparable orders of magnitude between present conditions and future predictions to justify the restoration projections. Otherwise, different basins and calibration approaches are to be used to adjust for large differences (for example, the projected index value is 10 or more times greater than the present value). Furthermore, the results of the hydrodynamic model simulations are to be used to calibrate mass-balance models that approximate the response in each basin to mixing and transport processes over time, establishing "average mixing" characteristics for each basin. In short, the outputs of modules have to be compatible with inputs of other modules, and mixing generalizations need to be applied.

The land-building module is restricted by the uncertainties in future subsidence rates and limited data on accretion rates. Hence, only generalized land changes can be predicted. This module is well-described and developed for all four target scenarios, with good spatial documentation. Clear algorithms for land-building and nourishment are defined. Salinity reduction, however, can only be estimated from land loss, as no precise data is available.

The habitat switching module consists of swamp forest, all types of marshes, open water, and upland habitats. Salinity levels, together with inundation, directly induce the changes between the freshwater, intermediate, brackish, and salt marshes. These changes affect the productivity of the habitat. The conceptual desktop model was specifically designed for this project and appeared to be well suited.

The habitat use module applies HSI models to assess habitat capacity for different life stages of fish, shellfish, and wildlife; that is, overall quality-weighted habitat. The inputs for these models are the outputs from the hydrodynamic models (monthly salinity and temperature and average water depth), together with habitat type and land to water ratios (fig. 2). A single index value of habitat capacity is computed by combining these factors. There were 12 HSI models that were already available for species selected as representative of the diverse habitats: white shrimp (Penaeus setiferus), brown shrimp (Penaeus aztecus), American oyster (Crassostrea virginica), gulf menhaden (Brevoortia patronus), spotted seatrout (Cynoscion nebulosus), Atlantic croaker (Micropogonias undulatus), largemouth bass (Micropterus salmoides), American alligator (Alligator mississippiensis), muskrat (Ondatra zibethicus), mink (Mustela vison), river otter (Lutra canadensis), and dabbling ducks (Anas Linnaeus). These were specifically tailored for the Louisiana coastal region $1-\mathrm{km}^{2}$ grid by reducing input information (removing noncompatible factors), redefining habitat suitability functions, and applying specific, factor-combining algorithms (geometric averages) to compute the final index. The results indicate that only one fish species (largemouth bass) benefited from increase of land, while others showed declines in habitat suitability. Species with a wide range of salt tolerance, 
such as white shrimp and gulf menhaden, were relatively unaffected under different restoration scenarios, whereas those with low tolerance were affected. In contrast, all wildlife species showed favorable increases in habitat suitability along with the expansion of land and freshwater wetlands. Both American alligator and dabbling duck had high index values for freshwater and intermediate marshes.

The final module, water quality, deals with estimation of nitrogen removal, chlorophyll- $a$ concentrations ("algae bloom"), and aquatic primary production rates. Output from the habitat switching and hydrodynamics modules together with other factors such as diversion flow and precipitation surplus were the inputs for this module. Once water quality was estimated, then suitability indices for ecosystem benefits were determined. Nitrogen removal was investigated by three models: annual N export and internal losses (Dettmann, 2001), nitrate-nitrogen loading for constructed wetlands (Mitsch and others, 2001), and water residence time related to phytoplankton denitrification (Setzinger and others, 2000). A simple regression associated chlorophyll concentrations to nitrogen loading.

\section{Benefits Assessment Protocols}

Six benefits assessment protocols were developed to evaluate the achievement of all alternative scenarios. These not only addressed the reversal of wetland loss but also looked at the broader ecosystem structure.

Benefit protocol 1 (B1): Primary productivity of land and water (habitat suitability productivity measure) and habitat use (HSI for each species, grouped into three classes based on common habitat salinity) will be combined into an annual habitat quality unit (HQU) for each subprovince at prediction years $0,10,20,30,40$, and 50 . Inputs are provided by the habitat switching, water quality, and habitat use modules.

Benefit protocol 2 (B2): Quality of habitat (HQU from protocol B1 above), quality of land (suitability index quality, a ratio of the amount of land preserved by scenario to the land amount which existed in 1932), and nitrogen removal (suitability index nitrogen, a ratio of amount of nitrogen in tons/yr removed for each scenario to that removed by Mississippi River diversions at 100,000 tons) will be combined into an annual overall suitability index (OSI) for each cell, totaled into benefits units (BU) for each subprovince at prediction years $0,10,20,30$, 40 , and 50. Inputs are provided from B1 and by the land-building and water quality modules.

Benefit protocol 3 (B3): Quality of land (acres of land produced by each scenario) is measured per subprovince after 50 years. Input is provided by the land-building module.

Benefit protocol 4 (B4): Nitrogen removal (percentage from each scenario to 480,000 tons, such as a 30 percent reduction in nitrogen loading) is measured in tons per year. Input is provided from the water quality module. 
Benefit protocol 5 (B5): Fish and wildlife quality (HSI for each species) for each of four habitat types are multiplied by habitat type acreage and combined into annual HU at years 0,10 , 20 , and 50 only. Input is provided by the habitat use module.

Benefit protocol 6 (B6): Quality is defined in various combinations of assessment based on the needs of specific interest agencies or groups. Habitat suitability index values of species are grouped for salinity ranges, harvest type (commercial, recreational, and oyster), and acreages of various habitat types (freshwater, intermediate, brackish or saline marshes, and forest wetlands). Input is generalized from all modules.

\section{Model Parameters and Uncertainties}

Each module was examined to assess its strengths and weaknesses, and recommendations for improvement were made. Three levels of model uncertainty (scientific rigor) and parameter uncertainty (quality of data) were assigned: "high" (based on extensive literature or data available), "moderate" (some data or models available, but need additional research), and "low" (based on professional judgment). Generally, these evaluations appear to need a more comprehensive application of standard methods for error and uncertainty analyses in model development, in order to insure accurate risk assessments. Furthermore, since the Louisiana coastal area is a low-energy system, any high-energy disturbances such as hurricanes would require different deterministic models, specifically designed for unpredictable events.

The most important module is the hydrodynamic module. All hydrodynamic outputs are critical inputs for other modules. Any improvement in data and assumptions will have a major impact on reducing scientific uncertainty that is due to the strong effects of geophysical processes and geomorphic features. For hydrodynamic factors of elevation, bathymetry, meteorology, tides, water flow, salinity, and sediment, model rigor was rated as moderate, while parameter quality was rated as moderate or low. A major recommendation is to link the threedimensional information on water levels, velocities, and nutrient transport in channels to marshes, with enhanced spatial and temporal resolution. In addition, coastal boundary conditions, wind effects, and sediment suspension should be better scrutinized.

The land-building module factors of historical change; the input, retention, density and volume of sediment; nutrient input; and salinity change were rated mostly as moderate or low in both model and parameter quality. There are extensive data available, and relationships among the factors above are well defined, but surprisingly, these data did not get used to the fullest extent in module development and thereby weakened the ratings. For future models, there should be an overall improvement in assumptions, as well as incorporation of more detailed and extensive data collection over a larger range of locations. 
Both model rigor and parameter quality were rated low over all factors of the habitat switching component of the habitat switching module. Long-term data are not available, and information would need to be interpolated by best-professional judgment from short-term salinity and flooding duration and height regimes. Thus, for conversions between wetland and water, the land-building module was used instead of the habitat switching module. Nevertheless, model rigor was rated high for the wetland primary production component of this module because of the abundance of information on salinity levels and on the direct association between production and availability of wetland area. Relationships between production and inundation factors, however, are not clearly determined and were rated low.

The habitat use module predicts areas of "quality-weighted habitat," the capacity of a system to support individuals for a given species, which may not translate well into actual abundance. One major problem is that the environmental factors are at spatial scales too coarse for fish and wildlife to respond to. In addition, the relationship between number of boundaries or edges of a land type to the land area is not well incorporated into model designs. Furthermore, many relationships were established intuitively. Thus, although model rigor was rated high for fish in the habitat use module because of considerable well-developed HSI models, parameter quality was rated low for all corresponding factors of salinity, temperature, wetland area, and water area and depth. Modeling rigor for the factors used in other wildlife models was mixed. The habitat type factor was rated high, whereas inundation height and wetland area factors were rated as low and moderate, respectively. Likewise, the parameter quality was again rated low for all wildlife factors.

Finally, the water quality module was overall rated moderate in model rigor but low in parameter quality.

In general, because the modules are interrelated, uncertainties will have compounding effects. The implications are that benefit protocols (B1, B2, B5, and B6) that use habitat switching and habitat use modules show larger compounded uncertainties than benefit protocols (B3 and B4) that use land-building and water quality modules. Furthermore, parameter quality was consistently assessed as low to moderate and needs to be addressed. A lot of data are available for coastal Louisiana, yet the models failed to incorporate more information. This failure is in part due to the spatial extent defined and nonuniform or limited data collection. Other model weaknesses involve issues of species diversity or richness across the study area and habitat connectivity that are not being accommodated by the above benefit protocols. Also, there may be too many generalizations and assumptions in the development of the models that could introduce unnecessary errors. All of the aforementioned limitations or drawbacks should be addressed in future improvements of the LCA evaluation methods.

To examine whether the models produced logical results, additional model evaluation should incorporate sensitivity analysis to verify that models were stable and performing as expected by using hypothetical data with incremental changes in the input variables (some sensitivity analyses were attempted). Moreover, all mathematical relationships would need to be reconfirmed as accurate and properly translated into code. Finally, an effective monitoring 
process should be implemented, providing essential feedback to improve the models and reduce scientific (especially parameter) uncertainties. A System-wide Assessment and Monitoring Plan (SWAMP) is currently under development that integrates biological, chemical, physical, and climate factors. The Coast-wide Reference Monitoring System (CRMS) for wetlands (Steyer and others, 2003) serves as a prototype for the development of monitoring programs for noncoastal (channels and rivers) and coastal waters. 


\section{Chapter 2 \\ Habitat Suitability Index (HSI) Models}

Habitat Suitability Index (HSI) models are based on biological information of a fish or wildlife species (U.S. Fish and Wildlife Service, 1980; Inhaber, 1976). This numerical index represents the capacity of a habitat to support a given species. The index value is computed as a ratio of the value of interest divided by a standard of comparison. Specifically, HSI is defined as the ratio of the estimate of habitat conditions to the optimum habitat conditions, where the HSI value ranges from 0 to 1 , inclusive:

$$
\mathrm{HSI}=\frac{\text { Observed Habitat Conditions }}{\text { Optimum Habitat Conditions }} \quad, 0 \leq \mathrm{HSI} \leq 1
$$

Note that a HSI value may be computed for any measurable value of an existing model output, as long as an optimal condition (maximum regional value) can be defined in the denominator.

In the event that the measure is categorized in classes, the HSI is simplified as a fixed value (value ${ }_{i}$ ) between 0 and 1 , for the class $i$ :

$$
\mathrm{HSI}=\text { value }_{\mathrm{i}} \quad, \mathrm{i}^{\text {th }} \text { class, } 0 \leq \mathrm{HSI} \leq 1
$$

or HSI is defined for two classes as 0 or 1 as:

$$
\begin{array}{ll}
\mathrm{HSI}=1 & \text {, condition suitable for species } \\
\mathrm{HSI}=0 & \text {, otherwise, condition unsuitable }
\end{array}
$$

Any subsequent assessment of overall habitat suitability that is based on the HSI will be defined in habitat units (HU):

$$
\text { HU }=\text { HSI x (area of available habitat) }
$$

The building blocks of HSI models are referred to as habitat variables (physical, chemical, and biological characteristics of the habitat). Breaking down the habitat into components helps to identify what the individual variable elements are. Usually, four types of components are considered (in order of importance): (1) seasonal habitats, (2) cover types, (3) life stages, and (4) special requirements (food or nesting habitat.) Additional variables include any spatial variables that indicate quantity, interspersion, or proximity of habitat elements.

Variables are combined into models through different types of relationships. Models using sentences ("word" models) usually involve threshold values, conditional statements, or spatial relationships. Models using mathematical equations to express relationships are called "mechanistic" models. These equations are derived from suitability graphs of individual 
variables, which display the relationship between the variable and a measure of suitability, either as a continuous variable or a histogram of classes. The variable is often denoted as Vi and its corresponding suitability index as $\mathrm{SI}_{\mathrm{Vi}}$. Variable indices may be combined into intermittent quantities as components, denoted as $\mathrm{C}$. Individual indices or intermittent components (generally all referred to as "components") are combined into a final index, usually designated as the HSI.

Different types of mathematical relationships include the limiting factor method, as well as cumulative, compensatory, and spatial relationships. The limiting factor method (minimum function) sets the suitability index to the value of the lowest variable index. Cumulative relationships add variable indices together: when the sum is less than or equal to 1, the index is set to the sum; otherwise, if the sum is greater than 1, the index is set to 1 . Compensatory relationships are used when one variable index value is too low or high and requires to be offset by others. The arithmetic or geometric mean is implemented to counterbalance these effects. Spatial equations are used to address distance and percentage of area where applicable.

When variables are combined into arithmetic or geometric means, the type of variable affects the overall index value. For continuous variables, the formulae are straightforward. When there is at least one class variable, the arithmetic mean is unaffected; however, the geometric mean may be adjusted. Categorical variables consisting of two classes with values 0 and 1 enter the equations as constants and need not be incorporated into the power of the geometric mean, such that power equals $1 / \mathrm{n}$ for the remaining $n$ variables.

Pattern recognition models are used when combinations of conditions have distinct patterns and are assigned a suitability index value. This type of modeling may easily become very complex when the dimensions of the combinations increase. A practical approach to reduce the complexity is the Bayesian probability model, an extension of pattern recognition models. Here, combinations are based on knowledge of Bayesian prior probabilities where conditional probabilities are computed, so that individual probabilities are not assigned to all combinations, thereby reducing the dimensionality. This procedure also weeds out unnecessary variables.

There are also other methods to statistically eliminate unnecessary or less-important variables. These include multiple regression models and discriminant analysis. Once a regression equation is determined, a HSI value may be computed as:

$$
\begin{aligned}
& \text { Predicted population value } Y=\alpha+\beta_{1} X_{1}+\beta_{2} X_{2}+\ldots+\beta_{n} X_{n} \\
& H S I=(\text { predicted value } Y) /(\text { maximum observed } Y)
\end{aligned}
$$

Discriminant analysis can be used to correspond the population from a certain habitat area with an appropriately defined population subgroup. Each population subgroup is assumed to be associated with specific habitat characteristics, and predictions are made using discriminant functions to determine if the habitat area's population is likely to occur within the subgroup. 


\section{Chapter 3 Spatially Explicit Species Index (SESI) Models}

Inasmuch as the Louisiana Coastal Area (LCA) Ecosystem Model has been developed for the Louisiana coastal regions, the Across Trophic Level System Simulation (ATLSS) program provides equivalent modeling approaches in southern Florida that are specifically designed for the Comprehensive Everglades Restoration Plan (CERP). Likewise, the ATLSS program provides a complex method to assess the impacts of various hydrodynamic alterations on species habitat in Florida. One level consists of Spatially Explicit Species Index (SESI) models used for foraging, breeding, and abundance, which are analogous to the aforementioned habitat suitability index (HSI) models in the LCA Comprehensive Ecosystem Restoration Plan (LCA study).

The traditional HSI models created for wildlife species evaluate the modifications to habitat conditions that are in response to hydrological alterations. The SESI models (Curnutt, 2000), however, offer more advanced characteristics such as a temporal component that integrates static and dynamic landscape features. Static features include fixed components such as topography, elevation, soil type, and vegetation types, whereas dynamic features involve changing aspects such as fluctuating water levels, unexpected disturbances like fire or hurricanes, and vegetation dynamics. Also, the dynamic features can be incorporated on a time resolution of a day. A "landscape structure" is the basis of these models and is defined by using geographic information systems (GIS). Equal-sized spatial cells $(111,000$ cells of a 500 by 500 $\mathrm{m}$ array) make up this landscape, where each contains values of the parameters specified in the model. The landscape structure is used to model the response of any species in the ecosystem and can easily be reused for other regions or applications. Local indices of habitat suitability, ranging from 0 to 1 , are computed that describe particular components (breeding, foraging, or abundance) of a species' biological requirements for the landscape scenario. Overall, the SESI models provide relatively more simplistic methods (rapidly-modeled approximations) to weigh spatial impacts of different scenarios for species across the landscape as compared to more comprehensive population or individual-based ATLSS models. The SESI models produce spatially explicit graphic representations of the response.

Continual development of SESI models included evaluation and refinement via sensitivity analyses to wetter or drier hydrological patterns. The results yielded consistency in the biological responses as expected, verifying model stability. Further developments of Webbased interfaces will allow authorized users to execute models and download and observe results by using the ATLSS Data Viewer (Johnston and DeAngelis, unpub. data). The SESI models are composed of several map layers, each representing a different ecological factor making up the index. Only the sum of these layers is currently available; however, individual map layers will be made accessible in the future to users, providing the ability to segregate more important contributing factors of the index at any given time and place. 
In addition, new vegetation succession models (VSMod) have been completed (The Institute for Environmental Modeling [TIEM], 2005) that address changes in major vegetation patterns resulting from projected hydrological and nutrient alterations and that incorporate disturbances such as fire. These types of models are of importance especially for species that are very habitat-vegetation specific. The VSMod models may be characterized as "cellular automata," where at any given time each cell is at a particular state (vegetation type). They are also "stochastic," implying statistical randomness whereby transitional probabilities between states depend on local hydrology and fire records and vary in time and across space. Thus, because of the stochastic properties, the model is run repeatedly to get an estimate of the average succession and associated variability. The output of the VSMod will serve as inputs for SESI models. The current VSMod version is based on 24 of 58 vegetation types as identified in the Florida GAP Analysis Program (FGAP) map. Nutrient data (total phosphorus levels) are provided by the ATLSS nutrient model. Fire scenarios are limited to three scenarios (low, medium, and high) created by the ATLSS fire model.

The SESI models are to be compared to the HSI models developed by the South Florida Water Management District (SFWMD). One major difference is that the Florida HSI models have a much coarser spatial resolution at a 2-mi (approximately 3,218-m) scale than the Florida SESI models at $500 \mathrm{~m}$. The HSI models for the LCA study have a 1,000-m resolution. Also, note that the Florida SESI models are currently driven basically by hydrodynamics. The SESI models, however, cannot simulate cumulative effects on population size resulting from periods of long-term high or low water levels. For example, extinction can not be predicted accurately. Other factors such as artificial habitat improvements, inexplicable migrations or forced removal (hunting), disease, water quality, fire, hurricanes, or invasive vegetative or wildlife species are not accounted for in any of the models.

The hydrologic metrics in the SESI models were developed according to the SFWMD's hydrology model. The output of this model was the basis for the SESI hydrological input. Water depths are derived by subtracting soil surface elevation above mean sea level from water surface elevation. Thus, in both Florida models (SESI and HSI), a water depth of zero translates to no water above the soil surface.

Brief model parameter descriptions for all species types utilized in the Florida SESI models are presented below: American alligator, wading birds, white-tailed deer, crayfish, cape sable seaside sparrow, apple snail, and snail kite (The Institute for Environmental Modeling [TIEM], 2004a). Species-specific habitat needs or scenario alteration results will be investigated between the Florida SESI and HSI models. This comparison will be restricted to the American alligator and several species of wading birds. 


\section{American Alligator}

The American alligator (Alligator mississipiensis) is one of the more ideal bioindicators of ecosystem health. As a major predator, its impacts on wildlife (both aquatic and land) and plant communities are substantial. Since its survival and population growth directly rely on hydrodynamics, any spatial or temporal changes relate easily to responses in alligator breeding. The Florida SESI alligator production index (API) is a rough approximation of annual breeding potential (probability of producing nests and offspring). Water levels (flooding) are key factors during mating season, as optimal nest success is dependent on water levels during nest construction and egg incubation. Vegetation cover type and elevation are also important. Hence, the index is a combination of several factors: breeding/nesting potential, nest flooding, and a static habitat type (rank).

\section{Wading Birds}

Wading birds are divided into two categories: short-legged such as white ibises (Eudocimus albus) and little blue herons (Egretta caerulea), and long-legged such as great egrets (Ardea albus) and wood storks (Mycteria americana). For wading birds, the availability or amount and timing of food (small freshwater fish and invertebrates) is the most critical factor during breeding. The radius of the colony site is important and is species-specific. Within it, the portion of surrounding area that is sufficient foraging habitat is defined. Furthermore, throughout the foraging area the water depth needs to be within suitable ranges. Thus, the foraging index is based on the number of continuous days of favorable breeding conditions (foraging cycle) and the portion of foraging area that is suitable surrounding the colony.

\section{White-tailed Deer}

White-tailed deer (Odocoilus virginianus) are susceptible to high water tables, causing continual migration to higher ground. Consequently, hydrology changes affect not only breeding (factors such as dry bedding sites and drowning prevention of fawns) but also foraging activities and availability of food. In addition, the length (number of months) of the hydroperiod in the preceding year affects foraging. Thus, the breeding potential index for deer is based on the "high water rule" (integral of the water depth over the reproductive season divided by the maximum level) multiplied by the factor representing the previous year's hydroperiod (MHp).

\section{Crayfish}

Crayfish are important in the food web in the wetlands. Not only do they consume snails, worms, tadpoles, insects, and vegetation, but they are also important in the diets for alligators, wading birds, fish, and other wildlife. Their production potential, timing, and abundance are imperative to the food supply of many other species. There are two species of crayfish in 
Florida, the Everglades crayfish (Procambarus alleni) and the slough crayfish (Procambarus fallax). Each occupies a distinct niche with different hydrology regimes (wet prairies versus slough habitats), so that separate indices are determined. The index is a product of several factors consisting of the current year hydroperiod, habitat type, and drydown pattern over the past 3 years.

\section{Cape Sable Seaside Sparrow}

The cape sable seaside sparrow (Ammodramus maritimus mirabilis) is an endangered species specific to The Everglades and Big Cypress National Preserve. It is very dependent on water level. The nests are built in grass tussocks far away from trees, when the water is below ground surface. If water levels do not recede early enough from the prior winter and early spring, its nest building is delayed. If water becomes elevated during breeding, then nests and eggs will be drowned and abandoned. Several broods a year can be produced. The breeding index is the product of the number of potential breeding cycles and vegetation quality.

\section{Apple Snail}

Like the crayfish, the freshwater apple snail (Pomacea paludosa) is a part of the food web, feeding on algae and decaying matter, and is also an important food source for wildlife, particularly the bird species snail kite (see below). Apple snails breed on plant stems above the water surface, so again water level plays an important role. Water level should be within tolerable ranges, since rises in levels can easily drown eggs, or drops in levels (drydown) can cause loss of eggs and death of newly hatched snails. The HSI for the apple snail predicts the optimal water level and yearly portion of potential recruitment, based on the ideal egg production capacity for each of the 8 months in the breeding season.

\section{Snail Kite}

The snail kite (Rostrhamus sociabilis) exclusively feeds on the apple snail, and thus its index is based on habitat quality that is ideal for apple snails (see above). The index depends on long-term hydrological factors that are large fluctuations over years, referred to as the "dryfactor" and "wetfactor." After a drydown, where the habitat suitability becomes zero, it is assumed to take 4 years to recover and reestablish a suitable habitat status (dryfactor is computed based on the time since the last drydown). On the other end, flooding should occur at least 80 percent of the time over a 10 -year period, but more than 98 percent makes the habitat unsuitable (wetfactor corresponds to the fraction of the 10-year period that is flooded beyond 80 percent). The HSI is the product of the ratio of the number of potential breeding cycles to the maximum potential and the minimum of the wetfactor and dryfactor. 


\section{Chapter 4 \\ The American Alligator Models}

\section{$\underline{\text { American Alligator }}$}

American alligators (Alligator mississippiensis, hereafter called "alligator") (The Institute for Environmental Modeling [TIEM], 2004b; Newsom and others, 1987; Rice and Slone, 2004; Rice and others, 2004), are amphibious reptiles that inhabit rivers, canals, lakes, bayous, swamps, and marshes of the gulf coast and the lower Atlantic Coastal Plain. Since only one species of alligator is found from Texas to Florida to North Carolina, it is assumed that because the general habitat ecosystems are similar throughout the coastal areas, their biological and environmental needs will be likewise analogous in Louisiana as in Florida. They are adaptive to the environment and feed on whatever is available. In general, alligators require both land and water, preferring fresh to brackish waters and intermediate marsh types, but not saline waters. They dig dens at the water's edge with underground entrances. Although alligators mate in deeper open water, females return to land and construct nests usually of mud and any available vegetation in nonflooding areas. The versatility noted in nest-building depends on the environment. Marshes low in salinity and containing shallow pot holes and ponds interspersed with grasses are favorable in both Louisiana and Florida. In lake environments, nests are made on sloping banks close to the water's edge. Peat batteries and elevated areas of dense shrubs or vines are used in wet prairies, and any elevated areas are utilized in swamp forests. From the middle of June to the first of July, females will lay about 40 eggs per clutch. After 65 days of incubation, the female will remove the top layer of the nest to release the young. Hatchlings remain with the females for about a year in the surrounding nest habitat. Immature alligators move to deeper waters throughout summer to winter, but have a preference for shallower habitats such as intermediate marshes during spring. Alligators become sexually active when they reach about 2-m long (8-10 years). Adult males prefer deep waters, whereas adult females are less mobile and restrict activity around their dens in marshes/swamps.

In terms of food requirements, the alligator will eat any smaller living thing: fish (about 60 percent), reptiles (25 percent, mostly turtles), invertebrates (crawfish, crabs, and snails), mammals (muskrats, rabbits, and nutria), and birds. The diet varies depending on the environment and availability of prey type. In freshwater and intermediate marshes, food consists mostly of mammals, followed by arthropods, fish, birds, and reptiles, respectively; whereas in brackish, more prey consists of fish and arthropods (crawfish and crabs) than mammals, birds, and reptiles. Young alligators eat primarily invertebrates (up to 98 percent of the diet.)

\section{Alligator Habitat Suitability Index of Louisiana}

A Habitat Suitability Index (HSI) model has been developed for the nesting season for Louisiana and Texas by using the habitat evaluation procedures (HEP) defined by the U.S. Fish and Wildlife Service (USFWS). The general HSI model of the USFWS, presented in Newsom and others (1987), is described below ( $\mathrm{SI}_{\mathrm{Vi}}$ refers to the suitability index of variable (Vi)). 
Model parameters and variables:

1. Habitat cover type

Freshwater marshes (palustrine emergent)

Vegetation: Panicum hemitomon, Alternanthera, Eleocharis, Sagittaria

Brackish and intermediate marshes (estuarine emergent)

Vegetation: Spartina, Sagittaria, Eleocharis, Scirpus, Juncus, Distichlis

$$
\mathrm{V} 0=\text { habitat type and minimum area (class variable) }
$$

$\mathrm{SI}_{\mathrm{V} 0}=1.0$

$\mathrm{SI}_{\mathrm{V} 0}=0.0$
, V0 is freshwater, intermediate or brackish marshes and minimum habitat area of 5 ha

, V0 is otherwise, final index value is set to zero

2. Breeding cover type

$\mathrm{V} 1=$ percentage of open water in wetland

$\mathrm{V} 2$ = percentage of open water in bayous, canals, and lakes

$$
\begin{array}{lrr}
\mathrm{SI}_{\mathrm{V} 1}=\mathrm{V} 1 / 20 & , 0<\mathrm{V} 1 \leq 20 & \text { (percentage) } \\
\mathrm{SI}_{\mathrm{V} 1}=1.0 & , 20<\mathrm{V} 1 \leq 40 & \\
\mathrm{SI}_{\mathrm{V} 1}=(100-\mathrm{V} 1) / 60 & , 40<\mathrm{V} 1 \leq 100 & \\
\mathrm{SI}_{\mathrm{V} 2}=\mathrm{V} 2 / 10 & , 0<\mathrm{V} 2 \leq 10 & \text { (percentage) } \\
\mathrm{SI}_{\mathrm{V} 2}=1.0 & , 10<\mathrm{V} 2 \leq 20 & \\
\mathrm{SI}_{\mathrm{V} 2}=(100-\mathrm{V} 2) / 80 & , 20<\mathrm{V} 2 \leq 100 &
\end{array}
$$

Nesting Cover type

$\mathrm{V} 1=$ percentage of open water in wetland, same as defined above $\mathrm{V} 3=$ vegetation mixed with open water (nontidal, class variable) $\mathrm{V} 4=$ percentage of ponded area, water $\geq 15 \mathrm{~cm}$ deep (nontidal) $\mathrm{V} 5=$ percentage of exposed substrate at low tide (tidal)

$$
\begin{array}{ll}
\mathrm{SI}_{\mathrm{V} 3}=1.0 & , \mathrm{~V} 3=10-15 \text { ponds } / 6 \mathrm{ha} \\
\mathrm{SI}_{\mathrm{V} 3}=0.50 & , \mathrm{~V} 3=3-10 \text { ponds } / 6 \mathrm{ha} \\
\mathrm{SI}_{\mathrm{V} 3}=0.20 & , \mathrm{~V} 3=\leq 2 \text { ponds } 6 \mathrm{ha} \\
\mathrm{SI}_{\mathrm{V} 4}=\mathrm{V} 4 / 100 & , \mathrm{~V} 4=\text { percentage of ponded area, water } \geq 15 \mathrm{~cm} \\
\mathrm{SI}_{\mathrm{V} 5}=(100-\mathrm{V} 5) / 100 & , \mathrm{~V} 5=\text { percentage of substrate }
\end{array}
$$

The following equations combine $\mathrm{SI}_{\mathrm{Vi}}$ into cover components habitat $\left(\mathrm{C}_{\mathrm{h}}\right)$, breeding $\left(\mathrm{C}_{\mathrm{b}}\right)$, nontidal nesting $\left(\mathrm{C}_{\mathrm{nn}}\right)$, and tidal nesting $\left(\mathrm{C}_{\mathrm{nt}}\right)$ : 

$\underline{\text { Components }}$
$\underline{\text { Equation }}$
$\mathrm{C}_{\mathrm{h}}$ (habitat)
$\mathrm{C}_{\mathrm{h}}=\mathrm{SI}_{\mathrm{V} 0}$
$\mathrm{C}_{\mathrm{b}}$ (breeding)
$\mathrm{C}_{\mathrm{b}}=\left(\mathrm{SI}_{\mathrm{V} 1} * \mathrm{SI}_{\mathrm{V} 2}\right)^{1 / 2}$ or $\mathrm{C}_{\mathrm{b}}=\mathrm{SI}_{\mathrm{V} 1} \quad$ if $\mathrm{SI}_{\mathrm{V} 2}$ is $\mathrm{n} / \mathrm{a}$
$\mathrm{C}_{\mathrm{nn}}$ (nesting, nontidal)
$\mathrm{C}_{\mathrm{nn}}=\left(\mathrm{SI}_{\mathrm{V} 1} * \mathrm{SI}_{\mathrm{V} 3} * \mathrm{SI}_{\mathrm{V} 4}\right)^{1 / 3}$
$\mathrm{C}_{\mathrm{nt}}$ (nesting, tidal)
$\mathrm{C}_{\mathrm{nt}}=\left[\left(\mathrm{SI}_{\mathrm{V} 1} * \mathrm{SI}_{\mathrm{V} 3} *\left(\mathrm{SI}_{\mathrm{V} 4} * \mathrm{SI}_{\mathrm{V} 5}\right)^{1 / 2}\right]^{1 / 3}\right.$

The HSI is computed as $\left(\mathrm{C}_{\mathrm{h}}\right.$ is a two-classed variable and does not affect the power of $\left.1 / 2\right)$ :
nontidal
$\mathrm{HSI}=\left(\mathrm{C}_{\mathrm{h}} * \mathrm{C}_{\mathrm{b}} * \mathrm{C}_{\mathrm{nn}}\right)^{1 / 2}$
tidal

$$
\mathrm{HSI}=\left(\mathrm{C}_{\mathrm{h}} * \mathrm{C}_{\mathrm{b}} * \mathrm{C}_{\mathrm{nt}}\right)^{1 / 2}
$$

A modified HSI model described in appendix C of the LCA study (USACE, 2004), is applied to the LCA study. The five variables and complex relationships of the aforementioned model (Newsom and others, 1987) are simplified into three new variables: habitat type (V1) (see fig. $7 A$ and $7 B$ ), land to water ratio as the percentage of land or marsh (V2), and marsh flooding or average yearly water depth (V3) (measured from the soil surface, brackish marshes only). The variable (V2) is related to (V1) of the previous model, where V2 $=1-\mathrm{V} 1$.

$$
\begin{array}{ll}
\mathrm{SI}_{\mathrm{V} 1}=0.0 & , \mathrm{~V} 1=\text { open water, saline marsh, hardwood forest } \\
\mathrm{SI}_{\mathrm{V} 1}=0.26 & , \mathrm{~V} 1=\text { swamp } \\
\mathrm{SI}_{\mathrm{V} 1}=0.55 & , \mathrm{~V} 1=\text { freshwater or brackish marsh } \\
\mathrm{SI}_{\mathrm{V} 1}=1.0 & , \mathrm{~V} 1=\text { intermediate marsh } \\
\mathrm{SI}_{\mathrm{V} 2}=\mathrm{V} 2 * 0.0167 & , 0 \leq \mathrm{V} 2<60 \quad \text { (percentage) } \\
\mathrm{SI}_{\mathrm{V} 2}=1.0 & , 60 \leq \mathrm{V} 2 \leq 80 \\
\mathrm{SI}_{\mathrm{V} 2}=5-(\mathrm{V} 2 * 0.05) & , 80<\mathrm{V} 2 \leq 100 \\
\mathrm{SI}_{\mathrm{V} 3}=0.0 & , \mathrm{~V} 3 \leq-0.5 \mathrm{~m} \\
\mathrm{SI}_{\mathrm{V} 3}=2.5+(\mathrm{V} 3 * 5) & ,-0.5<\mathrm{V} 3 \leq-0.3 \mathrm{~m} \\
\mathrm{SI}_{\mathrm{V} 3}=1.0 & ,-0.3<\mathrm{V} 3 \leq 0.0 \mathrm{~m} \\
\mathrm{SI}_{\mathrm{V} 3}=1-(\mathrm{V} 3 * 5) & , 0.0<\mathrm{V} 3 \leq 0.2 \mathrm{~m} \\
\mathrm{SI}_{\mathrm{V} 3}=0.0 & , \mathrm{~V} 3>0.2 \mathrm{~m}
\end{array}
$$

The HSI is defined as a geometric mean of the three $\mathrm{SI}_{\mathrm{Vi}}$ values directly (no components):

$$
\mathrm{HSI}=\left(\mathrm{SI}_{\mathrm{V} 1} * \mathrm{SI}_{\mathrm{V} 2} * \mathrm{SI}_{\mathrm{V} 3}\right)^{1 / 3}
$$




\section{Alligator Habitat Suitability Index (HSI) of Florida}

The Everglades of Florida have poor or harsh environmental conditions for alligators (Rice and others, 2004), which is probably due to low availability of food that is associated with hydrodynamic fluctuations. The alligators in The Everglades weigh less and are shorter than in other environments, whereby sexual maturity can be delayed from 10 to at least 18 years. Water depth and timing are critical for breeding, nest building, egg incubation, and survival conditions of hatchlings or immature alligators. Excessive and unpredictable flooding of nests in the marshes has been observed under current water management practices. As a result, alligators have readapted to higher elevations, but survival rates of the immature remains low.

Four components make up the HSI for alligators of SFWMD models (Rice and others, 2004): (1) breeding, (2) nest building, (3) nest flooding potential, and (4) survival of the young and body conditions of all ages. These components were based on the same information from the ATLSS models, but the index does not include habitat and elevation as in the ATLSS models. Furthermore, the index is computed for a larger scale (36-fold) as a 2 by $2-\mathrm{mi}^{2}$ grid in comparison with the ATLSS scale of 500 by $500 \mathrm{~m}^{2}$. All four components in the SFWMD model are mechanistic models (103 ESM, 1980), where variable relationships are translated into equations that are plotted as continuous curves, with the suitability index on the y-axis and the variable of interest on the $\mathrm{x}$-axis.

\section{Breeding}

The index for breeding is based on the number of days $(\mathrm{t})$ with pond depth below $0.5 \mathrm{ft}$ between May 16 of the previous year to April 15 of the current year.

$$
\begin{array}{ll}
\mathrm{SI}_{\text {breeding }}=1.0 & , \mathrm{t} \leq 50 \text { days } \\
\mathrm{SI}_{\text {breeding }}=(125-\mathrm{t}) / 75 & , 50<\mathrm{t} \leq 125 \text { days }(\text { range }=75 \text { days }) \\
\mathrm{SI}_{\text {breeding }}=0.0 & , \mathrm{t}>125 \text { days }
\end{array}
$$

\section{Nest Building (Prerequisite)}

Regression analysis was used to examine the significant relationship between mean water depth $\left(\mathrm{d}_{1}\right)$ and nest building for the mating season from April 16 to May 15 (dates differ from Rice and others, 2004, and are used throughout this report). The optimal depth is between 1.3 and $1.6 \mathrm{ft}$.

$$
\begin{array}{lll}
\mathrm{SI}_{\text {nest-building }}=0.0 & , \mathrm{~d}_{1} \leq 0.0 \mathrm{ft} \text { or } \mathrm{d}_{1}>4.0 \mathrm{ft} \\
\mathrm{SI}_{\text {nest-building }}=\mathrm{d}_{1} / 1.3 & & , 0.0<\mathrm{d}_{1} \leq 1.3 \mathrm{ft}(\text { range }=1.3 \mathrm{ft}) \\
\mathrm{SI}_{\text {nest-building }}=1.0 & & , 1.3<\mathrm{d}_{1} \leq 1.6 \mathrm{ft} \\
\mathrm{SI}_{\text {nest-building }}=\left(4.0-\mathrm{d}_{1}\right) / 2.4 & , 1.6<\mathrm{d}_{1} \leq 4.0 \mathrm{ft}(\text { range }=2.4 \mathrm{ft})
\end{array}
$$




\section{Nest Flooding}

A rise in water level of $0.5 \mathrm{ft}$ will result in the start of egg mortality, and a rise of 1.0 to $1.5 \mathrm{ft}$ will result in total mortality. This index performed poorly during certain low water levels, that is, where "flooding" was incorrectly predicted when water levels rose from below ground surface to ground surface. This problem was rectified to indicate flooding only when water levels reached $0.5 \mathrm{ft}$ above ground level. Water depth differences $\left(\Delta_{\max }\right)$ are measured as the maximum water depth during incubation (July 1 to August 31) minus mean water depth during nest building (June 15 to June 30). There is an inverse relationship of the index value with nest flooding; the value of the index increases with decreasing likelihood of nest flooding and thus is the measurement of nonflooding ${ }^{1}$.

$$
\begin{array}{ll}
\mathrm{SI}_{\text {nonflooding }}=1.0 & , \Delta_{\max } \leq 0.5 \mathrm{ft} \\
\mathrm{SI}_{\text {nonflooding }}=1.5-\Delta_{\max } & , 0.5<\Delta_{\max } \leq 1.5 \mathrm{ft} \\
\mathrm{SI}_{\text {nonflooding }}=0.0 & , \Delta_{\max }>1.5 \mathrm{ft}
\end{array}
$$

\section{Survival and Condition}

Hatchling or immature alligator survival critically depends on water levels. During drought periods, alligators concentrate in alligator holes or other types of holes. Cannibalism by large alligators is common. A minimum monthly average water depth was set at $-0.5 \mathrm{ft}$.

Body condition of all ages decreases with rise in water depth, with the threshold at 0.75 $\mathrm{ft}$. For water depths below ground surface $(0 \mathrm{ft})$, young survival is critical; for depths above ground surface, condition is important. The minimum of 12 monthly averages of the water depth $\left(\mathrm{d}_{2}\right)$ is used to compute the index component. Since recovery from a catastrophic drought takes several years, the final index is multiplied by the ratio of the number of years (yr) since the last drying period to less than $0.3 \mathrm{ft}$ divided by 3 years (limited to a maximum of 3 years).

$$
\begin{array}{ll}
\mathrm{SI}_{\text {surv\&cond }}=0.0 & , \mathrm{~d}_{2} \leq-2.0 \mathrm{ft} \\
\mathrm{SI}_{\text {surv\&cond }}=\left(\mathrm{d}_{2}+2.0\right) / 1.5 & ,-2.0<\mathrm{d}_{2} \leq-0.5 \mathrm{ft} \\
\mathrm{SI}_{\text {surv\&cond }}=1.0 & ,-0.5<\mathrm{d}_{2} \leq 0.75 \mathrm{ft} \\
\mathrm{SI}_{\text {surv\&cond }}=\left(2.85-0.8 \mathrm{~d}_{2}\right) / 2.25,0.75<\mathrm{d}_{2} \leq 3.0 \mathrm{ft} \\
\mathrm{SI}_{\text {surv\&cond }}=0.2 & , \mathrm{~d}_{2}>3.0 \mathrm{ft}
\end{array}
$$

overall $\mathrm{SI}_{\text {surv\&cond }}=\mathrm{SI}_{\text {surv\&cond }} *(\mathrm{yr} / 3)$

1

1 Differs from Rice and others (2004). Rice's index subscript "nest flooding" is changed to "nonflooding," redefined according to index values as the proportion of alligator nests not flooded (see fig. 7-6 in Rice and others (2004)). New symbolism is also applied in the subsequent HSI formula. 


\section{Habitat Suitability Index}

An overall composite suitability index using all four components is computed as a weighted arithmetic mean. Weighting is assigned according to the amount of data supporting the component against uncertainty; more data and less uncertainty lead to higher weights. Breeding and nest building are weighted the highest at three, followed by nest flooding (lacked habitat and elevation information) at two, and survival and condition at one. The weighted sum of all four components is divided by the sum of the weights, which is equal to nine.

$$
\mathrm{HSI}=\left(3 * \mathrm{SI}_{\text {breeding }}+3 * \mathrm{SI}_{\text {nest-building }}+2 * \mathrm{SI}_{\text {nonflooding }}+1 * \mathrm{SI}_{\text {surv\&cond }}\right) / 9
$$

\section{Evaluation of Alligator HSI Performance in Florida}

The above suitability index and its separate components were evaluated in three scenarios (natural, current, and restored). Several shortcomings are described below (Rice and others, 2004).

The index value for breeding suitability was developed from field data of annual water stage and female alligator densities in the slough areas. Thus, the value is high in the central slough regions and best suited there; however, it did not appear to work well for the prairie edges, which incidentally have the highest alligator density. The grid scale (2-mi by 2-mi) was too coarse to delineate suitability at the edges and did not represent these areas adequately.

Likewise, the index value for nest building suitability was higher in the slough than at the prairie edges. This index value, nevertheless, was low throughout all scenario evaluations, which suggests that the index may be too narrowly defined at the optimum water depth range of 1.3 to $1.6 \mathrm{ft}$, so that a broader range of 0.7 to $2.8 \mathrm{ft}$ for an index value of at least 0.5 may be more realistic. Locations of ideal conditions for nesting may require more precision; the index lacks additional microenvironmental variable information (such as elevation, vegetation, and flooding), which were not obtainable at the coarse grid scale.

The index value for nest flooding suitability was high and fairly insensitive to hydrological variations among the three scenarios, suggesting that differences in average water depth may not be the best measurement for suitability. Furthermore, for the Loxahatchee National Wildlife Refuge, the nest flooding component is not at all applicable since alligators nest in higher tree islands that are not susceptible to flooding, and suitability is always assigned the value of 1.0 .

The index value for survival and condition suitability behaved like that for the nest building: values were high in sloughs and low at the edges, but relatively low throughout all three scenarios. This is consistent with the historical characterization of The Everglade environment as being harsh for alligators. Not only is this index value weighted lowest in the composite index since it displays the most uncertainty, it also incorporates multiplication of a 
ratio over a 3-year period. This hinders future predictions, and uncertainties will magnify over time.

As seen above, the components making up the composite index were defined for the central slough regions of The Everglades and best suited for slough habitats. Values for the peripheral prairie edges were skewed, and alligator populations in the edges were not adequately depicted. Therefore, the application of the index throughout the entire Everglades region is not realistic and is actually inappropriate for alligator populations outside the slough regions. Again, the grid scale is too coarse to incorporate microtopographical or hydrological variations.

In terms of the individual components, the overall Florida HSI is mostly influenced by the highest weighted components of breeding and nest building. The spatial suitability patterns of the overall index coincided best with the nest building component, followed by enhancement from breeding information. The survival and condition index emulated the nest building index, and its influence was masked. Nest flooding had a restraining effect on the overall HSI, thereby restricting values between 0.2 and 0.8 , except in a few isolated areas. The aforementioned weighting and similarities between components suggest possible future overlapping of the components into one simpler index with a broader range of values. 


\section{Alligator Spatially Explicit Species Index (SESI) of Florida}

Since both alligator survival and population dynamics directly rely on hydrology, any spatial or temporal changes relate easily to responses in alligator breeding. The alligator production index (API) of the Florida SESI is a rough approximation of annual breeding potential; that is, the probability of producing nests and offspring (The Institute for Environmental Modeling [TIEM], 2004b; Rice and Slone, 2004). Water levels (flooding) are key factors during mating season, as optimal nest success is dependent on water levels during nest construction and during egg incubation. Vegetation cover type and elevation are also important. Thus, the index is a combination of three factors: breeding and nesting potential, nest flooding, and habitat quality type.

The spatial resolution of 500 by $500 \mathrm{~m}$ is adequate as it corresponds to the home range of the nesting female alligators. The temporal resolution is one day for water data (ft) and is static for vegetation type (rank). One index value is produced for a single year.

\section{Breeding and Nesting}

Based on the water depth over the previous year, $(P(\mathrm{Y}))$ is defined as the probability of alligator nesting for a given spatial cell $(\mathrm{x}, \mathrm{y})$. It is computed as the average of breeding $(P(\mathrm{Y} 1))$ and nest building $(P(Y 2))$. The aforementioned probabilities are analogous to suitability indices.

During the 11-month time period from May 16 of the previous year to April 15 of the current year of total days (T) (335 or 336 in leap year), the total number of dry days (t) for water depth below $0.5 \mathrm{ft}$ are counted per cell $(\mathrm{x}, \mathrm{y})$. The probability of breeding within a cell $(\mathrm{x}, \mathrm{y})$, $P(\mathrm{Y} 1)$, is computed based on a regression of the proportion of females nesting (Y1) on the proportion of dry days $(\mathrm{X} 1)(<0.5 \mathrm{ft})$, which then is rescaled for absolute maximum and minimum (Y1) values over the entire grid.

For each cell $(\mathrm{x}, \mathrm{y})$ in the study area:

$$
\begin{aligned}
\text { Proportion of dry_days } & =\text { dry_days/non_nesting_days } \\
& =\mathrm{t} / \mathrm{T} \\
& =\mathrm{X} 1
\end{aligned}
$$

Given proportion of females_nesting $=\mathrm{Y} 1$ and probability of breeding $=P(\mathrm{Y} 1)$,

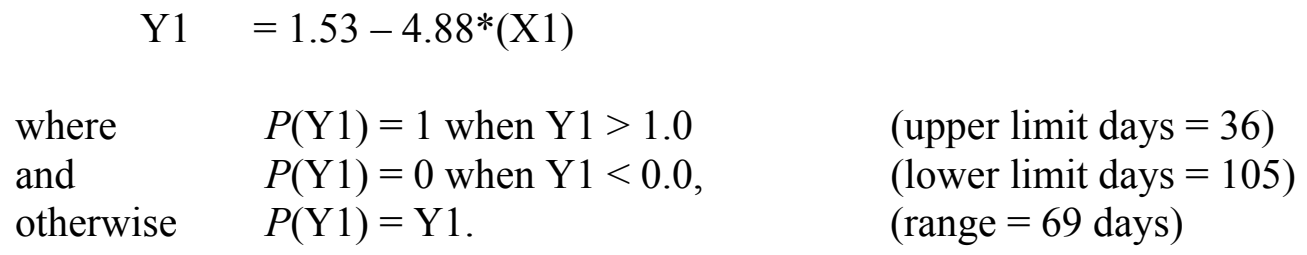


The absolute maximum and minimum $(P(\mathrm{Y} 1))$ values are computed for the rescaling:

$$
\begin{aligned}
& \operatorname{Max}=\operatorname{MAX}(P(\mathrm{Y} 1)) \\
& \operatorname{Min}=\operatorname{MIN}(P(\mathrm{Y} 1))
\end{aligned}, \text { over all cells }(\mathrm{x}, \mathrm{y}) \text { in the grid }
$$

For each cell $(\mathrm{x}, \mathrm{y})$, the rescaled probability scale, $P_{\mathrm{s}}(\mathrm{Y} 1)$, is computed as:

$$
P_{\mathrm{s}}(\mathrm{Y} 1)=\frac{1}{(\mathrm{Max}-\mathrm{Min})} *(P(\mathrm{Y} 1)-\mathrm{Min})
$$

During the peak mating season (April 16-May 15; 30 days), the average water depth (X2) is computed. At a specific value where (X2) equals $1.3 \mathrm{ft}$, the proportion of nest building (Y2) changes (see the regression equations below). The probability of building a nest at cell $(\mathrm{x}, \mathrm{y}), P(\mathrm{Y} 2)$, is computed accordingly.

For each cell $(\mathrm{x}, \mathrm{y})$ :

$$
\begin{array}{ll}
\mathrm{X} 2=\left(\sum \mathrm{x}_{\mathrm{i}}\right) / 30 \text { days } & \text {, where } \mathrm{x}_{\mathrm{i}} \text { is the daily water depth } \\
\mathrm{Y} 2=0.212+0.457 *(\mathrm{X} 2) & , \mathrm{X} 2 \leq 1.3 \mathrm{ft} \\
\mathrm{Y} 2=3.15-1.67 *(\mathrm{X} 2) & , \mathrm{X} 2>1.3 \mathrm{ft}
\end{array}
$$

$\begin{array}{ll}\text { where } & P(\mathrm{Y} 2)=1 \text { when } \mathrm{Y} 2>1.0 \\ \text { and } & P(\mathrm{Y} 2)=0 \text { when } \mathrm{Y} 2<0.0, \\ \text { otherwise } & P(\mathrm{Y} 2)=\mathrm{Y} 2 .\end{array}$

The overall probability of nesting $(P(\mathrm{Y}))$ within a cell $(\mathrm{x}, \mathrm{y})$ is the arithmetic mean of breeding $\left(P_{\mathrm{s}}(\mathrm{Y} 1)\right)$ and nest building $(P(\mathrm{Y} 2))$ :

$$
P(\mathrm{Y})=\frac{P}{\mathrm{~s}} \frac{(\mathrm{Y} 1)+P(\mathrm{Y} 2)}{2}
$$

\section{Flooding}

During the nest building period (June 15-June 30, 16 days), the mean water depth (X3) is computed for each cell. Then the maximum water level (X4) is determined for the incubation period (July 1-Aug. 31, 62 days). The factor of nest flooding (Y3) is based on the difference of this maximum water level and the mean water depth during nest building. Nonflooding, denoted as $1-\mathrm{Y} 3$, may be constructed as a suitability index (see the next section). 
For each cell $(\mathrm{x}, \mathrm{y})$ :

$$
\begin{aligned}
& \mathrm{X} 3=\left(\sum \mathrm{x}_{\mathrm{i}}\right) / 16 \text { days } \quad \text {, where } \mathrm{x}_{\mathrm{i}} \text { is the daily water depth } \\
& \text { of the nest building period } \\
& \mathrm{X} 4=\operatorname{MAX}\left(\mathrm{x}_{\mathrm{j}}\right) \\
& \mathrm{Y} 3=(\text { Max_incubation_water }- \text { mean_water_depth }) * 2 \\
& =(\mathrm{X} 4-\mathrm{X} 3) * 2
\end{aligned}
$$

\section{Habitat Type}

Forty-two Florida GAP Analysis Project (FGAP) vegetation types are ranked from 0.0 to 1.0 in suitability or relative habitat quality for usage in alligator nesting. Each cell is assigned the dominant vegetation type corresponding to a fixed rank value (Y4). There are seven bestsuitable habitats ranked as 1.0 and nine habitats ranging from 0.4 to 0.8 . The remaining are not suitable and ranked as 0.0 . When the cell is assigned the ranking of 0.0 , the entire API is set to zero (see below). Note that Y4 is a suitability index.

$$
\mathrm{Y} 4=\text { relative suitability rank assignment based on species ecology, 0.0-1.0 }
$$

\section{Alligator Production Index (API)}

The alligator production index (API) is the combination of nesting $(P(\mathrm{Y}))$, flooding $(\mathrm{Y} 3)$, and habitat (Y4). The index has an inverse relationship with flooding; decreases in flooding (increased nonflooding 1-Y3) result in higher index values. The composite index API is defined for each cell $(\mathrm{x}, \mathrm{y})$ as the weighted arithmetic mean:

$$
\begin{array}{rlr}
\text { API }= & \\
\sum_{\mathrm{i}=1}^{3} \mathrm{w}_{\mathrm{i}} & \\
& & \\
=0.0 & \text { for } \mathrm{Y} 4 \neq 0.0 \\
& & \text {, for } \mathrm{Y} 4=0.0
\end{array}
$$

where the weights are $\mathrm{w}_{1}=2.0, \mathrm{w}_{2}=3.0$, and $\mathrm{w}_{3}=1.0$. 


\section{Comparison of Florida Alligator HSI and SESI Models}

\section{Breeding}

The HSI model specifically selects 50 dry days and 125 dry days as the lower (index $=$ 1.0 ) and upper (index $=0.0$ ) limits, respectively. For the SESI equation on breeding, the limits are 36 days and 105 days, respectively, and represent a general shift of 14 days with a narrower range $(75=>69)$ and a slightly steeper slope. Thus, the HSI model generates higher values of the breeding component by about 20-30 percent from day 36 to 125 than the analogous SESI component in that range of days (fig. 4). The breeding component, however, is rescaled in the SESI model, which alters the probability of breeding. This depends on the minimum and maximum values found throughout all cells in the grid. For example, when the probability is close to the maximum, the component becomes inflated. On the other hand, the component decreases substantially when the probability is close to the minimum value (if $P(\mathrm{Y} 1)=$ minimum, then the component $=0$ ). Thus, the precise amount of change in the SESI model component varies, and the difference in the models becomes unknown. There is no rescaling in the HSI model.

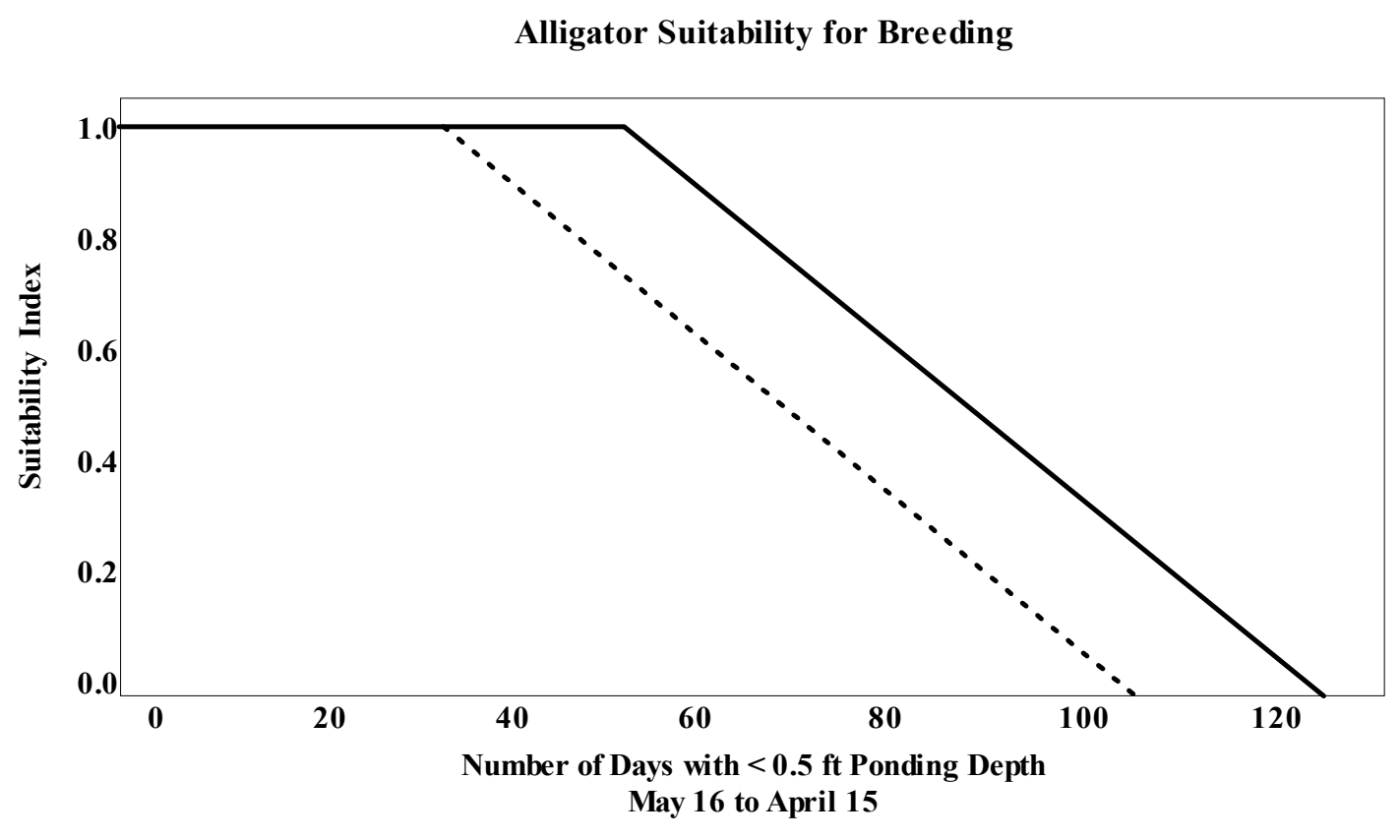

Figure 4. Suitability for breeding. The habitat suitability index (HSI) model is the solid line; the spatially explicit species index (SESI) model is the dotted line. Modified with permission from Rice and others (2004). 


\section{Nest Building}

In both the SESI and HSI models (fig. 5), the same value of $1.3 \mathrm{ft}$ is designated as the lower limit (index reaches maximum) on average water depth during the nesting period. The SESI model, however, reaches its peak when the index value is equal to 0.8 instead of 1.0 as in the HSI. The HSI model has a plateau between 1.3 and $1.6 \mathrm{ft}$ (index $=1.0$ ) and comes back down when the index equals 0.0 at $4 \mathrm{ft}$. The SESI model has no plateau and comes down from 1.3 quickly to $1.9 \mathrm{ft}$ (index $=0.0$ ). This is where the major difference lies in nest building definitions; the index returns to 0.0 at $1.9 \mathrm{ft}$ (SESI) as opposed to $4.0 \mathrm{ft}$ (HSI). Thus, the downslope of SESI is steeper at -1.66 , whereas the slope of HSI is -0.4167 . Moreover, HSI maintains an index value $\geq 0.5$ between water depths of 0.7 and $2.8 \mathrm{ft}$ (range of 2), while in SESI, the index range of values is narrower, between 0.62 and 1.6 (range of 1). Consequently, the HSI model generates overall larger values (up to 90 percent) with higher average water depth. It is, therefore, recommended that more research (field observations) be conducted to reassess the affect of water depths between 1.9 and 4 feet on nest building.

Furthermore, the SESI model combines the breeding and nesting building factors into one component (arithmetic average) as the overall probability of nesting. This may counterbalance the unpredictable nature of the rescaling in the breeding factor; that is, the "wild card" effect. Nevertheless, since the nest building factor is usually much lower in the SESI model than the HSI model, the average (SESI) will most likely be lower than the HSI model counterparts.

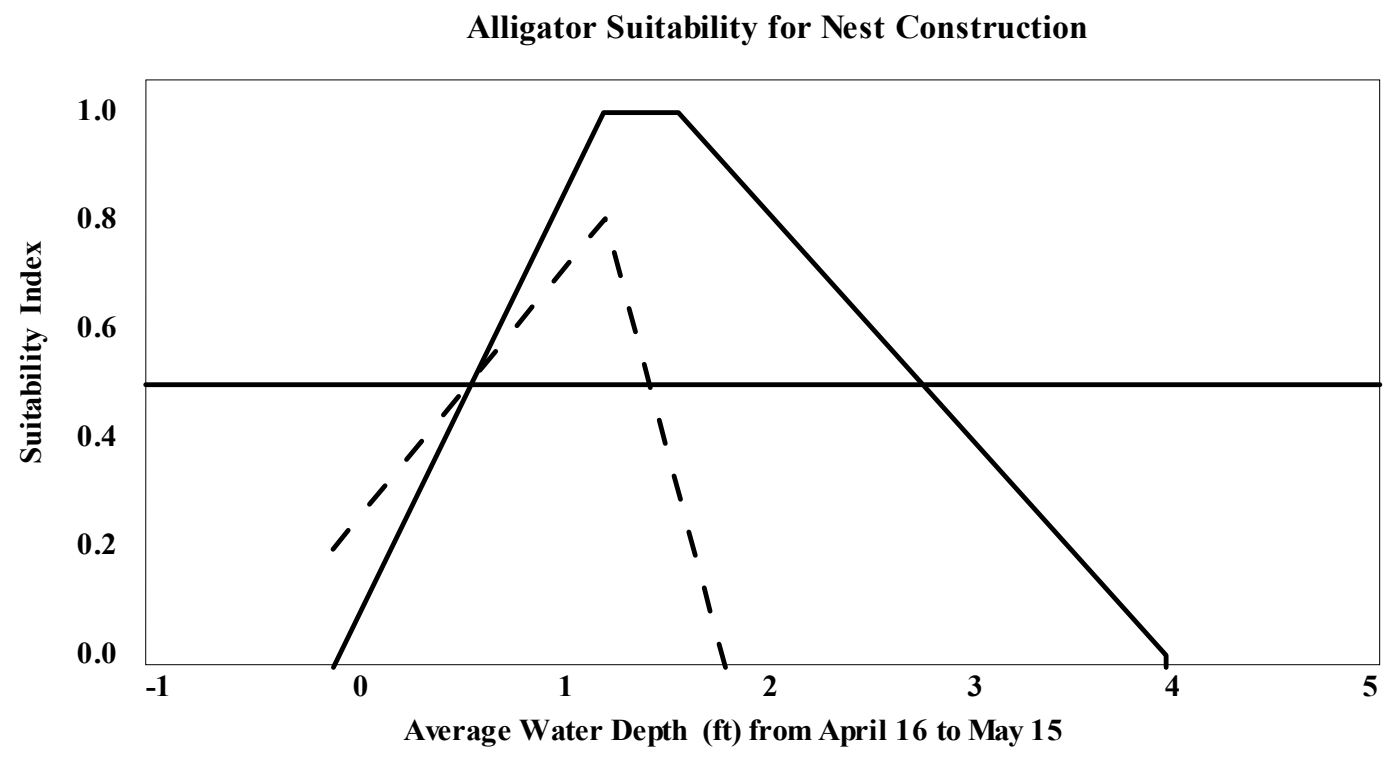

Figure 5. Suitability for nest building. The habitat suitability index (HSI) model is the solid line; the spatially explicit species index (SESI) model is the dotted line. The horizontal solid line shows the suitability threshold at index value of 0.5 . Modified with permission from Rice and others (2004). 


\section{Nest Flooding}

For both the SESI and HSI models, the mean water depth during nest building is computed, and the maximum water depth during incubation is measured. The difference $(\Delta)$ of the maximum and mean values is calculated. How this difference is defined and used in a nest nonflooding suitability index is not the same between the models. To match $\mathrm{SI}_{\text {nonflooding }}$ in HSI, the SESI flooding factor is converted to nonflooding (1 - Y3) in API. In the present form, as given in the API index of the previous section, the component (1 - Y3) may generate negative values. Thus, it is redefined here as a suitability function, compensated with a reset to zero:

SESI:

$$
\begin{aligned}
\mathrm{SI}_{\text {nonflooding }} & =1-(\Delta * 2) \\
& =(0.5-\Delta) * 2 \\
\mathrm{SI}_{\text {nonflooding }} & =1.0 \\
\mathrm{SI}_{\text {nonflooding }} & =0.0
\end{aligned}
$$

$$
\begin{aligned}
& , 0.0<\Delta \leq 0.5 \mathrm{ft} \\
& , \Delta \leq 0.0 \mathrm{ft}
\end{aligned}
$$$$
, \Delta>0.5 \mathrm{ft} \quad \text { (reset to } 0.0 \text { when negative) }
$$

HSI:

$$
\begin{aligned}
& \mathrm{SI}_{\text {nonflooding }}=1.5-\Delta \\
& \mathrm{SI}_{\text {nonflooding }}=1.0 \\
& \mathrm{SI}_{\text {nonflooding }}=0.0
\end{aligned}
$$

$$
\begin{aligned}
& , 0.5<\Delta \leq 1.5 \mathrm{ft} \\
& , \Delta \leq 0.5 \mathrm{ft} \\
& , \Delta>1.5 \mathrm{ft}
\end{aligned}
$$

The suitability index of nest nonflooding (HSI) generates significantly higher values by definition (fig. 6). For example, when the difference $(\Delta)$ is equal to 0.9 , the SESI nonflooding index value computed as -0.8 is reset to 0.0 , but the HSI nonflooding index value equals 0.6. The HSI model illustrates that alligator nests can deal with greater depths of flooding by up to a foot before critical egg mortality eventuates.

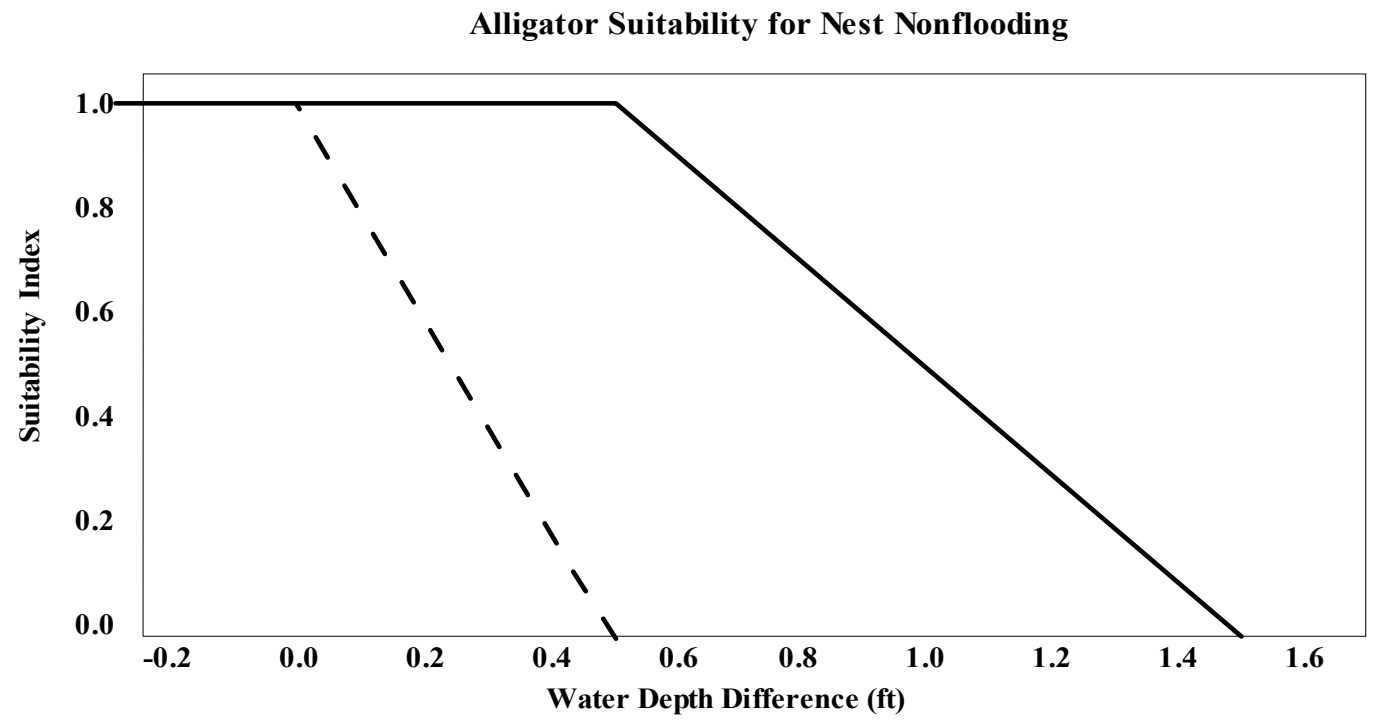

Figure 6. Suitability for nest nonflooding. The habitat suitability index (HSI) model is the solid line; the spatially explicit species index (SESI) model is the dotted line. Modified with permission from Rice and others (2004). 
Consequently, the overall index (API) in the SESI should be appropriately redefined by using the above suitability index function $\left(\mathrm{SI}_{\text {nonflooding }}=f(1-\mathrm{Y} 3)\right)$ for nonflooding:

$$
\begin{array}{rlr}
\mathrm{API}_{1}=\frac{\mathrm{w}_{1} * P(\mathrm{Y})+\mathrm{w}_{2} *(f(1-\mathrm{Y} 3))+\mathrm{w}_{3} * \mathrm{Y} 4}{\sum_{\mathrm{i}=1}^{3} \mathrm{w}_{\mathrm{i}}} & , \text { for } \mathrm{Y} 4 \neq 0.0 \\
& =0.0 & , \text { for } \mathrm{Y} 4=0.0
\end{array}
$$

Furthermore, the breeding time periods for mating, nest construction, and nest flooding need clarification. Both Florida models distinguish the mating period (SESI) or prerequisite nest building period (HSI) as being from April 16 to May 15, then there is a gap from May 16 to June 14 , followed by actual nest construction period from June 15 to 30 . Afterwards, the maximum water depth is measured during egg incubation from July 1 to August 30 . Thus, there are three critical periods of water depth measurements for successful breeding. Note that although the difference in water depths $(\Delta)$ between the maximum incubation and mean during nest construction is defined and the ranges are described, the actual value of the mean water depth for the nest construction during June 15 through 30 is not used, and any limitations on its values are not designated. Thus, water depth does not take into account possible flooding during heavy rains. That is, as long as the maximum water level during incubation is a little above this mean value of nest construction and can be described as nonflooding, in actuality both levels may be too high, resulting in lack of nest construction or egg mortality. Therefore, the use of only the difference measurement alone in both Florida models may be arguable, since it may not contain enough information; a mean value for nest construction may need to be incorporated in the nest flooding component. In addition, it is unknown why the time period gap of May 16 to June 14 is not accounted for. 


\section{Total Suitability Index}

In the overall composite API and HSI, the weights assigned for the breeding, nest building, and nest nonflooding components are not alike. The disparities in weights are in part due to the definition differences in the breeding and nest building components. Reiterating, in the API, the average is computed for breeding and nest building (equal weights of 2); however, there is an additional weight on breeding $(1 /(\max -\min ))$. Therefore, they are not weighted equally. In HSI, both breeding and nest building are separately assigned equal and higher weight values than in the API. The nest nonflooding component, however, is weighted more heavily in the API than in the HSI. The index formulae are rewritten below, emphasizing the dissimilarities in the weight coefficients between the components in bold.

Expanding the API for SESI (redefined $\mathrm{API}_{1}$ ) for all components, renamed as SI:

$$
\begin{aligned}
\mathrm{API}_{1} & =\frac{2 *\left\{\left[(1 /(\max -\mathrm{min})) * \mathrm{SI}_{\text {breeding }}+1 * \mathrm{SI}_{\text {nest-building }}\right] / 2\right\}+3 * \mathrm{SI}_{\text {nonflooding }}+1 * \mathrm{SI}_{\text {habitat }}}{6} \\
& =(\mathbf{1} / \mathbf{6}(\mathbf{m a x}-\mathbf{m i n})) * \mathrm{SI}_{\text {breeding }}+\mathbf{( 1 / 6 )} * \mathrm{SI}_{\text {nest-building }}+\mathbf{( 1 / 2 )} * \mathrm{SI}_{\text {nonflooding }}+\mathbf{( 1 / 6 )} * \mathrm{SI}_{\text {habitat }}
\end{aligned}
$$

where $\mathrm{SI}_{\text {breeding }}=P(\mathrm{Y} 1-\mathrm{Min}), \mathrm{SI}_{\text {nest-building }}=P(\mathrm{Y} 2), \mathrm{SI}_{\text {nonflooding }}=f(1-\mathrm{Y} 3)$, and $\mathrm{SI}_{\text {habitat }}=\mathrm{Y} 4$.

Likewise, rewriting the HSI for all components:

$\mathrm{HSI}=(\mathbf{1 / 3}) * \mathrm{SI}_{\text {breeding }}+(\mathbf{1 / 3}) * \mathrm{SI}_{\text {nest-building }}+(\mathbf{2} / 9) * \mathrm{SI}_{\text {nonflooding }}+(\mathbf{1} / 9) * \mathrm{SI}_{\text {surv \&cond }}$

As mentioned in previous sections, not only are the individual components most likely higher in the HSI model, but the coefficients themselves accentuate certain components more than others (see the expanded formulae above). The two components, survival/condition and habitat, that differ between the indices are lightly weighted and thereby have a lesser effect on the overall index. Furthermore, the API strongly emphasizes the nest nonflooding aspect as the predominant feature for alligator habitat suitability, representing half of the index value. All other API components are weighted alike at approximately 66 percent lower than nest nonflooding. The HSI spreads importance equally on breeding and nest building, followed closely by nest nonflooding. Thus, the generally higher breeding, nest building, and nest nonflooding components together with larger weights should produce an overall HSI value greater than the API value. This is illustrated in the examples of the following section on comparisons. 


\section{Comparison of All Alligator Models}

Three hypothetical habitat settings are constructed to compare all suitability index models: the Florida SESI (original API) and HSI models, as well as the general and modified Louisiana HSI (LCA study) models. In all models, hydrological metrics are equivalent; water depth is measured from soil surface. Table 1 portrays more typical data conditions for one cell $(\mathrm{x}, \mathrm{y})$ in intermediate marshes with moderate flooding. Data are added to accommodate the general and Louisiana HSI models concerning percentage of land or open water and pond parameters. Breeding rescaling in the SESI models is not applied $(\min =0, \max =1)$. Because intermediate and brackish marshes are both described as estuarine emergent, dominated by Spartina patens (Newsom, 1987) and predominantly different by the amount of salinity, the water depth (V3) variable equations for brackish marshes in the Louisiana HSI model are implemented for the intermediate marshes of these settings. The variable for the yearly average water depth (V3) in the Louisiana HSI model will be approximated in order to concur more realistically with settings that may be characterized by the various known water depth variables in both Florida models. The variable (V3) is thus computed as an average based on several variables from both Florida models: (1) the mean water depths of the SESI model for nest building (X2) and flooding (X3), (2) the maximum flooding water level (X4) of the SESI model, (3) the minimum average water depth $\left(\mathrm{d}_{2}\right)$ of the Florida HSI model, and (4) the product of the number of dry days $(\mathrm{t})$ with the average depth below $0.5 \mathrm{ft}$ of the SESI model and water depth $\left(\mathrm{d}_{2}\right)$ of the HSI model $\left(\left(0.5+\mathrm{d}_{2}\right) / 2\right.$, when $\left.\mathrm{d}_{2}<0.5 \mathrm{ft}\right)$ :

$$
\begin{array}{rlrl}
\mathrm{V} 3 & =\frac{\left[(365-\mathrm{t}) *\left(\mathrm{X} 2+\mathrm{X} 3+\mathrm{X} 4+\mathrm{d}_{2}\right) / 4\right]+\left[\mathrm{t} *\left(0.5+\mathrm{d}_{2}\right) / 2\right]}{365} & , \mathrm{~d}_{2}<0.5 \mathrm{ft} \\
& =\left(\mathrm{X} 2+\mathrm{X} 3+\mathrm{X} 4+\mathrm{d}_{2}\right) / 4 & & , \mathrm{~d}_{2} \geq 0.5 \mathrm{ft}
\end{array}
$$

Table 2 is a modification of table 1, where the values of nest building and flooding mean water depths are decreased to represent low flooding. Table 3 data deviate more from moderate conditions, characterized by more dry days but with heavier rains that result in deeper waters, more open water (65 percent), and less pond interspersion.

In all three settings, the Florida indices performed as expected and as theoretically verified in the previous section. The SESI model consistently produced lower index values than the HSI model. Very low API values were produced by the more extreme third setting (see explanations below).

In moderate and deep water depths, the HSI values for Florida and general models appear closer in value than those of either the SESI or Louisiana HSI (tables 1 and 3). Although they are based on very different components or definitions, they evidently behave similarly. For the first setting of typical conditions (table 1), these two index values for the Florida HSI and general HSI models are both high, representing a very good suitable habitat at approximately 
0.80 . The Louisiana HSI value is set to 0.0 because the moderate water depths in the marshes of the first setting are ruled as excessive for all wildlife in the LCA study, with no special adjustments for alligators (USACE, 2004). In contrast, both Florida SESI and HSI models and the general HSI model consider 1.0-1.5-ft depths as reasonable for alligator breeding and nesting. The second setting depicts shallower water depths within the suitable ranges of the Louisiana HSI model (table 2). In this case, the general HSI value exceeds 0.70 (good suitability), while the Louisiana HSI value is excellent at 0.88 ; however, values of the two Florida indices (SESI and HSI) drop to marginal suitability (around 0.4-0.5). Apparently, the Florida models favor slightly greater water depths.

For deeper waters and increased water areas of the third setting (table 3), all index values were lower than the first setting of typical conditions. Note that this setting was especially constructed to demonstrate computational issues. Both (Y1) and (Y2) become negative in the Florida SESI model, resetting the $(P(\mathrm{Y} 1))$ and $(P(\mathrm{Y} 2))$ to zero, so that the first component $(P(\mathrm{Y}))$ is computed as zero. Likewise, the flooding component (Y3) in SESI models exceeds one, whereby the value for nonflooding $(1-\mathrm{Y} 3=1-1.2=-0.2)$ resets to zero. Thus, the second component in the API is also zero. This clearly demonstrates the weakness in the SESI model equations for generating negative values that are then reset to zero, whereby producing an API value that is very low in comparison with values of other indices. 
Table 1. Comparison of all habitat suitability index (HSI) models for the American alligator (Alligator mississippiensis). Setting 1. Florida models are denoted as SESI (F) and HSI (F), general HSI model as HSI (G), and LCA study HSI model as HSI (L). Final index computations include component calculations.

Dataset parameters of setting 1:

100 dry days from May (previous year) to April

(11 months $=335$ days), $\min =0, \max =1$ mean water depth (Apr. 15-May 15) $=1.5 \mathrm{ft}(0.46 \mathrm{~m})$ mean water depth (June 15-30) $=1.0 \mathrm{ft}(0.30 \mathrm{~m})$, $\max ($ July-Aug. $)=1.3 \mathrm{ft}(0.40 \mathrm{~m})$ habitat type $=$ intermediate marsh (IM) min area $=5$ ha, nontidal open water $=40 \%$, percentage of land $=60 \%$ medium interspersion $=7$ ponds $/ 6$ ha $50 \%$ ponded area $\geq 0.15-\mathrm{m}$ depth $(0.5 \mathrm{ft})$ survival/condition, $\mathrm{d}_{2}=0.5 \mathrm{ft}(0.15 \mathrm{~m}), \mathrm{yr} / 3=1$

\begin{tabular}{|c|c|c|c|c|c|c|c|}
\hline \multicolumn{8}{|c|}{ INTERMEDIATE FACTORS (P(Y) or Y) or INDEX (SI) COMPUTATIONS } \\
\hline \multicolumn{2}{|c|}{ SESI (F) } & \multicolumn{2}{|c|}{ HSI (F) } & \multicolumn{2}{|c|}{ HSI (G) } & \multicolumn{2}{|c|}{ HSI (L) } \\
\hline Variable & Factor & Variable & Index & Variable & Index & Variable & Index \\
\hline $\begin{array}{l}\mathrm{X} 1=0.30 \\
\mathrm{Y} 1=0.073\end{array}$ & $P(\mathrm{Y} 1)=0.073$ & $\mathrm{t}=100$ & $\mathrm{SI}_{\text {breed }}=0.33$ & $\begin{array}{l}\mathrm{V} 0=\mathrm{IM} \\
\mathrm{V} 1=40 \% \\
\mathrm{~V} 2=\mathrm{n} / \mathrm{a}\end{array}$ & $\begin{array}{l}\mathrm{SI}_{\mathrm{V} 0}=1.0 \\
\mathrm{SI}_{\mathrm{V} 1}=1.0\end{array}$ & $\begin{array}{l}\mathrm{V} 1=\mathrm{IM} \\
\mathrm{V} 2=60 \%\end{array}$ & $\begin{array}{l}\mathrm{SI}_{\mathrm{V} 1}=1.0 \\
\mathrm{SI}_{\mathrm{V} 2}=1.0\end{array}$ \\
\hline $\mathrm{X} 2=1.5 \mathrm{ft}$ & $\begin{array}{l}P(\mathrm{Y} 2)=0.645 \\
P(\mathrm{Y})=0.36\end{array}$ & $\mathrm{~d}_{1}=1.5 \mathrm{ft}$ & $\mathrm{SI}_{\text {nest_b }}=1.0$ & $\begin{array}{l}\mathrm{V} 3=7 \\
\mathrm{~V} 4=50 \% \\
\mathrm{~V} 5=\mathrm{n} / \mathrm{a}\end{array}$ & $\begin{array}{l}\mathrm{SI}_{\mathrm{V} 3}=0.50 \\
\mathrm{SI}_{\mathrm{V} 4}=0.50\end{array}$ & $\mathrm{~V} 3^{1}=0.33 \mathrm{~m}$ & $\mathrm{SI}_{\mathrm{V} 3}=0.0$ \\
\hline $\begin{array}{l}\mathrm{X} 3=1.0 \mathrm{ft} \\
\mathrm{X} 4=1.3 \mathrm{ft}\end{array}$ & $\begin{array}{l}\mathrm{Y} 3=0.6 \\
1-\mathrm{Y} 3=0.4\end{array}$ & $\Delta_{\max }=0.3$ & $\mathrm{SI}_{\text {nonflood }}=1.0$ & & & & \\
\hline & $\mathrm{Y} 4=1.0$ & $\mathrm{~d}_{2}=0.5 \mathrm{ft}$ & $\mathrm{SI}_{\text {surv }} \mathrm{c}=1.0$ & & & & \\
\hline
\end{tabular}

FINAL INDEX COMPUTATION

\begin{tabular}{|c|c|c|c|}
\hline SESI (F) & $\operatorname{HSI}(\mathrm{F})$ & HSI (G) & HSI (L) \\
\hline $\begin{aligned} \mathrm{API}_{\mathrm{F}}= & {[(2 * .36)+(3 * .4)} \\
& +(1 * 1)] / 6 \\
= & \mathbf{0 . 4 9}\end{aligned}$ & $\begin{aligned} \mathrm{HSI}_{\mathrm{F}}= & {[(3 * .33)+(3 * 1)} \\
& +(2 * 1)+(1 * 1)] / 9 \\
= & \mathbf{0 . 7 8}\end{aligned}$ & $\begin{aligned} \mathrm{C}_{\mathrm{b}}= & \left(\mathrm{SI}_{\mathrm{V} 1} * \mathrm{SI}_{\mathrm{V} 2}\right)^{1 / 2} \\
= & \mathrm{SI}_{\mathrm{V} 1}=1.0 \\
\mathrm{C}_{\mathrm{nn}} & =\left(\mathrm{SI}_{\mathrm{V} 1} * \mathrm{SI}_{\mathrm{V} 3} * \mathrm{SI}_{\mathrm{V} 4}\right)^{1 / 3} \\
& =(1 * .5 * .5)^{1 / 3} \\
& =0.63 \\
\mathrm{C}_{\mathrm{h}}= & \mathrm{SI}_{\mathrm{V} 0}=1.0 \\
\mathrm{HSI}_{\mathrm{G}} & =\left(\mathrm{C}_{\mathrm{h}} * \mathrm{C}_{\mathrm{b}} * \mathrm{C}_{\mathrm{nn}}\right)^{1 / 2} \\
& =(1 * 1 * .63)^{1 / 2} \\
& =\mathbf{0 . 7 9}\end{aligned}$ & $\begin{aligned} \mathrm{HSI}_{\mathrm{L}} & =\left(\mathrm{SI}_{\mathrm{V} 1} * \mathrm{SI}_{\mathrm{V} 2} * \mathrm{SI}_{\mathrm{V} 3}\right)^{1 / 3} \\
& =(1 * 1 * 0)^{1 / 3} \\
& =\mathbf{0 . 0}\end{aligned}$ \\
\hline
\end{tabular}


Table 2. Comparison of all habitat suitability index (HSI) models for the American alligator (Alligator mississippiensis). Setting 2. Florida models are denoted as SESI (F) and HSI (F), general HSI model as HSI (G), and LCA study HSI model as HSI (L). Final index computations include component calculations.

Dataset parameters of setting 2:

100 dry days from May (previous year) to April

(11 months $=335$ days), $\min =0, \max =1$

mean water depth (Apr. 16-May 15) $=0.4 \mathrm{ft}(0.12 \mathrm{~m})$

mean water depth (June 15-30) $=0.2 \mathrm{ft}(0.06 \mathrm{~m})$, $\max ($ July-Aug. $)=0.5 \mathrm{ft}(0.15 \mathrm{~m})$ habitat type $=$ intermediate marsh (IM)

min area $=5$ ha, nontidal

open water $=40 \%$, percentage of land $=60 \%$

medium interspersion $=7$ ponds $/ 6$ ha

$30 \%$ ponded area $\geq 0.15 \mathrm{~m}$ depth $(0.5 \mathrm{ft})$

survival/condition, $\mathrm{d}_{2}=-0.2 \mathrm{ft}(-0.06 \mathrm{~m}), \mathrm{yr} / 3=1$

\begin{tabular}{|c|c|c|c|c|c|c|c|}
\hline \multicolumn{8}{|c|}{ INTERMEDIATE FACTORS (P(Y) or Y) or INDEX (SI) COMPUTATIONS } \\
\hline \multicolumn{2}{|c|}{ SESI (F) } & \multicolumn{2}{|c|}{ HSI (F) } & \multicolumn{2}{|c|}{ HSI (G) } & \multicolumn{2}{|c|}{ HSI (L) } \\
\hline Variable & Factor & Variable & Index & Variable & Index & Variable & Index \\
\hline $\begin{array}{l}\mathrm{X} 1=0.30 \\
\mathrm{Y} 1=0.073\end{array}$ & $P(\mathrm{Y} 1)=0.073$ & $\mathrm{t}=100$ & $\mathrm{SI}_{\text {breed }}=0.33$ & $\begin{array}{l}\mathrm{V} 0=\mathrm{IM} \\
\mathrm{V} 1=40 \% \\
\mathrm{~V} 2=\mathrm{n} / \mathrm{a}\end{array}$ & $\begin{array}{l}\mathrm{SI}_{\mathrm{V} 0}=1.0 \\
\mathrm{SI}_{\mathrm{V} 1}=1.0\end{array}$ & $\begin{array}{l}\mathrm{V} 1=\mathrm{IM} \\
\mathrm{V} 2=60 \%\end{array}$ & $\begin{array}{l}\mathrm{SI}_{\mathrm{V} 1}=1.0 \\
\mathrm{SI}_{\mathrm{V} 2}=1.0\end{array}$ \\
\hline $\mathrm{X} 2=0.4 \mathrm{ft}$ & $\begin{array}{l}P(\mathrm{Y} 2)=0.029 \\
P(\mathrm{Y})=0.066\end{array}$ & $\mathrm{~d}_{1}=0.4 \mathrm{ft}$ & $\mathrm{SI}_{\text {nest } \_} \mathrm{b}=0.31$ & $\begin{aligned} \mathrm{V} 3 & =7 \\
\mathrm{~V} 4 & =30 \% \\
\mathrm{~V} 5 & =\mathrm{n} / \mathrm{a}\end{aligned}$ & $\begin{array}{l}\mathrm{SI}_{\mathrm{V} 3}=0.50 \\
\mathrm{SI}_{\mathrm{V} 4}=0.30\end{array}$ & $\mathrm{~V} 3=0.062 \mathrm{~m}$ & $\mathrm{SI}_{\mathrm{V} 3}=0.69$ \\
\hline $\begin{array}{l}\mathrm{X} 3=0.2 \mathrm{ft} \\
\mathrm{X} 4=0.5 \mathrm{ft}\end{array}$ & $\begin{array}{l}\mathrm{Y} 3=0.6 \\
1-\mathrm{Y} 3=0.4\end{array}$ & $\Delta_{\max }=0.3 \mathrm{f}$ & $\mathrm{SI}_{\text {nonflood }}=1.0$ & & & & \\
\hline & $Y 4=1.0$ & $\mathrm{~d}_{2}=-0.2 \mathrm{ft}$ & $\mathrm{SI}_{\text {surv_c }}=1.0$ & & & & \\
\hline
\end{tabular}

FINAL INDEX COMPUTATION

SESI (F)

$$
\begin{aligned}
\mathrm{API}_{\mathrm{F}}= & {\left[\left(2^{*} .066\right)+\left(3^{*} .4\right)\right.} \\
& +(1 * 1)] / 6 \\
= & \mathbf{0 . 3 9}
\end{aligned}
$$

HSI (F)

$$
\begin{aligned}
\mathrm{HSI}_{\mathrm{F}}= & {[(3 * .33)+(3 * .31)} \\
& +(2 * 1)+(1 * 1)] / 9 \\
= & \mathbf{0 . 5 5}
\end{aligned}
$$

$$
\begin{aligned}
& \mathrm{C}_{\mathrm{b}}=\left(\mathrm{SI}_{\mathrm{V} 1} * \mathrm{SI}_{\mathrm{V} 2}\right)^{1 / 2} \quad \mathrm{HSI}_{\mathrm{L}}=\left(\mathrm{SI}_{\mathrm{V} 1} * \mathrm{SI}_{\mathrm{V} 2} * \mathrm{SI}_{\mathrm{V} 3}\right)^{1 / 3} \\
& =\mathrm{SI}_{\mathrm{V} 1}=1.0 \\
& =(1 * 1 * .69)^{1 / 3} \\
& =0.88 \\
& \mathrm{C}_{\mathrm{nn}}=\left(\mathrm{SI}_{\mathrm{V} 1} * \mathrm{SI}_{\mathrm{V}} * \mathrm{SI}_{\mathrm{V} 4}\right)^{1 / 3} \\
& =\left(1 * .5^{*} .3\right)^{1 / 3} \\
& =0.53 \\
& \mathrm{C}_{\mathrm{h}}=\mathrm{SI}_{\mathrm{V} 0}=1.0 \\
& \operatorname{HSI}_{\mathrm{G}}=\left(\mathrm{C}_{\mathrm{h}} * \mathrm{C}_{\mathrm{b}} * \mathrm{C}_{\mathrm{nn}}\right)^{1 / 2} \\
& =(1 * 1 * .53)^{1 / 2} \\
& =\mathbf{0 . 7 3}
\end{aligned}
$$


Table 3. Comparison of all habitat suitability index (HSI) models for the American alligator (Alligator mississippiensis). Setting 3. Florida models are denoted as SESI (F) and HSI (F), general HSI model as HSI (G), and LCA study HSI model as HSI (L). Final index computations include component calculations.

Dataset parameters of setting 3:

120 dry days from May (previous year) to April

(11 months $=335$ days), $\min =0, \max =1$ mean water depth (Apr. 16-May 15) $=2.0 \mathrm{ft}(0.61 \mathrm{~m})$ mean water depth (June 15-30)=2.0 ft $(0.61 \mathrm{~m})$, $\max ($ July-Aug. $)=2.6 \mathrm{ft}(0.79 \mathrm{~m})$ habitat type $=$ intermediate marsh (IM)

min area $=5$ ha, nontidal

open water $=65 \%$, percentage of land $=35 \%$

low interspersion $=2$ ponds $/ 6$ ha

$90 \%$ ponded area $\geq 0.15 \mathrm{~m}$ depth $(0.5 \mathrm{ft})$

survival/condition, $\mathrm{d}_{2}=1.0 \mathrm{ft}(0.30 \mathrm{~m}), \mathrm{yr} / 3=1$

\begin{tabular}{|c|c|c|c|c|c|c|c|}
\hline \multicolumn{8}{|c|}{ INTERMEDIATE FACTORS (P(Y) or Y) or INDEX (SI) COMPUTATIONS } \\
\hline & SI (F) & & SI (F) & & $\mathrm{I}(\mathrm{G})$ & HSI & ( $(\mathrm{L})$ \\
\hline Variable & Factor & Variable & Index & Variable & Index & Variable & Index \\
\hline $\begin{array}{l}\mathrm{X} 1=0.36 \\
\mathrm{Y} 1=-0.22\end{array}$ & $P(\mathrm{Y} 1)=0.0$ & $\mathrm{t}=120$ & $\mathrm{SI}_{\text {breed }}=0.067$ & $\begin{array}{l}\mathrm{V} 0=\mathrm{IM} \\
\mathrm{V} 1=65 \% \\
\mathrm{~V} 2=\mathrm{n} / \mathrm{a}\end{array}$ & $\begin{array}{l}\mathrm{SI}_{\mathrm{V} 0}=1.0 \\
\mathrm{SI}_{\mathrm{V} 1}=0.58\end{array}$ & $\begin{array}{l}\mathrm{V} 1=\mathrm{IM} \\
\mathrm{V} 2=35 \%\end{array}$ & $\begin{array}{l}\mathrm{SI}_{\mathrm{V} 1}=1.0 \\
\mathrm{SI}_{\mathrm{V} 2}=0.58\end{array}$ \\
\hline $\mathrm{X} 2=2.0 \mathrm{ft}$ & $\begin{array}{l}P(\mathrm{Y} 2)=0.0 \\
P(\mathrm{Y})=0.0\end{array}$ & $\mathrm{~d}_{1}=2.0 \mathrm{ft}$ & $\mathrm{SI}_{\text {nest } \_\mathrm{b}}=0.83$ & $\begin{array}{l}\mathrm{V} 3=2 \\
\mathrm{~V} 4=90 \% \\
\mathrm{~V} 5=\mathrm{n} / \mathrm{a}\end{array}$ & $\begin{array}{l}\mathrm{SI}_{\mathrm{V} 3}=0.20 \\
\mathrm{SI}_{\mathrm{V} 4}=0.90\end{array}$ & $\mathrm{~V} 3=0.58 \mathrm{~m}$ & $\mathrm{SI}_{\mathrm{V} 3}=0.0$ \\
\hline $\begin{array}{l}\mathrm{X} 3=2.0 \mathrm{ft} \\
\mathrm{X} 4=2.6 \mathrm{ft}\end{array}$ & $\begin{array}{c}\mathrm{Y} 3=1.2 \\
1-\mathrm{Y} 3=-0.2 \\
=0 \\
\mathrm{Y} 4=1.0\end{array}$ & $\Delta_{\max }=0.6 \mathrm{f}$ & $\mathrm{SI}_{\text {nonflood }}=0.90$ & & & & \\
\hline
\end{tabular}

FINAL INDEX COMPUTATION

\begin{tabular}{|c|c|c|c|}
\hline SESI (F) & HSI (F) & HSI (G) & HSI (L) \\
\hline $\begin{aligned} \mathrm{API}_{\mathrm{F}}= & {[(2 * 0)+(3 * 0)} \\
& +(1 * 1)] / 6 \\
= & \mathbf{0 . 1 7}\end{aligned}$ & $\begin{aligned} \mathrm{HSI}_{\mathrm{F}}= & {\left[\left(3^{*} .067\right)+(3 * .83)\right.} \\
& +(2 * .9)+(1 * .91)] / 9 \\
= & \mathbf{0 . 6 0}\end{aligned}$ & $\begin{aligned} & \mathrm{C}_{\mathrm{b}}=\left(\mathrm{SI}_{\mathrm{V} 1} * \mathrm{SI}_{\mathrm{V} 2}\right)^{1 / 2} \\
&= \mathrm{SI}_{\mathrm{V} 1}=0.58 \\
& \mathrm{C}_{\mathrm{nn}}=\left(\mathrm{SI}_{\mathrm{V} 1} * \mathrm{SI}_{\mathrm{V} 3} * \mathrm{SI}_{\mathrm{V} 4}\right)^{1 / 3} \\
&=(.58 * .2 * .9)^{1 / 3} \\
&=0.47 \\
& \mathrm{C}_{\mathrm{h}}= \mathrm{SI}_{\mathrm{V} 0}=1.0 \\
& \\
& \mathrm{HSI}_{\mathrm{G}}=\left(\mathrm{C}_{\mathrm{h}} * \mathrm{C}_{\mathrm{b}} * \mathrm{C}_{\mathrm{nn}}\right)^{1 / 2} \\
&=(1 * .53 * .47)^{1 / 2} \\
&=\mathbf{0 . 5 2}\end{aligned}$ & $\begin{aligned} \mathrm{HSI}_{\mathrm{L}} & =\left(\mathrm{SI}_{\mathrm{V} 1} * \mathrm{SI}_{\mathrm{V} 2} * \mathrm{SI}_{\mathrm{V} 3}\right)^{1 / 3} \\
& =\left(1 * .58^{*} .0\right)^{1 / 3} \\
& =\mathbf{0 . 0}\end{aligned}$ \\
\hline
\end{tabular}




\section{$\underline{\text { Statistical Analyses }}$}

Although three hypothetical settings were examined in the previous section, a more comprehensive comparison of the Florida SESI and HSI models may be warranted to capture the full spectrum throughout the regions. This will enhance a better understanding of the model performance, especially for unpredictable factors such as rescaling. Thus, in order to evaluate which model and features may be more applicable for the LCA study, a precursory direct comparison of the Florida SESI and HSI models for alligators is proposed.

One major drawback in performing any side-by-side comparison is the obvious grid dimension mismatch. The grid scale dimensions differ vastly, 500 by $500 \mathrm{~m}$ in SESI versus 2 by $2 \mathrm{mi}$ in HSI (representing an increase of grid cell area by 36 times). At this time, geostatistical methods are difficult to apply without conversion to the coarser grid, whereby there would be a substantial loss of information in the SESI models.

An alternate approach would be to sample both models at identical points and obtain the cell values for critical measurements (for example, dry days, water depths, habitat types, or condition factors). Then the separate index components and final composite index would be computed in both models. All cell measurement values would be statistically analyzed by using standard statistical packages (such as SAS/STAT ${ }^{\circledR}$ Software) to evaluate differences in the components and overall indices for both models. A random sampling design could be applied; however, a stratified sampling design by different habitat sites in all locations would insure adequate sampling in all habitats and help delineate more information within the habitats themselves (for example, habitat centers versus edges). Sampling of at least 100 points per habitat type and over all of its locations, totaling about 1,000 to 2,000 points overall is recommended. Also, this should be repeated for various types of years, such as for several "wet" years and "dry" years each. Furthermore, sampling could be applied in two directions: (1) initially select any SESI 500 by $500-\mathrm{m}$ cell $\left(\mathrm{x}_{1}, \mathrm{y}_{1}\right)$ and locate its corresponding 2 by 2 -mi cell $\left(\mathrm{x}_{\mathrm{h}}, \mathrm{y}_{\mathrm{h}}\right)$ in the HSI grid, or (2) select the 2 by 2-mi HSI cell $\left(\mathrm{x}_{\mathrm{h}}, \mathrm{y}_{\mathrm{h}}\right)$ first and then locate the 500 by 500-m cell $\left(\mathrm{x}_{\mathrm{c}}, \mathrm{y}_{\mathrm{c}}\right)$ closest to the center of this HSI cell. These different sampling methods could clarify and quantify the loss of information in the coarser grid by computing spatial distances between the two 500 by 500-m cells, $\left(\mathrm{x}_{1}, \mathrm{y}_{1}\right)$ and $\left(\mathrm{x}_{\mathrm{c}}, \mathrm{y}_{\mathrm{c}}\right)$, within the same 2 by 2 -mi cell $\left(\mathrm{x}_{\mathrm{h}}, \mathrm{y}_{\mathrm{h}}\right)$ and comparing their cell values.

Technical assistance in the generation of appropriate sampling datasets (tables of measurements or attributes per HSI and SESI cell that represent the sampled point) can be provided by The Institute for Environmental Modeling (TIEM) at University of Tennessee, Knoxville. Results from these investigations may entail some future model enhancements or modifications. Subsequent geostatistical analyses within each model type are envisioned. 


\section{General Evaluation of All Alligator Models}

Three habitat settings were attempted to investigate the behavior of the various alligator model indices. Note that in order to complete the computation of all components of these indices some models required the inclusion of more information. The question is whether the information added accuracy to fine-tune the model or whether it introduced extraneous variables with little bearing on the results. On the other hand, other models were designed by using more sparse information. This may have caused overgeneralization and sacrificed needed information.

\section{Florida Models}

In previous sections, the differences in equation definitions for analogous individual component suitability indices were presented and explained in detail and will not be repeated here.

One major obstacle in producing reliable Florida suitability indices appears to be the underlying specifications of the grid scales. The hydrological models from the South Florida Water Management District were initially designed on a coarse grid scale of 2 by 2-mi, and the subsequent Florida HSI models were structured on this grid. A grid scale of this magnitude has serious consequences; very large cells do not take into account microenvironmental differences in elevation, vegetation, flooding, and so on. If a side-by-side comparison between SESI (500 by $500-\mathrm{m}$ cells) and HSI models is to be attempted, one of the grid scales would have to be converted to the other. In the event that the finer grid of the SESI is converted to coarser, important information at the borders of habitats (such as peripheral prairie edges) would be lost with excessive generalization. For example, the large cell from the HSI model that is made up of 36 smaller SESI cells may not acquire a particular value if less than half of the smaller cells do not have this value. Microenvironmental information would be especially sacrificed. Therefore, the problem of inaccurate suitability indices for prairie edges previously described would be accentuated.

Furthermore, the Florida HSI may be misleading across diverse habitats as there is no environmental information in the formula. High index values may be computed for obvious unsuitable habitats. In contrast, the API in the SESI model incorporates habitat types with more precision, ranking many as suitable of 42 FGAP vegetation types. Therefore, the API value would be realistically computed lower in less desirable habitats. Care should be exercised, however, as habitat in the SESI model may be too finely partitioned into many types, or there may be lack of good judgment in assigning ranks.

Moreover, the weights of the individual components in the Florida HSI equation, as well as the individual component equations themselves, may be readily adjusted or redefined for any region, based on the ecological and hydrological information available. As explained earlier, these equations were designed for sloughs so that other habitats were not adequately depicted. 
Thus, for other regions there may be more or less uncertainty in specific components requiring weight modification. Also, different species ecologies and hydrodynamics may affect the component equations. This is an important observation; the model in this general form may not be applicable throughout all areas, but individual components or equations can be locally tailored. Hence, continual evaluation and calibration processes should also be individually adapted per region.

\section{Scoring All Models by Factor Categories}

All models will be compared by specific factors and scored as high (well represented or defined), mod (moderately represented), or low (lacking or poorly defined) (table 4).

1. Grid Scale. The Florida HSI scale is very coarse at 2 by $2 \mathrm{mi}$, the Louisiana HSI model uses an intermediate grid scale of 1,000 by $1,000 \mathrm{~m}$, and the SESI model is finest at 500 by $500 \mathrm{~m}$. There is no grid specification for the general HSI model.

2. Habitat. General suitable habitat is critical for breeding and survival of any species. This factor is included in all models except the Florida HSI, thereby constituting a major drawback for the Florida HSI model. The SESI model offers the most habitat definitions based on FGAP, whereas the general HSI model is restricted to marshes only. The Louisiana HSI model uses the moderately general habitat classification system of the LCA study, according to Chabrek (1972).

3. Water Depth. Water depths for breeding and nesting are very specific in both Florida models, where flooding during nesting is especially accentuated. Only an overall yearly water depth is actually measured in the Louisiana HSI model, but there are no details on depths during breeding or nesting; therefore, this may be too simplistic. The general HSI model required more information to be added concerning percentages of water area, ponded area and interspersion; however, the concept of actual water depth is used only in the definition of the percentage of ponded area with depth $\geq 15 \mathrm{~cm}$.

4. Percentage of Area. The general HSI model best depicts areas and interspersion. There may be, however, too much information that could be summarized into one variable such as in the percentage of land in the Louisiana HSI model. Percentage of areas are lacking in both Florida models.

5. Dry Days. The number of dry days (water depths $<0.5 \mathrm{ft}$ ) during the nonbreeding season is precise in both Florida models. These days get averaged into the yearly water depth of the Louisiana HSI and are not isolated; hence, their affect is unclear. As shown in tables 1-3, likely yearly averages of water depth are predicted based on breeding/nesting, flooding, and drydays information. There is no equivalent measurement in the general HSI model. 
6. Body Condition and Survival. Only the Florida HSI model addresses body condition and survival, which again is based on water depth. Its importance is questionable.

Table 4. Scoring of the American alligator (Alligator mississippiensis) models by factor categories. Florida models are denoted as SESI (F) and HSI (F), general HSI model as HSI (G), and LCA study HSI model as HSI (L). Scoring of categories: high (well represented or defined), mod (moderately represented), or low (lacking or poorly defined).

\begin{tabular}{lllll} 
FACTOR & SESI $(\mathrm{F})$ & HSI $(\mathrm{F})$ & HSI $(\mathrm{G})$ & HSI \\
\hline & & & & \\
Grid scale & high & low & low & mod \\
Habitat & high & low & mod & mod \\
Water depth & high & high & low & mod \\
Percentage of area & low & low & high & high \\
Dry days & high & high & low & low
\end{tabular}

Overall, the SESI model received more high scores than all other HSI models. The general HSI model lacked a lot of factors and received the lowest scores, except in the "percentage of area" category. The Florida and Louisiana HSI models faired about the same in number of low versus mod or high scores, although this trend is reversed in all categories except in the "water depth" category. In other words, when the Florida HSI model scored lower, the Louisiana HSI model scored higher, and vice versa. 


\section{Assessment of the Alligator Models}

In previous discussions, component comparisons appeared to indicate that some factors were more critical than others. The general HSI models relied more heavily on percentage of adequate suitable water areas and pond interspersion. These details evolved to general water depths in suitable habitats in other models. More precision in water depth measurements of breeding/nesting was highlighted in the Florida models. The yearly average water depths of Louisiana, however, can be somewhat simulated with knowledge of the breeding/nesting water depths and number of dry days throughout the rest of the year, where one feature can be substituted with other information. As formerly explained in the evaluation of Florida HSI performance for restoration scenarios, the effect of survival and body condition overlapped other components, and their contribution to the entire index was viewed as minimal, whereby their influences could be incorporated into other factors or omitted entirely (Rice and others, 2004).

The Florida and Louisiana models may be expected to produce dissimilar results even when subjected to the same data because of underlying influences: the hydrologic conditions, vegetative communities and food availability differ between Florida and Louisiana, as well as subsequent alligator density and growth rates (Rootes and others, 1991; Barr, 1997; Delany and Abercrombie, 1986; Jacobsen and Kushlan, 1989; Kushlan and Jacobsen, 1990; Loftus and Klund, 1994). None of the models appear to be accurate enough to account for these disparities between the two ecosystems.

Generally, the Florida and Louisiana alligator models were based on similar assumptions where emergent vegetation is required for the success of breeding/nesting. Both models attempt to simulate the need for intermediate flood duration to prevent drowning of requisite emergent vegetation. Nonetheless, the patterns of fluctuations in water levels for Florida and Louisiana differ and impose contrasting approaches to water depth measurement. Water levels in Louisiana are more dynamic, since marshes exhibit tidal influences. Therefore, hourly data measurements would be ideal to accurately estimate daily flooding durations in Louisiana; however, these are unattainable at this time. On the other hand, The Everglades is not tidal so that water levels are more stationary and flooding can be estimated from less-frequently measured data on water levels. The Florida models require defining components that reflect a landscape with periods of low and high water levels, whereas the Louisiana model requires an intermediate flooding duration, which is assumed to vary with average water depth as was observed at Marsh Island (Nyman, 2001). From this viewpoint, the detailed development of water depth measurements during breeding/nesting was a necessity in the Florida models but not imperative for the Louisiana model.

Precise habitat specifications may present a possible contention between the Florida and Louisiana models. The LCA study based the freshwater, intermediate, brackish and saline marshes on definitions from Chabreck (1972), see fig. 7B. The Louisiana model can be applied to swamps and all aforementioned marsh types; however, the best water level data were collected from brackish marshes (Nyman, 2001) and were used to set the general standards for suitable water depths (USACE, 2004). It is unknown, for example, to what extent freshwater marsh 
vegetation can tolerate more flooding than brackish marshes. Thus, the relationship between marsh flooding and alligator breeding/nesting in the Louisiana model was assumed to be the same in all marsh types even though it may overestimate the negative effects of flooding on nesting in freshwater marshes. The Florida SESI model meticulously segregates the habitat types but does not establish distinct relationships between flooding and habitat suitability based on habitat.

Furthermore, marsh types are not static ecosystems. In some locations, they can change back and forth from year to year depending upon local rainfall. In other situations, they can gradually become more extreme (more fresh or saline) over time. For example, Nyman (2001) showed that at Marsh Island, Louisiana, most of the recording stations for water level were classified as brackish between 1993 and 2000, with a minority initially classified as intermediate. By the end of that period, all were classified as brackish. Hence, characterization of habitat would be more explicit based upon species composition in the emergent plant community rather than on water depth or salinity. The general HSI and Florida SESI models use this approach by classifying habitat according to dominant vegetation type.

Another major difference among the suitability indices is in the mathematical qualities of the final index formula itself; that is, the arithmetic mean versus the geometric mean. There may be controversy in the appropriateness of certain formula application. Arithmetic averaging of favorable with unfavorable conditions to give a final estimate of averaged conditions may not always be biologically realistic. For example, if a species requires two critical conditions to use a habitat but only one occurs, the habitat will not be used. The arithmetic or weighted arithmetic mean, however, will always give some sort of positive index value except when all components are zero. The Florida HSI is an example. There may be undesirable deep waters, yet if any one component is not zero, the index will produce a positive value however small. The index can be perceived as depicting the likelihood or chance of habitat usage; the smaller the index value, the more unlikely that this habitat will be used. From this perspective, the arithmetic mean has merit and should not be discounted.

On the other hand, if all but one component is very suitable, the unsuitable component may lower the entire arithmetic mean index value only slightly. If the geometric mean using the product of components is applied instead, the entire index is computed as zero for any one or more zero components and may reflect more biologically sensible results. Hence, the use of geometric means in the Louisiana HSI model was deemed appropriate by the model developers because alligators will not nest in areas where salinity or flooding exceeds tolerance levels. For this reason, the arithmetic mean formula could also be amended to compensate when a specific condition is not met. This concept was applied to the final API of the SESI model; it is a weighted arithmetic mean that is overruled by the habitat type rank; that is, when the habitat is unsuitable and its value is ranked zero, then the entire index is set to zero. Ultimately, critics of using the arithmetic mean may compromise and accept arithmetical averaging within a factor or intermittent component as appropriate but not when combining components into the final index. 
Nevertheless, even the general HSI uses geometric means for computing its individual components. Only the SESI breeding/nesting component uses the arithmetic average.

In summary, since the two ecosystems represented by The Everglades and Louisiana coastal regions are very different, the indices as presented are probably well-suited for their particular environments, as they underwent continual calibrations or development based on field observations. They are not, however, interchangeable, and one may not be necessarily better for the other environment.

Nevertheless, certain features were consistently considered or stood out as potential better candidates, as demonstrated by the previous scoring assessment of the models by features: "grid scale," "habitat," "water depth," and "percentage of area." A complete discussion is given in chapter 6, together with a proposed habitat suitability model for the LCA study.

A

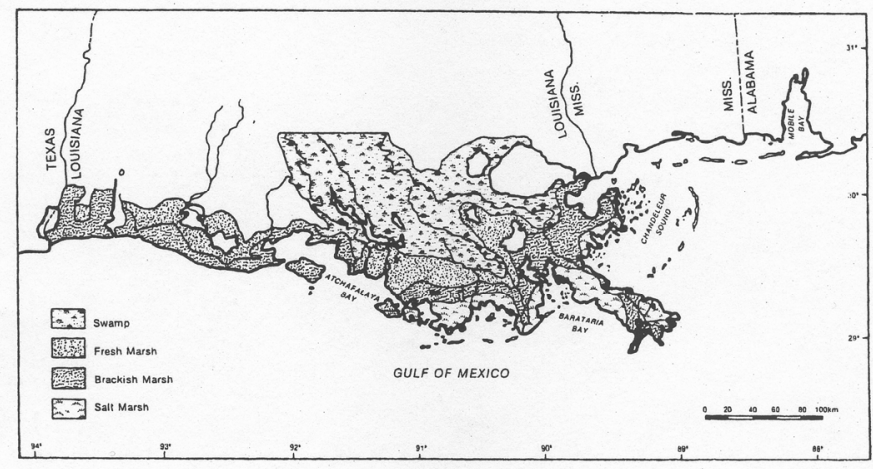

$B$

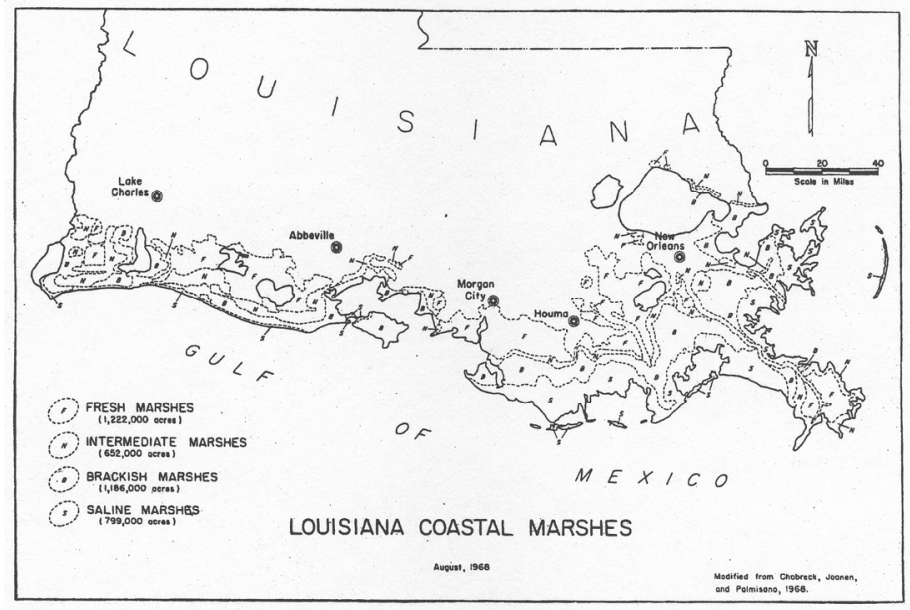

Figure 7. Wetland habitat types of coastal Louisiana. A. Swamp and three marsh types (adapted from Portnoy, 1977). B. All four marsh types with acreages (including intermediate marsh) (adapted with permission from Chabrek, 1972). 


\section{Chapter 5 \\ The Wading Bird Models}

\section{$\underline{\text { Wading Birds }}$}

Birds in general are the most visible or conspicuous wildlife throughout the coastal Louisiana wetland regions (Connor and Day, 1987). Wading birds, numbering about 250,000 yearly in coastal Louisiana (Michot and others, 2003), congregate in large colonies and do not migrate (Connor and Day, 1987). Unfortunately, wading birds were not modeled in the LCA study (USACE, 2004), and this constitutes a major drawback of the study. Nevertheless, the response of wading birds is one of the more significant constituents in assessing the progress of restoration and will be addressed in this report. Several species of wading birds will be highlighted here and their generalized suitability indices evaluated, which may be applied to coastal Louisiana. The great blue heron, great egret, white ibis, and wood stork are described below.

\section{Great Blue Heron}

Throughout North America, the great blue heron (Ardae herodias) is among the most widely distributed wading birds, occupying a variety of habitats (freshwater rivers and lakes, freshwater and brackish marshes, lagoons, mangroves, and coastal wetlands) (Short and Cooper, 1985). The colony of great blue herons depends on feeding locations, with the sites of nesting colonies usually located near water. Preferred nesting habitats are any tree species (especially dead trees), but in the absence of trees nesting habitats may vary, where shrubs, cliffs or rock ledges, or any large engineered structure may be utilized. The nest, consisting of a platform of sticks or twigs that is lined with stems, reeds, or grasses, is typically built 5-15 m above ground. Nesting colonies are usually isolated but with conspicuous nests; protection by tree canopy or any other cover does not appear to be essential. The same sites may be reused yearly. Colony abandonment can result from several types of disruption, such as (1) feeding or nesting habitat changes, such as shifts in feeding sites, (2) habitat destruction by human disturbance, or (3) gradual alterations in marshes or loss of wetlands. Most heron colonies in the gulf coast are in cypress and tupelo swamps. Other wading bird species may also occupy the same colony sites, including other herons and egret and ibis species. Breeding is from March to May, with clutch sizes of 2 to 3 eggs. Incubation is from 27 to 28 days, with fledging at about 75 days.

The feeding behavior dictates colony site locations. Herons feed alone or in flocks, where "social feeding" patterns are strongly correlated with colony nest sites. Potential feeding sites are within commuting distance of nesting colonies, usually within 4 to $5 \mathrm{~km}$ but can be up to $20 \mathrm{~km}$. The diet of herons consists mostly of fish, but it can also include other soft animal tissue prey such as frogs, tadpoles, insects, reptiles, crabs, crayfish, and snails. The foraging activity is, therefore, typically concentrated in shallow water containing emergent or submergent vegetation, where common actions involve walking and standing in place, with probing and 
pecking, or hovering over water to locate prey. Although uncommon, foraging can occur in open water with diving and swimming. When the prey density is decreased, feeding sites will shift across the landscape to sites of higher densities.

\section{Great Egret}

Great egrets (Ardea alba) are very large wading birds (a large white heron) (Chapman and Howard, 1984). They nest in mixed-species colonies along with other heron species, ibises, and pelicans, beginning in early March and ending in August. Clutch sizes range from one to six eggs with a three to four average. Similar to great blue herons, incubation for great egrets is from 23 to 27 days, but the young mature faster and leave nests earlier, at about 45 days. Great egrets are more versatile in nesting, using crowns of trees and shrubs, as well as ground when there is a lack of suitable nest sites. Tree nests are generally located higher (about 5-10 m) than those of other wading birds, but usually below nests of the great blue heron. Nests are large $(2 \mathrm{ft}$ in diameter) and need several limbs for support. Louisiana colonies are located in coastal freshwater and brackish water marshes. Colony sites can also be reused and usually coincide with those of the great blue heron, who begin nesting prior to egrets.

Food requirements for great egrets are similar to those of great blue herons, with fish making up 80 percent of the diet, along with other animal prey (see above). Feeding sites are usually within $4 \mathrm{~km}$ of the colony. Likewise, foraging is in shallow water near wetlands. There is no preference for freshwater, brackish, or saline habitats. Foraging actions involve slowwading, standing and pecking, but rarely diving. Because of their long legs, they may forage in deeper water than other herons $(10-25 \mathrm{~cm})$. Egrets may forage in groups or solitarily, often reusing the same feeding site until depletion of prey, whereby they will then move to new sites.

\section{White Ibis}

White ibises (Eudocimus albus) are medium-sized wading birds with a decurved bill (Hingtgen and others, 1985). They breed in mixed-species colonies along with other ibises, herons, and egrets, reusing colony sites yearly. Similar to those of great egrets, the nests are located from ground level up to 9-m high. Breeding season extends from March to November, with clutch sizes averaging two eggs in Louisiana. Fledging occurs in 40 days, but at the rate of only one per nest. The asynchronous hatching of chicks often causes starvation for the laterhatched chicks, resulting in 40 percent nest mortality.

Foraging habitats of white ibises are consistent with those of the other wading birds as described above, usually within $4 \mathrm{~km}$ of the colony site. White ibises favor feeding in flocks. Water depths of 0 to $25 \mathrm{~cm}$ represent suitable shallow habitats, with a preference of 5 to $10 \mathrm{~cm}$. The diet, however, consists of only 30 percent fish; there are generally higher percentages of crabs, shrimp, crayfish, and insects consumed. 


\section{Wood Stork}

The wood stork (Mycteria americana) is an endangered species on Federal and State registers (Mitchell, 1999). It is a very large (over 4-ft tall with a wing-span of $5.5 \mathrm{ft}$ ), longlegged wading bird with white plumage and a decurved bill. The wood stork is the only stork species of 17 worldwide species that breeds regularly in the United States. Historically, nesting occurred from Texas to South Carolina, but it is now concentrated in Florida, Georgia, and South Carolina. There are a few breeding populations in Texas and Louisiana coastal regions in the summer, considered to be residual scatterings from southeastern Mexico breeding sites.

Wood storks aggregate into large species-specific colonies and forage in flocks. Nests are usually built in tall, older, and larger-diameter trees at heights of 2 to $10 \mathrm{~m}$ but also can be as high as 12 to $30 \mathrm{~m}$ in cypress and with as many as 25 pairs in a single tree. Engineered structures can be readily adapted when natural trees are lacking. Dependent on the location, more southerly nesting colonies start early from November through January, and chicks fledge before the rains in June. In central and northern sites, colonies form later in February through April, and fledging occurs during mid summer. Successful colony locations are reused yearly. Woods storks appear to be less sensitive to human disturbance than other wading birds. Clutches usually consist of two to four eggs, with incubation lasting from 28 to 32 days. Fledging occurs in about 60 days. Similar to those of blue great herons, wood stork nests are large (2-3 feet in diameter) and are platforms of sticks and twigs that are lined with greenery.

The foraging range of wood storks is substantially larger than that of any of the aforementioned wading birds: typically within $20 \mathrm{~km}$ and as far as $130 \mathrm{~km}$ from colonies. Wood storks are both diurnal and nocturnal feeders. About 70 to 90 percent of the diet is fish, and it may also include crustaceans, amphibians, reptiles, and insects. Feeding behavior includes standing, groping, and even stirring the shallow water with their feet. Because of their long legs, they may feed in waters up to $50-\mathrm{cm}$ deep (preferred range is $<40 \mathrm{~cm}$ ). 


\section{General Wading Bird Habitat Suitability Indices (Louisiana)}

Habitat suitability index (HSI) models have been designed for the nesting season of wading birds (Short and Cooper, 1985; Chapman and Howard, 1984; Hingtgen, 1985), according to the Habitat Evaluation Procedures (HEP) developed by the U.S. Fish and Wildlife Service (USFWS). These generalized models may be employed for Louisiana and Texas coastal regions. Specific models for the great blue heron, great egret, and white ibis are presented below, herein referred to as general HSI models. All models were modified to incorporate a suitable habitat class variable as V0. Also, the basis for hydrological measurements is equivalent in all the models, where water depth is measured relative to soil surface. Since the stork does not normally inhabit Louisiana in sufficient numbers, it is henceforth omitted from all HSI model representations, comparisons, and discussions applicable to Louisiana.

\section{Great Blue Heron}

The following model is appropriate throughout United States. For continuous variables, the parameter (Vi) was graphed against the suitability index $\left(\mathrm{SI}_{\mathrm{Vi}}\right)$ (Short and Cooper, 1985), and the corresponding equations are derived (see below). Otherwise, conditional sentences are utilized for noncontinuous variables. Habitat suitability is defined as a two-classed variable (V0). Two different formulae combine the $\mathrm{SI}_{\mathrm{Vi}}$ values into separate foraging and nesting (reproductive) components, and a total index is computed. Note that there is a human disturbance factor in both components, since herons are apparently very sensitive to such disturbances.

Model parameters and variables:

1. Suitable habitat, $\mathrm{V}^{2}$ :

Feeding: Estuarine

Lacustrine

Riverine

(herbaceous or emergent marsh, scrub-shrub, and forested wetlands)

Nesting: $\quad$ Estuarine

Palustrine

(forested wetlands)

\begin{tabular}{|c|c|}
\hline $\mathrm{SI}_{\mathrm{V} 0}=1.0$ & $\begin{array}{l}\mathrm{V} 0=\text { one of the suitable feeding habitats } \\
\text { and one of the nesting habitats listed above } \\
\mathrm{V} 0=\text { otherwise, the final index is set to zero }\end{array}$ \\
\hline$S l_{\mathrm{V} 0}=0.0$ &,$V 0=$ otherwise, the final index is set to zero \\
\hline
\end{tabular}


2. Distance between foraging areas and colony, V1:

$$
\begin{array}{ll}
\mathrm{SI}_{\mathrm{V} 1}=1.0 & , \mathrm{~V} 1 \leq 1 \mathrm{~km} \\
\mathrm{SI}_{\mathrm{V} 1}=1.1-(0.1 * \mathrm{~V} 1) & , 1<\mathrm{V} 1<10 \mathrm{~km} \\
\mathrm{SI}_{\mathrm{V} 1}=0.1 & , 10 \mathrm{~km} \leq \mathrm{V} 1
\end{array}
$$

3. Water depth, V2:

$$
\begin{array}{ll}
\mathrm{SI}_{\mathrm{V} 2}=1.0 & , 0<\mathrm{V} 2 \leq 50 \mathrm{~cm} \text { and firm substrate } \\
\mathrm{SI}_{\mathrm{V} 2}=0.0 & , \mathrm{~V} 2=\text { otherwise }
\end{array}
$$

4. Human and road disturbance, V3:

$$
\begin{array}{ll}
\mathrm{SI}_{\mathrm{V} 3}=1.0 \quad, \mathrm{~V} 3=\text { no disturbance } 4 \text { hours following sunrise } \\
& \begin{array}{l}
\text { or } \geq 100 \mathrm{~m} \text { away from humans, } \\
\text { or } \geq 50 \mathrm{~m} \text { away from roads }
\end{array} \\
\mathrm{SI}_{\mathrm{V} 3}=0.0 \quad, \mathrm{~V} 3=\text { any one or more above conditions is not met }
\end{array}
$$

The overall foraging index $(\mathrm{FI})^{3}$ is the geometric mean of indices for variables V0-V3 (one continuous variable V1):

$$
\mathrm{FI}=\left(\mathrm{SI}_{\mathrm{V} 0} * \mathrm{SI}_{\mathrm{V} 1} * \mathrm{SI}_{\mathrm{V} 2} * \mathrm{SI}_{\mathrm{V} 3}\right)^{1}
$$

5. Potential nest site, V4:

$$
\begin{array}{ll}
\mathrm{SI}_{\mathrm{V} 4}=1.0 \quad, \mathrm{~V} 4=\min 0.4 \text { ha of tree grove } \\
\text { and } \text { within } 250 \mathrm{~m} \text { of water } \\
\text { and } \min \text { tree height }=5 \mathrm{~m}, \text { man } \\
\mathrm{SI}_{\mathrm{V} 4}=0.0 \quad, \mathrm{~V} 4=\text { otherwise }
\end{array}
$$

6. Human and road/structure disturbance around nest site, V5:

$$
\begin{array}{ll}
\qquad \mathrm{SI}_{\mathrm{V} 5}=1.0 & \begin{array}{c}
\mathrm{V} 5=\text { no disturbance within } 250 \mathrm{~m} \text { on land } \\
\text { or } \text { no disturbance within } 150 \mathrm{~m} \text { on water }
\end{array} \\
\mathrm{SI}_{\mathrm{V} 5}=0.0 & , \mathrm{~V} 5=\text { otherwise } \\
{ }^{3} \text { Differs from Short and Cooper (1985) by inclusion of } \mathrm{SI} \text { for } \mathrm{V} 0=\text { suitable foraging habitat type, class variable. }
\end{array}
$$


7. Proximity of colonies (distance between colonies), V6:

$$
\begin{array}{ll}
\mathrm{SI}_{\mathrm{V} 6}=1.0 & , \mathrm{~V} 6 \leq 1 \mathrm{~km} \\
\mathrm{SI}_{\mathrm{V} 6}=(20-\mathrm{V} 6) / 19 & , 1<\mathrm{V} 6 \leq 20 \mathrm{~km} \\
\mathrm{SI}_{\mathrm{V} 6}=0.0 & , 20 \mathrm{~km}<\mathrm{V} 6
\end{array}
$$

The nesting index, called the reproductive life requisite index $(\mathrm{RI})^{4}$, is computed from the geometric mean of indices for V0, V1, and V4 through V6 (only V1 and V6 are continuous, hence square root):

$$
\mathrm{RI}=\left(\mathrm{SI}_{\mathrm{V} 0} * \mathrm{SI}_{\mathrm{V} 1} * \mathrm{SI}_{\mathrm{V} 4} * \mathrm{SI}_{\mathrm{V} 5} * \mathrm{SI}_{\mathrm{V} 6}\right)^{1 / 2}
$$

The final $\mathrm{HSI}^{4}$ value is the geometric mean of the all indices for V0 through V6 (V1 and V6 are continuous). The use of the geometric mean of all indices in the final HSI weighs all variables equally:

$$
\mathrm{HSI}=\left(\mathrm{SI}_{\mathrm{V} 0} * \mathrm{SI}_{\mathrm{V} 1} * \mathrm{SI}_{\mathrm{V} 2} * \mathrm{SI}_{\mathrm{V} 3} * \mathrm{SI}_{\mathrm{V} 4} * \mathrm{SI}_{\mathrm{V} 5} * \mathrm{SI}_{\mathrm{V} 6}\right)^{1 / 2}
$$

Note this is not equivalent to the product of FI and RI as figure 4 of Short and Cooper (1985) suggests:

$$
\mathrm{HSI} \neq \mathrm{FI} * \mathrm{RI}=\left(\mathrm{SI}_{\mathrm{V} 0} * \mathrm{SI}_{\mathrm{V} 1} * \mathrm{SI}_{\mathrm{V} 2} * \mathrm{SI}_{\mathrm{V} 3}\right) *\left(\mathrm{SI}_{\mathrm{V} 0} * \mathrm{SI}_{\mathrm{V} 1} * \mathrm{SI}_{\mathrm{V} 4} * \mathrm{SI}_{\mathrm{V} 5} * \mathrm{SI}_{\mathrm{V} 6}\right)^{1 / 2}
$$

Thus, the rationale behind isolating and calculating separate FI and RI components is not clear. The following great egret model conserves these two components as separate HSI entities.

4 Again, differs from Short and Cooper (1985) by inclusion of SI for V0 = suitable foraging habitat type. 


\section{Great Egret}

The following model (Chapman and Howard, 1984) was developed for Texas and Louisiana coastal areas but may also be generally applied to other areas in the United States. Again, habitat suitability is defined as a two-classed variable (V0), and companion $\mathrm{SI}_{\mathrm{Vi}}$ equations were derived for continuous variables (V1-V7). The following equations combine the $\mathrm{SI}_{\mathrm{Vi}}$ values into two separate HSI models for foraging and nesting. There is no attempt to combine both models into a single overall index because these models apply to small study areas. Inasmuch as great egrets usually confine their feeding within a 4-km radius from nesting colony sites, they may also travel up to $35 \mathrm{~km}$ to more favorable feeding sites outside of the study area. Thus, the study area may not contain suitable habitat for both foraging and nesting and may downgrade a valuable nesting area. Nevertheless, aquatic habitats for feeding are abundant in Texas and Louisiana. Also, human disturbance is incorporated in the nesting index only.

Model parameters and variables:

1. Suitable habitat systems (with subsystems where applicable), V0 ${ }^{5}$ :

$\begin{array}{lll}\text { Nesting - } & \text { Estuarine - } & \text { Intertidal } \\ & \text { Palustrine } & \\ \text { Feeding - } & \text { Estuarine - } & \text { Intertidal } \\ & \text { Riverine - } & \text { Tidal, Lower Perennial, and Intermittent } \\ & \text { Lacustrine - } & \text { Littoral } \\ \text { Palustrine } & \end{array}$

Foraging radius $\leq 4 \mathrm{~km}$

$$
\begin{aligned}
& \mathrm{SI}_{\mathrm{V} 0}=1.0 \quad, \mathrm{~V} 0=\text { one of above suitable nesting habitats } \\
& \text { and one of above feeding habitats } \\
& \text { and foraging radius } \leq 4 \mathrm{~km} \\
& \mathrm{SI}_{\mathrm{V} 0}=0.0 \quad, \mathrm{~V} 0=\text { otherwise, index set to zero }
\end{aligned}
$$

2. Percentage of area with water depth 10-23 cm deep, V1 (in tidal areas, use mean low tide depth; in nontidal areas, use average summer depth):

$$
\mathrm{SI}_{\mathrm{V} 1}=\mathrm{V} 1 / 100 \quad, 0 \leq \mathrm{V} 1 \leq 100
$$

3. Percentage of submerged/emergent vegetation cover in above areas, V2:

$$
\begin{array}{ll}
\mathrm{SI}_{\mathrm{V} 2}=0.1 & , \mathrm{~V} 2 \leq 0 \\
\mathrm{SI}_{\mathrm{V} 2}=\mathrm{V} 2 / 40 & , 0<\mathrm{V} 2<40 \\
\mathrm{SI}_{\mathrm{V} 2}=1.0 & , 40 \leq \mathrm{V} 2 \leq 60 \\
\mathrm{SI}_{\mathrm{V} 2}=(100-\mathrm{V} 2) / 40 & , 60<\mathrm{V} 2
\end{array}
$$

5

Differs from Chapman and Howard (1984) by inclusion of suitable foraging habitat type (V0), class variable. 
The foraging index (FI), called the "feeding HSI model" in Chapman and Howard, 1984, is computed as the amended arithmetic mean of $\mathrm{SI}_{\mathrm{V} 1}$ and $\mathrm{SI}_{\mathrm{V} 2}$, conditioned on habitat suitability $\left(\mathrm{SI}_{\mathrm{V} 0}\right)$ :

$$
\begin{aligned}
\mathrm{FI} & =\left(\mathrm{SI}_{\mathrm{V} 1}+\mathrm{SI}_{\mathrm{V} 2}\right) / 2 & & , \mathrm{SI}_{\mathrm{V} 0}=1.0 \\
& =0 & & , \mathrm{SI}_{\mathrm{V} 0}=0.0
\end{aligned}
$$

4. Percentage of island area covered by woody vegetation $\geq 1 \mathrm{~m}$ in height, V3:

$$
\begin{array}{ll}
\mathrm{SI}_{\mathrm{V} 3}=0.0 & , \mathrm{~V} 3 \leq 0 \\
\mathrm{SI}_{\mathrm{V} 3}=\mathrm{V} 3 / 60 & , 0<\mathrm{V} 3<60 \\
\mathrm{SI}_{\mathrm{V} 3}=1.0 & , 60 \leq \mathrm{V} 3
\end{array}
$$

5. Mean water depth (non-island), V4:

$$
\begin{array}{ll}
\mathrm{SI}_{\mathrm{V} 4}=0.0 & , \mathrm{~V} 4 \leq 0.0 \mathrm{~m} \\
\mathrm{SI}_{\mathrm{V} 4}=\mathrm{V} 4 / 0.6 & , 0.0<\mathrm{V} 4<0.6 \mathrm{~m} \\
\mathrm{SI}_{\mathrm{V} 4}=1.0 & , 0.6 \mathrm{~m} \leq \mathrm{V} 4
\end{array}
$$

6. Mean height of woody vegetation (non-island), V5:

$$
\begin{array}{ll}
\mathrm{SI}_{\mathrm{V} 5}=0.0 & , \mathrm{~V} 5 \leq 0.0 \mathrm{~m} \\
\mathrm{SI}_{\mathrm{V} 5}=\mathrm{V} 5 / 7.0 & , 0.0<\mathrm{V} 5<7.0 \mathrm{~m} \\
\mathrm{SI}_{\mathrm{V} 5}=1.0 & , 7.0 \mathrm{~m} \leq \mathrm{V} 5
\end{array}
$$

7. Distance to road or structure, V6:

$$
\begin{array}{ll}
\mathrm{SI}_{\mathrm{V} 6}=0.0 & , 0.0 \leq \mathrm{V} 6 \leq 0.5 \mathrm{~km} \\
\mathrm{SI}_{\mathrm{V} 6}=(\mathrm{V} 6-0.5) / 0.5 & , 0.5<\mathrm{V} 6 \leq 1.0 \mathrm{~km} \\
\mathrm{SI}_{\mathrm{V} 6}=1.0 & , 1.0 \mathrm{~km}<\mathrm{V} 6
\end{array}
$$

8. Distance to other human disturbance, V7:

$$
\begin{array}{ll}
\mathrm{SI}_{\mathrm{V} 7}=0.0 & , 0.0 \leq \mathrm{V} 7 \leq 10 \mathrm{~m} \\
\mathrm{SI}_{\mathrm{V} 7}=(\mathrm{V} 7-10) / 40 & , 10<\mathrm{V} 7 \leq 40 \mathrm{~m} \\
\mathrm{SI}_{\mathrm{V} 7}=1.0 & , 40 \mathrm{~m}<\mathrm{V} 7
\end{array}
$$


The nesting index, called the "nesting HSI model" in Chapman and Howard, 1984, defines intermittent components for cover and disturbance, based on the geometric mean of appropriate combinations of individual $\mathrm{SI}_{\mathrm{Vi}}{ }^{6}$. Two cover components are defined, depending on whether the nesting habitat is on an island:

\begin{tabular}{ll}
\multicolumn{1}{c}{ Components } & Equation \\
$\mathrm{C}_{\mathrm{i}}=$ Cover $_{\text {islands }}$ & $\left(\mathrm{SI}_{\mathrm{V} 0} * \mathrm{SI}_{\mathrm{V} 3}\right)^{1}$ \\
$\mathrm{C}_{\mathrm{n}}=$ Cover $_{\text {non-islands }}$ & $\left(\mathrm{SI}_{\mathrm{V} 0} * \mathrm{SI}_{\mathrm{V} 4} * \mathrm{SI}_{\mathrm{V} 5}\right)^{1 / 2}$ \\
$\mathrm{D}=$ Disturbance & $\left(\mathrm{SI}_{\mathrm{V} 6} * \mathrm{SI}_{\mathrm{V} 7}\right)^{1 / 2}$
\end{tabular}

The overall nesting value of the HSI model is distinguished by island status and corresponds to either the "cover" or "disturbance" component, whichever is lower:

$$
\begin{aligned}
& \mathrm{HSI}_{\text {island }}=\min \left(\mathrm{C}_{\mathrm{i}}, \mathrm{D}\right) \\
& \mathrm{HSI}_{\text {non-island }}=\min \left(\mathrm{C}_{\mathrm{n}}, \mathrm{D}\right)
\end{aligned}
$$

6 Differs from Chapman and Howard (1984) by inclusion of SI for V0 = suitable foraging habitat type, class variable. 


\section{White Ibis}

The following model is generally developed for all of the United States (Hingtgen and others, 1985). Once more, equations are derived from plots of the $\mathrm{SI}_{\mathrm{Vi}}$ for continuous variables (V1-V5). The following formulae combine the $\mathrm{SI}_{\mathrm{Vi}}$ values into two separate HSI models, "island" (uplands) and "non-island" (wetlands, including mangrove islands). The foraging habitat was not originally included in the model; however, Hingtgen and others (1985) suggest that foraging habitat must be available within a $23-\mathrm{km}$ radius of the colony (10 $\mathrm{km}$ is preferable) and with shallow water depths of 0 to $25 \mathrm{~cm}(5-10 \mathrm{~cm}$ is preferable); otherwise the HSI value is set to zero. This is redefined and incorporated into the amended two-classed variable (V0) for suitable habitat. Again, a nonspecific, general human disturbance factor is included in the nesting index, but it is not separated into road or structures versus other human activities.

Model parameters and variables:

1. Suitable habitats, $\mathrm{V}^{7}$ :

Nesting and feeding (no distinction given)

Islands

Estuarine wetlands

Palustrine wetlands

Foraging radius $\leq 10 \mathrm{~km}$ and shallow water depths.

$$
\begin{array}{ll}
\mathrm{SI}_{\mathrm{V} 0}=1.0 \quad, \mathrm{~V} 0=\text { one of the suitable nesting/feeding habitats } \\
& \text { and foraging radius } \leq 10 \mathrm{~km} \\
& \text { and } 5 \mathrm{~cm}<\text { water depth } \leq 10 \mathrm{~cm} \\
\mathrm{SI}_{\mathrm{V} 0}=0.0 \quad, \mathrm{~V} 0=\text { otherwise, if any one of conditions is not } \\
\text { met, the index is set to zero }
\end{array}
$$

2. Distance of island from mainland, V1:

$$
\begin{array}{ll}
\mathrm{SI}_{\mathrm{V} 1}=0.0 & , \mathrm{~V} 1 \leq 0.0 \mathrm{~km} \\
\mathrm{SI}_{\mathrm{V} 1}=\mathrm{V} 1 / 0.4 & , 0.0<\mathrm{V} 1 \leq 0.4 \mathrm{~km} \\
\mathrm{SI}_{\mathrm{V} 1}=1.0 & , 0.4 \mathrm{~km}<\mathrm{V} 1
\end{array}
$$

3. Island surface area, categorized into three classes, V2:

$$
\begin{aligned}
\qquad \mathrm{SI}_{\mathrm{V} 2}=1.0 & , \mathrm{~V} 2<36 \text { ha } \\
\mathrm{SI}_{\mathrm{V} 2}=0.5 & , 36 \text { ha } \leq \mathrm{V} 2 \leq 130 \text { ha } \\
\mathrm{SI}_{\mathrm{V} 2}=0.1 & , 130 \text { ha }<\mathrm{V} 2
\end{aligned}
$$


4. Average vegetation height, categorized into four classes, V3:

$$
\begin{array}{ll}
\mathrm{SI}_{\mathrm{V} 3}=0.6 & , 0 \leq \mathrm{V} 3<1.0 \mathrm{~m} \\
\mathrm{SI}_{\mathrm{V} 3}=0.8 & , 1.0 \leq \mathrm{V} 3<2.0 \mathrm{~m} \\
\mathrm{SI}_{\mathrm{V} 3}=0.9 & , 2.0 \leq \mathrm{V} 3 \leq 4.0 \mathrm{~m} \\
\mathrm{SI}_{\mathrm{V} 3}=1.0 & , 4 \mathrm{~m}<\mathrm{V} 3
\end{array}
$$

5. Distance to general, nonspecific human disturbance, V4:

$$
\begin{array}{ll}
\mathrm{SI}_{\mathrm{V} 4}=0.0 & , 0.0 \leq \mathrm{V} 4 \leq 0.5 \mathrm{~km} \\
\mathrm{SI}_{\mathrm{V} 4}=(\mathrm{V} 4-0.5) / 1.5 & , 0.5<\mathrm{V} 4 \leq 2.0 \mathrm{~km} \\
\mathrm{SI}_{\mathrm{V} 4}=1.0 & , 2.0 \mathrm{~km}<\mathrm{V} 4
\end{array}
$$

6. Percentage of wetlands in the colony area that is flooded during nesting season, V5:

$$
\mathrm{SI}_{\mathrm{V} 5}=\mathrm{V} 5 / 100 \quad, 0 \leq \mathrm{V} 5 \leq 100
$$

The HSI value ${ }^{8}$ is computed for each habitat type, island and non-island (wetland), as the geometric mean that includes the preferable distance radius for food source and water depths:

$$
\begin{aligned}
& \mathrm{HSI}_{\text {island }}=\left(\mathrm{SI}_{\mathrm{V} 0} * \mathrm{SI}_{\mathrm{V} 1} * \mathrm{SI}_{\mathrm{V} 2} * \mathrm{SI}_{\mathrm{V} 3} * \mathrm{SI}_{\mathrm{V} 4}\right){ }^{1 / 4} \\
& \mathrm{HSI}_{\text {non-island }}=\left(\mathrm{SI}_{\mathrm{V} 0} * \mathrm{SI}_{\mathrm{V} 3} * \mathrm{SI}_{\mathrm{V} 4} * \mathrm{SI}_{\mathrm{V} 5}\right)^{1 / 3}
\end{aligned}
$$

\footnotetext{
${ }^{8}$ Differs from Hingtgen and others (1985) by inclusion of SI for V0 = suitable foraging habitat type, class variable.
} 


\section{Comparison of General HSI Models for Great Blue Heron, Great Egret, and White Ibis}

Inasmuch as these species are all classified as wading birds and generally occupy the same colony sites and use the same foraging areas, each model was uniquely and independently developed with some common features as well as dissimilar features. Both the great egret and white ibis models were theoretically developed and verified by many specialists in biology using recommended methods for collecting data, but these models were not field tested. Likewise, the great blue heron model is theoretical and biologically validated; however, field testing of the heron model is not specified and is unknown. Thus, any type of calibrations for all models is not described.

In a comparison of the two long-legged wading birds (great blue herons and great egrets), both models define separate foraging and nesting index components. The major difference is that the great blue heron model combines the two components into a single HSI, whereas the great egret model retains the components as separate HSI entities. Water depth at feeding sites is a critical element in both models and is used as either a percentage of area within a suitable range of depth (egret V1) or as a binary class variable of zero or one if within suitable range (heron V2). The great egret model goes a step further and expresses a variable for submerged vegetation in these areas (V2). The concept of a feeding radius about the colony site is actually incorporated as a separate variable only in the great blue heron model as the distance from nesting colony to suitable feeding sites (V1). Although the great egret's foraging habitats were explained in terms of being within $4 \mathrm{~km}$ of the colony, a separate variable is never defined in the original HSI model of Chapman and Howard (1984). Hence, the great egret model presented here is modified to insert the radius into the suitable habitat variable (V0). Human disturbance (V3) is another factor included in the foraging index component for the great blue heron model but not in the great egret model. Finally, the foraging index for the great blue heron is a geometric mean, whereas for the great egret it is an arithmetic mean.

Three variables are used to describe the great blue heron nesting index component, whereas five variables are used in the great egret nesting index. One variable, the potential nesting site in the great blue heron model (V4), compensates for the separate variables in the great egret model for area of tree grove needed (V3) and minimum height of woody vegetation (V5). Likewise, one great blue heron model variable describing human disturbance (V5) consolidates both human disturbance variables in the great egret model (V6 and V7). Proximity of adjacent colonies (V6) is a factor in the great blue heron model only. The great egret model, however, adds a distinction between islands and non-island environments. Geometric means are computed for the nesting components in both species.

Although the foraging habitat for white ibises (medium-legged wading birds) must be available within $23 \mathrm{~km}$ (preferred 10-km radius) and the water depth $<25 \mathrm{~cm}$ (preferred 5-10 $\mathrm{cm}$ ), the foraging suitability is not computed at all as an index component in the original white ibis model of Hingtgen and others (1985). Nevertheless, this information was combined and added as the suitable habitat variable (V0) and included into the final modified HSI computation. 
The nesting component has five variables and is likewise differentiated by land type for island versus non-island (wetland), as in the great egret model. Variables describing vegetation height and human disturbance are incorporated in both island and non-island equations. For islands, additional measurements of surface area and distance from mainland are included. For non-island wetlands, percentage of flooding is considered. Two nesting HSI are computed representing each land type. If the aforementioned foraging radius or water depth exceeds the preference ranges, the entire HSI becomes zero because the habitat index $\left(\mathrm{SI}_{\mathrm{V} 0}\right)$ equals zero in the geometric mean.

Several sample datasets representing diverse habitat settings were created to demonstrate the differences among the indices computed for the three wading bird types (tables 5-8). All three species are assumed to be cohabitating the same colony site that consists of a large area of 25 ha (approximately $1 \mathrm{~km}^{2}$ ). All distance measurements are from the perimeter of the colony site. Note that the variables V1-V7 do not coincide in definition (see model specifications for each species above). The first table contains more typical measurements for all variables (table 5). The following table (table 6) displays an environment with deeper foraging waters and more distant feeding sites. The nesting site, however, has more favorable features such as taller trees, closer proximity of adjacent colony, and farther disturbance distances. Table 7 modifies table 6, demonstrating the detrimental effect of a road close to the potential nesting colony. Finally, table 8 is an adaptation of table 5 specifically for island colony habitats. 
Table 5. Comparison of all general habitat suitability index (HSI) models for the wading birds: great blue heron (Ardea herodias), great egret (Ardea alba), and white ibis (Eudocimus albus). Setting 1. Final index computations include component calculations.

Dataset parameters of setting 1:

$60 \%$ of feeding site with water depth of $10 \mathrm{~cm}$ and firm substrate

$75 \%$ emergent vegetation in water depths of $10 \mathrm{~cm}$

Feeding site is $2 \mathrm{~km}$ from colony, in estuarine intertidal emergent wetland

Feeding site is $500 \mathrm{~m}$ from roads/structures and other human disturbances

Colony is in estuarine intertidal forested wetland (non-island)

Colony is on 25 ha of tree grove within $150 \mathrm{~m}$ of water

Mean woody vegetation height of $5 \mathrm{~m}$

Mean water depth in colony site is $0.5 \mathrm{~m}, 60 \%$ flooded during nesting

Distance from colony to road/structure and human activity disturbances are both $750 \mathrm{~m}$

Proximity of next colony is $10 \mathrm{~km}$

\begin{tabular}{|c|c|c|c|c|c|}
\hline \multicolumn{6}{|c|}{ INTERMEDIATE INDEX (SI) COMPUTATIONS } \\
\hline \multicolumn{2}{|c|}{ GREAT BLUE HERON } & \multicolumn{2}{|c|}{ GREAT EGRET } & \multicolumn{2}{|c|}{ WHITE IBIS } \\
\hline Variable & Index & Variable & Index & Variable & Index \\
\hline $\mathrm{V} 0=$ estuarine & $\mathrm{SI}_{\mathrm{V} 0}=1.0$ & $\begin{array}{r}\mathrm{V} 0=\text { estuarine, } \\
2 \mathrm{~km} \text { radius }\end{array}$ & $\mathrm{SI}_{\mathrm{V} 0}=1.0$ & $\begin{array}{c}\mathrm{V} 0=\text { estuarine, } \\
2 \mathrm{~km} \mathrm{rad} \\
10 \mathrm{~cm}\end{array}$ & $\begin{array}{l}\mathrm{SI}_{\mathrm{V} 0}=1.0 \\
\mathrm{~s}\end{array}$ \\
\hline $\mathrm{V} 1=2 \mathrm{~km}$ & $\mathrm{SI}_{\mathrm{V} 1}=0.90$ & $\mathrm{~V} 1=60 \%$ & $\mathrm{SI}_{\mathrm{V} 1}=0.60$ & $\mathrm{~V} 1=\mathrm{n} / \mathrm{a}$ & \\
\hline $\mathrm{V} 2=10 \mathrm{~cm}$ & $\mathrm{SI}_{\mathrm{V} 2}=1.0$ & $\mathrm{~V} 2=75 \%$ & $\mathrm{SI}_{\mathrm{V} 2}=0.70$ & $\mathrm{~V} 2=\mathrm{n} / \mathrm{a}$ & \\
\hline $\mathrm{V} 3=500 \mathrm{~m}$ & $\mathrm{SI}_{\mathrm{V} 3}=1.0$ & $\mathrm{~V} 3=\mathrm{n} / \mathrm{a}$ & & $\mathrm{V} 3=5 \mathrm{~m}$ & $\mathrm{SI}_{\mathrm{V} 3}=1.0$ \\
\hline $\begin{aligned} \mathrm{V} 4= & 25 \mathrm{ha}, \\
& 150 \mathrm{~m} \text { to } \\
& 5 \mathrm{~m} \text { tree } \mathrm{h}\end{aligned}$ & $\begin{array}{l}\mathrm{SI}_{\mathrm{V} 4}=1.0 \\
\text { ater, } \\
\text { ight }\end{array}$ & $\mathrm{V} 4=0.5 \mathrm{~m}$ & $\mathrm{SI}_{\mathrm{V} 4}=0.83$ & $\mathrm{~V} 4=0.75 \mathrm{~km}$ & $\mathrm{SI}_{\mathrm{V} 4}=0.17$ \\
\hline $\mathrm{V} 5=750 \mathrm{~m}$ & $\mathrm{SI}_{\mathrm{V} 5}=1.0$ & $\mathrm{~V} 5=5 \mathrm{~m}$ & $\mathrm{SI}_{\mathrm{V} 5}=0.71$ & $\mathrm{~V} 5=60 \%$ & $\mathrm{SI}_{\mathrm{V} 5}=0.60$ \\
\hline $\mathrm{V} 6=10 \mathrm{~km}$ & $\mathrm{SI}_{\mathrm{V} 6}=0.53$ & $\begin{array}{l}\mathrm{V} 6=750 \mathrm{~m} \\
\mathrm{~V} 7=750 \mathrm{~m}\end{array}$ & $\begin{array}{l}\mathrm{SI}_{\mathrm{V} 6}=0.50 \\
\mathrm{SI}_{\mathrm{V} 7}=1.0\end{array}$ & ---- & \\
\hline
\end{tabular}

\begin{tabular}{|c|c|c|}
\hline $\begin{aligned} \mathrm{FI} & =\left(\mathrm{SI}_{\mathrm{V} 0} * \mathrm{SI}_{\mathrm{V} 1} * \mathrm{SI}_{\mathrm{V} 2} * \mathrm{SI}_{\mathrm{V} 3}\right) \\
& =\mathbf{0 . 9 0}\end{aligned}$ & $\begin{aligned} \mathrm{FI} & =\left(\mathrm{SI}_{\mathrm{V} 1}+\mathrm{SI}_{\mathrm{V} 2}\right) / 2 \\
& =\mathbf{0 . 6 5}\left(\mathrm{SI}_{\mathrm{V} 0}=1, \text { food radius } \leq 4 \mathrm{~km}\right)\end{aligned}$ & \\
\hline $\begin{aligned} \mathrm{RI} & =\left(\mathrm{SI}_{\mathrm{V} 0} * \mathrm{SI}_{\mathrm{V} 1} * \mathrm{SI}_{\mathrm{V} 4} * \mathrm{SI}_{\mathrm{V} 5} * \mathrm{SI}_{\mathrm{V} 6}\right)^{1 / 2} \\
& =\mathbf{0 . 6 9}\end{aligned}$ & $\begin{aligned} \mathrm{C}_{\mathrm{n}} & =\left(\mathrm{SI}_{\mathrm{V} 0} * \mathrm{SI}_{\mathrm{V} 4} * \mathrm{SI}_{\mathrm{V} 5}\right)^{1 / 2} \\
& =0.77 \\
\mathrm{D} & =\left(\mathrm{SI}_{\mathrm{V} 6} * \mathrm{SI}_{\mathrm{V} 7}\right)^{1 / 2} \\
& =0.71\end{aligned}$ & \\
\hline $\begin{aligned} \mathrm{HSI}_{\text {overall }} & =\left(\prod_{\mathrm{Vi}=0}^{6} \mathrm{SI}_{\mathrm{Vi}}\right)^{1 / 2} \\
& =\mathbf{0 . 6 9}\end{aligned}$ & $\begin{array}{l}\mathrm{HSI}_{\text {nest-non-island }}=\min \left(\mathrm{C}_{\mathrm{n}}, \mathrm{D}\right) \\
\quad=\mathbf{0 . 7 1} \\
\text { (nesting only) }\end{array}$ & $\begin{aligned} & \mathrm{HSI}_{\text {overall-non-island }}=\left(\mathrm{SI}_{\mathrm{V} 0} * \mathrm{SI}_{\mathrm{V} 3} * \mathrm{SI}_{\mathrm{V} 4} * \mathrm{SI}_{\mathrm{V} 5}\right)^{1 / 3} \\
&=\mathbf{0 . 4 7} \\
&(\text { food radius }<10 \mathrm{~km}, \text { water depth }=10 \mathrm{~cm})\end{aligned}$ \\
\hline
\end{tabular}

(min 0.4 ha tree grove, within $250 \mathrm{~m}$ of water) 
Table 6. Comparison of all general habitat suitability index (HSI) models for the wading birds: great blue heron (Ardea herodias), great egret (Ardea alba), and white ibis (Eudocimus albus). Setting 2. Final index computations include component calculations.

Dataset parameters of setting 2:

$30 \%$ of feeding site with water depth of $10 \mathrm{~cm}$ and firm substrate

$60 \%$ of feeding site with water depth of $35 \mathrm{~cm}$

$30 \%$ emergent vegetation in water depths of $10 \mathrm{~cm}$

Feeding site is $7 \mathrm{~km}$ from colony, in estuarine intertidal emergent wetland

Feeding site is $200 \mathrm{~m}$ from roads/structures and other human disturbances

Colony is in estuarine intertidal forested wetland (non-island)

Colony is on 25 ha of tree grove within $200 \mathrm{~m}$ of water

Mean woody vegetation height of $10 \mathrm{~m}$

Mean water depth in colony site is $0.5 \mathrm{~m}, 80 \%$ flooded during nesting

Distance from colony to road and human activity disturbance are both $1 \mathrm{~km}$

Proximity of next colony is $1 \mathrm{~km}$

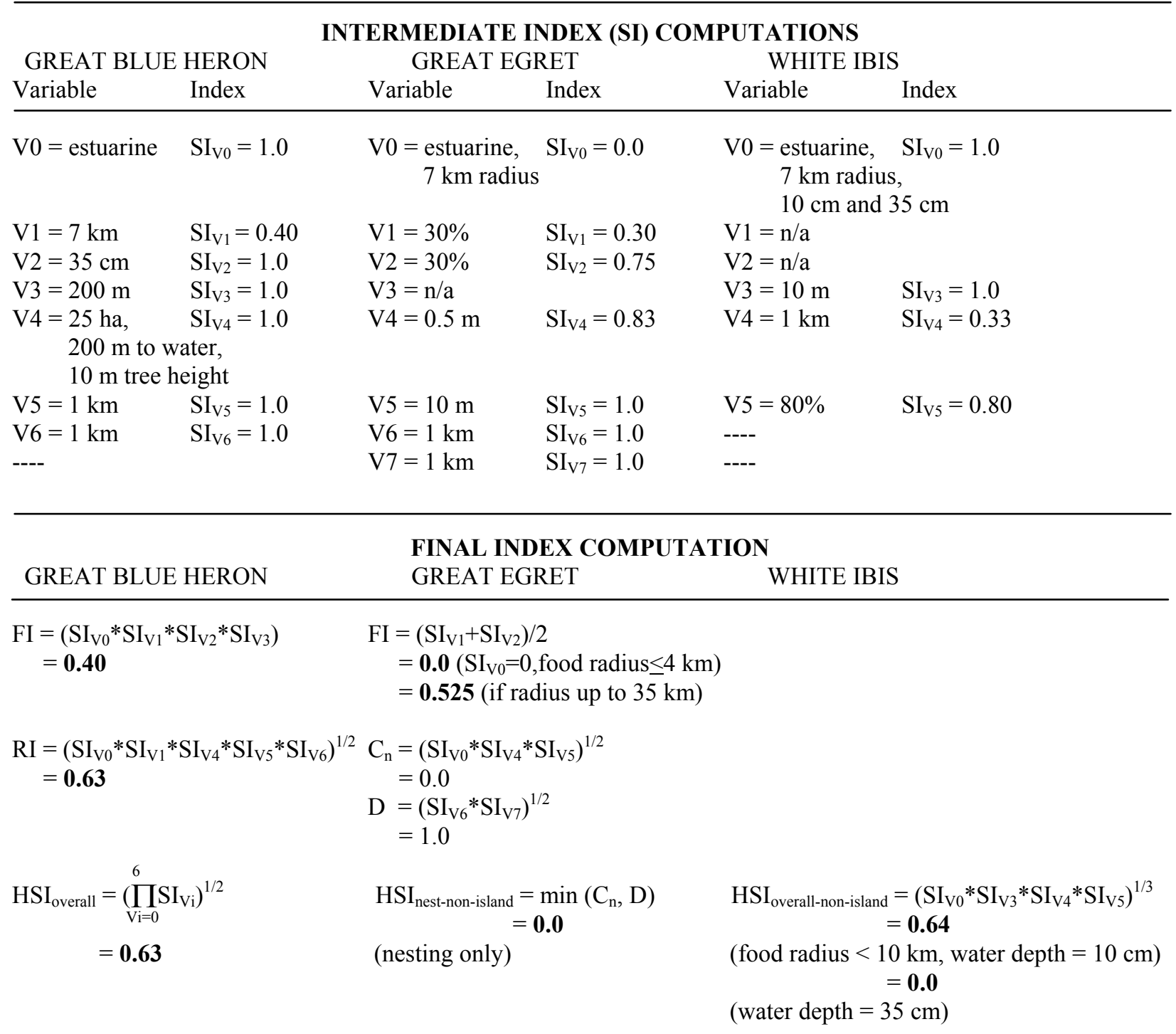


Table 8. Comparison of all general habitat suitability index (HSI) models for the wading birds: great blue heron (Ardea herodias), great egret (Ardea alba), and white ibis (Eudocimus albus). Setting 4. Final index computations include component calculations.

Data set parameters of setting 4:

$60 \%$ of feeding site with water depth of $10 \mathrm{~cm}$ and firm substrate

$75 \%$ emergent vegetation in water depths of $10 \mathrm{~cm}$

Feeding site is $2 \mathrm{~km}$ from colony, in estuarine intertidal emergent wetland

Feeding site is $500 \mathrm{~m}$ from roads/structures and other human disturbances

Colony in island, mainland distance to island $0.3 \mathrm{~km}$, surface area 50 ha

Colony is on 25 ha of tree grove within $150 \mathrm{~m}$ of water

Mean woody vegetation height of $5 \mathrm{~m}$

$30 \%$ island woody vegetation

Distance from colony to road/structure and human activity disturbances are both $750 \mathrm{~m}$

Proximity of next colony is $10 \mathrm{~km}$

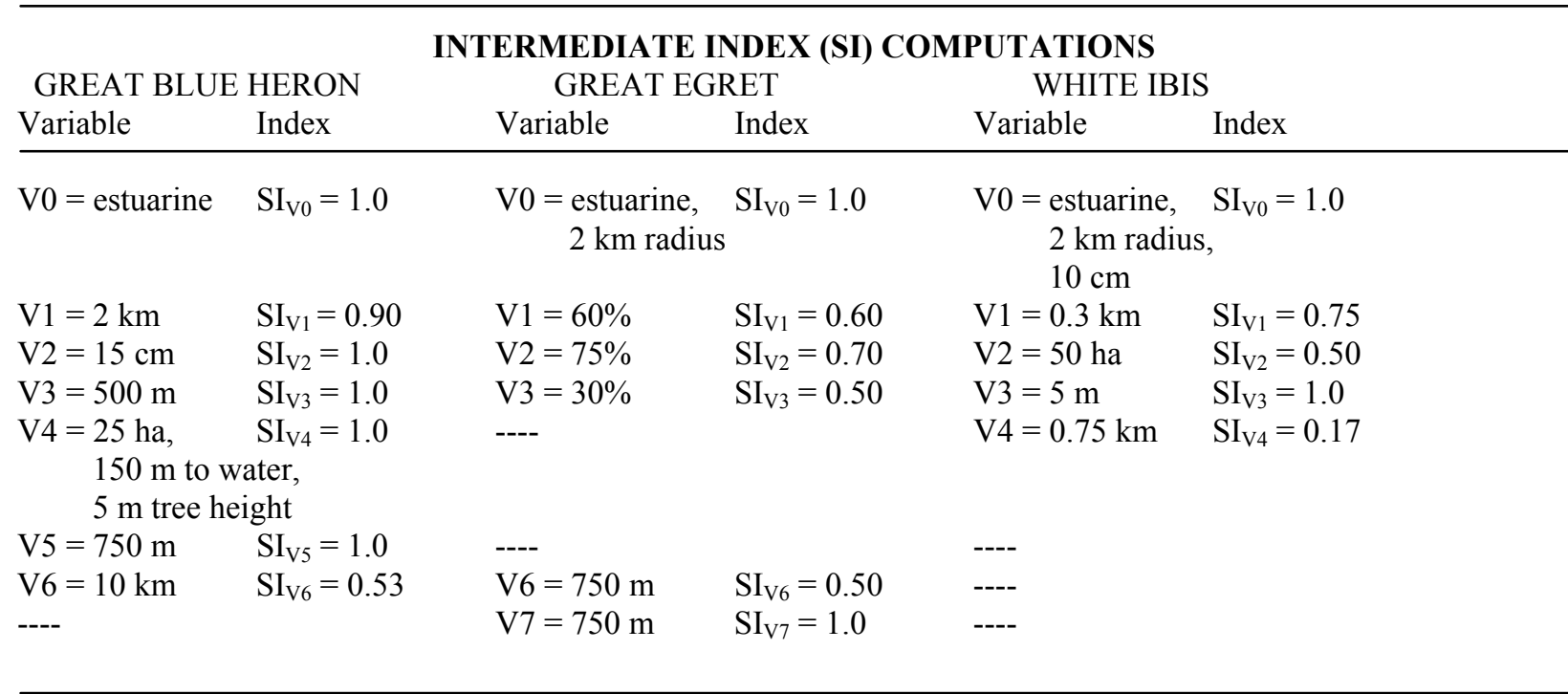

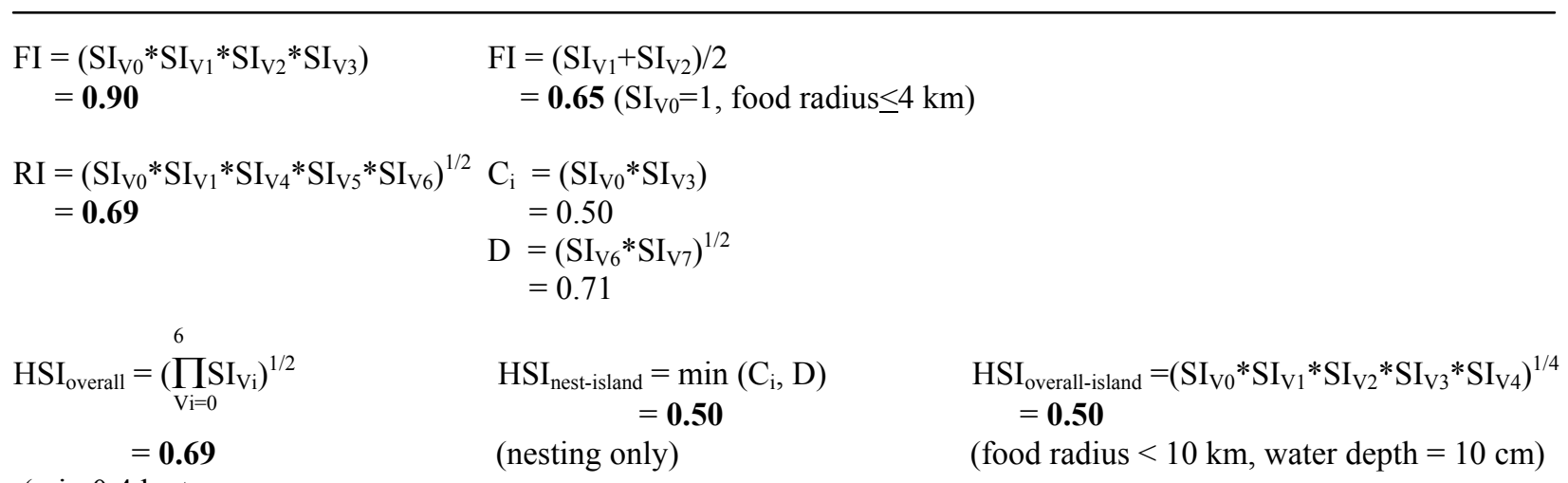

(min 0.4 ha tree grove, within $250 \mathrm{~m}$ of water) 
With more typical conditions, table 5 demonstrates that the suitability indices for longlegged wading birds of the great blue herons $(\mathrm{HSI}=0.69)$ and great egrets $(\mathrm{FI}=0.65 ; \mathrm{HSI}=$ 0.71 ) are high and very similar. Although the white ibis model did not originally have a foraging component, it is, nevertheless, represented in $\mathrm{SI}_{\mathrm{V} 0}$ with suitable foraging radius and shallow foraging water depth. For white ibises, however, the tolerances for human or road/structure disturbances are lower than for great blue herons and great egrets, whereby the entire white ibis HSI value becomes lower $(\mathrm{HSI}=0.47)$.

The setting depicted in table 6, showing deeper foraging waters and more distant feeding sites, decreases both great blue heron and great egret foraging components to 0.40 and 0.525 , respectively. Inasmuch as the proximity of the colony has a positive effect on great blue herons, the nesting component is also affected by the distance to feeding sites. In this case, the feeding site distance is greater and lessens the colony proximity effect in the great blue heron index. Likewise, these factors override in the great egret model, albeit the colony has desirable features such as taller trees for nesting and farther disturbance distances. For the white ibis, in the areas where the water depth is within suitable depths, the index value is 0.64 ; otherwise, it is zero in deeper waters $(35 \mathrm{~cm})$. Thus, the overall index value for the white ibis may be considered zero, since over half of the area (60 percent) is unsuitable.

Table 7 is based on table 6, but alters the disturbance factor by denoting a road close to the colony nesting site. This sets the nesting components to zero for all three species; the close road disturbances will cancel any other favorable aspects in the nesting components. Note that the white ibis model does not differentiate between the kinds of disturbances and the variable (V4) is set to the closest disturbance of $200 \mathrm{~m}$.

An example of the island setting for nesting is depicted in table 8 (other parameters are based on table 5). This affects only the great egret and white ibis models, where both generate like values of 0.50 for the nesting index and overall HSI. 


\section{Recommendations}

Generally, all three models portraying wading birds contain a lot of similarities as well as differences. One of the most notable distinctions among the models is the separation of foraging and nesting components and their use in an index. The great blue heron model appears to be more complete; it assigns one value to the overall suitability index for a colony site, combining all foraging and nesting components. Because the great egret model insists on separation of the index components, a single index value is never computed so that a general impression of overall suitability is not achieved. The justification for this index separation in Chapman and Howard (1984) is questionable and unsubstantiated whereby recommendations are encouraged for combining the components in future model development or enhancements. Furthermore, the complete lack of computing a foraging component in the original white ibis model equations (Hingtgen and others, 1985) constitutes a critical disadvantage for this model. The indirect application as described by Hingtgen and others should have been compensated as a separate component.

As previously noted, the foraging habitat and land types were not clearly defined as components throughout the original models. Other than prerequisite verbal expressions stating the application of these models to specific environments, the land type is not included in any manner as variables or components. Foraging habitat water depth, however, is represented in some form. It is directly measured in the great blue heron model, indirectly associated as the area of suitable depth in the great egret model, and not explicitly expressed at all as a component in the white ibis model but indirectly affects the overall HSI when it exceeds the limit. Foraging distance radius is used in the great blue heron model; however, it is not directly used in the great egret and white ibis model equations but is again implied in the indices. Thus, the versions presented here attempted to fully incorporate all features into the index computations, using newly defined habitat (V0) and its corresponding suitability index ( $\left.\mathrm{SI}_{\mathrm{V} 0}\right)$ to override the original equations.

For the nesting component, both woody vegetation height and human or road disturbance are factors consistently used in the equations of all species. The island concept is not introduced in the great blue heron model, even though great blue herons often occupy the same colony sites as great egrets and white ibises.

Therefore, any synchronization of the factors and components into generalized wading bird indices may be desirable. Two distinct wading bird models may be defined separately for long-legged (great blue herons and great egrets) and short-legged (white ibises ${ }^{9}$ ) as in the Florida models. Based on the performance of the models under various conditions, it is recommended in this report that the general wading bird model consists of the following components: "habitat type," "foraging" information, and "nesting/colony" information. Proposed definitions and formulas are presented in chapter 6 .

9

White ibises as medium-legged birds are henceforth reclassified as short-legged according to the Florida models. 


\section{Florida Wading Bird Habitat Suitability Models}

The effects of habitat restoration alternatives can be readily monitored by the response of wading birds (Gawlik and others, 2004). Both South Florida Water Management District's (HSI) and ATLSS (SESI) modeling programs recognize the importance of wading birds and independently developed detailed models. These are not based on the previously described general HSI models of Short and Cooper (1985), Chapman and Howard (1984) and Hingtgen and others (1985), although various variables are similarly identified as characteristic of the species. Furthermore, a distinction between sizes of birds is made in both of the Florida models, as ranges of measurements are tailored for physical restrictions or needs. The wading birds are classified into two categories in the SESI models: short-legged (white ibis and little blue herons (Egretta caerulea)) and long-legged (wood storks, great egrets, snowy egrets (Egretta thula), and great blue herons). An indirect separation of wood stork versus white ibises and little blue herons are designated in the HSI models.

\section{Wading Bird Habitat Suitability Index (HSI) of Florida}

For wading birds, the availability or amount and timing of food (small freshwater fish and invertebrates) is the most critical factor during breeding. Wading bird feeding success depends on the density of fish in shallow water. A distinction is made between the general increase of fish populations in prolonged hydroperiods and high densities of fish in smaller patches created by the process of drying out the marsh surface. Regardless of general fish abundance in deep waters, wading bird feeding is confined to shallow depths especially after drydowns when fish are observed dying out and fish concentrations increase 20 to 150 fold (Carter and others, 1973; Loftus and Eklund, 1994; Howard and others, 1995). Fish in patches within sparse vegetation are particularly vulnerable to capture (Kushlan, 1976). Wading birds have evolved in their adaptation to rapidly identify these patches in order to reduce search time (Kushlan, 1981; Erwin, 1983). Hydrologic patterns that maximize the number of shallow patches are preferable and indicate good nesting potentials (Smith and Collopy, 1995). Thus, throughout the foraging area, there must be specific water depth requirements as well as records of recession rates (drying).

The HSI for wading birds is based on only two physical processes that concentrate prey, water depth and water recession rates (Gawlik and others, 2004). These components are also mechanistic models (103 ESM, 1980), where variable relationships are translated into equations that are plotted as continuous curves. The index is computed from the South Florida Water Management District models for The Everglades on a 2 by 2-mi grid in weekly time steps.

\section{Water Depth}

There is a quadratic relationship between the number of wading birds at feeding sites with weekly average water depth (d) from November to April (prebreeding and breeding). Ideal water 
depths range between 0.0 and $0.5 \mathrm{ft}$. The index value is zero when water exceeds $0.8 \mathrm{ft}$ or is less than $0.3 \mathrm{ft}$ below the marsh surface.

$$
\begin{array}{ll}
\mathrm{SI}_{\text {depth }}=0.0 & , \mathrm{~d} \leq-0.3 \mathrm{ft} \text { or } \mathrm{d}>0.8 \mathrm{ft} \\
\mathrm{SI}_{\text {depth }}=(\mathrm{d}+0.3) / 0.3 & ,-0.3<\mathrm{d} \leq 0.0 \mathrm{ft} \\
\mathrm{SI}_{\text {depth }}=1.0 & , 0.0<\mathrm{d} \leq 0.5 \mathrm{ft} \\
\mathrm{SI}_{\text {depth }}=(0.8-\mathrm{d}) / 0.3 & , 0.5<\mathrm{d} \leq 0.8 \mathrm{ft}
\end{array}
$$

\section{Water Recession Rate}

The average change in water depth $\left(\Delta_{\text {av_weekly }}\right)$ from November to April is used to compute the water recession suitability index. A negative value represents receding water, whereas a positive value corresponds to rising water.

$$
\begin{array}{ll}
\mathrm{SI}_{\text {recession }}=0.0 & , \Delta_{\text {av_weekly }} \leq-0.6 \mathrm{ft} \text { or } \Delta_{\text {av_weekly }}>0.05 \mathrm{ft} \\
\mathrm{SI}_{\text {recession }}=\left(\Delta_{\text {av_weekly }}+0.6\right) / 0.44 & ,-0.6<\Delta_{\text {av_weekly }} \leq-0.16 \mathrm{ft} \\
\mathrm{SI}_{\text {recession }}=1.0 & ,-0.16<\Delta_{\text {av_weekly }} \leq-0.05 \mathrm{ft} \\
\mathrm{SI}_{\text {recession }}=\left(0.05-\Delta_{\text {av_weekly }}\right) / 0.1 & ,-0.05<\Delta_{\text {av_weekly }} \leq 0.05 \mathrm{ft}
\end{array}
$$

\section{Habitat Suitability Index}

The overall wading bird suitability index for each grid cell is computed as the minimum of water depth or recession rate at each weekly period:

$$
\mathrm{SI}_{\text {cell }}=\min \left(\mathrm{SI}_{\text {depth }}, \mathrm{SI}_{\text {recession }}\right)
$$

The cell, however, does not describe the full-season, landscape-level HSI (Gawlik and others, 2004). The value of each cell is not static but varies during the dry season. Wading birds move and follow a suitable habitat as it changes across the landscape. At any point in time, there are cells that have not reached their peak suitability, cells that are at their peak, or those that have passed their peak. To accommodate this variability, an average landscape suitability score $\left(\mathrm{SI}_{\text {land }}\right)$ is computed for approximately one-quarter of the cells each week with the highest $\mathrm{SI}_{\text {cell }}$ values, corresponding to 150 out of a total of 666 grid cells ( 2 by 2-mi) of The Everglades.

Moreover, the landscape is divided into two zones: coastal and interior. Accordingly, a set of 50 from 217 coastal zone cells and a set of 100 from 449 interior zone cells are drawn, corresponding to a different group of cells each week. Therefore, the $\mathrm{SI}_{\text {land }}$ value does not represent a specific grid cell but is assigned to an entire zone, and the value cannot be effectively mapped.

$$
\begin{aligned}
& \mathrm{SI}_{\text {high }}=\mathrm{SI}_{\text {cell }} \text { in upper quartile (high-valued) of zone } \\
& \mathrm{SI}_{\text {land }}=\text { weekly average } \mathrm{SI}_{\text {high }}
\end{aligned}
$$


The number and distribution of wading bird nests vary according to hydrology and food availability. An additional annual summary variable, comparable to an overall HSI, is created to describe weekly patterns for a given year. This variable (HSI) is inferred from correlations between $\mathrm{SI}_{\text {land }}$ and the number of nests. Two different forms of the variable are generated, dependent on species. They are based on the nesting season: March through April for white ibis and little blue herons, and January through March for wood storks. Likewise, these summary variables (HSI) do not correspond to individual grid cells and cannot be mapped.

$$
\begin{aligned}
& \text { HSI }_{\text {stork }}=\text { average } \mathrm{SI}_{\text {land }}(\mathrm{Jan} .- \text { Mar. }) \\
& \operatorname{HSI}_{\mathrm{ibis}-\text { heron }}=\max \left(0,1-\left(\text { number of weeks } \mathrm{SI}_{\text {land }}(\text { March }- \text { April }) \leq 0.5 / 6\right)\right)
\end{aligned}
$$

The average $\mathrm{SI}_{\text {land }}$ over the three-month nesting season is computed as the HSI for wood storks. For white ibis and little blue herons, the number of weeks that $\mathrm{SI}_{\text {land }}$ is low (less than or equal to 0.5 ) during nesting season is negatively correlated with the number of nests, thereby decreasing the amount of nests. Accordingly, nest success depends on a high $\mathrm{SI}_{\text {land }}$ value (exceeding 0.5) for 1 to 5 weeks during the nesting season; 1 - (ratio of the number of weeks with $\mathrm{SI}_{\text {land }} \leq 0.5$ over 6 weeks). When the number of weeks with unfavorably low $\mathrm{SI}_{\text {land }}$ values exceeds the threshold of 6 weeks, the quantity of $\left(1-\right.$ ratio of the number of weeks with $\mathrm{SI}_{\text {land }} \leq 0.5$ over 6 weeks) becomes negative, and the HSI value is set to zero.

\section{Evaluation of Wading Bird HSI Performance in Florida}

In summary, because the suitability indices for both the ibis-heron and the wood stork groups are not defined at specific spatial locations but are defined as varying functions of adequate habitat suitability over landscape areas, no overall habitat suitability $\mathrm{SI}_{\text {land }}$ maps can be generated for the final wading bird HSI. The changing patterns of weekly landscape indices $\left(\mathrm{SI}_{\text {land }}\right)$ can be best summarized in a time series graph display. For spatial displays, only weekly values of $\mathrm{SI}_{\text {cell }}$ representing each grid cell can be mapped.

Comparisons of restoration scenarios were attempted in Gawlik and others (2004). The coastal and interior zones behaved differently when comparing the natural, current, and restored system simulations for the yearly summary HSI over the time period of 1966 to 1994 . For the white ibises and little blue herons, habitat suitability in the coastal zone was moderately high for the natural system $(>0.6)$ and lower in the current system; however, it could be restored to near natural levels, with an 80 percent chance of suitability exceeding 0.8 . In the interior zone, there were more annual fluctuations, making it difficult to distinguish between scenarios. Thus, the chances of attaining good suitability were equally likely among all three scenarios (70 percent chance of suitability greater than 0.6 in the current system, and 80 percent in natural and restored systems). 
Over the same time period of 1966 to 1994, the coastal zone showed almost no difference among the natural, current, and restored systems in the HSI for wood storks $(>0.8)$, with little fluctuation. There were, however, substantially more annual fluctuations in suitability for the interior zone (suitability of current $>$ natural $>$ restored), with only 60-70 percent chances of suitability greater than 0.6 .

Comparisons of the Florida HSI models with the three general HSI models applicable to Louisiana will not be possible for the complete datasets representing several hypothetical settings in tables 5-8. The Florida HSI models consider only the foraging water depth and the average change (recession) in water depth; factors for nesting or disturbance are not included. The general HSI models do not have the water recession factor. Furthermore, Florida models are defined as weekly landscape measurements that are averaged over the breeding season. Nevertheless, an attempt to look at one common factor, foraging water depth, will be presented here. Tables 9 and 10 will include only water depth information from tables 5 and 8 , respectively. Long-legged wading birds correspond to the great blue heron and great egret in the general HSI models and the wood stork in the Florida HSI model. Short-legged birds correspond to the white ibis in the general HSI model and to both white ibis and little blue herons in the Florida HSI model. Note that herons are not represented by the same leg type across the models; great blue herons as long-legged birds are defined in the general HSI models, whereas little blue herons as short-legged birds are defined in the Florida models. The Florida water depth index $\left(\mathrm{SI}_{\text {depth }}\right)$ does not distinguish between leg types and uses the same equations for both.

The water depth of $10 \mathrm{~cm}$ in shallow feeding sites shown in table 9 is suitable for both long- and short-legged groups. Of interest is the great egret of the general HSI model, where the percentage of this suitable area fine tunes the index value to 0.6. The setting in table 10 emphasizes a feeding site with two widely distinct water depths for which separate indices were computed. Where only 30 percent of the area has shallow water depths of $10 \mathrm{~cm}$, all birds maintained an index value of 1.0 for this depth, except the great egret, whose index value is low at 0.3 when adjusted for area size. Over half of the area (70 percent), however, has deeper waters at $35 \mathrm{~cm}$ so that index values are set to zero and should logically prevail over the index for the entire potential site, except for the great blue heron, which tolerates depths up to $50 \mathrm{~cm}$. Based on the aforementioned arguments, it may be concluded that the percentage area of suitable water depth is critical. Thus, this feature should be considered in future models.

Furthermore, there is no distinction for water depth between leg types at the initial component stage $\left(\mathrm{SI}_{\mathrm{depth}}\right)$ of the Florida HSI model, and it is only addressed later in the final HSI formula stage ( $\mathrm{HSI}_{\text {stork }}$ and $\left.\mathrm{HSI}_{\text {ibis-heron}}\right)$. Biological evidence may contradict and call for a separation in preliminary water depth suitability based on physical properties of leg types.

Since the above comparison is only based on one factor, the final Florida HSI models may have significant changes when the water recession component and the later differentiation for leg type are applied. Moreover, the nesting components in the general HSI models also have a major influence in the overall indices. Thus, the aforementioned comparison is to be taken in its context only and cannot be broadly implicated. 
Table 9. Comparison of foraging water depths in all habitat suitability index (HSI) models for the wading birds: great blue heron (Ardea herodias), little blue heron (Egretta caerulea), great egret (Ardea alba), white ibis (Eudocimus albus), and wood stork (Mycteria americana), separated by short- and long-legged groups. Setting 1. Florida models are denoted with (F) and general models with $(\mathrm{G})$.

Dataset parameter for setting 1:

$60 \%$ of feeding site with water depth of $10 \mathrm{~cm}(0.33 \mathrm{ft})$; remaining feeding site is land.

\begin{tabular}{|c|c|c|c|c|c|}
\hline \multicolumn{6}{|c|}{$\begin{array}{l}\text { FORAGING WATER DEPTH INDEX (SI) COMPUTATION } \\
\text { Long-legged Wading Birds }\end{array}$} \\
\hline \multicolumn{2}{|c|}{ GREAT BLUE HERON (G) } & \multicolumn{2}{|c|}{$\operatorname{GREAT} \operatorname{EGRET}(\mathrm{G})$} & \multicolumn{2}{|c|}{ WOOD STORK (F) } \\
\hline Variable & Index & Variable & Index & Variable & Index \\
\hline $\mathrm{V} 2=10 \mathrm{~cm}$ & $\mathrm{SI}_{\mathrm{V} 2}=1.0$ & $\mathrm{~V} 1=60 \%$ & $\mathrm{SI}_{\mathrm{V} 1}=0.60$ & depth $=0.33 \mathrm{ft}$ & $\mathrm{SI}_{\text {depth }}=1.0$ \\
\hline \multicolumn{6}{|c|}{ Short-legged Wading Birds } \\
\hline \multicolumn{2}{|c|}{ WHITE IBIS (G) } & \multicolumn{2}{|c|}{ WHITE IBIS (F) } & \multicolumn{2}{|c|}{ LITTLE BLUE HERON (F) } \\
\hline Variable & Index & Variable & Index & Variable & Index \\
\hline $\mathrm{V}^{1}=10 \mathrm{~cm}$ & $\mathrm{SI}_{\mathrm{V} 0}=1.0$ & depth $=0.3$ & $\mathrm{SI}_{\text {depth }}=1.0$ & depth $=0.33 \mathrm{ft}$ & $\mathrm{SI}_{\text {depth }}=1.0$ \\
\hline
\end{tabular}

Table 10. Comparison of foraging water depths in all habitat suitability index (HSI) models for the wading birds: great blue heron (Ardea herodias), little blue heron (Egretta caerulea), great egret (Ardea alba), white ibis (Eudocimus albus), and wood stork (Mycteria americana), separated by short- and long-legged groups. Setting 2. Florida models are denoted with (F) and general models with $(\mathrm{G})$.

Dataset parameter for setting 2:

$30 \%$ of feeding site with water depth of $10 \mathrm{~cm}(0.33 \mathrm{ft}) ; 70 \%$ of feeding site with water depth of $35 \mathrm{~cm}(1.15 \mathrm{ft})$.

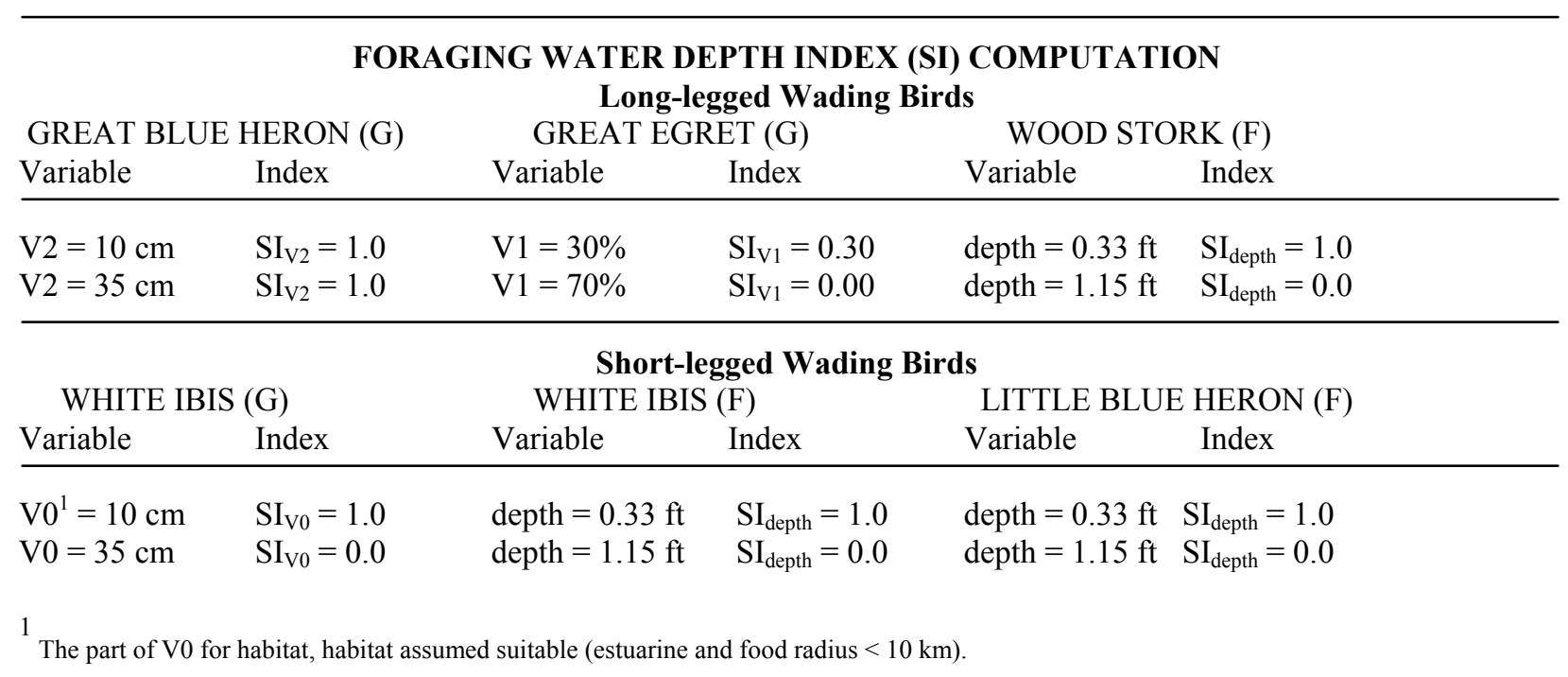




\section{Wading Bird Spatially Explicit Species Index (SESI) of Florida}

The Florida SESI model is a combination of many factors that have already been identified for the success of wading bird breeding: foraging radius of colony, water depth and percentage of area, receding water depth, percentage of area of suitable habitat, and human disturbance factors (urban habitat limit). These factors constitute effective foraging and habitat conditions. There are two additional factors introduced to improve the model: (1) the number of days of flooding preceding the breeding season and (2) the number of successful foraging cycles completed during nesting or breeding.

Basically, the wading bird breeding success is dependent on two factors: (1) the number of continuous days with favorable foraging conditions forming cycles during the breeding season (Jan.-July), and (2) percentage of area that is appropriate habitat. A colony site is successful if it is surrounded by sufficient foraging habitat. Suitable habitat types per the Florida Gap Analysis Program (FGAP) include freshwater marsh and environments dominated by mangroves, Muhlenbergia filipes, Eleocharis cellulosa, Typha (domingensis, latiflora), and Spartina patens. The overall suitability index, called the total foraging potential index (FPI) in the SESI model, for a probable site to be a suitable nesting colony is determined by the collective foraging suitability of all cells in the core area surrounding the colony's central cell (The Institute for Environmental Modeling [TIEM], 2004c; Gross, 2004). It is calculated as the product of the suitable habitat in the core area surrounding the colony center and the number of completed cycles under suitable hydrologic conditions. Only water depths within certain ranges are acceptable for wading birds to catch fish or other prey.

Hydrologic factors drive this SESI model. It does not reflect factors such as hunting, disease, migrations, disturbances (hurricanes or fire), or habitat vegetation changes. It also does not address cumulative effects of periods of high or low water levels on population dynamics. The spatial resolution of 500 by $500 \mathrm{~m}$ is applied. One index value is produced for a single year.

\section{Parameters}

\begin{tabular}{lll} 
Parameter & Short-legged & Long-legged \\
\hline Colony radius & $1.5 \mathrm{~km}$ & $3.0 \mathrm{~km}$ \\
Foraging cycle length & 21 days & 54 days \\
Water depth, lower limit & $0 \mathrm{~cm}$ & $5 \mathrm{~cm}$ \\
Water depth, upper limit & $20 \mathrm{~cm}$ & $35 \mathrm{~cm}$ \\
Start season date & Jan 1 & Jan 1 \\
End season date & May 31 & July 15 \\
Min of good habitat area & 50 percent & 50 percent \\
Urban habitat limit & 25 percent & 25 percent \\
Min area of right water depth 20 percent & 20 percent \\
Reversal threshold & 20 percent & 20 percent \\
Reversal area limit & 80 percent & 80 percent \\
Preceding flooding min & 120 days & 120 days
\end{tabular}


The foraging index in the SESI model is not computed using traditional arithmetic or geometric mean formulae. An attempt is made here to synchronize as much as possible the variable/component presentation resembling other indices of this report. See parameters for specific limits of each leg group.

\section{Variables}

1. $\quad$ Neighborhood HSI $(\mathbf{x}, \mathbf{y})=\quad \sum$ (HSI values of individual cells $\left(\mathrm{x}_{\mathrm{j}}, \mathrm{y}_{\mathrm{k}}\right)$ in foraging radius)

(total number of cells in foraging area radius of colony)

Definition: Proportion of good habitat surrounding the colony potential site cell $(\mathrm{x}, \mathrm{y})$.

$\begin{array}{lll}\text { For each cell }\left(\mathrm{x}_{\mathrm{j}}, \mathrm{y}_{\mathrm{k}}\right): & \operatorname{HSI}\left(\mathrm{x}_{\mathrm{j}}, \mathrm{y}_{\mathrm{k}}\right)=1.0 & \text {, if suitable } \\ & \operatorname{HSI}\left(\mathrm{x}_{\mathrm{j}}, \mathrm{y}_{\mathrm{k}}\right)=0.0 & \text {, otherwise }\end{array}$

Suitable habitat types: freshwater marsh, mangroves, Muhlenbergia spp., Eleocharis spp., Typha spp., and Spartina spp.

Preliminarily, use only a foraging area with $<25$ percent urban disturbance. Only colony central cells $(\mathrm{x}, \mathrm{y})$ with sufficient suitable habitat ( $>50$ percent of radius area) are potential suitable colony sites; other cells are excluded and set to zero.

Redefine as individual variables $(\mathrm{Vi})$ and corresponding indices $\left(\mathrm{SI}_{\mathrm{Vi}}\right)$ :

$$
\begin{array}{ll}
\mathrm{SI}_{\mathrm{V} 0}\left(\mathrm{x}_{\mathrm{j}}, \mathrm{y}_{\mathrm{k}}\right)=1.0 & , \mathrm{~V} 0=\begin{array}{c}
\text { suitable habitat type within radius }(\mathrm{km}), \\
\text { specific for leg group, containing } \mathrm{n} \text { cells }
\end{array} \\
\mathrm{SI}_{\mathrm{V} 0}\left(\mathrm{x}_{\mathrm{j}}, \mathrm{y}_{\mathrm{k}}\right)=0.0 & , \mathrm{~V} 0=\text { otherwise } \\
\mathrm{SI}_{\mathrm{V} 1}(\mathrm{x}, \mathrm{y})=1.0 & , \mathrm{~V} 1>\begin{array}{c}
50 \text { percent radius area for colony central } \\
\text { cell }(\mathrm{x}, \mathrm{y})
\end{array} \\
\mathrm{SI}_{\mathrm{V} 1}(\mathrm{x}, \mathrm{y})=0.0 & , \mathrm{~V} 1 \leq 50 \text { percent } \\
\mathrm{SI}_{\mathrm{V} 2}\left(\mathrm{x}_{\mathrm{j}}, \mathrm{y}_{\mathrm{k}}\right)=1.0 & , \mathrm{~V} 2=>50 \text { percent of cell has no urban disturbance } \\
\mathrm{SI}_{\mathrm{V} 2}\left(\mathrm{x}_{\mathrm{j}}, \mathrm{y}_{\mathrm{k}}\right)=0.0 & , \mathrm{~V} 2=\text { otherwise }
\end{array}
$$

An intermittent component $\left(\mathrm{C}_{\mathrm{V} 2}\right)$ for the colony central cell $(\mathrm{x}, \mathrm{y})$ is computed for urban disturbance ( $>75$ percent disturbance free in foraging area): 


$$
\begin{array}{ll}
\mathrm{C}_{\mathrm{V} 2}(\mathrm{x}, \mathrm{y})=1.0 & , \sum^{\mathrm{n}} \mathrm{SI}_{\mathrm{V} 2} / \mathrm{n}>0.75 \\
\mathrm{C}_{\mathrm{V} 2}(\mathrm{x}, \mathrm{y})=0.0 & , \sum^{\mathrm{n}} \mathrm{SI}_{\mathrm{V} 2} / \mathrm{n} \leq 0.75
\end{array}
$$

For each leg group, the above suitability components are combined into a geometric mean (class variables) for the colony central cell $(\mathrm{x}, \mathrm{y})$ and the individual radius cells $\left(\mathrm{x}_{\mathrm{j}}, \mathrm{y}_{\mathrm{k}}\right)$ in the arithmetic mean of $\mathrm{SI}_{\mathrm{V} 0}$ :

$$
\mathrm{C}_{\text {foraging }}(\mathrm{x}, \mathrm{y})=\left[\left(\sum^{\mathrm{n}} \mathrm{SI}_{\mathrm{V} 0} / \mathrm{n}\right) * \mathrm{SI}_{\mathrm{V} 1} * \mathrm{C}_{\mathrm{V} 2}\right]
$$

2. Foraging Cycle Potential(x,y) $=\sum$ (number of actual completed cycles recorded for the colony cell $(\mathrm{x}, \mathrm{y}))$ :

Definition: One cycle is the continuous period of days with favorable water depths (see below for the minimum fraction of cells requirements). A cycle refers to the number of days essential to successfully start nesting and produce offspring.

For each cell $\left(\mathrm{x}_{\mathrm{j}}, \mathrm{y}_{\mathrm{k}}\right)$ :

$$
\begin{aligned}
& \operatorname{depth}\left(\mathrm{x}_{\mathrm{j}}, \mathrm{y}_{\mathrm{k}}\right)=1 \quad \text {, if within suitable range } \\
& \operatorname{depth}\left(\mathrm{x}_{\mathrm{j}}, \mathrm{y}_{\mathrm{k}}\right)=0 \quad \text {, otherwise }
\end{aligned}
$$

Fraction $($ cells $)=\sum$ (number of favorable cells)

$$
\sum \text { (total foraging area cells) }
$$

Definition: Proportion of cells within foraging area at suitable water depths.

Preliminarily, only cells that were flooded $\geq 120$ days prior to the breeding season are included. In order to continue counting sequential days of a successful cycle, at any given day, a minimum of 20 percent of all cells in a colony area must be within suitable water depth ranges, or else the cycle is terminated and restarted when the fraction of cells reaches $>20$ percent. The cycle is also terminated when there is a reversal of water depth $(\mathrm{a}>20$ percent increase in depth over the previous time step) covering $>80$ percent of area. When the continuous number of favorable days reaches the cycle length of 21 days (short-legged) or 54 days (long-legged), the number of cycles (foraging cycle potential for colony cell $(\mathrm{x}, \mathrm{y}))$ is incremented by 1 . 
Maximum Foraging Cycles $=151 / 21=7.2$ (short-legged) or 197/54 $=3.6$ (long-legged)

Normalized Foraging Cycle $(\mathbf{x}, \mathbf{y})=$ Foraging Cycle Potential $(\mathrm{x}, \mathrm{y})$

Maximum Foraging Cycle

Redefine as individual variables ( $\mathrm{Vi})$ and corresponding indices $\left(\mathrm{SI}_{\mathrm{V}}\right)$ for any given day (d) in a breeding season, $\mathrm{d}=1,2, \ldots, \mathrm{m}$, where $(\mathrm{m})$ is the maximum number of days:

$$
\begin{array}{ll}
\mathrm{SI}_{\mathrm{V} 3}\left(\mathrm{x}_{\mathrm{j}}, \mathrm{y}_{\mathrm{k}}, \mathrm{d}\right)=1.0 & \begin{array}{l}
\text { lower limit } \leq \mathrm{V} 3 \leq \text { upper limit water depth }, \\
\text { specific for leg group }
\end{array} \\
\mathrm{SI}_{\mathrm{V} 3}\left(\mathrm{x}_{\mathrm{j}}, \mathrm{y}_{\mathrm{k}}, \mathrm{d}\right)=0.0 & , \mathrm{~V} 3<\text { lower limit or } \mathrm{V} 3>\text { upper limit } \\
\mathrm{SI}_{\mathrm{V} 4}(\mathrm{x}, \mathrm{y}, \mathrm{d})=1.0 & , \mathrm{~V} 4 \geq 20 \text { percent area of suitable water depth } \mathrm{V} 3 \\
\mathrm{SI}_{\mathrm{V} 4}(\mathrm{x}, \mathrm{y}, \mathrm{d})=0.0 & , \mathrm{~V} 4<20 \text { percent } \\
\mathrm{SI}_{\mathrm{V} 5}(\mathrm{x}, \mathrm{y}, \mathrm{d})=1.0 & , \mathrm{~V} 5 \geq 120 \text { days prebreeding flooded } \\
\mathrm{SI}_{\mathrm{V} 5}(\mathrm{x}, \mathrm{y}, \mathrm{d})=0.0 & , \mathrm{~V} 5<120 \\
\mathrm{SI}_{\mathrm{V} 6}(\mathrm{x}, \mathrm{y}, \mathrm{d})=1.0 & , \mathrm{~V} 6 \leq 20 \text { percent water depth reversal in }>80 \\
\mathrm{SI}_{\mathrm{V} 6}(\mathrm{x}, \mathrm{y}, \mathrm{d})=0.0 & \text { percent area }
\end{array}
$$

For any given day (d), the above suitability components are combined into a geometric mean (class variables) for the colony central cell $(\mathrm{x}, \mathrm{y}, \mathrm{d})$ and individual radius cells $\left(\mathrm{x}_{\mathrm{j}}, \mathrm{y}_{\mathrm{k}}, \mathrm{d}\right)$ in the arithmetic mean of $\mathrm{SI}_{\mathrm{V} 3}$, computed for each leg group:

$$
\mathrm{C}_{\text {nesting }}(\mathrm{x}, \mathrm{y}, \mathrm{d})=\left[\left(\sum^{\mathrm{n}} \mathrm{SI}_{\mathrm{V} 3} / \mathrm{n}\right) * \mathrm{SI}_{\mathrm{V} 4} * \mathrm{SI}_{\mathrm{V} 5} * \mathrm{SI}_{\mathrm{V} 6}\right]
$$

The following is an algorithm for computing the cycles (The Institute for Environmental Modeling [TIEM], 2004c):

Define $\mathrm{d} 1=$ start day of a breeding cycle; $\mathrm{d} 2=$ end day of this cycle; $\mathrm{d} 2-\mathrm{d} 1=$ one cycle length; and $\mathrm{c}=$ count of cycles, with $\mathrm{mc}=$ maximum number of cycles in breeding season. Compute a component for completed cycles, specific for each leg group. One complete cycle $\left(\mathrm{SI}_{\text {cycle }}(\mathrm{x}, \mathrm{y}, \mathrm{c})\right)$ consists of continuous days where all $\mathrm{C}_{\text {nesting }}(\mathrm{x}, \mathrm{y}, \mathrm{d})>0$, for $\mathrm{d} 1 \leq \mathrm{d} \leq \mathrm{d} 2$. Start the next cycle at $\mathrm{d} 1=\mathrm{d} 2+1$. If, at any day in the sequence, $\mathrm{C}_{\text {nesting }}(\mathrm{x}, \mathrm{y}, \mathrm{d})=0$, the cycle is stopped and restarted on the day (d) when $\mathrm{C}_{\text {nesting }}(\mathrm{x}, \mathrm{y}, \mathrm{d})>0$ resumes, whereby the start day is readjusted to a new $\mathrm{d} 1=\mathrm{d}$. If (d) reaches the end of the season and the cycle is not resumed, then for all remaining (c), $\operatorname{SI}_{\text {cycle }}(\mathrm{x}, \mathrm{y}, \mathrm{c})=0$. Thus, the start day of the next cycle is not static but shifts according to favorable water depth conditions. Starting at $c=1$, increment (c) for each newly completed cycle, $\mathrm{c}=\mathrm{c}+1$, until the end of the season. All remaining (c) correspond to incomplete cycles. 
For $\mathrm{c}=1,2, \ldots, \mathrm{mc}$ :

$$
\begin{array}{ll}
\mathrm{SI}_{\text {cycle }}(\mathrm{x}, \mathrm{y}, \mathrm{c})=1 & , \text { complete cycle, } \mathrm{C}_{\text {nesting }}(\mathrm{x}, \mathrm{y}, \mathrm{d})>0 \text { for all }(\mathrm{d}), \mathrm{d} 1 \leq \mathrm{d} \leq \mathrm{d} 2 \\
\mathrm{SI}_{\text {cycle }}(\mathrm{x}, \mathrm{y}, \mathrm{c})=0 & \begin{array}{l}
\text {, incomplete cycle, } \mathrm{C}_{\text {nesting }}(\mathrm{x}, \mathrm{y}, \mathrm{d})=0 \text { in } \mathrm{d} 1 \leq \mathrm{d} \leq \mathrm{d} 2, \\
\text { stop the cycle and shift cycle start day }(\mathrm{d} 1) \text { if possible }
\end{array}
\end{array}
$$

Consequently, there will be a finite number of observed, completed cycles with component values equaling one, followed by the remaining incompleted cycles with values equal to zero. Note that if no cycles are completed in an entire breeding season, then $\operatorname{SI}_{\text {cycle }}(\mathrm{x}, \mathrm{y}, 1)=0$, and all subsequent $\mathrm{SI}_{\text {cycle }}(\mathrm{x}, \mathrm{y}, \mathrm{c})=0$ as well.

The cycle potential component represents the number of observed, completed cycles over the maximum number of cycles (mc) (arithmetic mean):

$$
\mathrm{C}_{\text {cycle_pot }}(\mathrm{x}, \mathrm{y})=\sum_{\mathrm{c}=1}^{\mathrm{mc}} \mathrm{SI}_{\text {cycle }}(\mathrm{x}, \mathrm{y}, \mathrm{c}) / \mathrm{mc}
$$

\section{Total Wading Bird Suitability Index}

The total wading bird suitability index (FPI) is computed for a potential colony site $(\mathrm{x}, \mathrm{y})$ as the following product:

$$
\text { FPI }(\mathbf{x}, \mathbf{y})=\text { Neighborhood HSI }(x, y) * \text { Normalized Foraging Cycle }(x, y)
$$

The maximum value of one for the total index is achieved when all cells have suitable habitat and the maximum number of cycles is completed. The index is set to zero when no cycles are completed or when the percentage of cells with suitable habitat (Neighborhood HSI) is less than 50 percent.

The suitability index may be alternately redefined as the product of two suitability intermittent components (not a geometric mean):

$$
\operatorname{FPI}(\mathrm{x}, \mathrm{y})=\left(\mathrm{C}_{\text {foraging }}(\mathrm{x}, \mathrm{y}) * \mathrm{C}_{\text {cycle_pot }}(\mathrm{x}, \mathrm{y})\right)
$$




\section{Comments Concerning SESI Model Definitions}

Generally, the SESI model presentations do not appear to coincide between the Microsoft Office Power Point ${ }^{\circledR}$ provided in Gross (2004) and the flowchart coding sequences and terminology (The Institute for Environmental Modeling [TIEM], 2004c). The presentation clearly defines the colony as an entity, with a central cell denoting the potential colony site and the individual cells within the surrounding foraging radius. Identification of a suitable habitat for the colony and the number of cycles are computed based on all cells collectively in the colony, resulting in a final, total suitability index that can be mapped for each potential colony site cell $(\mathrm{x}, \mathrm{y})$. The adjacent cells are selected and analyzed for their colony site potential, and the index values are mapped as a continuous surface, with decreasing values at outer habitat limits.

There may be possible definition problems. The main concern is maintaining consistency in the precise meaning of "cell" in all SESI documentation; that is, when the cell (x,y) refers to the colony potential site only or when it refers to the surrounding cell in the foraging radius (for example, what does "for (x,y) in study area" mean?). The flowchart appears to need clarification to address the type of cell $(\mathrm{x}, \mathrm{y})$ when computing certain components: (1) cell $(\mathrm{x}, \mathrm{y})$ in water depth and cycle determinations; (2) the individual habitat index called StudyArea(x,y); (3) the cycle count NC(x,y); (4) the FeedingRadiusFactor(x,y); and (5) the total index called IndexMap(x,y). The flowchart lacks precise cell notation for an "inner loop," where "LoLimit $<$ water depth $<$ HiLimit" and "depth for day(i) $>$ depth for day(i-1)" are determined and should correspond to each individual surrounding cell. Furthermore, the overall percentages for cells to meet suitability criteria need to be computed at the end of this inner loop before resuming the rest of the outer loop to determine cycle counts. Although the textual explanation for the flowchart appears to be very explicit, in its present form, the "sparse" coding on the middle box of the flowchart diagram itself does not show this logic. The cycle count cannot be continued, incremented, or interrupted at each cell determination for water depth in the loop as the coding suggests, or the colony will result with surrounding cells in different cycle counts. Thus, all cells in the foraging radius must be first exhausted in a water depth loop before the cycle status is determined. The authors verified that in order to fit the flowchart into one page, coding condensation was attempted, which sacrificed these important details. The alternate formula denoted as $\mathrm{C}_{\text {nesting }}(\mathrm{x}, \mathrm{y}, \mathrm{d})$ introduced in this report assumes separate notation for the colony cell as $(\mathrm{x}, \mathrm{y})$ and the surrounding cell as $\left(\mathrm{x}_{\mathrm{j}}, \mathrm{y}_{\mathrm{k}}\right)$.

In addition, the definition of "maximum foraging cycles" is not clear. According to the dates specified for breeding season start and end, the maximum foraging cycles are calculated as 7.2 (short-legged) and 3.6 (long-legged). The "foraging cycle potential," however, is an exact count of completed cycles that is incremented by one only when the cycle length is reached. The question is whether the maximum foraging cycles should be in whole units of full cycles (change 7.2 to 7 and 3.6 to 3 full cycles). If both counts refer to whole cycles, then their ratio as the normalized foraging cycle potential are simple fractions such as $1 / 3$. Otherwise, the ratios represent smaller numbers $(1 / 3=0.333$ versus $1 / 3.6=0.278)$, and the index is erroneously reduced in value. The alternate formula using $\mathrm{C}_{\text {cycle_pot }}(\mathrm{x}, \mathrm{y})$ assumes whole units for both counts. 


\section{Comparison of Florida Wading Bird SESI and HSI Models}

There are several major differences between the Florida SESI and HSI models. First of all, the HSI model makes no distinction between short- and long-legged birds in the early stages of model development for water depth and recession components. At the end, an ultimate landscape-based index is generated dependent on species type. In addition, a precise habitat variable is not integrated into the HSI model. (Habitat is loosely implied when the one-quarter subset of cells with the highest index values is selected from coastal and inner zones.) On the other hand, the SESI model is specific for the two leg groups throughout. It describes a foraging radius for examining water depth and habitat suitability, as well as counts cycles for breeding success (both concepts are not incorporated in the HSI models). Finally, the greatest difference in the models is in the computation of the index. The HSI model generates a weekly index from which the annual summary variable depicting weekly trends is computed but cannot be mapped as defined. The SESI generates a single, mappable, annual index per cell.

\section{Water Depth}

Water depth measurements are for different but overlapping time periods in the HSI and SESI models: November-April in the HSI model (weekly), January-May for short-legged birds, and January-July for long-legged birds in the SESI model (daily). A comparison between models will be made for January through April, regardless of measurement time unit (fig. 8).

The HSI index approximates a quadratic equation with a single range for all species, with $-0.3 \mathrm{ft}$ (below marsh surface) and $0.8 \mathrm{ft}$ as lower and upper limits (indices $=0$ ), respectively. The index value reaches one when the depth ranges between 0.0 and $0.5 \mathrm{ft}$. The SESI model defines a twoclassed variable (index $=0$ or 1$)$, where the suitable ranges are $0-20 \mathrm{~cm}(0-0.65 \mathrm{ft})$ for shortlegged birds and 5-35 cm (0.16-1.15 ft) for long-legged birds; these are step functions in contrast to quadratic functions. Comparing the ideal ranges where the index value equals one, a general shift to wider ranges and tolerance for higher water depths are seen in the SESI models (about a 10 percent increase for short-legged birds and a twofold increase for long-legged birds.)

\section{Water Recession}

Change in water depths is important in both the HSI and SESI models; both track whether or not water is decreasing. The HSI model defines the water recession as a separate index component with very specific ranges (similar to a quadratic equation). The SESI model implements this information when calculating the cycles, checking for a 20 percent depth increase over the previous time step (reversal of depth) over a large area. Suitable ranges are not defined per se in the SESI model, and thus no graphic comparison between the HSI and SESI models is attempted here. 


\section{Total Suitability Index}

The formulae for the indices employ very different components. The HSI model considers only weekly index values for water depth or recession and correlates them with number of nests for an annual summary measurement. The SESI model uses the daily water depth information in a cycle concept, combining the proportion of successful cycles with suitable habitat in foraging radius area. Thus, the SESI model appears to develop the weekly and water depth concepts a step further than the HSI by determining a cycle and incorporating the habitat information into a more preferable and comprehensive index. A direct comparison of model formulae, components, or weight coefficients is therefore not possible, as previously applied in the alligator models.

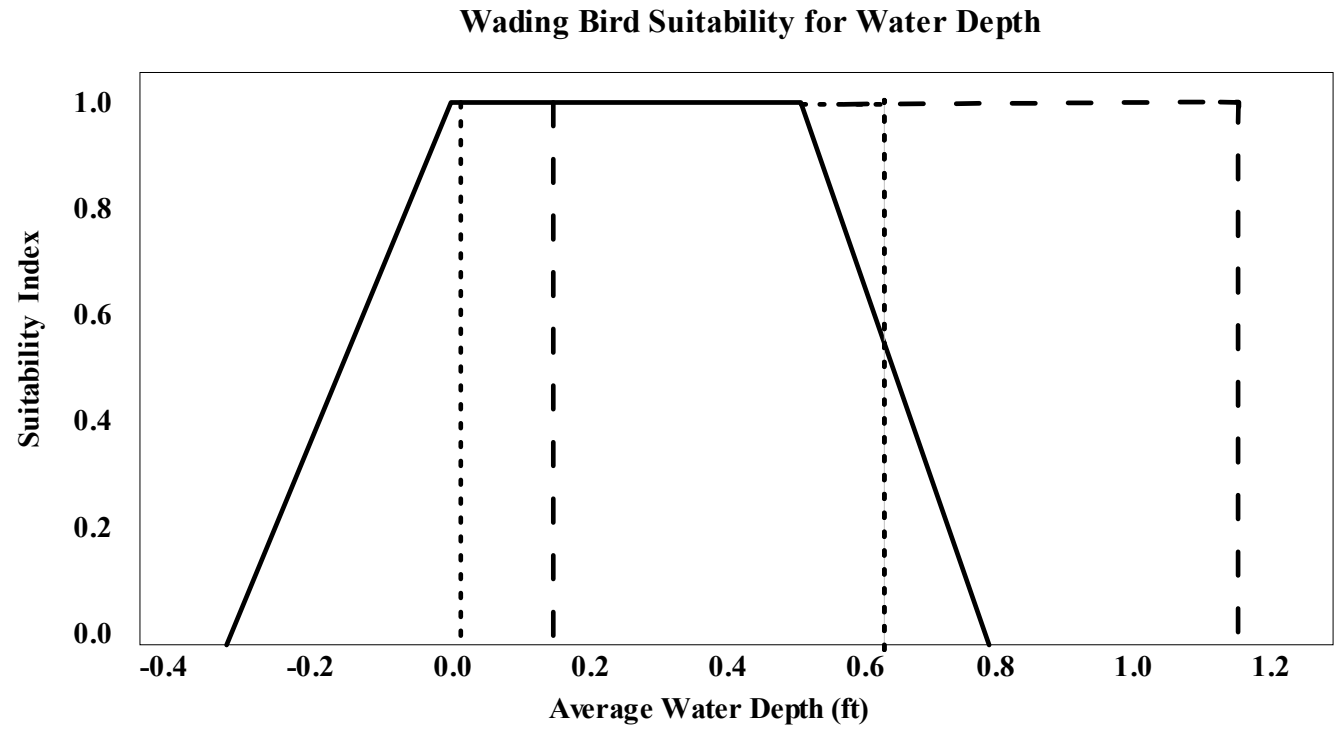

Figure 8. Water depth. The habitat suitability index (HSI) model is the solid line; the Spatially Explicit Species Index (SESI) long-legged model is the long dotted line; and the SESI shortlegged model is the short dotted line. Modified with permission from Gawlik and others (2004). 


\section{Comparison of Florida Models with General HSI Models}

As previously described, the SESI models utilize a very unique and different concept of the foraging cycle, which renders the SESI model incompatible with any HSI model, Florida or general. There are, however, several other factors that are noteworthy to mention. The colony feeding radius in SESI models is more limited (smaller) than in HSI models and differs between the short-legged $(1.5 \mathrm{~km})$ and long-legged $(3.0 \mathrm{~km})$ birds. The general HSI models allow for much larger radii: $10 \mathrm{~km}$ for herons, $4 \mathrm{~km}$ (and up to $20 \mathrm{~km}$ ) for egrets, and $10 \mathrm{~km}$ (and up to 23 $\mathrm{km}$ ) for ibises. There appears to be no pattern separating long- and short-legged groups. Also, although not modeled as a general HSI, the wood stork may travel up to $130 \mathrm{~km}$ to feeding sites. Thus, the colony radii specified in the SESI models may be unrealistically confining or small compared to the search-for-food and flight capacity factors of wading birds.

Other factors include the changes in water depth, suitable habitat area, disturbance, and woody vegetation characteristics. Water depth changes are monitored in both the Florida HSI (water recession) and SESI models (with reversal thresholds and area limits); however, the general HSI models do not include this factor. The idea of percentage of area of suitable habitat that was used in the great egret general HSI model is implemented in the Florida SESI model as the minimum areas of suitable habitat (50 percent) and suitable water depth ( 20 percent). The $\mathrm{road} / \mathrm{structure}$ or human disturbance factor of the general HSI models is depicted in the SESI model as the minimum urban habitat limit (25 percent). The SESI models, however, do not have any specific nesting factors, such as woody vegetation height requirements. Thus, it appears that the SESI model incorporates some of the better general HSI features as described earlier but lacks others.

To examine the effect of the water depth together with percentage of area in the SESI model between the short- and long-legged bird groups, an elementary comparison is attempted in tables 11 and 12, with similar setting manipulations as in tables 9 and 10. Habitat type is assumed as suitable for (V0). The setting is intentionally revised in table 12 and differs from table 10, whereby the percentage of suitable water depth areas is adjusted to demonstrate the impact of the 20 percent limit, and the feeding radius is decreased to a suitable $1 \mathrm{~km}$ for both leg groups.

Even though the water depth and percentage of area are shown as suitable in table 11, it is apparent that the SESI model is very sensitive for the smaller radius limit, which easily affects the $\mathrm{SI}_{\mathrm{V} 0}$ for short-legged birds and sets the $\mathrm{C}_{\text {foraging }}$ component and subsequent final index value to zero. Repeating, all HSI models assume larger radii, and this may be more realistic. Table 12 emphasizes that percentage of area as well as water depth is very important, setting the index values to zero when these factors are not suitable. The short-legged birds failed on both factors; when combining $\mathrm{SI}_{\mathrm{V} 3}$ and $\mathrm{SI}_{\mathrm{V} 4}$ for each area, either depth or percentage of area becomes zero. 
Table 11. Comparison of water depth, percent of area and foraging radius in Spatially Explicit Species Index (SESI) models for the wading birds: great blue heron (Ardea herodias), great egret (Ardea alba), snowy egret (Egretta thula), and wood stork (Mycteria americana) as long-legged birds; white ibis (Eudocimus albus) and little blue heron (Egretta caerulea) as short-legged birds. Setting 1.

Dataset parameter of setting 1:

$60 \%$ of feeding site with water depth of $10 \mathrm{~cm}$.

Feeding site is within $2.0 \mathrm{~km}$.

INDEX (SI) COMPUTATION

\begin{tabular}{llll}
\multicolumn{2}{c}{ LONG-LEGGED BIRDS } & \multicolumn{2}{c}{ SHORT-LEGGED BIRDS } \\
Variable & Index & Variable & Index \\
\hline $\mathrm{V} 3=10 \mathrm{~cm}$ & $\mathrm{SI}_{\mathrm{V} 3}=1.0$ & $\mathrm{~V} 3=10 \mathrm{~cm}$ & $\mathrm{SI}_{\mathrm{V} 3}=1.0$ \\
$\mathrm{~V} 4=60 \%$ & $\mathrm{SI}_{\mathrm{V} 4}=1.0$ & $\mathrm{~V} 4=60 \%$ & $\mathrm{SI}_{\mathrm{V} 4}=1.0$ \\
$\mathrm{~V} 0=2 \mathrm{~km}$ & $\mathrm{SI}_{\mathrm{V} 0}=1.0$ & $\mathrm{~V} 0=2 \mathrm{~km}$ & $\mathrm{SI}_{\mathrm{V} 0}=0.0$
\end{tabular}

Table 12. Comparison of water depth, percent of area and foraging radius in Spatially Explicit Species Index (SESI) models for the wading birds: great blue heron (Ardea herodias), great egret (Ardea alba), snowy egret (Egretta thula), and wood stork (Mycteria americana) as long-legged birds; white ibis (Eudocimus albus) and little blue heron (Egretta caerulea) as short-legged birds. Setting 2.

Dataset parameter of setting 2:

$15 \%$ of feeding site with water depth of $10 \mathrm{~cm}$. $85 \%$ of feeding site with water depth of $35 \mathrm{~cm}$.

Feeding site is within $1.0 \mathrm{~km}$.

\section{INDEX (SI) COMPUTATION}

\begin{tabular}{llll}
\multicolumn{2}{c}{ LONG-LEGGED BIRDS } & \multicolumn{2}{c}{ SHORT-LEGGED BIRDS } \\
Variable & Index & Variable & Index \\
\hline $\mathrm{V} 3=10 \mathrm{~cm}$ & $\mathrm{SI}_{\mathrm{V} 3}=1.0$ & $\mathrm{~V} 3=10 \mathrm{~cm}$ & $\mathrm{SI}_{\mathrm{V} 3}=1.0$ \\
$\mathrm{~V} 4=15 \%$ & $\mathrm{SI}_{\mathrm{V} 4}=0.0$ & $\mathrm{~V} 4=15 \%$ & $\mathrm{SI}_{\mathrm{V} 4}=0.0$ \\
& & & \\
$\mathrm{~V} 3=35 \mathrm{~cm}$ & $\mathrm{SI}_{\mathrm{V} 3}=1.0$ & $\mathrm{~V} 3=35 \mathrm{~cm}$ & $\mathrm{SI}_{\mathrm{V} 3}=0.0$ \\
$\mathrm{~V} 4=85 \%$ & $\mathrm{SI}_{\mathrm{V} 4}=1.0$ & $\mathrm{~V} 4=85 \%$ & $\mathrm{SI}_{\mathrm{V} 4}=1.0$ \\
$\mathrm{~V} 0=1 \mathrm{~km}$ & $\mathrm{SI}_{\mathrm{V} 0}=1.0$ & $\mathrm{~V} 0=1 \mathrm{~km}$ & $\mathrm{SI}_{\mathrm{V} 0}=1.0$
\end{tabular}




\section{$\underline{\text { Statistical Analyses }}$}

A sampling design for a point-by-point statistical comparison of the Florida SESI and HSI models will be more challenging to fit. The SESI models produce fixed, once-a-year index values per grid cell, whereas HSI values may be expressed as a weekly grid cell map or as a yearly time series of averaged weekly indices. Because each HSI model grid cell has a weekly $\mathrm{SI}_{\text {cell }}$ index (from which a subset of cells representing the quarter of the highest values over all cells is selected to generate the weekly average value for $\mathrm{SI}_{\text {land }}$ ), each week constitutes a different subset of cells. Thus, there will be an apparent problem in making a comparison by using a single set of sampled data points on a stationary map of the suitability index for wading birds. Only the weekly subset of HSI model cells can be used if their coordinates are provided and would have to coincide exactly with points on the SESI model. It follows that sampling in the HSI model supersedes that of the SESI model, where the exact cell position in SESI needs to be located according to the HSI model. The cell position, however, fluctuates from week to week when the foraging and nesting habitat shifts across the landscape over time. The aforementioned constitutes a major obstacle.

Several sampling methods may be proposed for statistical comparisons. One process would be to choose a single subset of grid cells in the HSI model, regardless of the averaged weekly landscape SI values and yearly summary HSI value. A one-week subset is selected as either the most representative or in the middle of a breeding cycle. The center of the 2 by 2-mi HSI grid cell is used to identify the closest corresponding 500 by $500-\mathrm{m}$ SESI cell. For these two related cells, the model index values $\left(\mathrm{SI}_{\text {cell }}\right.$ and FPI) and water measurements can be statistically compared. Note that at this stage, this approach does not incorporate HSI model weekly averages or final annual summary index computations with species identification. Perhaps the only way to differentiate species in HSI models would be according to the breeding week selection (Jan.-Mar. for long-legged birds, and Mar.-Apr. for short-legged birds.) The appropriate FPI value in the SESI model per each species would be subsequently matched.

An alternative method would be to follow one subset of cells throughout the weeks and calculate $\mathrm{SI}_{\text {cell }}$ weekly values. In this case, it would be necessary to modify the species-specific annual index definition in the HSI model by calculating directly from the $\mathrm{SI}_{\text {cell }}$ value, bypassing the selective quartile averaging per region of the landscape $\left(\mathrm{SI}_{l a n d}\right)$.

In conclusion, it appears that because of the vast differences in the way the indices are derived in both models, any statistical comparison would be difficult to apply without some modifications of index definitions in the HSI model.

\section{General Evaluation of All Wading Bird Models}

All of the general HSI models for individual wading bird species were independently developed for the United States coastal regions, and any of them could be readily applied to Louisiana. Certain features were basic and common among these models, while others were 
more distinct. The Florida models appeared to be more individualistic, building upon basics but also implementing further advanced concepts such as modulations across the landscape over time and breeding cycles. Again, an attempt to score the models by factors will be presented below.

\section{Scoring All Models by Factor Categories}

Table 13 presents the comparison of all models by specific factors. Scores are assigned as high (well represented or defined), mod (moderately represented), or low (lacking or poorly defined). Species will be separated into short- and long-legged groups.

1. Grid Scale. The Florida HSI scale is very coarse at 2 by $2 \mathrm{mi}$, and the SESI model is finer at 500 by $500 \mathrm{~m}$. There are no grid specifications for all general HSI species models.

2. Habitat. The suitable habitat factor (V0) was added for all general HSI models; these models originally only described the appropriate prerequisite habitat assumptions for model application. The great egret and white ibis general HSI models make a further distinction between island and non-island habitats. There are no habitat requirements in the Florida HSI model. The SESI model defines suitable habitat as HSI values in the Neighborhood HSI variable.

3. Foraging radius. The foraging radius is a critical factor that should be represented in all models. It is separately designated in the great blue heron general HSI model, and within the habitat variable (V0) of the great egret and white ibis general HSI models. There is no foraging radius given in the Florida HSI model. Foraging radii are very specific for short- and longlegged birds in the SESI model.

4. Water Depth, Foraging. Water depth for foraging areas is well-defined in all general HSI models. An overall water depth for feeding/breeding is denoted in the Florida HSI model. Water depths of the foraging radius are given in the SESI model.

5. Water Depth, Nesting. Water depth for nesting is given in the great egret general HSI model only. It is not defined in the great blue heron general HSI model and is implicit in the white ibis general HSI model as percentage of flooding. Again, the overall water depth for feeding/breeding is denoted in the Florida HSI model. A water depth for foraging cycle (breeding) is denoted in the Florida SESI model.

6. Water Recession. Only the Florida models implement water recession, as a direct measurement in the HSI model and as reversal threshold and percentage of area in the SESI model. All general HSI models lack this concept. 
7. Percentage of Area. The great egret general HSI model best depicts percentages of areas for water depth, submergent vegetation cover, and woody vegetation. It is described as the percentage of flooded colony area during nesting in the white ibis general HSI model.

Percentage of area is not described in the great blue heron general HSI or Florida HSI models. Minimum percentages of area are given for habitats and water depths in the SESI model.

8. Woody Vegetation. Woody vegetation cover or height is given in the general HSI models: potential nest site (V4) in the great blue heron model, island (V3) and non-island (V5) in the great egret model, and height classes (V3) in the white ibis model. Vegetation is not addressed in either of the Florida models (HSI and SESI).

9. Disturbance. Human or road disturbance is emphasized in all general HSI models as specific distances. Percentages of urban habitat in foraging areas are used in the Florida SESI model but not in the Florida HSI model.

10. Colony Proximity. The closeness of the next adjacent colony is defined only in the great blue heron general HSI model. All other models lack this concept.

11. Landscape. Only the Florida HSI model considers general landscape modulations over time in the habitat. All other models assume a static habitat.

12. Breeding Cycle. Only the SESI model calculates completed breeding cycles. All other models lack this concept.

Once more, the Florida SESI model prevailed with more high scores than all other HSI models (7-8 in SESI versus 4-6 in all HSI models). Conversely, the SESI model had the lowest count of low scores (3 in SESI versus 5-8 in all HSI models). All models scored high in water depth as the primary driving force of wading bird feeding and nesting. The Florida HSI model is strictly a hydrological model and again lacked most factors, thereby receiving the lowest scores overall except in the water depth and recession categories. Certain factors such as woody vegetation and disturbance were emphasized in the general HSI models, whereas the landscape and breeding cycles were unique to the Florida models. In other words, the models either scored high in their respective well-defined factors that were characteristic of the models, or they lacked information altogether and were scored low in other factors. Few factors were scored as mod for moderately or implicitly defined. 
Table 13. Scoring of the wading bird models by factor categories, separated by short- and longlegged groups. Florida models are denoted as SESI (F) and HSI (F), and general HSI models as HSI (G) for the great blue heron (Ardea herodias), great egret (Ardea alba), wood stork (Mycteria americana), and white ibis (Eudocimus albus). Scoring of categories: high (well represented or defined), mod (moderately represented), or low (lacking or poorly defined).

Long-Legged Wading Birds

\begin{tabular}{|c|c|c|c|c|}
\hline FACTOR & $\begin{array}{l}\text { GREAT BLUE HERON } \\
\text { HSI (G) }\end{array}$ & $\begin{array}{l}\text { GREAT EGRET } \\
\text { HSI (G) }\end{array}$ & $\begin{array}{l}\text { WOOD STORK } \\
\text { HSI (F) }\end{array}$ & SESI (F) \\
\hline Grid Scale & low & low & low & high \\
\hline Habitat & $\bmod$ & high & low & high \\
\hline $\begin{array}{l}\text { Foraging } \\
\text { Radius }\end{array}$ & high & $\bmod$ & low & high \\
\hline $\begin{array}{l}\text { Water Depth } \\
\text { Foraging }\end{array}$ & high & high & high & high \\
\hline $\begin{array}{l}\text { Water Depth } \\
\text { Nesting }\end{array}$ & low & high & high & high \\
\hline $\begin{array}{l}\text { Water } \\
\text { Recession }\end{array}$ & low & low & high & high \\
\hline $\begin{array}{l}\text { Percentage } \\
\text { of Area }\end{array}$ & low & high & low & high \\
\hline $\begin{array}{l}\text { Woody } \\
\text { Vegetation }\end{array}$ & high & high & low & low \\
\hline Disturbance & high & high & low & $\bmod$ \\
\hline $\begin{array}{l}\text { Colony } \\
\text { Proximity }\end{array}$ & high & low & low & low \\
\hline Landscape & low & low & high & low \\
\hline $\begin{array}{l}\text { Breeding } \\
\text { Cycle }\end{array}$ & low & low & low & high \\
\hline
\end{tabular}


Table 13. Continued

\section{Short-Legged Wading Birds}

\begin{tabular}{|c|c|c|c|}
\hline FACTOR & $\begin{array}{l}\text { WHITE IBIS } \\
\text { HSI (G) }\end{array}$ & $\begin{array}{l}\text { WHITE IBIS } \\
\text { HSI (F) }\end{array}$ & SESI (F) \\
\hline Grid Scale & low & low & high \\
\hline Habitat & high & low & high \\
\hline $\begin{array}{l}\text { Foraging } \\
\text { Radius }\end{array}$ & $\bmod$ & low & high \\
\hline $\begin{array}{l}\text { Water Depth } \\
\text { Foraging }\end{array}$ & high & high & high \\
\hline $\begin{array}{l}\text { Water Depth } \\
\text { Nesting }\end{array}$ & low & high & high \\
\hline $\begin{array}{l}\text { Water } \\
\text { Recession }\end{array}$ & low & high & high \\
\hline $\begin{array}{l}\text { Percentage } \\
\text { of Area }\end{array}$ & high & low & high \\
\hline $\begin{array}{l}\text { Woody } \\
\text { Vegetation }\end{array}$ & high & low & low \\
\hline Disturbance & high & low & $\bmod$ \\
\hline $\begin{array}{l}\text { Colony } \\
\text { Proximity }\end{array}$ & low & low & low \\
\hline Landscape & low & high & low \\
\hline $\begin{array}{l}\text { Breeding } \\
\text { Cycle }\end{array}$ & low & low & high \\
\hline
\end{tabular}




\section{Assessment of the Wading Bird Models}

Inasmuch as there are no wading bird models defined for the LCA study, the general HSI models for the great blue heron, great egret, and white ibis developed by the U.S. Fish and Wildlife Service provide insight into the model characteristics and parameters that, although generalized for the United States, may be applied to coastal Louisiana with confidence. Independently developed Florida HSI and SESI models offer additional distinct features that appear to be better suited for the Florida environment. Nevertheless, the underlying concepts of definitive hydrological requirements for feeding are universal for all models and are essential for a successful colony establishment.

Other secondary features concerning type of vegetation (woody) and human/urban disturbance occurred in many of the models and should be deemed important for the formation of a good colony site. Without the proper tree vegetation or appropriate tools to build a nest, it is unlikely that a good, long-lasting colony site will become established. Conditions, however, may occur where birds adapt and construct nests in shrubs, rock/cliffs, or engineered structures; highly suitable feeding sites may dictate the proximity of the colony site regardless of vegetation. In any case, dependable and suitable colony sites have a tendency to be continually utilized year after year. Any introduction of continuous disturbance such as industrial and residential developments or traffic (roads) may instantaneously disrupt and inhibit colonization because wading birds are very sensitive.

Although a shifting landscape concept may be intuitive for any model development since the environment is not stationary, incorporation of a landscape variable into a model is theoretically difficult so that a single suitability index for a colony site cell cannot be obtained, as noted in the discussion of the Florida HSI model. Furthermore, breeding cycles propose an attractive idea that also assumes variable water depth conditions, which may disrupt and inhibit cycles. Both the landscape shifting and breeding cycle parameters may operate effectively in the restricted environment of The Everglades; however, their wide-scale application to a broad landscape as throughout all coastal Louisiana may be questionable and may furthermore be difficult to monitor or implement.

Categorizing wading birds by length of legs is introduced in the Florida SESI model only. Different feeding radii are assigned per leg group. Throughout the previous comparisons, it has been demonstrated that the feeding radii for the SESI model may be too short or too specific for The Everglades. In the general HSI models (Short and Cooper, 1985; Chapman and Howard, 1984; Hingtgen and others, 1985), biologists have noted much wider feeding radii, with birds traveling over $20 \mathrm{~km}$. Therefore, as indicated before, the SESI model radii may be too restrictive. Moreover, the concept of categorization by leg type was extended to the general HSI models in all comparisons, but there appeared to be an inadequate representation of short-legged wading birds. Such categorization in any future models would necessitate a clear definition of leg length and itemization of more possible wading bird species into each group. 
In any case, The Everglades models are probably well-suited for that particular environment, based on new biological concepts such as fluctuating landscape and breeding cycles that are substantiated by field observations. Nonetheless, the previous scoring assessment suggests that some specific factors may be better candidates: "grid scale," "habitat," "foraging radius," "water depth" for both foraging and nesting, "percentage of area," "woody vegetation," and "urban/human disturbance." Recommendations for a newly-proposed model that can be applied to the LCA study are presented in chapter 6. 


\section{Chapter 6 \\ Assessment and Recommendations for Louisiana and Florida Models}

\section{General Assessment}

Wildlife abundance based on the habitat suitability models of The Everglades and coastal Louisiana is more difficult to compare because of the confounding effect of the different levels of ecosystem productivity between these two regions. The Everglades region is considered nutrient-limited, whereas most of the coastal marshes of Louisiana are more nutrient rich (Connor and Day, 1987; Chabreck, 1970). In the absence of nutrient limitation, ecosystem productivity increases until it is restricted by salinity or other stress factors (Connor and Day, 1987; Gunther, 1961). Optimal conditions occur when there are high nutrient levels and frequent flushing of marshes by tidal action (Connor and Day, 1987; Schelske and Odom, 1961).

Therefore, greater wildlife and fish productivity can be expected in coastal Louisiana than in Florida. For example, American alligator (Alligator nississippiensis) growth rates are faster in tidal brackish marshes than in nontidal fresh marshes (Rootes and others, 1991).

Other factors affecting food sources may complicate model comparisons, such as the lack of annual wet and dry cycles in the tidal coastal marshes of Louisiana that are essential to concentrate fish for alligators and wading birds in the nontidal Florida environment (Connor and Day, 1987; Howard and others,1995; Kushlan, 1976, 1981). Since the water levels are less dynamic in the nontidal Everglades, the Florida models require periods of low and high water levels; whereas, the Louisiana models require simply an intermediate flooding duration. Thus, the number of dry days or water recession rates would be unnecessary variables for the Louisiana models. Furthermore, there are other relationships to consider: (1) the inverse relationship between water salinity and plant flood tolerance, and (2) the general difference in flood tolerances between tidal and nontidal marshes. Nevertheless, none of the models can be used to help explain or measure the ecosystem dissimilarities.

Overall, the Florida models may be more responsive to environmental conditions since they incorporate more variables and relationships. In contrast, the American alligator (herein called "alligator") habitat suitability index (HSI) model of the Louisiana Coastal Area (LCA) study and the wading bird general HSI models that are applicable to Louisiana are more simplistic. Economics, however, would dictate and limit the resources to collect enough data to apply such detailed Florida models to many species (over 10 taxa), 4 million acres of coastal marshland (Chabreck, 1970), and dozens of restoration scenarios in the LCA study. While more sensitive models than those in the LCA study may be desirable, the current models display enough confidence that there are true differences in restoration efficiency when they indicate clear distinctions among restoration scenarios and vice versa (USACE, 2004).

In terms of the success of each module in the LCA study, protocols rated most modules as moderate or low (USACE, 2004). At the time, LCA subprovince 1 (Ponchartrain basin) and 
subprovince 4 (chenier plain) appeared to have the best hydrodynamic models; however, major disturbances like Hurricanes Katrina and Rita (August and October of 2005) have since reshaped the ecosystems substantially, thus destroying habitat for wildlife so that current models are not applicable.

Other factors contributed to hampering efforts in the development and comparisons of models from both regions. Spatial scaling was repeatedly a major hindrance for establishing relationships among factors so that many associations were determined intuitively. Also, data collection was often nonexistent, nonuniform, or limited in certain regions, so that more widespread aggressive field work is advocated.

Habitat classification systems were not consistent across all HSI models. The wildlife habitat in the LCA study was divided into 10 categories: bottomland hardwood forest, swamp, freshwater marsh (attached and floating), intermediate marsh, brackish marsh, saline (saltwater) marsh, open water, ridge (spoilbanks), and maritime forest (mangrove). Marsh classification was based on Penfound and Hathaway (1938). The Florida models (HSI and Spatially Explicit Species Index (SESI)) use the Florida Gap Analysis Program (FGAP) system with finer rankings (over 50) based on primary vegetation type. The general HSI models developed by the U.S. Fish and Wildlife Service relied upon the classification system of wetlands by Cowardin and others (1979). This system identifies a hierarchy of classification, with five major wetland systems (palustrine, riverine, lacustrine, marine, and estuarine) and various classes based on flooding regime or vegetation type (emergent, scrub/shrub, forested, unconsolidated bottom, unconsolidated shore, and open water), along with other subgroup levels for a very comprehensive and sophisticated system that is more universally adaptable for any generalized use.

In addition, various mathematical methods are employed to compute any combination of factors into a single component or index, such as the geometric mean, arithmetic mean, or the minimum of several factors. The method of choice depends on the desired magnitude of importance for the factor. The minimum function represents the strongest argument by eliminating influences of all higher-valued factors. This is followed by the geometric mean that combines all factors but can be readily reduced to zero suitability for any one nonsuitable factor of zero ("all or none"), and then the arithmetic averaging that balances all factors and maintains a nonzero result if not all zero.

Finally, what is the interpretation of the exact actual value of the index? Does the finetuning of weights or the addition of more components or factors improve the precision of the index? In other words, what is the biological significance by increasing the index value, for example, from 0.70 to 0.75 ? In the previous index comparisons, conducted by using various hypothetical settings (tables 1-3, 5-12), only relative comparisons of values appeared to make sense biologically; that is, the index in one model is "lower" or "higher," or rated as "bad" or "good" compared to another model. The problem of the index being too regionally specific has already been addressed. Reiterating, the index represents the chance or likelihood of habitat 
usage, so that the larger the index value, the more likely this habitat will be used. This represents a theoretical or probabilistic approach; however, the values can also be interpreted in broader biological classes. For example, the range of values may be split into quartiles and assigned a categorical interpretation: $0-0.24$ as low; $0.25-0.49$ as $l o w$ to mid; $0.50-0.74$ as mid to high; and 0.75-1.0 as high. Alternatively, the values may be split into thirds and assigned low, mid, and high categories. Furthermore, a problem arises when the factors assume binary values ( 1 or "yes," 0 or "no") only, so that no gradual changes can be portrayed. These are best accommodated in the geometric mean as constants.

Empirical probabilities are introduced in the alligator SESI model for the probability of nesting $(P(Y))$ only. Assigning suitability ranks for the SESI habitat component may be viewed as designating a priori probabilities. Incidentally, the earlier formula of the SESI index was denoted as the product of three components as shown in the presentation provided in Microsoft Office Power Point ${ }^{\circledR}$ format (see Rice and Slone, 2004). This is analogous to the joint probability of three independent probability component events:

$$
\text { Index }=P(\text { suitable habitat })=P(\mathrm{~A} \text { and } \mathrm{B} \text { and } \mathrm{C})=P(\text { nesting }) * P(\text { habitat }) * P(\text { nonflooding })
$$

The reason for the change to a weighted arithmetic mean in the most recent version is unknown (The Institute for Environmental Modeling [TIEM], 2004b), although it can be speculated that the nonflooding component may not be properly defined as a probability in this version. If the two components representing the proportion of actual breeding cycles to the maximum potential, and the proportion of suitable habitat can be related to probabilities, then the final SESI index product can be regarded as a joint probability. In any case, it may be desirable in future model enhancements to incorporate more empirical probabilities (for example, the proportion of nests or offspring in relationship to the population for a particular habitat). Then the index interpretation as "likelihood of success" would be more clearly understood. Instead, the approach for determining most indices and components throughout the existing models appeared to be the process of finding cut-off values that define simple ranges for the maximum plateau, where suitability equals one, and connecting to limit value(s) where suitability equals zero with linear function(s). 


\section{Recommendations for the Alligator LCA Study Model}

The two ecosystems represented by The Everglades and Louisiana coastal regions are very different in hydrology, vegetation, food availability, animal density and growth dynamics. The indices as presented are probably well-suited for their particular environments, since they underwent continual calibrations and development based on field observations.

Nevertheless, certain features were consistently considered or stood out as potential better candidates, as shown by the previous scoring assessment of the models by factors:

1. Grid scale is a fundamental factor. The intermediate LCA study grid scale of 1,000 by 1,000 $\mathrm{m}$ appears to be sensitive enough for adequate modeling, especially of habitat edges and microenvironments, and does not necessitate further refinement.

2. Habitat designation is very important, and the LCA study HSI model may benefit from finer rankings by primary vegetation type, as used in FGAP (SESI model). The criticism of the LCA study model being generalized for the marsh types and not considering the relationship with flooding is probably valid. Regressions of flooding with marsh types may need to be performed to establish this relationship to be incorporated as a separate component in the model. Moreover, the wetland habitat classification system by Cowardin and others (1979) may be an overall better choice for all wildlife in coastal Louisiana.

3. Water depth is the primary factor for alligator habitat suitability. The Louisiana yearly water depth furnishes too little information. Monthly averages can vary widely as observed at Marsh Island (Nyman, 2001, fig. 6.) Therefore, it is strongly recommended to incorporate seasonal (breeding/nesting) average water levels and flooding levels as is defined in both Florida models. The SESI model breeding/nesting component may be too specific and complex in derivation. The simpler Florida HSI model's mean value for the water depth $\left(\mathrm{d}_{1}\right)$ in nest building (prerequisite) and flooding $\left(\Delta_{\max }\right)$ are preferred since the Louisiana environments are more basic. Additional information of the mean water depth (define as $\mathrm{d}_{3}$ ) during nest construction (June 15-June 30$)$ may be beneficial. The $\left(\mathrm{d}_{1}\right),\left(\mathrm{d}_{3}\right)$, and $\left(\Delta_{\max }\right)$ measurements may be arithmetically averaged with the yearly water depth into a single water component, and, if necessary, new suitability ranges can be established (the current ranges may be too shallow). Although the Louisiana marshes are tidal, the existing daily water measurements should suffice. Furthermore, the concept of the number of dry days used in the Florida models becomes immaterial when a yearly average is computed in the LCA study HSI model. Also, although body condition and survival are based on water depth, this component is considered inconsequential and weighted the least in the Florida HSI; thus, it can be disregarded from modeling, as previously suggested.

4. Percentage of open water area was not incorporated in either of the Florida models. This feature is regarded as very significant for alligator habitats and is a wise choice for the LCA study HSI model. The open water area requirements for alligators are best described in Newsom (1987), whereby the general HSI model scrupulously defines percentage of water areas that are 
designed for all alligator environments universally along the gulf coast. The lack of this factor in the Florida models may be location specific, but its inclusion would probably enhance the Florida models. That is, water depth may be very suitable in a particular cell of a region, but if the proportion of land is too high, then the entire habitat becomes less suitable regardless. The percentage of open-water area in the LCA study HSI model is derived from the Newsom (1987) model and suffices in its simpler present form (pond interspersion details may not be required).

5. Usage of the geometric mean as the index formula type is probably audacious as it can instantaneously eradicate suitability of the entire habitat for any influence of a component that is unfavorable. This may be too extreme, as shown in the hypothetical settings of tables 1 and 3. It is recommended to either widen the suitability ranges or to use an "amended" arithmetic mean with conditions that set the index value to zero (see the previous discussion of the SESI API).

In conclusion, the alligator HSI model for Louisiana may be too simple in its present form. It was developed in conjunction with other wildlife models in the LCA study; however, certain features may need to be reconsidered for inclusion or modification (see above). More field testing and model calibrations are also encouraged. Recommendations for improvements in the LCA study model are presented below. These build upon the current LCA study model since most factors were predetermined and generalized over all wildlife. The Florida HSI model features were more compatible than the SESI model and therefore were blended with the LCA study model.

\section{Proposed LCA Study Model for Alligators}

The definition of the habitat factor (V1) is dependent on the classification of habitats for all wildlife species used in the LCA study. Although other habitat classification systems may be more desirable, such as finer rankings by primary vegetation types in both the Florida models (HSI and SESI) or the generalized classification system of Cowardin and others (1979) for wetland systems, this proposed model will nevertheless apply those habitat categories that are consistent with the current LCA study:

$$
\begin{array}{ll}
\mathrm{SI}_{\mathrm{V} 1}=0.0 & , \mathrm{~V} 1=\text { open water, saline, bottomland hardwood } \\
& \text { forest } \\
\mathrm{SI}_{\mathrm{V} 1}=0.26 & , \mathrm{~V} 1=\text { swamp } \\
\mathrm{SI}_{\mathrm{V} 1}=0.55 & , \mathrm{~V} 1=\text { freshwater or brackish marsh } \\
\mathrm{SI}_{\mathrm{V} 1}=1.0 & , \mathrm{~V} 1=\text { intermediate marsh }
\end{array}
$$

The percentage of marsh area (V2) is retained in the original form of the LCA study:

$$
\begin{array}{ll}
\mathrm{SI}_{\mathrm{V} 2}=\mathrm{V} 2 * 0.0167 & , 0 \leq \mathrm{V} 2<60 \\
\mathrm{SI}_{\mathrm{V} 2}=1.0 & , 60 \leq \mathrm{V} 2 \leq 80 \\
\mathrm{SI}_{\mathrm{V} 2}=5-(\mathrm{V} 2 * 0.05) & , 80<\mathrm{V} 2 \leq 100
\end{array}
$$


The yearly water depth will be divided into several parts: nonbreeding season (V3), breeding/nesting season (V4), and nonflooding (V5). Although hourly measurements in the tidal marshes of Louisiana would be ideal, only daily measurements are currently available. In actuality, (V3) will be computed as the average of daily measurements (not monthly) by using the yearly LCA study ranges for September 1 (previous year) to April 15 (current year). The estimated average from variables (X2), (X3), and (X4) of the Florida SESI and $\left(\mathrm{d}_{2}\right)$ of the Florida HSI models will be used for all hypothetical setting comparisons (see the section "Comparison of All Alligator Models" in chapter 4). Also, the range was extended to $1 \mathrm{ft}(0.3$ $\mathrm{m}$ ) based on model comparison information from tables 1-3 and the average water depth of -0.3 $\pm 0.6 \mathrm{~m}$ measured at Marsh Island in the 1990s (Nyman, 2001).

$$
\begin{array}{ll}
\mathrm{SI}_{\mathrm{V} 3}=0.0 & , \mathrm{~V} 3 \leq-0.5 \mathrm{~m} \\
\mathrm{SI}_{\mathrm{V} 3}=2.5+(\mathrm{V} 3 * 5) & ,-0.5<\mathrm{V} 3 \leq-0.3 \mathrm{~m} \\
\mathrm{SI}_{\mathrm{V} 3}=1.0 & ,-0.3<\mathrm{V} 3 \leq 0.0 \mathrm{~m} \\
\mathrm{SI}_{\mathrm{V} 3}=1-(\mathrm{V} 3 * 3.33) & , 0.0<\mathrm{V} 3 \leq 0.3 \mathrm{~m} \\
\mathrm{SI}_{\mathrm{V} 3}=0.0 & , \mathrm{~V} 3>0.3 \mathrm{~m}
\end{array}
$$

Variable (V4) will be based on the Florida HSI formula for nest building water depth $\left(\mathrm{d}_{1}\right)$ (converted to meters and rewritten in the same format) for April 16-May 15, but with limit modifications. The upper limit may be unrealistically high at $4.0 \mathrm{ft}$, requiring confirmation in the field. Thus, the limit will be decreased here to $2.0 \mathrm{ft}(0.61 \mathrm{~m})$, similar to the SESI model limit of $1.9 \mathrm{ft}$ (see fig. 5), but maintaining the optimal range of 1.3 to $1.6 \mathrm{ft}(0.40-0.49 \mathrm{~m})$. If desired, this factor can be extended to combine the two Florida mating and nest building time periods into a single water depth average from April 16 to June 30. All parts of the equation need to be field validated in Louisiana and are subject to change.

$$
\begin{aligned}
& \mathrm{SI}_{\mathrm{V} 4}=0.0 \quad, \mathrm{~V} 4 \leq 0.0 \mathrm{~m} \\
& \mathrm{SI}_{\mathrm{V} 4}=\mathrm{V} 4 / 0.4 \\
& =\mathrm{V} 4 * 2.5 \quad, 0.0<\mathrm{V} 4 \leq 0.40 \mathrm{~m} \\
& \mathrm{SI}_{\mathrm{V} 4}=1.0 \quad, 0.40<\mathrm{V} 4 \leq 0.49 \mathrm{~m} \\
& \mathrm{SI}_{\mathrm{V} 4}=(0.61-\mathrm{V} 4) / 0.12 \\
& =5.09-(\mathrm{V} 4 * 8.33) \quad, 0.49<\mathrm{V} 4 \leq 0.61 \mathrm{~m} \\
& \mathrm{SI}_{\mathrm{V} 4}=0.0 \\
& \text {, V4 }>0.61 \mathrm{~m}
\end{aligned}
$$

Variable (V5) will be based on the nonflooding component of the Florida HSI and SESI models, where water depth differences $\left(\Delta_{\max }\right)$ is equal to maximum water depth (July 1-Aug. 31) minus mean water depth (June 15-June 30); that is, V5 $=\Delta_{\max }$ (converted to meters). For this factor, there is a 1-ft difference in the Florida SESI and HSI models for the upper limit of the downslope of $\left(\Delta_{\text {max }}\right)$; the HSI model tolerates more flooding (see fig. 6). The factor here will be defined according to the wider range of the HSI model. If not integrated into (V4) above, the mean water depth $\left(\mathrm{d}_{3}\right)$ during nest construction from June 15 to June 30 needs to be clarified separately here. It probably cannot exceed the limit of $2 \mathrm{ft}(0.61 \mathrm{~m})$ for $(\mathrm{V} 4)$, so that $\mathrm{SI}_{\mathrm{V} 5}$ could also be conditioned on the mean water depth value $\left(\mathrm{d}_{3}\right)$. 
Based on $\left(\Delta_{\max }\right)$ alone:

$$
\begin{array}{ll}
\mathrm{SI}_{\mathrm{V} 5}=1.0 & , \Delta_{\max } \leq 0.15 \mathrm{~m} \\
\mathrm{SI}_{\mathrm{V} 5}=1.48-\left(\Delta_{\max } * 3.22\right) & , 0.15<\Delta_{\max } \leq 0.46 \mathrm{~m} \\
\mathrm{SI}_{\mathrm{V} 5}=0.0 & , \Delta_{\max }>0.46 \mathrm{~m}
\end{array}
$$

or also conditioned on $\left(\mathrm{d}_{3}\right)$;

$$
\begin{array}{ll}
\mathrm{SI}_{\mathrm{V} 5}=1.0 & , \Delta_{\max } \leq 0.15 \mathrm{~m} \text { and } \mathrm{d}_{3}<0.61 \mathrm{~m} \\
\mathrm{SI}_{\mathrm{V} 5}=1.48-\left(\Delta_{\max } * 3.22\right) & , 0.15<\Delta_{\max } \leq 0.46 \mathrm{~m} \text { and } \mathrm{d}_{3}<0.61 \mathrm{~m} \\
\mathrm{SI}_{\mathrm{V} 5}=0.0 & , \Delta_{\max }>0.46 \mathrm{~m} \text { or } \mathrm{d}_{3} \geq 0.61 \mathrm{~m}
\end{array}
$$

\section{Water Depth Component and Final Index}

The water depth component could be defined as the arithmetic average of the indices for (V3), (V4), and (V5):

$$
\mathrm{C}_{\mathrm{water}}=\left(\mathrm{SI}_{\mathrm{V} 3}+\mathrm{SI}_{\mathrm{V} 4}+\mathrm{SI}_{\mathrm{V} 5}\right) / 3
$$

The final HSI value could be denoted as a geometric mean of three factors/components:

$$
\mathrm{HSI}=\left(\mathrm{SI}_{\mathrm{V} 1} * \mathrm{SI}_{\mathrm{V} 2} * \mathrm{C}_{\mathrm{water}}\right)^{1 / 3}
$$

or as an amended arithmetic mean, conditioned on the habitat type:

$$
\begin{aligned}
\mathrm{HSI} & =\left(3 * \mathrm{SI}_{\mathrm{V} 1}+3 * \mathrm{SI}_{\mathrm{V} 2}+\mathrm{SI}_{\mathrm{V} 3}+\mathrm{SI}_{\mathrm{V} 4}+\mathrm{SI}_{\mathrm{V} 5}\right) / 9 & & , \text { for } \mathrm{SI}_{\mathrm{V} 1} \neq 0.0 \\
& =0.0 & & \text { for } \mathrm{SI}_{\mathrm{V} 1}=0.0
\end{aligned}
$$

\section{Evaluation of Proposed Alligator LCA Study Model}

As a quick reference, a condensed version of the proposed alligator LCA study model is presented in appendix 1 by using the geometric mean in the final HSI formula.

The proposed HSI model for the LCA study is computed for the three hypothetical settings displayed in tables 1-3 and compared to the other HSI models shown in tables 14-16 below. An additional setting is presented in table 17, where water depths $\left(\mathrm{d}_{1}\right)$ and $\left(\mathrm{d}_{3}\right)$ during mating or breeding and nest building are below the 2-ft limit, and flooding during incubation is within the acceptable range, but the winter is again very dry (120 dry days and low $\left.\mathrm{d}_{2}\right)$. Table 18 modifies table 17 by increasing the flooding during incubation to detrimental stages. Water 
depths $\left(d_{1}\right)$ and $\left(d_{3}\right)$ are treated separately for all five settings in (V4) and (V5), respectively. Both the arithmetic and geometric versions of the final HSI formula are computed.

A typical setting was presented in table 14, where the previous Florida and general HSI models were computed as high at almost 0.8 , but the current LCA study HSI was zero. The proposed LCA study model draws information from the other HSI models so that its index is elevated to almost 0.9 in both formula options. This translates to very favorable suitability conditions for alligator breeding based on the hydrological arguments in the Florida models; however, field verification in Louisiana may be required. Moreover, the tidal influences in the Louisiana marshes create periods of higher water levels that may not be picked up by the daily average measurements. Higher water levels are therefore constantly occurring but hidden in the current LCA study HSI model; this may require hourly monitoring in selected coastal marsh regions to validate. Such information would support the argument that the current range of water depth in the LCA study is suspected to be too shallow and that the vegetation and wildlife, such as alligators, of the coastal marshes can really tolerate higher water levels, leading to the proposed model enhancement in the water depth components.

The second setting with shallow water depths as shown in table 15 increased the current LCA study HSI to almost 0.9 . This coincides with both of the proposed HSI formulae for the LCA study, which incidentally also produce high index values at about 0.9 . The Florida HSI model, however, favors deeper waters and decreased the chance of suitability to only 0.50 , whereas suitability in the general HSI model remained at about 0.7 . Thus, both shallow and typical settings generate high HSI values for the proposed LCA study, corresponding to highlysuitable alligator breeding habitats.

For the deeper water depths but drier winters described in the setting of table 16, the proposed LCA study HSI values decrease suitability to about $0.5-0.6$, matching other lower HSI values except the current value in the LCA study at zero. It is speculated that the drydown in the winter allowed for emergent vegetation to thrive, even if there was more rain in the spring that produced higher water depths that were still feasible for breeding.

The new setting in table 17 decreases the water depth to marginal during mating/breeding and nest building periods and is especially designed to generate a nonzero value for the $\mathrm{SI}_{\mathrm{V} 3}$ component in the proposed LCA study model but a zero value the current LCA study model. The proposed LCA study HSI values are moderately higher at about 0.75 than the Florida HSI value of about 0.6 and definitely demonstrate a suitable habitat as compared to the current LCA study. Table 18 illustrates changes resulting from possible destructive flooding during incubation, such as excessive rain associated with tropical depressions or hurricanes. Then the proposed LCA study HSI value drops to an approximate 0.6 suitability while the Florida HSI value drops lower to 0.36 . In this case, the proposed LCA study index may need adjustment and the low, unsuitable Florida HSI value may be more realistic.

Comparing the two versions of the HSI formula, the arithmetic mean generated almost identical results to the geometric mean in tables 14,15 , and 17 . The arithmetic mean was about 10 percent higher than the geometric mean in tables 16 and 18, where both settings introduce 
radical changes in water depths. Thus, the geometric mean may be more sensible in extreme conditions.

In any event, the proposed alligator HSI model for the LCA study offers more flexibility in the hydrology component than the current LCA study HSI model. It may better depict the chance of suitability given more information about water levels in critical mating, breeding, nesting, and egg incubation periods, features that were attractive in both Florida models. The ranges for water factors (V3), (V4), and (V5) may need further calibration as more field observations of alligator breeding in coastal Louisiana become available during different periods. 
Table 14. Comparison of all habitat suitability index (HSI) models for the American alligator (Alligator mississippiensis) with the proposed LCA study model. Setting 1. The Florida model is denoted as HSI (F), the LCA study HSI model as HSI (L), and the proposed model (geometric mean with water component) as HSI (new L). An alternate HSI formula (arithmetic mean) for the proposed model is denoted as Alt HSI. Included at the bottom is the value of the general HSI model denoted as HSI $(\mathrm{G})$ with no intermediate computations. Final index computations include component calculations.

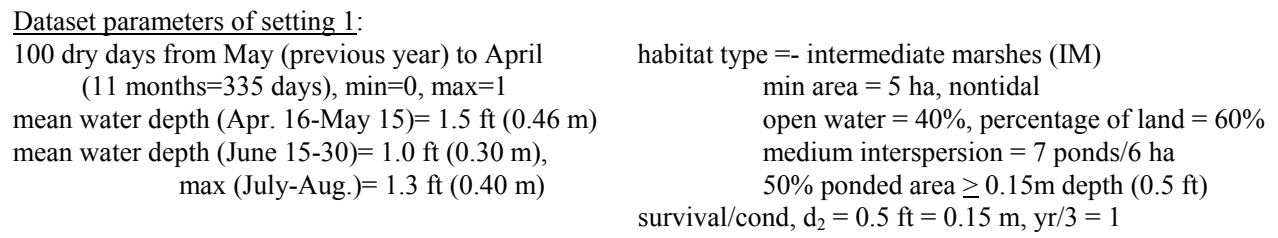

\begin{tabular}{llllll}
\hline & \multicolumn{5}{c}{ INTERMEDIATE INDEX (SI) COMPUTATIONS } \\
\multicolumn{2}{c}{ HSI (F) } & \multicolumn{2}{c}{ HSI (L) } & \multicolumn{2}{c}{ HSI (new L) } \\
Variable & Index & Variable & Index & Variable & Index \\
\hline & & & & & \\
$\mathrm{t}=100$ & $\mathrm{SI}_{\text {bred }}=0.33$ & $\mathrm{~V} 1=\mathrm{IM}$ & $\mathrm{SI}_{\mathrm{V} 1}=1.0$ & $\mathrm{~V} 1=\mathrm{IM}$ & $\mathrm{SI}_{\mathrm{V} 1}=1.0$ \\
& & $\mathrm{~V} 2=60 \%$ & $\mathrm{SI}_{\mathrm{V} 2}=1.0$ & $\mathrm{~V} 2=60 \%$ & $\mathrm{SI}_{\mathrm{V} 2}=1.0$ \\
$\mathrm{~d}_{1}=1.5 \mathrm{ft}$ & $\mathrm{SI}_{\text {nest_b }}=1.0$ & $\mathrm{~V} 3=0.33 \mathrm{~m}$ & $\mathrm{SI}_{\mathrm{V} 3}=0.0$ & $\mathrm{~V} 3=0.33 \mathrm{~m}$ & $\mathrm{SI}_{\mathrm{V} 3}=0.0$ \\
$\Delta_{\mathrm{max}}=0.3 \mathrm{ft}$ & $\mathrm{SI}_{\text {nonflood }}=1.0$ & & & $\mathrm{~V} 4=0.46 \mathrm{~m}$ & $\mathrm{SI}_{\mathrm{V} 4}=1.0$ \\
$\mathrm{~d}_{2}=0.5 \mathrm{ft}$ & $\mathrm{SI}_{\text {surv }}=1.0$ & & & $\mathrm{~V} 5=0.09 \mathrm{~m}$ & $\mathrm{SI}_{\mathrm{V} 5}=1.0$ \\
& & & & & \\
\hline
\end{tabular}

FINAL INDEX COMPUTATION

$$
\begin{aligned}
\mathrm{HSI}_{\mathrm{F}}= & {[(3 * .33)+(3 * 1)} \\
& +(2 * 1)+(1 * 1)] / 9 \\
= & \mathbf{0 . 7 8}
\end{aligned}
$$

$$
\begin{aligned}
\mathrm{HSI}_{\mathrm{L}} & =\left(\mathrm{SI}_{\mathrm{V} 1} * \mathrm{SI}_{\mathrm{V} 2} * \mathrm{SI}_{\mathrm{V} 3}\right)^{1 / 3} \\
& =(1 * 1 * 0)^{1 / 3} \\
& =\mathbf{0 . 0}
\end{aligned}
$$

$$
\begin{aligned}
\mathrm{C}_{\mathrm{water}} & =\left(\mathrm{SI}_{\mathrm{V} 3}+\mathrm{SI}_{\mathrm{V} 4}+\mathrm{SI}_{\mathrm{V} 5}\right) / 3 \\
& =(0+1+1) / 3 \\
& =0.67
\end{aligned}
$$

$$
\begin{aligned}
& \mathrm{HSI}_{\text {new_L }}=\left(\mathrm{SI}_{\mathrm{V} 1} * \mathrm{SI}_{\mathrm{V} 2} * \mathrm{C}_{\mathrm{water}}\right)^{1 / 3} \\
& =(1 * 1 * .67)^{1 / 3} \\
& =\mathbf{0 . 8 7}
\end{aligned}
$$

$$
\begin{aligned}
\text { Alt HSI }_{\text {new }_{-} \mathrm{L}=} & \left(3 * \mathrm{SI}_{\mathrm{V} 1}+3 * \mathrm{SI}_{\mathrm{V} 2}+\mathrm{SI}_{\mathrm{V} 3}\right. \\
& \left.+\mathrm{SI}_{\mathrm{V} 4}+\mathrm{SI}_{\mathrm{V} 5}\right) / 9 \\
= & {[(3 * 1)+(3 * 1)+0+1+1] / 9 } \\
= & \mathbf{0 . 8 9}
\end{aligned}
$$

For $\operatorname{HSI}(\mathrm{G}), \mathrm{HSI}_{\mathrm{G}}=\mathbf{0 . 7 9}$ 
Table 15. Comparison of all habitat suitability index (HSI) models for the American alligator (Alligator mississippiensis) with the proposed LCA study model. Setting 2. The Florida model is denoted as HSI (F), the LCA study HSI model as HSI (L), and the proposed model (geometric mean with water component) as HSI (new L). An alternate HSI formula (arithmetic mean) for the proposed model is denoted as Alt HSI. Included at the bottom is the value of the general HSI model denoted as HSI $(\mathrm{G})$ with no intermediate computations. Final index computations include component calculations.

Dataset parameters of setting 2:

100 dry days from May (previous year) to April (11 months $=335$ days) $\min =0, \max =1$ mean water depth $($ Apr. 16-May 15) $=0.4 \mathrm{ft}(0.12 \mathrm{~m})$ mean water depth (June 15-30) $=0.2 \mathrm{ft}(0.06 \mathrm{~m})$, $\max ($ July-Aug. $)=0.5 \mathrm{ft}(0.15 \mathrm{~m})$ habitat type $=$ intermediate marsh (IM)

min area $=5$ ha, nontidal

open water $=40 \%$, percentage of land $=60 \%$

medium interspersion $=7$ ponds $/ 6$ ha

$30 \%$ ponded area $\geq 0.15 \mathrm{~m}$ depth $(0.5 \mathrm{ft})$

survival/condition, $\mathrm{d}_{2}=-0.2 \mathrm{ft}(-0.06 \mathrm{~m}), \mathrm{yr} / 3=1$

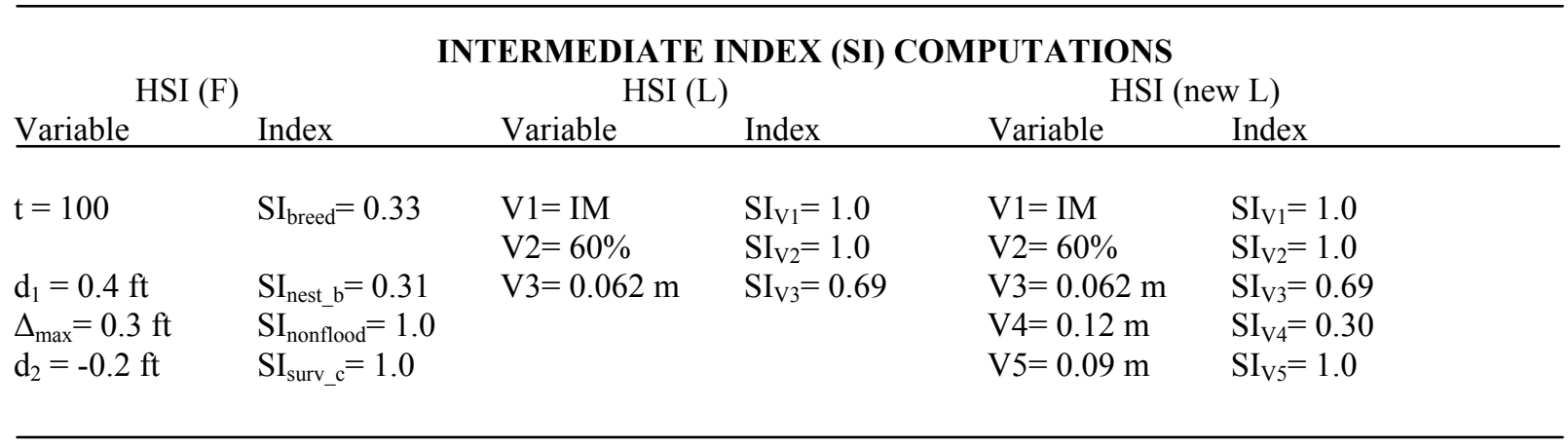

FINAL INDEX COMPUTATION

HSI (F)
HSI (L)

$$
\begin{aligned}
\mathrm{HSI}_{\mathrm{L}} & =\left(\mathrm{SI}_{\mathrm{V} 1} * \mathrm{SI}_{\mathrm{V} 2} * \mathrm{SI}_{\mathrm{V} 3}\right)^{1 / 3} \\
& =(1 * 1 * .69)^{1 / 3} \\
& =\mathbf{0 . 8 8}
\end{aligned}
$$

HSI (new L)

$$
\begin{aligned}
\mathrm{C}_{\text {water }} & =\left(\mathrm{SI}_{\mathrm{V} 3}+\mathrm{SI}_{\mathrm{V} 4}+\mathrm{SI}_{\mathrm{V} 5}\right) / 3 \\
& =(.69+.30+1) / 3 \\
& =0.66
\end{aligned}
$$

$$
\begin{gathered}
\mathrm{HSI}_{\text {new_L }_{\mathrm{L}}}=\left(\mathrm{SI}_{\mathrm{V} 1} * \mathrm{SI}_{\mathrm{V} 2} * \mathrm{C}_{\mathrm{water}}\right)^{1 / 3} \\
=(1 * 1 * .66)^{1 / 3} \\
=\mathbf{0 . 8 7}
\end{gathered}
$$

$$
\begin{aligned}
\text { Alt } \mathrm{HSI}_{\mathrm{new}_{-} \mathrm{L}}= & \left(3 * \mathrm{SI}_{\mathrm{V} 1}+3 * \mathrm{SI}_{\mathrm{V} 2}+\mathrm{SI}_{\mathrm{V} 3}\right. \\
& \left.+\mathrm{SI}_{\mathrm{V} 4}+\mathrm{SI}_{\mathrm{V} 5}\right) / 9 \\
= & {[(3 * 1)+(3 * 1)+.69+.30+1] / 9 } \\
= & \mathbf{0 . 8 9}
\end{aligned}
$$

For $\operatorname{HSI}(\mathrm{G}), \mathrm{HSI}_{\mathrm{G}}=\mathbf{0 . 7 3}$ 
Table 16. Comparison of all habitat suitability index (HSI) models for the American alligator (Alligator mississippiensis) with the proposed LCA study model. Setting 3. The Florida model is denoted as HSI (F), the LCA study HSI model as HSI (L), and the proposed model (geometric mean with water component) as HSI (new L). An alternate HSI formula (arithmetic mean) for the proposed model is denoted as Alt HSI. Included at the bottom is the value of the general HSI model denoted as HSI (G) with no intermediate computations. Final index computations include component calculations.

Dataset parameters of setting 3:

120 dry days from May (previous year) to April

(11 months $=335$ days), $\min =0, \max =1$

mean water depth (Apr. 16-May 15) $=2.0 \mathrm{ft}(0.61 \mathrm{~m})$

mean water depth (June 15-30)=2.0 ft $(0.61 \mathrm{~m})$, $\max ($ July-Aug. $)=2.6 \mathrm{ft}(0.79 \mathrm{~m})$ habitat type $=$ intermediate marsh (IM) min area $=5$ ha, nontidal open water $=65 \%$, percentage of land $=35 \%$ low interspersion $=2$ ponds $/ 6$ ha $90 \%$ ponded area $\geq 0.15 \mathrm{~m}$ depth $(0.5 \mathrm{ft})$ survival/condition, $\mathrm{d}_{2}=1.0 \mathrm{ft}(0.30 \mathrm{~m}), \mathrm{yr} / 3=1$

\begin{tabular}{|c|c|c|c|c|c|}
\hline & & TERMEDIAT & NDEX (SI) & PUTATIONS & \\
\hline HSI & & HSI & & HSI & W L) \\
\hline$\underline{\text { Variable }}$ & Index & Variable & Index & Variable & Index \\
\hline $\mathrm{t}=120$ & $\mathrm{SI}_{\text {breed }}=0.067$ & $\begin{array}{l}\mathrm{V} 1=\mathrm{IM} \\
\mathrm{V} 2=35 \%\end{array}$ & $\begin{array}{l}\mathrm{SI}_{\mathrm{V} 1}=1.0 \\
\mathrm{SI}_{\mathrm{V} 2}=0.58\end{array}$ & $\begin{array}{l}\mathrm{V} 1=\mathrm{IM} \\
\mathrm{V} 2=35 \%\end{array}$ & $\begin{array}{l}\mathrm{SI}_{\mathrm{V} 1}=1.0 \\
\mathrm{SI}_{\mathrm{V} 2}=0.58\end{array}$ \\
\hline $\begin{array}{l}\mathrm{d}_{1}=2.04 \mathrm{ft} \\
\Delta_{\max }=0.6 \mathrm{ft} \\
\mathrm{d}_{2}=1.0 \mathrm{ft}\end{array}$ & $\begin{array}{l}\mathrm{SI}_{\text {nest_b }}=0.83 \\
\mathrm{SI}_{\text {nonflood }}=0.90 \\
\mathrm{SI}_{\text {surv_c }}=0.91\end{array}$ & $\mathrm{~V} 3=0.58 \mathrm{~m}$ & $\mathrm{SI}_{\mathrm{V} 3}=0.0$ & $\begin{aligned} \mathrm{V} 3 & =0.58 \mathrm{~m} \\
\mathrm{~V} 4 & =0.61 \mathrm{~m} \\
\mathrm{~V} 5 & =0.18 \mathrm{~m}\end{aligned}$ & $\begin{array}{l}\mathrm{SI}_{\mathrm{V} 3}=0.0 \\
\mathrm{SI}_{\mathrm{V} 4}=0.0 \\
\mathrm{SI}_{\mathrm{V} 5}=0.90\end{array}$ \\
\hline
\end{tabular}

FINAL INDEX COMPUTATION

HSI (F)

$$
\begin{aligned}
\mathrm{HSI}_{\mathrm{F}}= & {\left[\left(3^{*} .067\right)+\left(3^{*} .83\right)\right.} \\
& \left.+\left(2^{*} .9\right)+\left(1^{*} .91\right)\right] / 9 \\
= & \mathbf{0 . 6 0}
\end{aligned}
$$

HSI (L)

$$
\begin{aligned}
\mathrm{HSI}_{\mathrm{L}} & =\left(\mathrm{SI}_{\mathrm{V} 1} * \mathrm{SI}_{\mathrm{V} 2} * \mathrm{SI}_{\mathrm{V} 3}\right)^{1 / 3} \\
& =\left(1 * .58^{*} 0\right)^{1 / 3} \\
& =\mathbf{0 . 0}
\end{aligned}
$$

HSI (new L)

$$
\begin{aligned}
& \mathrm{C}_{\mathrm{water}}=\left(\mathrm{SI}_{\mathrm{V} 3}+\mathrm{SI}_{\mathrm{V} 4}+\mathrm{SI}_{\mathrm{V} 5}\right) / 3 \\
&=(0+0+.91) / 3 \\
&= 0.30 \\
& \mathrm{HSI}_{\text {new }} \mathrm{L}=\left(\mathrm{SI}_{\mathrm{V} 1} * \mathrm{SI}_{\mathrm{V} 2} * \mathrm{C}_{\mathrm{water}}\right)^{1 / 3} \\
&=(1 * .58 * .30)^{1 / 3} \\
&= \mathbf{0 . 5 6} \\
&{\text { Alt } \mathrm{HSI}_{\text {new }} \mathrm{L}=}^{=}\left(3 * \mathrm{SI}_{\mathrm{V} 1}+3 * \mathrm{SI}_{\mathrm{V} 2}+\mathrm{SI}_{\mathrm{V} 3}\right. \\
&=\left.+\mathrm{SI}_{\mathrm{V} 4}+\mathrm{SI}_{\mathrm{V} 5}\right) / 9 \\
&= {[(3 * 1)+(3 * .58)+0+0+.91] / 9 } \\
&= \mathbf{0 . 6 3}
\end{aligned}
$$

For HSI (G), $\mathrm{HSI}_{\mathrm{G}}=\mathbf{0 . 5 2}$ 
Table 17. Comparison of all habitat suitability index (HSI) models for the American alligator (Alligator mississippiensis) with the proposed LCA study model. Setting 4. The Florida model is denoted as HSI (F), the LCA study HSI model as HSI (L), and the proposed model (geometric mean with water component) as HSI (new L). An alternate HSI formula (arithmetic mean) for the proposed model is denoted as Alt HSI. Included at the bottom is the value of the general HSI model denoted as HSI $(\mathrm{G})$ with no intermediate computations. Final index computations include component calculations.

Dataset parameters of setting 4:

120 dry days from May (previous year) to April (11 months $=335$ days), $\min =0, \max =1$ mean water depth (Apr. 16-May 15)=1.5 ft $(0.46 \mathrm{~m})$ mean water depth (June 15-30)=1.5 ft $(0.46 \mathrm{~m})$, $\max ($ July-Aug. $)=1.9 \mathrm{ft}(0.58 \mathrm{~m})$ habitat type $=$ intermediate marsh (IM)

min area $=5$ ha, nontidal

open water $=65 \%$, percentage of land $=35 \%$

medium interspersion $=2$ ponds $/ 6$ ha

$90 \%$ ponded area $\geq 0.15 \mathrm{~m}$ depth $(0.5 \mathrm{ft})$

survival/condition, $\mathrm{d}_{2}=-0.5 \mathrm{ft}(-0.09 \mathrm{~m}), \mathrm{yr} / 3=1$

\begin{tabular}{|c|c|c|c|c|c|}
\hline \multicolumn{6}{|c|}{ INTERMEDIATE INDEX (SI) COMPUTATIONS } \\
\hline \multicolumn{2}{|c|}{ HSI (F) } & \multicolumn{2}{|c|}{ HSI (L) } & \multicolumn{2}{|c|}{ HSI (new L) } \\
\hline$\underline{\text { Variable }}$ & Index & Variable & Index & Variable & Index \\
\hline $\mathrm{t}=120$ & $\mathrm{SI}_{\text {breed }}=0.067$ & $\mathrm{~V} 1=\mathrm{IM}$ & $\mathrm{SI}_{\mathrm{V} 1}=1.0$ & $\mathrm{~V} 1=\mathrm{IM}$ & $\mathrm{SI}_{\mathrm{V} 1}=1.0$ \\
\hline & & $\mathrm{V} 2=35 \%$ & $\mathrm{SI}_{\mathrm{V} 2}=0.58$ & $\mathrm{~V} 2=35 \%$ & $\mathrm{SI}_{\mathrm{V} 2}=0.58$ \\
\hline $\mathrm{d}_{1}=1.50 \mathrm{ft}$ & $\mathrm{SI}_{\text {nest_b}}=1.0$ & $\mathrm{~V} 3=0.29 \mathrm{~m}$ & $\mathrm{SI}_{\mathrm{V} 3}=0.0$ & $\mathrm{~V} 3=0.29 \mathrm{~m}$ & $\mathrm{SI}_{\mathrm{V} 3}=0.05$ \\
\hline$\Delta_{\max }=0.4 \mathrm{ft}$ & $\mathrm{SI}_{\text {nonflood }}=1.0$ & & & $\mathrm{~V} 4=0.46 \mathrm{~m}$ & $\mathrm{SI}_{\mathrm{V} 4}=1.0$ \\
\hline $\mathrm{d}_{2}=-0.5 \mathrm{ft}$ & $\mathrm{SI}_{\text {surv_c }}=0.0$ & & & $\mathrm{~V} 5=0.12 \mathrm{~m}$ & $\mathrm{SI}_{\mathrm{V} 5}=1.0$ \\
\hline
\end{tabular}

FINAL INDEX COMPUTATION

HSI (F)

$\begin{aligned} \operatorname{HSI}_{\mathrm{F}}= & {[(3 * .067)+(3 * 1)} \\ & +(2 * 1)+(1 * 0)] / 9 \\ = & \mathbf{0 . 5 8}\end{aligned}$
HSI (L)

$$
\begin{aligned}
\mathrm{HSI}_{\mathrm{L}} & =\left(\mathrm{SI}_{\mathrm{V} 1} * \mathrm{SI}_{\mathrm{V} 2} * \mathrm{SI}_{\mathrm{V} 3}\right)^{1 / 3} \\
& =(1 * .58 * 0)^{1 / 3} \\
& =\mathbf{0 . 0}
\end{aligned}
$$

HSI (new L)

$$
\begin{aligned}
\mathrm{C}_{\mathrm{water}} & =\left(\mathrm{SI}_{\mathrm{V} 3}+\mathrm{SI}_{\mathrm{V} 4}+\mathrm{SI}_{\mathrm{V} 5}\right) / 3 \\
& =(.05+1+1) / 3 \\
& =0.68
\end{aligned}
$$

$$
\begin{aligned}
& \mathrm{HSI}_{\text {new_L }_{\mathrm{L}}}=\left(\mathrm{SI}_{\mathrm{V} 1} * \mathrm{SI}_{\mathrm{V} 2} * \mathrm{C}_{\mathrm{water}}\right)^{1 / 3} \\
& =(1 * .58 * .68)^{1 / 3} \\
& =\mathbf{0 . 7 3}
\end{aligned}
$$

$$
\begin{aligned}
\text { Alt HSI }_{\text {new } \_\mathrm{L}}= & \left(3 * \mathrm{SI}_{\mathrm{V} 1}+3 * \mathrm{SI}_{\mathrm{V} 2}+\mathrm{SI}_{\mathrm{V} 3}\right. \\
& \left.+\mathrm{SI}_{\mathrm{V} 4}+\mathrm{SI}_{\mathrm{V} 5}\right) / 9 \\
= & {[(3 * 1)+(3 * .58)+.05+1+1] / 9 } \\
= & \mathbf{0 . 7 5}
\end{aligned}
$$

For $\operatorname{HSI}(\mathrm{G}), \mathrm{HSI}_{\mathrm{G}}=\mathbf{0 . 5 2}$ 
Table 18. Comparison of all habitat suitability index (HSI) models for the American alligator (Alligator mississippiensis) with the proposed LCA study model. Setting 5. The Florida model is denoted as HSI (F), the LCA study HSI model as HSI (L), and the proposed model (geometric mean with water component) as HSI (new L). An alternate HSI formula (arithmetic mean) for the proposed model is denoted as Alt HSI. Included at the bottom is the value of the general HSI model denoted as HSI $(\mathrm{G})$ with no intermediate computations. Final index computations include component calculations.

Dataset parameters of setting 4:

120 dry days from May (previous year) to April (11 months $=335$ days), $\min =0, \max =1$ mean water depth (Apr. 16-May 15)=1.5 ft $(0.46 \mathrm{~m})$ mean water depth (June 15-30)=1.5 ft $(0.46 \mathrm{~m})$, $\max ($ July-Aug. $)=3.1 \mathrm{ft}(0.94 \mathrm{~m})$ habitat type $=$ intermediate marsh (IM)

min area $=5$ ha, nontidal

open water $=65 \%$, percentage of land $=35 \%$

medium interspersion $=2$ ponds $/ 6$ ha

$90 \%$ ponded area $\geq 0.15 \mathrm{~m}$ depth $(0.5 \mathrm{ft})$

survival/condition, $\mathrm{d}_{2}=-0.5 \mathrm{ft}(-0.09 \mathrm{~m}), \mathrm{yr} / 3=1$

\begin{tabular}{|c|c|c|c|c|c|}
\hline \multicolumn{6}{|c|}{ INTERMEDIATE INDEX (SI) COMPUTATIONS } \\
\hline \multicolumn{2}{|c|}{ HSI (F) } & \multicolumn{2}{|c|}{ HSI (L) } & \multicolumn{2}{|c|}{ HSI (new L) } \\
\hline$\underline{\text { Variable }}$ & Index & Variable & Index & Variable & Index \\
\hline $\mathrm{t}=120$ & $\mathrm{SI}_{\text {breed }}=0.067$ & $\mathrm{~V} 1=\mathrm{IM}$ & $\mathrm{SI}_{\mathrm{V} 1}=1.0$ & $\mathrm{~V} 1=\mathrm{IM}$ & $\mathrm{SI}_{\mathrm{V} 1}=1.0$ \\
\hline & & $\mathrm{V} 2=35 \%$ & $\mathrm{SI}_{\mathrm{V} 2}=0.58$ & $\mathrm{~V} 2=35 \%$ & $\mathrm{SI}_{\mathrm{V} 2}=0.58$ \\
\hline $\mathrm{d}_{1}=1.50 \mathrm{ft}$ & $\mathrm{SI}_{\text {nest_b}}=1.0$ & $\mathrm{~V} 3=0.29 \mathrm{~m}$ & $\mathrm{SI}_{\mathrm{V} 3}=0.0$ & $\mathrm{~V} 3=0.29 \mathrm{~m}$ & $\mathrm{SI}_{\mathrm{V} 3}=0.05$ \\
\hline$\Delta_{\max }=1.6 \mathrm{ft}$ & $\mathrm{SI}_{\text {nonflood }}=0.0$ & & & $\mathrm{~V} 4=0.46 \mathrm{~m}$ & $\mathrm{SI}_{\mathrm{V} 4}=1.0$ \\
\hline $\mathrm{d}_{2}=-0.5 \mathrm{ft}$ & $\mathrm{SI}_{\text {surv_c }}=0.0$ & & & $\mathrm{~V} 5=0.48 \mathrm{~m}$ & $\mathrm{SI}_{\mathrm{V} 5}=0.0$ \\
\hline
\end{tabular}

FINAL INDEX COMPUTATION

HSI (F)

$\begin{aligned} \mathrm{HSI}_{\mathrm{F}}= & {[(3 * .067)+(3 * 1)} \\ & +(2 * 0)+(1 * 0)] / 9 \\ = & \mathbf{0 . 3 6}\end{aligned}$
HSI (L)

$$
\begin{aligned}
\mathrm{HSI}_{\mathrm{L}} & =\left(\mathrm{SI}_{\mathrm{V} 1} * \mathrm{SI}_{\mathrm{V} 2} * \mathrm{SI}_{\mathrm{V} 3}\right)^{1 / 3} \\
& =(1 * .58 * 0)^{1 / 3} \\
& =\mathbf{0 . 0}
\end{aligned}
$$

HSI (new L)

$$
\begin{aligned}
\mathrm{C}_{\mathrm{water}} & =\left(\mathrm{SI}_{\mathrm{V} 3}+\mathrm{SI}_{\mathrm{V} 4}+\mathrm{SI}_{\mathrm{V} 5}\right) / 3 \\
& =(.05+1+0) / 3 \\
& =0.35
\end{aligned}
$$

$$
\begin{gathered}
\mathrm{HSI}_{\text {new_L }}=\left(\mathrm{SI}_{\mathrm{V} 1} * \mathrm{SI}_{\mathrm{V} 2} * \mathrm{C}_{\mathrm{water}}\right)^{1 / 3} \\
=(1 * .58 * .35)^{1 / 3} \\
=\mathbf{0 . 5 9}
\end{gathered}
$$

$$
\begin{aligned}
\text { Alt HSI }_{\text {new } \_\mathrm{L}}= & \left(3 * \mathrm{SI}_{\mathrm{V} 1}+3 * \mathrm{SI}_{\mathrm{V} 2}+\mathrm{SI}_{\mathrm{V} 3}\right. \\
& \left.+\mathrm{SI}_{\mathrm{V} 4}+\mathrm{SI}_{\mathrm{V} 5}\right) / 9 \\
= & {[(3 * 1)+(3 * .58)+.05+1+0] / 9 } \\
= & \mathbf{0 . 6 4}
\end{aligned}
$$

For $\operatorname{HSI}(\mathrm{G}), \mathrm{HSI}_{\mathrm{G}}=\mathbf{0 . 5 2}$ 


\section{Recommendations for the Wading Bird LCA Study Model}

The arguments supporting the general ecosystem differences between The Everglades and coastal marshes of Louisiana apply to wading birds as well as alligators and will not be repeated in this section. Likewise, the discussions of grid-scale requirements and mathematical forms of the equations used for the LCA study is the same for any proposed wildlife model.

Since the LCA study does not have HSI developed for the wading birds, the general HSI models (U.S. Fish and Wildlife Service) for the great blue heron (Ardea herodias), great egret (Ardea alba), and white ibis (Eudocimus albus) will be used instead to generate a proposed HSI model for coastal Louisiana. Analogous to the previously proposed alligator model, the common features of the various LCA study models for all wildlife will be preserved as much as possible, with enhancements and modifications derived from the general HSI models. Florida SESI and HSI models were highly specialized in the foraging cycle and shifting landscape concepts; therefore, these features are difficult to adapt to the current LCA study model structure and are not considered.

For wading birds, the availability or amount and timing of food (small freshwater fish and invertebrates) is the most critical factor during breeding. Thus, the habitat must be suitable to be able to provide adequate food supplies. Of equal importance is the distance of feeding sites from the colony site. This factor is denoted as "within a specified radius" around the colony site, where the portion of surrounding area in the radius that constitutes sufficient foraging habitat is decisive. Consequently, various kinds of water depth measurements are necessary for the model. The availability of the appropriate types of woody vegetation also plays an important role for nesting. Finally, any urban or human disturbance can easily disrupt colonization or foraging behavior and is taken into consideration. The following wading bird HSI model is proposed for the LCA study, based on the aforementioned features.

\section{Proposed LCA Study Model for Wading Birds}

Again, the definitions for the habitat factor (V1) of the potential colony site cell may be based on the habitat classification system used for all wildlife species in the LCA study: bottomland hardwood forest, swamp, freshwater marsh (attached and floating), intermediate marsh, brackish marsh, saline marsh, open water, ridge, and maritime forest. There is no separation for island versus non-island habitats such as in the great blue heron general HSI model. Furthermore, it is necessary to differentiate between the types of habitat that are suitable for the colony site versus the surrounding foraging area within a designated radius. Suitability index $\left(\mathrm{SI}_{\mathrm{V} 1}\right)$ values are computed based on the relative density per $\mathrm{km}^{2}$ for each habitat category $(\mathrm{k})$, where $\mathrm{SI}_{\mathrm{V} 1}=1.0$ for the habitat with the maximum density and all others are the proportion of the respective density to the maximum:

$$
\mathrm{SI}_{\mathrm{V} 1}=(\text { density of category } \mathrm{k}) /(\max \text { density }) \quad, \mathrm{V} 1 \text { = category } \mathrm{k} \text { habitat }
$$


Some general nesting colony densities can be estimated based on the tables of abundance values in Portnoy (1977; table 6) for swamps, marshes, and beaches (see table 19 below). The abundance values in forests are assumed to be equivalent to that of cypress swamps, and the abundance values in open water and ridges are assumed to be equivalent to that of beaches. Intermediate marsh abundance is approximated from the average of freshwater and brackish marshes. Relative densities are reexpressed as the percentage of total nesting breeding adults in colonies observed per habitat type over all habitats.

Table 19. Abundance values as percentage of total breeding adults for wading birds: great blue heron (Ardea herodias), great egret (Ardea alba), and white ibis (Eudocimus albus).

\begin{tabular}{|c|c|c|c|c|c|}
\hline \multirow[b]{2}{*}{ Species } & \multicolumn{4}{|c|}{ HABITAT TYPE } & \multirow[b]{2}{*}{$\begin{array}{l}\text { Beaches } \\
\text { and open water }\end{array}$} \\
\hline & $\begin{array}{l}\text { Swamp } \\
\text { and forest }\end{array}$ & $\begin{array}{l}\text { Freshwater } \\
\text { marsh }\end{array}$ & $\begin{array}{l}\text { Brackish } \\
\text { marsh }\end{array}$ & $\begin{array}{l}\text { Saline } \\
\text { marsh }\end{array}$ & \\
\hline Great blue heron & $92 \%$ & $8 \%$ & $0 \%$ & $0 \%$ & $0 \%$ \\
\hline Great egret & $30 \%$ & $24 \%$ & $20 \%$ & $27 \%$ & $0 \%$ \\
\hline White ibis & $73 \%$ & $14 \%$ & $<1 \%$ & $13 \%$ & $0 \%$ \\
\hline
\end{tabular}

For example, the great egret's suitability function for nesting colony site $\left(\mathrm{SI}_{\mathrm{Vlc}}\right)$ is computed as:

$$
\begin{array}{lr}
\mathrm{SI}_{\mathrm{V} 1 \mathrm{c}}=1.0 & , \mathrm{~V} 1 \mathrm{c}=\text { swamp and forests } \\
\mathrm{SI}_{\mathrm{V} 1 \mathrm{c}}=0.80 & , \mathrm{~V} 1 \mathrm{c}=\text { freshwater marsh } \\
\mathrm{SI}_{\mathrm{V} 1 \mathrm{c}}=0.73 & , \mathrm{~V} 1 \mathrm{c}=\text { intermediate marsh } \\
\mathrm{SI}_{\mathrm{V} 1 \mathrm{c}}=0.67 & \quad \text { (average of fresh \& } \mathrm{b} \\
\mathrm{SI}_{\mathrm{V} 1 \mathrm{c}}=0.90 & , \mathrm{~V} 1 \mathrm{c}=\text { brackish marsh } \\
\mathrm{SI}_{\mathrm{V} 1 \mathrm{c}}=0.0 & , \mathrm{~V} 1 \mathrm{c}=\text { saline marsh } \\
& , \mathrm{V} 1 \mathrm{c}=\text { open water, beaches }
\end{array}
$$

Since the data in table 19 were from 1977, the distinct $\mathrm{SI}_{\mathrm{V} 1}$ values should be updated from current field observations and synchronized across the long- and short-legged bird groups; therefore, they are not furnished here. The $\mathrm{SI}_{\mathrm{V} 1}$ are to be defined from relative densities or totals (percentages) for each habitat category (k) per site type (foraging or colony).

Because of the lack of the aforementioned information on current habitat density, alternate two-classed variables based on the U.S. Fish and Wildlife Service's wetland classification system (Cowardin, 1979) are proposed instead for the colony site (V1c) and surrounding foraging area (V1f), to be applied in this model henceforth. The great egret general HSI model offers the most detailed nesting and feeding habitat descriptions (see the section "Habitat Suitability Index (HSI) Models: Model Applicability - Cover Types" and table 2 in 
Chapman and others, 1984) and is assumed to be applicable to all wading birds since both longand short-legged groups occupy the same habitats.

Colony sites:

$$
\begin{aligned}
& \mathrm{SI}_{\mathrm{V} 1 \mathrm{c}}=1.0 \quad, \mathrm{~V} 1 \mathrm{c}=\text { one of the following suitable nesting habitats: } \\
& \text { Estuarine - Intertidal - Scrub-shrub (E2SS) } \\
& \text { - Forested (E2FO) } \\
& \text { Palustrine - Scrub-shrub (PSS) } \\
& \text { - Forested (PFO) } \\
& \text { (hardwood forests and swamps) } \\
& \text { (future models: include islands within } 0.4 \mathrm{~km} \text { of feeding areas) } \\
& \mathrm{SI}_{\mathrm{V} 1 \mathrm{c}}=0.0 \quad, \mathrm{~V} 1 \mathrm{c}=\text { otherwise }
\end{aligned}
$$

Foraging sites:

$$
\begin{aligned}
& \mathrm{SI}_{\mathrm{V} 1 \mathrm{f}}=1.0, \mathrm{~V} 1 \mathrm{f}=\text { one of the suitable feeding habitats within foraging radius: } \\
& \text { Estuarine - Intertidal (E2AB,E2EM,E2FO,E2SB,E2SS,E2US) } \\
& \text { Riverine - Tidal (R1AB,R1EM,R1UB,R1US) } \\
& \text { - Lower Perennial - (R2AB,R2EM,R2UB,R2US) } \\
& \text { - Intermittent - Stream bed (R4SB) } \\
& \text { Lacustrine - Littoral - (L2AB,L2EM,L2UB,L2US) } \\
& \text { Palustrine - (PAB,PFO,PEM,PSS,PUB,PUS) } \\
& \text { (herbaceous/emergent wetlands or all marsh types, forests/shrubs, } \\
& \text { swamps, unconsolidated shore (flats and beaches)) } \\
& \mathrm{SI}_{\mathrm{V} 1 \mathrm{f}}=0.0 \quad, \mathrm{~V} 1 \mathrm{f}=\text { otherwise }
\end{aligned}
$$

The percentage of land in a cell (V2) is generally assumed to be optimal when half of the cell is land and the other half water (USACE, 2004). For wading birds, the measurement for this factor is again divided into two parts: the potential colony site cell versus the area of surrounding foraging cells. Likewise, flooding water depth (V3) is defined in both kinds of cells. Thus, the variables (V2) and (V3) will be expanded and redefined for each cell type and are presented separately in the "Foraging Information" and "Nesting/Colony Information" subsections below. Also, note that these subsections are further divided for long- and short-legged bird groups.

\section{Foraging Information}

$\begin{array}{ll}\text { V1r } & \begin{array}{l}\text { Foraging radius as the limit of distance for feeding sites from colony site } \\ \text { (defined as part of habitat V1) }\end{array} \\ \text { V2f } & \text { Foraging percentage of land } \\ \text { V3f } & \text { Foraging water depth }\end{array}$

(The disturbance factor is not included in the foraging component in this proposed HSI model.) 
Long-legged birds: All models for long-legged birds describe different radii limits, except the Florida HSI model wherein no radius is defined. The general HSI models denote the optimal distance limit of $1 \mathrm{~km}$ for great blue herons that tapers off to $10 \mathrm{~km}$, but an absolute specific distance of $4 \mathrm{~km}$ for great egrets with zero suitability for distances beyond. Likewise, the SESI model radius for long-legged birds is specific at $3 \mathrm{~km}$, followed by zero suitability. A compromise could be attained by computing the average radius and tapering to an extreme limit, since birds have been observed foraging at much farther distances when compelled (Chapman and Howard, 1984). The average radius limit from all wading bird general HSI models is calculated as $2.7 \mathrm{~km}$ but rounded up to the nearest $\mathrm{km}(\sim 3 \mathrm{~km})$ since the LCA study grid is fixed at 1,000 by $1,000-\mathrm{m}$ cells. The upper extreme is set at $10 \mathrm{~km}$ as per the great blue heron general HSI model.

$$
\begin{array}{ll}
\mathrm{SI}_{\mathrm{Vlr}}=1.0 & , \mathrm{~V} 1 \mathrm{r} \leq 3 \mathrm{~km} \\
\mathrm{SI}_{\mathrm{V} 1 \mathrm{r}}=(10-\mathrm{V} 1 \mathrm{r}) / 7 & , 3<\mathrm{V} 1 \mathrm{r} \leq 10 \mathrm{~km} \\
\mathrm{SI}_{\mathrm{V} 1 \mathrm{r}}=0.0 & , 10 \mathrm{~km}<\mathrm{V} 1 \mathrm{r}
\end{array}
$$

The equation for the percentage of area (V1) with suitable water depth in the great egret general HSI model can be used to determine the foraging percentage of land (V2f). Percentage of land is then assumed to be the complement: $\mathrm{V} 2 \mathrm{f}=1-(\mathrm{V} 1$ of great egret model).

$$
\mathrm{SI}_{\mathrm{V} 2 \mathrm{f}}=1-(\mathrm{V} 2 \mathrm{f} / 100) \quad, 0 \leq \mathrm{V} 2 \mathrm{f} \leq 100 \quad \text { (percent) }
$$

The foraging percentage of land, however, is not universally adapted throughout the wading bird models. The general suitability equations based on optimal conditions with half land and half water from the LCA study may be applied instead, repeating here (substituting V2f for V2):

$$
\begin{array}{ll}
\mathrm{SI}_{\mathrm{V} 2 \mathrm{f}}=\mathrm{V} 2 \mathrm{f} * 0.025 & , 0 \leq \mathrm{V} 2 \mathrm{f}<40 \\
\mathrm{SI}_{\mathrm{V} 2 \mathrm{f}}=1.0 & , 40 \leq \mathrm{V} 2 \mathrm{f} \leq 60 \\
\mathrm{SI}_{\mathrm{V} 2 \mathrm{f}}=2.5-(\mathrm{V} 2 \mathrm{f} * 0.025) & , 60<\mathrm{V} 2 \mathrm{f} \leq 100
\end{array}
$$

Likewise, a compromise can be determined for computing the foraging water depth limits by averaging the lower and upper limits and tapering to the minimum and maximum over all models.

$$
\begin{array}{ll}
\mathrm{SI}_{\mathrm{V} 3 \mathrm{f}}=0.0 & , \mathrm{~V} 3 \mathrm{f} \leq 0 \mathrm{~cm} \\
\mathrm{SI}_{\mathrm{V} 3 \mathrm{f}}=\mathrm{V} 3 \mathrm{f} / 4 & , 0 \mathrm{~cm}<\mathrm{V} 3 \mathrm{f} \leq 4 \mathrm{~cm} \\
\mathrm{SI}_{\mathrm{V} 3 \mathrm{f}}=1.0 & , 4<\mathrm{V} 3 \mathrm{f} \leq 30 \mathrm{~cm} \\
\mathrm{SI}_{\mathrm{V} 3 \mathrm{f}}=(50-\mathrm{V} 3 \mathrm{f}) / 20 & , 30<\mathrm{V} 3 \mathrm{f} \leq 50 \mathrm{~cm} \\
\mathrm{SI}_{\mathrm{V} 3 \mathrm{f}}=0.0 & , 50 \mathrm{~cm}<\mathrm{V} 3 \mathrm{f}
\end{array}
$$


Short-legged birds: The white ibis general HSI model allows for a very wide radius of $10 \mathrm{~km}$, whereas the SESI model defines a tight radius of $1.5 \mathrm{~km}$. Similarly, short-legged birds will forage at farther distances when necessary (Hingtgen and others, 1985). A compromise can be reached by setting the lowest limit and tapering off to $10 \mathrm{~km}$. Again, because of LCA study grid dimensions, the lowest limit is adjusted up to $2 \mathrm{~km}$ from $1.5 \mathrm{~km}$.

$$
\begin{array}{ll}
\mathrm{SI}_{V 1 r}=1.0 & , \mathrm{~V} 1 \mathrm{r} \leq 2.0 \mathrm{~km} \\
\mathrm{SI}_{V 1 \mathrm{r}}=(10-\mathrm{V} 1 \mathrm{r}) / 8 & , 2.0 \mathrm{~km}<\mathrm{V} 1 \mathrm{r} \leq 10 \mathrm{~km} \\
\mathrm{SI}_{V 1 \mathrm{r}}=0.0 & , 10 \mathrm{~km}<\mathrm{V} 1 \mathrm{r}
\end{array}
$$

Foraging percentage of land is not given in the white ibis general HSI model, but shallow water depths are required in the foraging habitat $(0-25 \mathrm{~cm}$ with $5-10 \mathrm{~cm}$ as the optimal range). The same concept from the great egret general HSI model for percentage of area with suitable water depth equations may be implemented for the foraging percentage of land (V2f) of shortlegged wading birds. Otherwise, the general equations from the LCA study may be used.

$$
\mathrm{SI}_{\mathrm{V} 2 \mathrm{f}}=1-(\mathrm{V} 2 \mathrm{f} / 100) \quad, 0 \leq \mathrm{V} 2 \mathrm{f} \leq 100 \quad \text { (percent) }
$$

or

$$
\begin{array}{ll}
\mathrm{SI}_{\mathrm{V} 2 \mathrm{f}}=\mathrm{V} 2 \mathrm{f} * 0.025 & , 0 \leq \mathrm{V} 2 \mathrm{f}<40 \\
\mathrm{SI}_{\mathrm{V} 2 \mathrm{f}}=1.0 & , 40 \leq \mathrm{V} 2 \mathrm{f} \leq 60 \\
\mathrm{SI}_{\mathrm{V} 2 \mathrm{f}}=2.5-(\mathrm{V} 2 \mathrm{f} * 0.025) & , 60<\mathrm{V} 2 \mathrm{f} \leq 100
\end{array}
$$

Likewise, a compromise for the foraging water depth limits can be found by computing the lower and upper limit averages, then tapering off to the minimum and maximum over the white ibis general HSI, Florida HSI, and SESI models.

$$
\begin{array}{ll}
\mathrm{SI}_{\mathrm{V} 3 \mathrm{f}}=0.0 & , \mathrm{~V} 3 \mathrm{f} \leq 0 \mathrm{~cm} \\
\mathrm{SI}_{\mathrm{V} 3 \mathrm{f}}=\mathrm{V} 3 \mathrm{f} / 2 & , 0 \mathrm{~cm}<\mathrm{V} 3 \mathrm{f} \leq 2 \mathrm{~cm} \\
\mathrm{SI}_{\mathrm{V} 3 \mathrm{f}}=1.0 & , 2<\mathrm{V} 3 \mathrm{f} \leq 15 \mathrm{~cm} \\
\mathrm{SI}_{\mathrm{V} 3 \mathrm{f}}=(25-\mathrm{V} 3 \mathrm{f}) / 10 & , 15<\mathrm{V} 3 \mathrm{f} \leq 25 \mathrm{~cm} \\
\mathrm{SI}_{\mathrm{V} 3 \mathrm{f}}=0.0 & , 25 \mathrm{~cm}<\mathrm{V} 3 \mathrm{f}
\end{array}
$$




\section{Foraging Component}

The two foraging habitat suitability indices may be merged into one habitat component $\left(\mathrm{C}_{\mathrm{V} 1 \mathrm{f}}\right)$, where $\mathrm{C}_{\mathrm{V} 1 \mathrm{f}}=1.0$ only when foraging habitats are suitable within appropriate radius limits. When (V1f) is defined as a two-classed variable by using the U.S. Fish and Wildlife classification system (Cowardin, 1979) and (V1r) is continuous, then $\mathrm{C}_{\mathrm{V} 1 \mathrm{f}}$ (where power $=1$ ):

$$
\mathrm{C}_{\mathrm{V} 1 \mathrm{f}}=\left(\mathrm{SI}_{\mathrm{V} 1 \mathrm{f}} * \mathrm{SI}_{\mathrm{V} 1 \mathrm{r}}\right)
$$

Otherwise, when (V1f) is defined as a multiclassed variable such as it is in the current LCA study models, then $\mathrm{C}_{\mathrm{V} 1 \mathrm{f}}($ where power $=1 / 2)$ :

$$
\mathrm{C}_{\mathrm{V} 1 \mathrm{f}}=\left(\mathrm{SI}_{\mathrm{V} 1 \mathrm{f}} * \mathrm{SI}_{\mathrm{V} 1 \mathrm{r}}\right)^{1 / 2}
$$

Furthermore, all foraging components and indices may be combined into a separate foraging component $\left(\mathrm{C}_{\mathrm{F}}\right)$ by using various methods depending on level of importance (see previous discussion): geometric mean, arithmetic mean, or minimum of all components/indices.

or

$$
\mathrm{C}_{\mathrm{F}}=\left(\mathrm{C}_{\mathrm{V} 1 \mathrm{f}} * \mathrm{SI}_{\mathrm{V} 2 \mathrm{f}} * \mathrm{SI}_{\mathrm{V} 3 \mathrm{f}}\right)^{1 / 3}
$$

or

$$
\mathrm{C}_{\mathrm{F}}=\left(\mathrm{C}_{\mathrm{V} 1 \mathrm{f}}+\mathrm{SI}_{\mathrm{V} 2 \mathrm{f}}+\mathrm{SI}_{\mathrm{V} 3 \mathrm{f}}\right) / 3
$$

$$
\mathrm{C}_{\mathrm{F}}=\min \left(\mathrm{C}_{\mathrm{V} 1 \mathrm{f}}, \mathrm{SI}_{\mathrm{V} 2 \mathrm{f}}, \mathrm{SI}_{\mathrm{V} 3 \mathrm{f}}\right)
$$

As an alternative, the habitat component may be redefined to consist of both foraging and nesting colony sites but not the foraging radius. In this version, habitat would be included as a separate component in the final index (see the forthcoming section "Final Index"):

or

$$
\mathrm{C}_{\mathrm{V} 1}=\left(\mathrm{SI}_{\mathrm{V} 1 \mathrm{c}} * \mathrm{SI}_{\mathrm{V} 1 \mathrm{f}}\right) \quad \text {, if two-classed variables V1c and V1f }
$$

or $\quad \mathrm{C}_{\mathrm{V} 1}=\left(\mathrm{SI}_{\mathrm{V} 1 \mathrm{c}} * \mathrm{SI}_{\mathrm{V} 1 \mathrm{f}}\right)^{1 / 2} \quad$, if multiclassed variables V1c and $\mathrm{V} 1 \mathrm{f}$

Then the foraging component $\left(\mathrm{C}_{\mathrm{F}}\right)$ includes the foraging radius only $(\mathrm{V} 1 \mathrm{r})$ :

or

$$
\mathrm{C}_{\mathrm{F}}=\left(\mathrm{SI}_{\mathrm{V} 1 \mathrm{r}} * \mathrm{SI}_{\mathrm{V} 2 \mathrm{f}} * \mathrm{SI}_{\mathrm{V} 3 \mathrm{f}}\right)^{1 / 3}
$$

or

$$
\mathrm{C}_{\mathrm{F}}=\left(\mathrm{SI}_{\mathrm{V} 1 \mathrm{r}}+\mathrm{SI}_{\mathrm{V} 2 \mathrm{f}}+\mathrm{SI}_{\mathrm{V} 3 \mathrm{f}}\right) / 3
$$

$$
\mathrm{C}_{\mathrm{F}}=\min \left(\mathrm{SI}_{\mathrm{V} 1 \mathrm{r}}, \mathrm{SI}_{\mathrm{V} 2 \mathrm{f}}, \mathrm{SI}_{\mathrm{V} 3 \mathrm{f}}\right)
$$




\section{Nesting Colony Information}

V3c Colony site cell water depth

V4 Woody vegetation height

V5 Proximity of next colony

V6 Disturbance from road/structure and human/urban activity

Long-legged birds: Nesting water depth (V3c) (non-island, some flooding desired to deter predators) and woody vegetation height (V4) will be adapted from the great egret general HSI model:

$$
\begin{array}{ll}
\mathrm{SI}_{\mathrm{V} 3 \mathrm{c}}=0.0 & , \mathrm{~V} 3 \mathrm{c} \leq 0.0 \mathrm{~m} \\
\mathrm{SI}_{\mathrm{V} 3 \mathrm{c}}=\mathrm{V} 3 \mathrm{c} / 0.6 & , 0.0<\mathrm{V} 3 \mathrm{c}<0.6 \mathrm{~m} \\
\mathrm{SI}_{\mathrm{V} 3 \mathrm{c}}=1.0 & , 0.6 \mathrm{~m} \leq \mathrm{V} 3 \mathrm{c} \\
\mathrm{SI}_{\mathrm{V} 4}=0.0 & , \mathrm{~V} 4 \leq 0.0 \mathrm{~m} \\
\mathrm{SI}_{\mathrm{V} 4}=\mathrm{V} 4 / 7.0 & , 0.0<\mathrm{V} 4<7.0 \mathrm{~m} \\
\mathrm{SI}_{\mathrm{V} 4}=1.0 & , 7.0 \mathrm{~m} \leq \mathrm{V} 4
\end{array}
$$

The proximity of the next colony (V5) is defined in the great blue heron general HSI model only and will be utilized here. A new colony will usually become established near old colonies, and thus the colonies are spatially clumped closely together.

$$
\begin{array}{ll}
\mathrm{SI}_{\mathrm{V} 5}=1.0 & , \mathrm{~V} 5 \leq 1 \mathrm{~km} \\
\mathrm{SI}_{\mathrm{V} 5}=(20-\mathrm{V} 5) / 19 & , 1<\mathrm{V} 5 \leq 20 \mathrm{~km} \\
\mathrm{SI}_{\mathrm{V} 5}=0.0 & , 20 \mathrm{~km}<\mathrm{V} 5
\end{array}
$$

The disturbance factor will be defined in terms of distance (V6) measured from the colony site boundary. For the LCA study model, the size of the colony site is assumed to cover the entire 1,000 by 1,000-m cell. Disturbance within the colony site cell automatically disqualifies the site from suitability. Since wading birds from both leg groups often cohabit the same colony site, all information will be considered together and synchronized for both groups. The SESI model describes the percentage of urban disturbance instead of a distance measurement and thus cannot be used here. All general HSI models recognize wading bird sensitivity to disturbance and set the lower limit below $1 \mathrm{~km}: 0.25 \mathrm{~km}$ for great blue herons, 0.5 $\mathrm{km}$ for great egrets (road disturbances), and $0.5 \mathrm{~km}$ for white ibises. The great egret general HSI also identifies human disturbances with very low tolerance $(10-40 \mathrm{~m})$, but this will not be included in the proposed model. An optimal upper limit of $1.0 \mathrm{~km}$ (great egrets) or $2.0 \mathrm{~km}$ (white ibises) is defined. In the proposed model, distance limits below $1.0 \mathrm{~km}$ will be considered in spite of the spatial resolution of 1,000 by $1,000 \mathrm{~m}$. As a compromise, the same disturbance function will be used for both long- and short-legged models: the colony site is not suitable when 
disturbances are closer than $0.5 \mathrm{~km}$ and optimally suitable when disturbances are at least $1.0 \mathrm{~km}$ away.

$$
\begin{array}{ll}
\mathrm{SI}_{\mathrm{V} 6}=0.0 & , 0.0 \leq \mathrm{V} 6 \leq 0.5 \mathrm{~km} \\
\mathrm{SI}_{\mathrm{V} 6}=(\mathrm{V} 6-0.5) / 0.5 & , 0.5<\mathrm{V} 6 \leq 1.0 \mathrm{~km} \\
\mathrm{SI}_{\mathrm{V} 6}=1.0 & , 1.0 \mathrm{~km}<\mathrm{V} 6
\end{array}
$$

Short-legged birds: Nesting water depth (V3c) may be redefined as the percentage of colony area flooded during nesting season. A more accurate measurement may be obtained if the actual water depth limit for flooding is established in non-island sites. White ibises generally nest at lower heights than do larger wading birds within the same colony site, where nests above $1.0 \mathrm{~m}$ are considered free from flooding (Hingtgen and others, 1985).

As percentage of flooded colony area:

$$
\mathrm{SI}_{\mathrm{V} 3 \mathrm{c}}=\mathrm{V} 3 \mathrm{c} / 100 \quad, 0 \leq \mathrm{V} 3 \mathrm{c} \leq 100 \quad \text { (percent) }
$$

As nesting water depth (preferred):

$$
\begin{array}{ll}
\mathrm{SI}_{\mathrm{V} 3 \mathrm{c}}=0.0 & , \mathrm{~V} 3 \mathrm{c} \leq 0.0 \mathrm{~m} \\
\mathrm{SI}_{\mathrm{V} 3 \mathrm{c}}=\mathrm{V} 3 \mathrm{c} / 1.0 & , 0.0<\mathrm{V} 3 \mathrm{c} \leq 1.0 \mathrm{~m} \\
\mathrm{SI}_{\mathrm{V} 3 \mathrm{c}}=1.0 & , 1.0 \mathrm{~m}<\mathrm{V} 3 \mathrm{c}
\end{array}
$$

Woody vegetation height (V4) will be adapted from the white ibis general HSI model. The proximity of the next colony (V5) is specified only in the great blue heron general HSI model, but will be implemented here since wading birds share the same colony sites. Human and road disturbance (V6) will be the same as that for long-legged birds.

Average vegetation height, categorized into four classes, V4:

$$
\begin{array}{ll}
\mathrm{SI}_{\mathrm{V} 4}=0.6 & , 0 \leq \mathrm{V} 4<1.0 \mathrm{~m} \\
\mathrm{SI}_{\mathrm{V} 4}=0.8 & , 1.0 \leq \mathrm{V} 4<2.0 \mathrm{~m} \\
\mathrm{SI}_{\mathrm{V} 4}=0.9 & , 2.0 \leq \mathrm{V} 4 \leq 4.0 \mathrm{~m} \\
\mathrm{SI}_{\mathrm{V} 4}=1.0 & , 4 \mathrm{~m}<\mathrm{V} 4
\end{array}
$$

Proximity of the next colony, V5:

$$
\begin{array}{ll}
\mathrm{SI}_{\mathrm{V} 5}=1.0 & , \mathrm{~V} 5 \leq 1 \mathrm{~km} \\
\mathrm{SI}_{\mathrm{V} 5}=(20-\mathrm{V} 5) / 19 & , 1<\mathrm{V} 5 \leq 20 \mathrm{~km} \\
\mathrm{SI}_{\mathrm{V} 5}=0.0 & , 20 \mathrm{~km}<\mathrm{V} 5
\end{array}
$$


Distance to human disturbance, V6:

$$
\begin{array}{ll}
\mathrm{SI}_{\mathrm{V} 6}=0.0 & , 0.0 \leq \mathrm{V} 6 \leq 0.5 \mathrm{~km} \\
\mathrm{SI}_{\mathrm{V} 6}=(\mathrm{V} 6-0.5) / 0.5 & , 0.5<\mathrm{V} 6 \leq 1.0 \mathrm{~km} \\
\mathrm{SI}_{\mathrm{V} 6}=1.0 & , 1.0 \mathrm{~km}<\mathrm{V} 6
\end{array}
$$

\section{Nesting Component}

Similarly, all nesting indices may be combined into a separate nesting component. As in the great blue heron general HSI model, the habitat factor for the colony site (SI $\mathrm{V}_{\mathrm{Vlc}}$ ) will be also included. Again, the nesting component $\left(\mathrm{C}_{\mathrm{N}}\right)$ may be defined using the geometric mean, arithmetic mean, or minimum of all components/indices.

$$
\begin{array}{lll} 
& \mathrm{C}_{\mathrm{N}}=\left(\mathrm{SI}_{\mathrm{V} 1 \mathrm{c}} * \mathrm{SI}_{\mathrm{V} 3 \mathrm{c}} * \mathrm{SI}_{\mathrm{V} 4} * \mathrm{SI}_{\mathrm{V} 5} * \mathrm{SI}_{\mathrm{V} 6}\right)^{1 / 4} & \text { if two-classed variable V1c } \\
\text { or } & \mathrm{C}_{\mathrm{N}}=\left(\mathrm{SI}_{\mathrm{V} 1 \mathrm{c}} * \mathrm{SI}_{\mathrm{V} 3 \mathrm{c}} * \mathrm{SI}_{\mathrm{V} 4} * \mathrm{SI}_{\mathrm{V} 5} * \mathrm{SI}_{\mathrm{V} 6}\right)^{1 / 5} & \text { if multiclassed variable V1c } \\
\text { or } & \mathrm{C}_{\mathrm{N}}=\left(\mathrm{SI}_{\mathrm{V} 1 \mathrm{c}}+\mathrm{SI}_{\mathrm{V} 3 \mathrm{c}}+\mathrm{SI}_{\mathrm{V} 4}+\mathrm{SI}_{\mathrm{V} 5}+\mathrm{SI}_{\mathrm{V} 6}\right) / 5 &
\end{array}
$$

or

$$
\mathrm{C}_{\mathrm{N}}=\min \left(\mathrm{SI}_{\mathrm{V} 1 \mathrm{c}}, \mathrm{SI}_{\mathrm{V} 3 \mathrm{c}}, \mathrm{SI}_{\mathrm{V} 4}, \mathrm{SI}_{\mathrm{V} 5}, \mathrm{SI}_{\mathrm{V} 6}\right)
$$

$\mathrm{C}_{\mathrm{N}}$ can be defined without the habitat variable (V1c) when habitat is expressed in a separate component (see final index alternative version below):

or

$$
\mathrm{C}_{\mathrm{N}}=\left(\mathrm{SI}_{\mathrm{V} 3 \mathrm{c}} * \mathrm{SI}_{\mathrm{V} 4} * \mathrm{SI}_{\mathrm{V} 5} * \mathrm{SI}_{\mathrm{V} 6}\right)^{1 / 4}
$$

or

$$
\mathrm{C}_{\mathrm{N}}=\left(\mathrm{SI}_{\mathrm{V} 3 \mathrm{c}}+\mathrm{SI}_{\mathrm{V} 4}+\mathrm{SI}_{\mathrm{V} 5}+\mathrm{SI}_{\mathrm{V} 6}\right) / 4
$$

$$
\mathrm{C}_{\mathrm{N}}=\min \left(\mathrm{SI}_{\mathrm{V} 3 \mathrm{c}}, \mathrm{SI}_{\mathrm{V} 4}, \mathrm{SI}_{\mathrm{V} 5}, \mathrm{SI}_{\mathrm{V} 6}\right)
$$

\section{Final Index}

Both the feeding and nesting components will be combined into the final HSI, as either the geometric or arithmetic mean:

or

$$
\mathrm{HSI}=\left(\mathrm{C}_{\mathrm{F}} * \mathrm{C}_{\mathrm{N}}\right)^{1 / 2}
$$

$$
\mathrm{HSI}=\left(\mathrm{C}_{\mathrm{F}}+\mathrm{C}_{\mathrm{N}}\right) / 2
$$


In the alternative version with a separate habitat component $\left(\mathrm{C}_{\mathrm{V} 1}\right)$, the final HSI is redefined as:

$$
\begin{aligned}
& \mathrm{HSI}=\left(\mathrm{C}_{\mathrm{V} 1} * \mathrm{C}_{\mathrm{F}} * \mathrm{C}_{\mathrm{N}}\right)^{1 / 2} \quad \text {, if two-classed variables V1c and V1f } \\
& \mathrm{HSI}=\left(\mathrm{C}_{\mathrm{V} 1} * \mathrm{C}_{\mathrm{F}} * \mathrm{C}_{\mathrm{N}}\right)^{1 / 3} \quad \text {, if multiclassed variables V1c and V1f }
\end{aligned}
$$

or

$$
\mathrm{HSI}=\left(\mathrm{C}_{\mathrm{V} 1}+\mathrm{C}_{\mathrm{F}}+\mathrm{C}_{\mathrm{N}}\right) / 3
$$

Ultimately, a geometric mean of all variables may be defined, without separation of foraging and nesting components.

If V1c and V1f are two-classed variables:

$$
\mathrm{HSI}=\left(\mathrm{SI}_{\mathrm{V} 1 \mathrm{c}} * \mathrm{SI}_{\mathrm{V} 1 \mathrm{f}} * \mathrm{SI}_{\mathrm{V} 1 \mathrm{r}} * \mathrm{SI}_{\mathrm{V} 2 \mathrm{f}} * \mathrm{SI}_{\mathrm{V} 3 \mathrm{f}} * \mathrm{SI}_{\mathrm{V} 3 \mathrm{c}} * \mathrm{SI}_{\mathrm{V} 4} * \mathrm{SI}_{\mathrm{V} 5} * \mathrm{SI}_{\mathrm{V} 6}\right)^{1 / 7}
$$

If V1c and V1f are multiclassed variables:

$$
\mathrm{HSI}=\left(\mathrm{SI}_{\mathrm{V} 1 \mathrm{c}} * \mathrm{SI}_{\mathrm{V} 1 \mathrm{f}} * \mathrm{SI}_{\mathrm{V} 1 \mathrm{r}} * \mathrm{SI}_{\mathrm{V} 2 \mathrm{f}} * \mathrm{SI}_{\mathrm{V} 3 \mathrm{f}} * \mathrm{SI}_{\mathrm{V} 3 \mathrm{c}} * \mathrm{SI}_{\mathrm{V} 4} * \mathrm{SI}_{\mathrm{V} 5} * \mathrm{SI}_{\mathrm{V} 6}\right)^{1 / 9}
$$

That is,

$$
\mathrm{HSI}=\left(\prod_{\mathrm{Vi}=1}^{\mathrm{n}} \mathrm{SI}_{\mathrm{Vi}}\right)^{1 / \mathrm{n}}
$$

Note that the above version of the geometric mean emphasizes the equal importance of all individual factors. When any one condition (Vi) is completely unsuitable, then that suitability factor $\mathrm{SI}_{\mathrm{Vi}}$ as zero would yield a zero value for the entire HSI and would disqualify the whole potential colony site with corresponding foraging area. 


\section{Evaluation of Proposed Wading Bird LCA Study Model}

Several versions of the wading bird HSI models for the LCA study will be explored. The first version implements the following: (1) the preferred U.S. Fish and Wildlife Service's wetland classification system for habitat in (V1c) and (V1f) instead of (V1) from the current LCA study, and (2) the percentage of land (V2) of the current LCA study instead of (V2f) from the great egret general HSI model. Geometric means are computed for the habitat component $\left(\mathrm{C}_{\mathrm{V} 1 \mathrm{f}}\right)$ (using V1f and V1r) and the final HSI, whereas arithmetic means are used for both foraging and nesting components $\left(\mathrm{C}_{\mathrm{F}}\right.$ and $\left.\mathrm{C}_{\mathrm{N}}\right)$. The second version modifies the first by calculating the geometric means instead for both $\mathrm{C}_{\mathrm{F}}$ and $\mathrm{C}_{\mathrm{N}}$. The third and fourth versions apply the alternative approach of isolating the habitat component as $\left(\mathrm{C}_{\mathrm{V} 1}\right)$ (using V1c and V1f) that is included as a separate component in the final index computation. All versions of the proposed wading bird models for the LCA study are condensed and presented in appendix 2 as a reference.

The three non-island settings initially introduced in tables 5-7 for all general HSI models will be utilized for comparisons with the proposed LCA study HSI models. These will be separated by leg group and are presented in tables 20-22 (versions 1 and 2) and tables 23-25 (versions 3 and 4). In all settings, the suitability of foraging and nesting habitats was selected as high in order to evenly influence all models (both $\mathrm{SI}_{\mathrm{V} 1 \mathrm{c}}$ and $\mathrm{SI}_{\mathrm{V} 1 \mathrm{f}}=1.0$ ). In addition, the foraging component is not defined separately in the white ibis general HSI model, but SIVo was designed to constitute this component and will be referred to in discussions of foraging below. Consequently, the overall HSI in the white ibis model is assumed to be analogous to the nesting component in the discussions for short-legged birds below.

The proposed wading bird HSI model for the LCA study generates higher final index values of around 0.80 for both leg groups in the typical setting shown in table 20, representing about a 20 percent (version 1) or 13 percent (version 2) increase in the long-legged birds, but a larger 80 percent (version 1) or 65 percent (version 2) increase for short-legged birds. The foraging component value is high for both bird groups (about 1.0, except for the great egret at 0.65). The nesting component (moderate) is similar among the long-legged bird models at about 0.70 (versions 1 and 2). For short-legged birds, the nesting component value is substantially higher (50 percent in version 1 and 30 percent in version 2) than that of the white ibis because of the change in higher tolerance for disturbance. This change in tolerance may be more realistic, as response to disturbance is presumed the same for all wading birds. For the nesting components, the arithmetic mean version is about 15 percent greater than the geometric mean version. Thus, the use of the arithmetic mean (version 1) instead of the geometric means (version 2) in the foraging and nesting component computations increases the final index values by 7 percent. The formula for the final HSI proposed for the LCA study balances the two components equally and thereby generates a high value as compared to other models.

The second setting, shown in table 21 , depicts a reversal of conditions with deeper waters and more distant foraging sites, but taller colony vegetation and more remote disturbances. In this case, the foraging conditions are lower, but colony site conditions are more suitable and 
manifest higher nesting component values for the proposed LCA study model in both bird groups. Consequently, the balancing of the two components in the final HSI for the LCA study generates likewise high values for the long-legged birds at about $0.70-0.75$ for water depths at $10 \mathrm{~cm}$ and $0.65-0.70$ at $35 \mathrm{~cm}$. Again, the change in disturbance tolerance increases the nesting component in short-legged birds by 30 to 40 percent so that the final index is higher at 0.70 (10 $\mathrm{cm})$. The deeper foraging waters of $35 \mathrm{~cm}$, however, reduce suitability of long-legged bird foraging below 0.50 in both versions. Furthermore, deep water depths especially are unfavorable for short-legged birds and produce a very low foraging index of 0.20 (version 1 ) or 0.0 (version 2) despite that colony conditions are very encouraging (0.84-0.96). Accordingly, the proposed HSI for the LCA study in version 1 decreases but still maintains some likelihood of lessened suitability at 0.40 for short-legged birds. The use of the geometric mean in version 2 also reduced the nesting component and the subsequent final index, but to an absolute zero. The white ibis general HSI model likewise showed zero tolerance for deep waters. Repeating, there is a general 5-15 percent reduction in components and index values when using the geometric mean.

The last setting in table 22 upset the conditions of table 21 with a road disturbance very close to the colony site. This diminishes the nesting component in version 1 of the proposed HSI model for the LCA study but does not cancel out all other factors as in all general HSI models (zero overall suitability). Suitability therefore decreases in the proposed model (version 1) to about 0.60 for long-legged birds and as low as 0.40 (water depth $=35 \mathrm{~cm}$ ) for short-legged birds. The geometric mean (version 2) matches the other general HSI models whereby the nesting components in both leg groups result in zero values and, consequently, zero in the final index.

Also note that for short-legged wading birds, the alternative use of the percentage of flooded area information at the colony site mildly affects the nesting component value. Higher percentages increase the value of the overall nesting component comparatively; that is, at 60 percent, the component value increases by $0.02-0.03$, at 80 percent by $0.06-0.11$.

The proposed definition of the final HSI as the geometric or arithmetic mean of two components equally weighted in importance tends to magnify the value of the final index. The other general HSI models combine habitat and foraging information into one class variable or enter these factors as separate binary class variables into the equations. One model (great egret) separates the components entirely. In other words, the general HSI models simplify or compress information, whereas the proposed model expands and elaborates the details. Also, note that both the geometric mean HSI (HSI new_L $_{-}$) and arithmetic mean HSI (AlternateHSI new_L $_{-}$) for the proposed LCA study model produce similar results when at least one component is not zero. Reiterating, by defining the foraging and nesting components as arithmetic means in version 1 , all individual factors must be zero in order to produce a final index value of zero (see previous discussion in "Assessment of the Alligator Models" section in chapter 4). Hence, version 1 of the proposed model will have a predisposition to generate nonzero index values, however small. The geometric means of version 2 generate lower component and index values, which present a stronger argument to produce a suitability of zero for any one unfavorable condition, thereby matching the general HSI models in extreme conditions, such as in the third setting. 
Table 20. Comparison of general habitat suitability index (HSI) models for wading birds with the proposed LCA study models, separated by short- and long-legged groups. Setting 1 (versions 1 (v. 1) and 2 (v. 2)). Wading birds include great blue heron (Ardea herodias), great egret (Ardea alba), and white ibis (Eudocimus albus). General HSI models are denoted as HSI (G) and the proposed model as HSI (new L). Final index computations include component calculations.

Dataset parameters of setting 1:

$60 \%$ of feeding site with water depth of $10 \mathrm{~cm}$ and firm substrate ( $40 \%$ land); $75 \%$ emergent vegetation in water depths of $10 \mathrm{~cm}$.

Feeding site is $2 \mathrm{~km}$ from colony, in estuarine intertidal emergent wetland (E2EM), and is $500 \mathrm{~m}$ from disturbances (roads, structures, and human).

Colony is in estuarine intertidal forested wetland (non-island) (E2FO).

Colony is on 25 ha of tree grove within $150 \mathrm{~m}$ of water, proximity of next colony is $10 \mathrm{~km}$.

Mean woody vegetation height of $5 \mathrm{~m}$, mean water depth in colony site is $0.5 \mathrm{~m}$ (60\% flooded during nesting).

Distance from colony to road/structure and human activity disturbances are both $750 \mathrm{~m}$.

\begin{tabular}{|c|c|c|c|c|c|}
\hline \multicolumn{6}{|c|}{ INTERMEDIATE INDEX (SI) COMPUTATIONS } \\
\hline \multicolumn{2}{|c|}{ GREAT BLUE HERON HSI (G) } & \multicolumn{2}{|c|}{ GREAT EGRET HSI (G) } & \multicolumn{2}{|c|}{ HSI (new L) } \\
\hline Variable & Index & Variable & Index & Variable & Index \\
\hline $\mathrm{V} 0=$ estuarine & $\mathrm{SI}_{\mathrm{V} 0}=1.0$ & $\begin{array}{r}\mathrm{V} 0=\text { estuarine, } \\
2 \mathrm{~km} \text { radius }\end{array}$ & $\mathrm{SI}_{\mathrm{V} 0}=1.0$ & $\begin{array}{l}\mathrm{V} 1 \mathrm{c}=\mathrm{E} 2 \mathrm{FO} \\
\mathrm{V} 1 \mathrm{f}=\mathrm{E} 2 \mathrm{E} \\
\mathrm{V} 1 \mathrm{r}=2 \mathrm{~km}\end{array}$ & $\begin{array}{l}\mathrm{SI}_{\mathrm{V} 1 \mathrm{c}}=1.0 \\
\mathrm{SI}_{\mathrm{V} 1 \mathrm{f}}=1.0 \\
\mathrm{SI}_{\mathrm{Vlr}}=1.0\end{array}$ \\
\hline $\mathrm{V} 1=2 \mathrm{~km}$ & $\mathrm{SI}_{\mathrm{V} 1}=0.90$ & $\mathrm{~V} 1=60 \%$ & $\mathrm{SI}_{\mathrm{V} 1}=0.60$ & & \\
\hline $\mathrm{V} 2=10 \mathrm{~cm}$ & $\mathrm{SI}_{\mathrm{V} 2}=1.0$ & $\mathrm{~V} 2=75 \%$ & $\mathrm{SI}_{\mathrm{V} 2}=0.70$ & $\mathrm{~V} 2 \mathrm{f}=40 \%$ & $\mathrm{SI}_{\mathrm{V} 2 \mathrm{f}}=1.0$ \\
\hline $\mathrm{V} 3=500 \mathrm{~m}$ & $\mathrm{SI}_{\mathrm{V} 3}=1.0$ & $\mathrm{~V} 3=\mathrm{n} / \mathrm{a}$ & & $\begin{array}{l}\mathrm{V} 3 \mathrm{c}=0.5 \mathrm{~m} \\
\mathrm{~V} 3 \mathrm{f}=10 \mathrm{~cm}\end{array}$ & $\begin{array}{l}\mathrm{SI}_{\mathrm{V} 3 \mathrm{c}}=0.83 \\
\mathrm{SI}_{\mathrm{V} 3 \mathrm{f}}=1.0\end{array}$ \\
\hline $\begin{array}{l}\mathrm{V} 4=25 \mathrm{ha}, \\
150 \mathrm{~m} \text { to wate }\end{array}$ & $\begin{array}{l}\mathrm{SI}_{\mathrm{V} 4}=1.0 \\
, 5 \mathrm{~m} \text { tree height }\end{array}$ & $\mathrm{V} 4=0.5 \mathrm{~m}$ & $\mathrm{SI}_{\mathrm{V} 4}=0.83$ & $\mathrm{~V} 4=5 \mathrm{~m}$ & $\mathrm{SI}_{\mathrm{V} 4}=0.71$ \\
\hline $\mathrm{V} 5=750 \mathrm{~m}$ & $\mathrm{SI}_{\mathrm{V} 5}=1.0$ & $\mathrm{~V} 5=5 \mathrm{~m}$ & $\mathrm{SI}_{\mathrm{V} 5}=0.71$ & $\mathrm{~V} 5=10 \mathrm{~km}$ & $\mathrm{SI}_{\mathrm{V} 5}=0.53$ \\
\hline V6 = $10 \mathrm{~km}$ & $\mathrm{SI}_{\mathrm{V} 6}=0.53$ & $\begin{array}{l}\mathrm{V} 6=750 \mathrm{~m} \\
\mathrm{~V} 7=750 \mathrm{~m}\end{array}$ & $\begin{array}{l}\mathrm{SI}_{\mathrm{V} 6}=0.50 \\
\mathrm{SI}_{\mathrm{V} 7}=1.0\end{array}$ & $\mathrm{~V} 6=0.75 \mathrm{~km}$ & $\mathrm{SI}_{\mathrm{V} 6}=0.50$ \\
\hline
\end{tabular}

GREAT BLUE HERON HSI (G)

FINAL INDEX COMPUTATION

GREAT EGRET HSI $(\mathrm{G})$

HSI (new L)

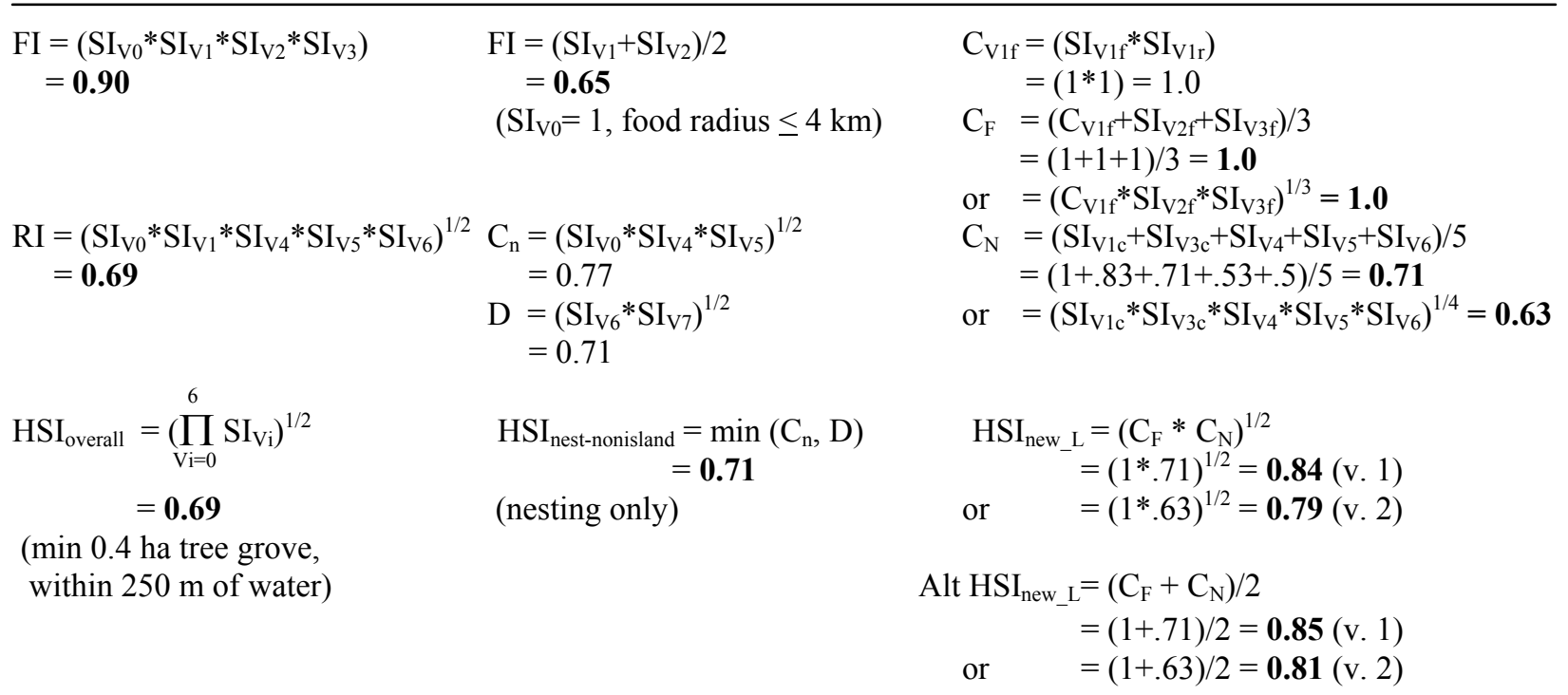


Table 20. Continued.

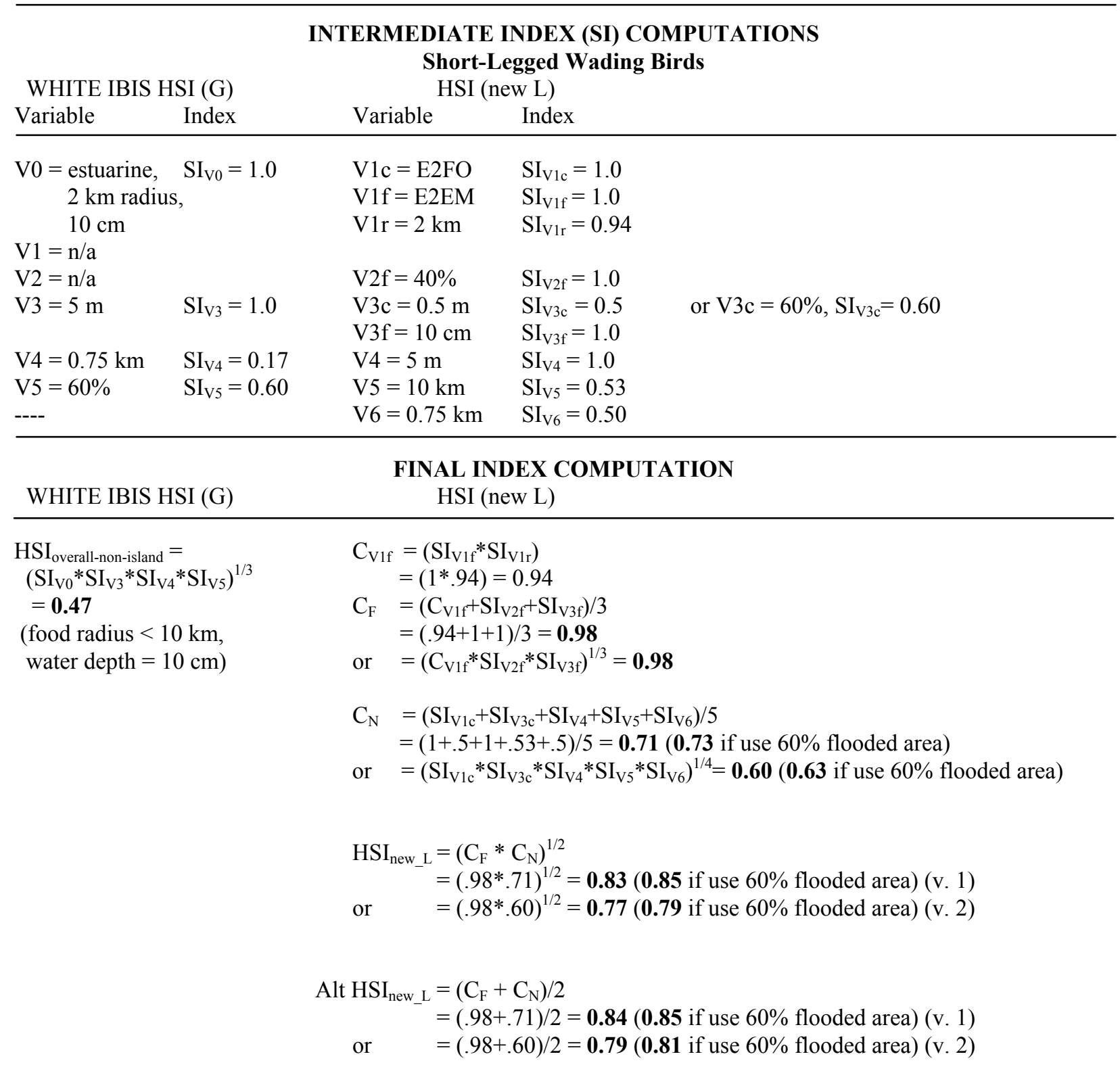


Table 21. Comparison of general habitat suitability index (HSI) models for wading birds with the proposed LCA study models, separated by short- and long-legged groups. Setting 2 (versions 1 (v. 1) and 2 (v. 2)). Wading birds include: great blue heron (Ardea herodias), great egret (Ardea alba), and white ibis (Eudocimus albus). General HSI models are denoted as HSI (G) and the proposed model as HSI (new L). Final index computations include component calculations.

Dataset parameters of setting 2:

$30 \%$ of feeding site with water depth of $10 \mathrm{~cm}$ and firm substrate; $60 \%$ of feeding site with water depth of $35 \mathrm{~cm}, 1-90 \%=10 \%$ land. $30 \%$ emergent vegetation in water depths of $10 \mathrm{~cm}$.

Feeding site is $7 \mathrm{~km}$ from colony, in estuarine intertidal emergent wetland (E2EM), and is $200 \mathrm{~m}$ from disturbances (roads, structures, and human).

Colony is in estuarine intertidal forested wetland (non-island) (E2FO).

Colony is on 25 ha of tree grove within $200 \mathrm{~m}$ of water; proximity of next colony is $1 \mathrm{~km}$.

Mean woody vegetation height of $10 \mathrm{~m}$; mean water depth in colony site is $0.5 \mathrm{~m}$ ( $80 \%$ flooded during nesting).

Distance from colony to road and human activity disturbance are both $1 \mathrm{~km}$.

\begin{tabular}{|c|c|c|c|c|c|c|}
\hline \multicolumn{7}{|c|}{$\begin{array}{l}\text { INTERMEDIATE INDEX (SI) COMPUTATIONS } \\
\text { Long-Legged Wading Birds }\end{array}$} \\
\hline \multicolumn{2}{|c|}{ GREAT BLUE HERON HSI (G) } & \multicolumn{2}{|c|}{ GREAT EGRET HSI $(\mathrm{G})$} & \multicolumn{3}{|c|}{ HSI (new L) } \\
\hline Variable & Index & Variable & Index & & Variable & Index \\
\hline $\mathrm{V} 0=$ estuarine & $\mathrm{SI}_{\mathrm{V} 0}=1.0$ & $\begin{aligned} \mathrm{V} 0= & \text { estuarine, } \\
& 7 \mathrm{~km} \text { radius }\end{aligned}$ & $\mathrm{SI}_{\mathrm{V} 0}=0.0$ & & $\begin{aligned} \mathrm{V} 1 \mathrm{c} & =\mathrm{E} 2 \mathrm{FO} \\
\mathrm{V} 1 \mathrm{f} & =\mathrm{E} 2 \mathrm{EM} \\
\mathrm{V} 1 \mathrm{r} & =7 \mathrm{~km}\end{aligned}$ & $\begin{array}{l}\mathrm{SI}_{\mathrm{Vlc}}=1.0 \\
\mathrm{SI}_{\mathrm{Vlf}}=1.0 \\
\mathrm{SI}_{\mathrm{Vlr}}=0.43\end{array}$ \\
\hline $\mathrm{V} 1=7 \mathrm{~km}$ & $\mathrm{SI}_{\mathrm{V} 1}=0.40$ & $\mathrm{~V} 1=30 \%$ & $\mathrm{SI}_{\mathrm{V} 1}=0.30$ & & & \\
\hline $\mathrm{V} 2=35 \mathrm{~cm}$ & $\mathrm{SI}_{\mathrm{V} 2}=1.0$ & $\mathrm{~V} 2=30 \%$ & $\mathrm{SI}_{\mathrm{V} 2}=0.75$ & & $V 2 f=10 \%$ & $\mathrm{SI}_{\mathrm{V} 2 \mathrm{f}}=0.25$ \\
\hline $\mathrm{V} 3=200 \mathrm{~m}$ & $\mathrm{SI}_{\mathrm{V} 3}=1.0$ & $\mathrm{~V} 3=\mathrm{n} / \mathrm{a}$ & & & $\begin{array}{l}\mathrm{V} 3 \mathrm{c}=0.5 \mathrm{~m} \\
\mathrm{~V} 3 \mathrm{f}=10 \mathrm{~cm}\end{array}$ & $\begin{array}{l}\mathrm{SI}_{\mathrm{V} 3 \mathrm{c}}=0.83 \\
\mathrm{SI}_{\mathrm{V} 3 \mathrm{f}}=1.0\end{array}$ \\
\hline $\begin{array}{l}\mathrm{V} 4=25 \text { ha, } \\
200 \mathrm{~m} \text { to water, }\end{array}$ & $\begin{array}{l}\mathrm{SI}_{\mathrm{V} 4}=1.0 \\
10 \mathrm{~m} \text { tree height }\end{array}$ & $\mathrm{V} 4=0.5 \mathrm{~m}$ & $\mathrm{SI}_{\mathrm{V} 4}=0.83$ & or & $\begin{array}{l}\mathrm{V} 3 \mathrm{f}=35 \mathrm{~cm} \\
\mathrm{~V} 4=10 \mathrm{~m}\end{array}$ & $\begin{array}{l}\mathrm{SI}_{\mathrm{V} 3 \mathrm{f}}=0.75 \\
\mathrm{SI}_{\mathrm{V} 4}=1.0\end{array}$ \\
\hline $\mathrm{V} 5=1 \mathrm{~km}$ & $\mathrm{SI}_{\mathrm{V} 5}=1.0$ & $\mathrm{~V} 5=10 \mathrm{~m}$ & $\mathrm{SI}_{\mathrm{V} 5}=1.0$ & & $\mathrm{~V} 5=1 \mathrm{~km}$ & $\mathrm{SI}_{\mathrm{V} 5}=1.0$ \\
\hline $\mathrm{V} 6=1 \mathrm{~km}$ & $\mathrm{SI}_{\mathrm{V} 6}=1.0$ & $\mathrm{~V} 6=1 \mathrm{~km}$ & $\mathrm{SI}_{\mathrm{V} 6}=1.0$ & & $\mathrm{~V} 6=1 \mathrm{~km}$ & $\mathrm{SI}_{\mathrm{V} 6}=1.0$ \\
\hline---- & & $\mathrm{V} 7=1 \mathrm{~km}$ & $\mathrm{SI}_{\mathrm{V} 7}=1.0$ & & ---- & \\
\hline
\end{tabular}

GREAT BLUE HERON HSI (G)

FINAL INDEX COMPUTATION

GREAT EGRET HSI $(\mathrm{G}) \quad$ HSI (new L)

\begin{tabular}{|c|c|c|}
\hline $\begin{aligned} \mathrm{FI} & =\left(\mathrm{SI}_{\mathrm{V} 0} * \mathrm{SI}_{\mathrm{V} 1} * \mathrm{SI}_{\mathrm{V} 2} * \mathrm{SI}_{\mathrm{V} 3}\right) \\
& =\mathbf{0 . 4 0}\end{aligned}$ & $\begin{array}{l}\mathrm{FI}=\left(\mathrm{SI}_{\mathrm{V} 1}+\mathrm{SI}_{\mathrm{V} 2}\right) / 2 \\
\quad=\mathbf{0 . 0} \\
\left(\mathrm{SI}_{\mathrm{V} 0}=0, \text { food radius } \leq 4 \mathrm{~km}\right) \\
\quad=\mathbf{0 . 5 2 5} \\
\text { (if radius up to } 35 \mathrm{~km})\end{array}$ & $\begin{aligned} \mathrm{C}_{\mathrm{V} 1 \mathrm{f}} & =\left(\mathrm{SI}_{\mathrm{V} 1 \mathrm{f}} * \mathrm{SI}_{\mathrm{V} 1 \mathrm{r}}\right) \\
& =(1 * .43)=0.43 \\
\mathrm{C}_{\mathrm{F}} & =\left(\mathrm{C}_{\mathrm{V} 1 \mathrm{f}}+\mathrm{SI}_{\mathrm{V} 2 \mathrm{f}}+\mathrm{SI}_{\mathrm{V} 3 \mathrm{f}}\right) / 3 \\
& =(.43+.25+1) / 3=\mathbf{0 . 5 6} \quad(10 \mathrm{~cm}) \\
& =(.43+.25+.75) / 3=\mathbf{0 . 4 8}(35 \mathrm{~cm}) \\
\text { or } & =\left(\mathrm{C}_{\mathrm{V} 1 \mathrm{f}}{ }^{*} \mathrm{SI}_{\mathrm{V} 2 \mathrm{f}} * \mathrm{SI}_{\mathrm{V} 3 \mathrm{f}}\right)^{1 / 3}=\mathbf{0 . 4 8}(10 \mathrm{~cm}) \\
& =\mathbf{0 . 4 3}(35 \mathrm{~cm})\end{aligned}$ \\
\hline $\begin{aligned} \mathrm{RI} & =\left(\mathrm{SI}_{\mathrm{V} 0} * \mathrm{SI}_{\mathrm{V} 1} * \mathrm{SI}_{\mathrm{V} 4} * \mathrm{SI}_{\mathrm{V} 5} * \mathrm{SI}_{\mathrm{V} 6}\right)^{1 / 2} \\
& =\mathbf{0 . 6 3}\end{aligned}$ & $\begin{aligned} \mathrm{C}_{\mathrm{n}} & =\left(\mathrm{SI}_{\mathrm{V} 0} * \mathrm{SI}_{\mathrm{V} 4} * \mathrm{SI}_{\mathrm{V} 5}\right)^{1 / 2} \\
& =0.0 \\
\mathrm{D} & =\left(\mathrm{SI}_{\mathrm{V} 6} * \mathrm{SI}_{\mathrm{V} 7}\right)^{1 / 2} \\
& =1.0\end{aligned}$ & $\begin{aligned} \mathrm{C}_{\mathrm{N}} & =\left(\mathrm{SI}_{\mathrm{V} 1 \mathrm{c}}+\mathrm{SI}_{\mathrm{V} 3 \mathrm{c}}+\mathrm{SI}_{\mathrm{V} 4}+\mathrm{SI}_{\mathrm{V} 5}+\mathrm{SI}_{\mathrm{V} 6}\right) / 5 \\
& =(1+.83+1+1+1) / 5=\mathbf{0 . 9 7} \\
\text { or } & =\left(\mathrm{SI}_{\mathrm{V} 1 \mathrm{c}} * \mathrm{SI}_{\mathrm{V} 3 \mathrm{c}} * \mathrm{SI}_{\mathrm{V} 4} * \mathrm{SI}_{\mathrm{V} 5} * \mathrm{SI}_{\mathrm{V} 6}\right)^{1 / 4}=\mathbf{0 . 9 5}\end{aligned}$ \\
\hline $\begin{aligned} \mathrm{HSI}_{\text {overall }} & =\left(\prod_{\mathrm{Vi}=0} \mathrm{SI}_{\mathrm{V}_{\mathrm{i}}}\right)^{1 / 2} \\
& =\mathbf{0 . 6 3}\end{aligned}$ & $\begin{array}{l}\mathrm{HSI}_{\text {nest-non-island }}=\min \left(\mathrm{C}_{\mathrm{n}}, \mathrm{D}\right) \\
\quad=\mathbf{0 . 0} \\
\text { (nesting only) }\end{array}$ & $\begin{aligned} \operatorname{HSI}_{\text {new_L }_{-}} & =\left(\mathrm{C}_{\mathrm{F}} * \mathrm{C}_{\mathrm{N}}\right)^{1 / 2} \\
& =\left(.56^{*} .97\right)^{1 / 2}=\mathbf{0 . 7 4}(10 \mathrm{~cm})(\mathrm{v} .1) \\
& =\left(.48^{*} .97\right)^{1 / 2}=\mathbf{0 . 6 8}(35 \mathrm{~cm})(\mathrm{v} .1) \\
& =\left(.48^{*} .95\right)^{1 / 2}=\mathbf{0 . 6 7}(10 \mathrm{~cm})(\mathrm{v} .2) \\
& =\left(.43^{*} .95\right)^{1 / 2}=\mathbf{0 . 6 4}(35 \mathrm{~cm})(\mathrm{v} .2)\end{aligned}$ \\
\hline
\end{tabular}


Table 21. Continued

$$
\begin{aligned}
\text { Alt HSI }_{\text {new_L }} & =\left(\mathrm{C}_{\mathrm{F}}+\mathrm{C}_{\mathrm{N}}\right) / 2 \\
& =(.56+.97) / 2=\mathbf{0 . 7 6}(10 \mathrm{~cm})(\mathrm{v} .1) \\
& =(.48+.97) / 2=\mathbf{0 . 7 2}(35 \mathrm{~cm})(\mathrm{v} .1) \\
& =(.48+.95) / 2=\mathbf{0 . 7 1}(10 \mathrm{~cm})(\mathrm{v} .2) \\
& =(.43+.95) / 2=\mathbf{0 . 6 9}(35 \mathrm{~cm})(\mathrm{v} .2)
\end{aligned}
$$

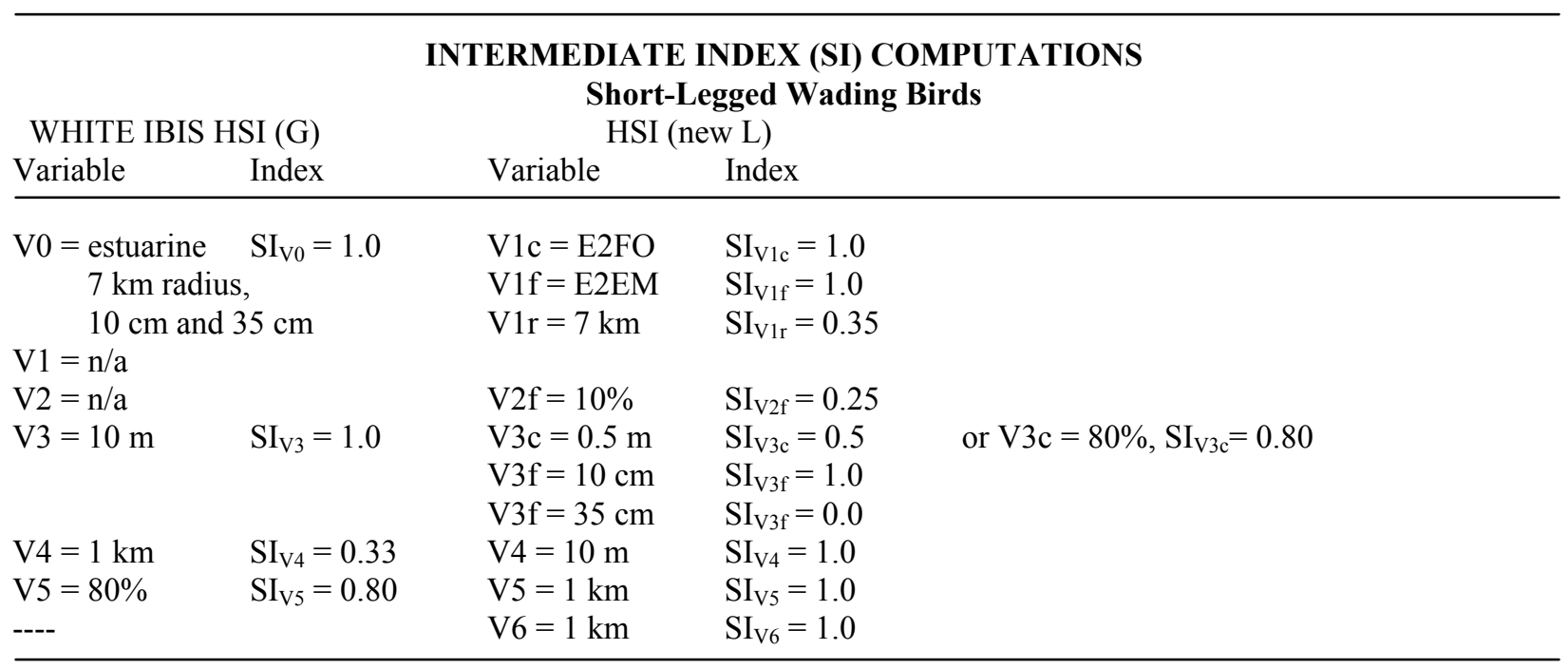

\section{WHITE IBIS HSI (G)}

$$
\begin{aligned}
& \mathrm{HSI}_{\text {overall-non-island }}= \\
& \left(\mathrm{SI}_{\mathrm{V} 0} * \mathrm{SI}_{\mathrm{V} 3} * \mathrm{SI}_{\mathrm{V} 4} * \mathrm{SI}_{\mathrm{V} 5}\right)^{1 / 3} \\
& =\mathbf{0 . 6 4} \\
& (\text { food radius }<10 \mathrm{~km}, \\
& \text { water depth }=10 \mathrm{~cm}) \\
& =\mathbf{0 . 0} \\
& (\text { water depth }=35 \mathrm{~cm})
\end{aligned}
$$

\section{FINAL INDEX COMPUTATION} HSI (new L)

$$
\begin{aligned}
& \mathrm{C}_{\mathrm{V} 1 \mathrm{f}}=\left(\mathrm{SI}_{\mathrm{V} 1 \mathrm{f}} * \mathrm{SI}_{\mathrm{V} 1 \mathrm{r}}\right) \\
& =(1 * .35)=0.35 \\
& \mathrm{C}_{\mathrm{F}}=\left(\mathrm{C}_{\mathrm{V} 1 \mathrm{f}}+\mathrm{SI}_{\mathrm{V} 2 \mathrm{f}}+\mathrm{SI}_{\mathrm{V} 3 \mathrm{f}}\right) / 3 \\
& =(.35+.25+1) / 3=\mathbf{0 . 5 3}(10 \mathrm{~cm}) \\
& =(.35+.25+0) / 3=\mathbf{0 . 2 0}(35 \mathrm{~cm}) \\
& \text { or }=\left(\mathrm{C}_{\mathrm{V} 1 \mathrm{f}} * \mathrm{SI}_{\mathrm{V} 2 \mathrm{f}} * \mathrm{SI}_{\mathrm{V} 3 \mathrm{f}}\right)^{1 / 3}=\mathbf{0 . 4 4}(10 \mathrm{~cm}) \\
& =\mathbf{0 . 0}(35 \mathrm{~cm}) \\
& \mathrm{C}_{\mathrm{N}}=\left(\mathrm{SI}_{\mathrm{V} 1 \mathrm{c}}+\mathrm{SI}_{\mathrm{V} 3 \mathrm{c}}+\mathrm{SI}_{\mathrm{V} 4}+\mathrm{SI}_{\mathrm{V} 5}+\mathrm{SI}_{\mathrm{V} 6}\right) / 5 \\
& =(1+.5+1+1+1) / 5=\mathbf{0 . 9 0}(\mathbf{0 . 9 6} \text { if use } 80 \% \text { flooded area }) \\
& \text { or }=\left(\mathrm{SI}_{\mathrm{V} 1 \mathrm{c}} * \mathrm{SI}_{\mathrm{V} 3 \mathrm{c}} * \mathrm{SI}_{\mathrm{V} 4} * \mathrm{SI}_{\mathrm{V} 5} * \mathrm{SI}_{\mathrm{V} 6}\right)^{1 / 4}=\mathbf{0 . 8 4}(\mathbf{0 . 9 5} \text { if use } 80 \% \text { flooded area) } \\
& \mathrm{HSI}_{\text {new_L }}=\left(\mathrm{C}_{\mathrm{F}} * \mathrm{C}_{\mathrm{N}}\right)^{1 / 2} \\
& =(.53 * .90)^{1 / 2}=\mathbf{0 . 6 9}(10 \mathrm{~cm})(\mathbf{0 . 7 1} \text { if use } 80 \% \text { flooded area })(\mathrm{v} .1) \\
& =(.20 * .90)^{1 / 2}=\mathbf{0 . 4 2}(35 \mathrm{~cm})(\mathbf{0 . 4 4} \text { if use } 80 \% \text { flooded area })(\mathrm{v} .1) \\
& \text { or } \quad=(.44 * .84)^{1 / 2}=\mathbf{0 . 6 1}(10 \mathrm{~cm})(\mathbf{0 . 6 5} \text { if use } 80 \% \text { flooded area })(\mathrm{v} .2) \\
& =\left(0^{*} .84\right)^{1 / 2}=\mathbf{0 . 0}(35 \mathrm{~cm})(\mathbf{0 . 0} \text { if use } 80 \% \text { flooded area })(\mathrm{v} .2) \\
& \text { Alt } \mathrm{HSI}_{\text {new L }}=\left(\mathrm{C}_{\mathrm{F}}+\mathrm{C}_{\mathrm{N}}\right) / 2 \\
& =(.53+.90) / 2=\mathbf{0 . 7 2}(10 \mathrm{~cm})(\mathbf{0 . 7 4} \text { if use } 80 \% \text { flooded area })(\mathrm{v} .1) \\
& =(.20+.90) / 2=\mathbf{0 . 5 5}(35 \mathrm{~cm})(\mathbf{0 . 5 8} \text { if use } 80 \% \text { flooded area })(\mathrm{v} .1) \\
& \text { or } \quad=(.44+.84) / 2=\mathbf{0 . 6 4}(10 \mathrm{~cm})(\mathbf{0 . 7 0} \text { if use } 80 \% \text { flooded area })(\mathrm{v} .2) \\
& =(0+.84) / 2=\mathbf{0 . 4 2}(35 \mathrm{~cm})(\mathbf{0 . 4 7} \text { if use } 80 \% \text { flooded area })(\mathrm{v} .2)
\end{aligned}
$$


Table 22. Comparison of general habitat suitability index (HSI) models for wading birds with the proposed LCA study models, separated by short- and long-legged groups. Setting 3 (versions 1 (v. 1) and 2 (v. 2)). Wading birds include great blue heron (Ardea herodias), great egret (Ardea alba), and white ibis (Eudocimus albus). General HSI models are denoted as HSI (G) and the proposed model as HSI (new L). Final index computations include component calculations.

Dataset parameters in setting 3:

$30 \%$ of feeding site with water depth of $10 \mathrm{~cm}$ and firm substrate; $60 \%$ of feeding site with water depth of $35 \mathrm{~cm}, 1-90 \%=10 \%$ land. $30 \%$ emergent vegetation in water depths of $10 \mathrm{~cm}$.

Feeding site is $7 \mathrm{~km}$ from colony, in estuarine intertidal emergent wetland (E2EM), and is $200 \mathrm{~m}$ from disturbances (roads, structures, and human). Colony is in estuarine intertidal forested wetland (non-island) (E2FO).

Colony is on 25 ha of tree grove within $200 \mathrm{~m}$ of water; proximity of next colony is $10 \mathrm{~km}$.

Mean woody vegetation height of $10 \mathrm{~m}$; mean water depth in colony site is $0.5 \mathrm{~m}$ ( $80 \%$ flooded during nesting).

Distance from colony to road is $200 \mathrm{~m}$; human activity disturbance is $1 \mathrm{~km}$.

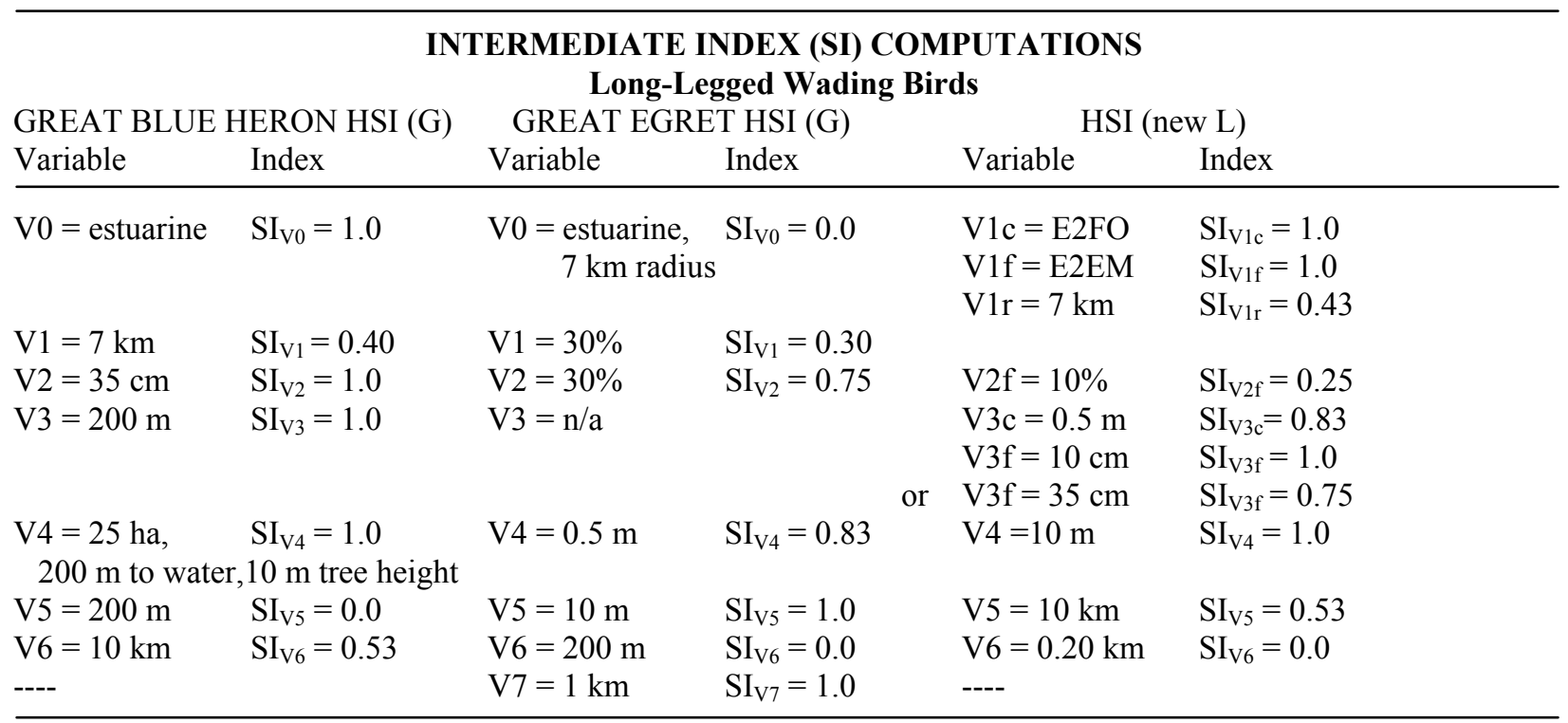

GREAT BLUE HERON HSI (G)

\section{FINAL INDEX COMPUTATION}

GREAT EGRET HSI (G)

HSI (new L)

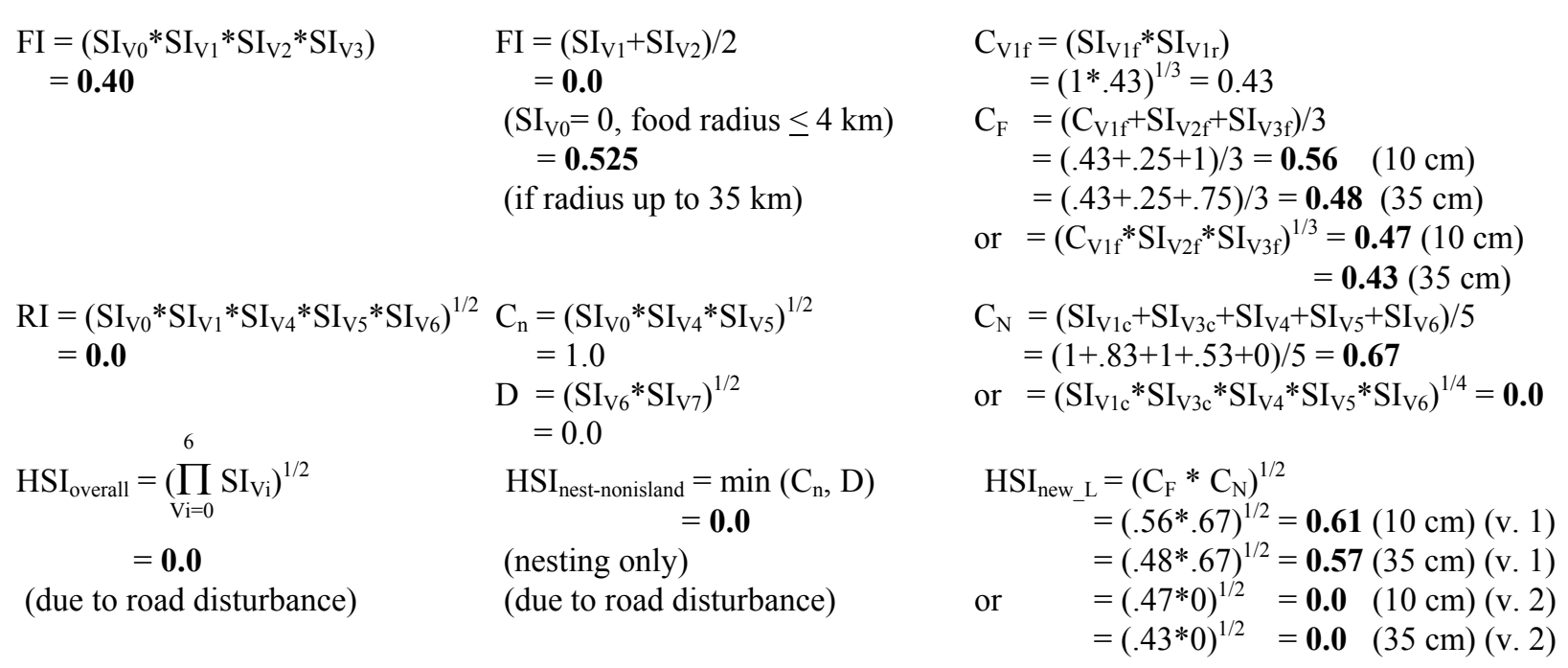


Table 22. Continued

$$
\begin{aligned}
\text { Alt HSI }_{\text {new_L }} & =\left(\mathrm{C}_{\mathrm{F}}+\mathrm{C}_{\mathrm{N}}\right) / 2 \\
& =(.56+.67) / 2=\mathbf{0 . 6 1}(10 \mathrm{~cm})(\mathrm{v} .1) \\
& =(.48+.67) / 2=\mathbf{0 . 5 7}(35 \mathrm{~cm})(\mathrm{v} .1) \\
& =(.47+0) / 2=\mathbf{0 . 2 3}(10 \mathrm{~cm})(\mathrm{v} .2) \\
& =(.43+0) / 2=\mathbf{0 . 2 1}(35 \mathrm{~cm})(\mathrm{v} .2)
\end{aligned}
$$

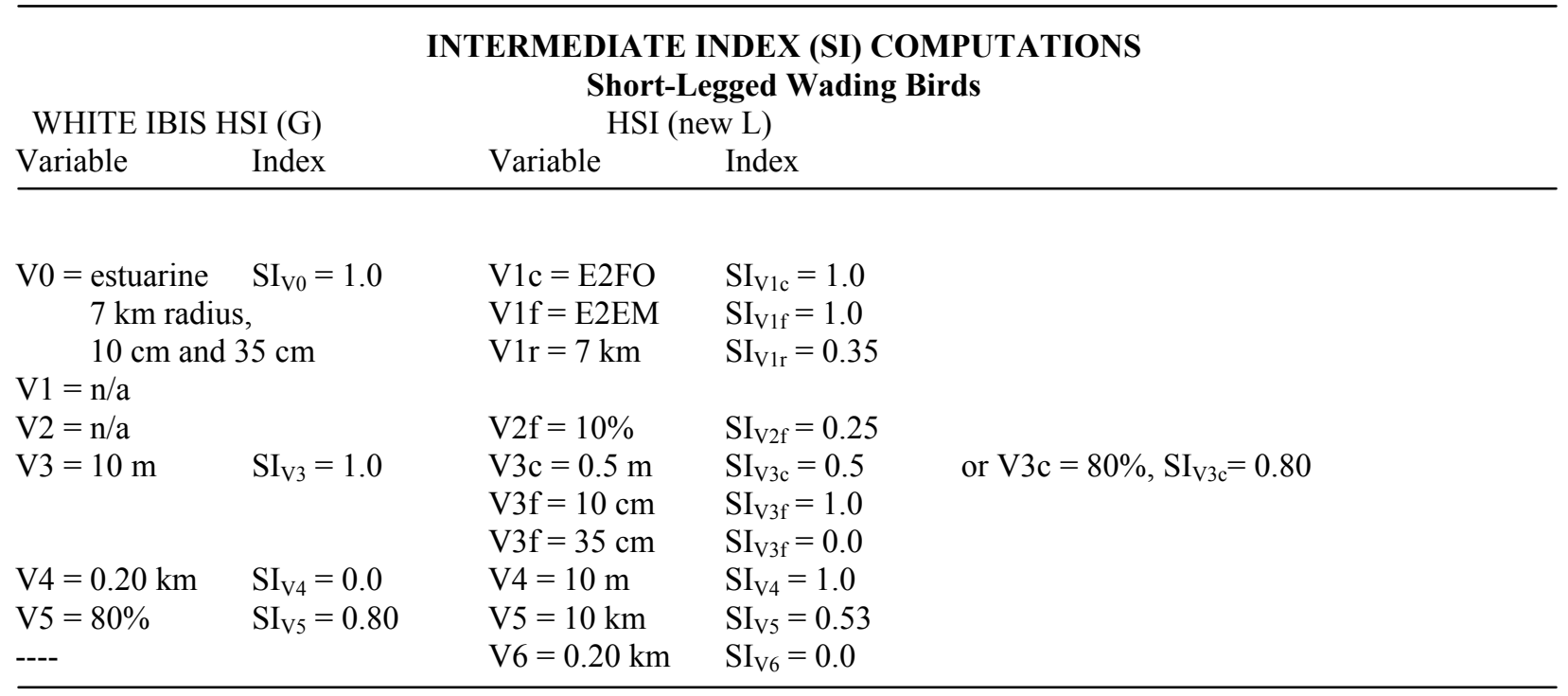

WHITE IBIS HSI (G)

$$
\begin{aligned}
& \mathrm{HSI}_{\text {overall-non-island }}= \\
& \left(\mathrm{SI}_{\mathrm{V} 0} * \mathrm{SI}_{\mathrm{V} 3} * \mathrm{SI}_{\mathrm{V} 4} * \mathrm{SI}_{\mathrm{V} 5}\right)^{1 / 3} \\
& =\mathbf{0 . 0} \\
& (\text { food radius }<10 \mathrm{~km}, \\
& (\text { water depth }=10 \mathrm{~cm}) \\
& \quad=\mathbf{0 . 0} \\
& (\text { water depth }=35 \mathrm{~cm})
\end{aligned}
$$

\section{FINAL INDEX COMPUTATION} HSI (new L)

$$
\begin{aligned}
& \mathrm{C}_{\mathrm{V} 1 \mathrm{f}}=\left(\mathrm{SI}_{\mathrm{V} 1 \mathrm{f}} * \mathrm{SI}_{\mathrm{V} 1 \mathrm{r}}\right) \\
& =(1 * .35)=0.35 \\
& \mathrm{C}_{\mathrm{F}}=\left(\mathrm{C}_{\mathrm{V} 1 \mathrm{f}}+\mathrm{SI}_{\mathrm{V} 2 \mathrm{f}}+\mathrm{SI}_{\mathrm{V} 3 \mathrm{f}}\right) / 3 \\
& =(.35+.25+1) / 3=\mathbf{0 . 5 3}(10 \mathrm{~cm}) \\
& =(.35+.25+0) / 3=\mathbf{0 . 2 0}(35 \mathrm{~cm}) \\
& \text { or }=\left(\mathrm{C}_{\mathrm{V} 1 \mathrm{f}} * \mathrm{SI}_{\mathrm{V} 2 \mathrm{f}} * \mathrm{SI}_{\mathrm{V} 3 \mathrm{f}}\right)^{1 / 3}=\mathbf{0 . 4 4}(10 \mathrm{~cm}) \\
& =\mathbf{0 . 0}(35 \mathrm{~cm}) \\
& \mathrm{C}_{\mathrm{N}}=\left(\mathrm{SI}_{\mathrm{V} 1 \mathrm{c}}+\mathrm{SI}_{\mathrm{V} 3 \mathrm{c}}+\mathrm{SI}_{\mathrm{V} 4}+\mathrm{SI}_{\mathrm{V} 5}+\mathrm{SI}_{\mathrm{V} 6}\right) / 5 \\
& =(1+.5+1+.53+0) / 5=\mathbf{0 . 6 1}(\mathbf{0 . 6 7} \text { if use } 80 \% \text { flooded area }) \\
& \text { or }=\left(\mathrm{SI}_{\mathrm{V} 1 \mathrm{c}} * \mathrm{SI}_{\mathrm{V} 3 \mathrm{c}} * \mathrm{SI}_{\mathrm{V} 4} * \mathrm{SI}_{\mathrm{V} 5} * \mathrm{SI}_{\mathrm{V} 6}\right)^{1 / 4}=\mathbf{0 . 0}(\mathbf{0 . 0} \text { if use } 80 \% \text { flooded area }) \\
& \mathrm{HSI}_{\text {new L }}=\left(\mathrm{C}_{\mathrm{F}} * \mathrm{C}_{\mathrm{N}}\right)^{1 / 2} \\
& =\left(.53^{*} .61\right)^{1 / 2}=\mathbf{0 . 5 7}(10 \mathrm{~cm})(\mathbf{0 . 5 9} \text { if use } 80 \% \text { flooded area })(\mathrm{v} .1) \\
& =(.20 * .61)^{1 / 2}=\mathbf{0 . 3 5}(35 \mathrm{~cm})(\mathbf{0 . 3 7} \text { if use } 80 \% \text { flooded area })(\mathrm{v} .1) \\
& \text { or } \quad=(.44 * 0)^{1 / 2}=\mathbf{0 . 0}(10 \mathrm{~cm})(\mathbf{0 . 0} \text { if use } 80 \% \text { flooded area })(\mathrm{v} .2) \\
& =(0 * 0)^{1 / 2}=\mathbf{0 . 0}(35 \mathrm{~cm})(\mathbf{0 . 0} \text { if use } 80 \% \text { flooded area })(\mathrm{v} .2)
\end{aligned}
$$$$
\begin{aligned}
\text { Alt HSI }_{\text {new } \_\mathrm{L}} & =\left(\mathrm{C}_{\mathrm{F}}+\mathrm{C}_{\mathrm{N}}\right) / 2 \\
& =(.53+.61) / 2=\mathbf{0 . 5 7}(10 \mathrm{~cm})(\mathbf{0 . 6 0} \text { if use } 80 \% \text { flooded area })(\mathrm{v} .1) \\
& =(.20+.61) / 2=\mathbf{0 . 4 0}(35 \mathrm{~cm})(\mathbf{0 . 4 3} \text { if use } 80 \% \text { flooded area })(\mathrm{v} .1) \\
& =(.44+0) / 2=\mathbf{0 . 2 2}(10 \mathrm{~cm})(\mathbf{0 . 2 2} \text { if use } 80 \% \text { flooded area })(\mathrm{v} .2) \\
& =(0+0) / 2=\mathbf{0 . 0}(35 \mathrm{~cm})(\mathbf{0 . 0} \text { if use } 80 \% \text { flooded area })(\mathrm{v} .2)
\end{aligned}
$$ 
Tables $23-25$ present the comparisons of general HSI models with the proposed LCA study model that uses the third version of formulae which incorporates habitat as a separate component in the final index. The arithmetic means are again used for the intermediate foraging and nesting components, as in version 1 . In the typical setting shown in table 23, the final geometric-mean index value is 5 percent lower than that of version 1 at 0.80 , and the final arithmetic-mean index value is 4 percent higher at 0.88 for long-legged birds. The nesting component is 10 percent lower for short-legged birds, decreasing the final geometric-mean index value by 5 percent to 0.79 but increasing the final arithmetic-mean index by 4 percent to 0.87 . Thus, the inclusion of a separate habitat component $\left(\mathrm{C}_{\mathrm{v} 1}\right)$ lowers the final geometric-mean index value but raises the final arithmetic-mean index value. Regardless, the typical setting is still very highly rated in the proposed LCA study model.

The deeper foraging waters but better nesting conditions shown in the second setting (table 24) produce almost identical results as those of version 1 for both long-and short-legged birds in the foraging and nesting components as well as in the final geometric-mean index. Again, the final arithmetic-mean index is higher, at about 10 percent for the long-legged birds and 10-25 percent for short-legged birds. The second setting is still rated as moderately high for long-legged birds but appropriately demonstrates a low suitability below 0.50 for short-legged birds in deep water foraging areas.

In the third setting (table 25), the use of the arithmetic mean in the nesting component does not erase suitability of the entire component when there is a road disturbance, so that a low value of 0.50 to 0.60 is still generated in version 3 . Without the nesting habitat factor in the equation of version 3, the nesting component is rationally lower by 12 percent (long-legged) and 16 percent (short-legged) than it is in version 1. A moderate nonzero value for the final index is still retained for both bird groups; however, the reorganization of components in the final index formula does create index values that are at least 5-10 percent lower than in version 1 . The final index values are around 0.55 for both water depths in long-legged birds, and the index value drops very low to 0.30 in deep foraging waters for the short-legged birds. Thus, the index still appears to be largely controlled by the foraging water depths and does not completely rule out the nesting site based on disturbance factors. In this case, a geometric mean formula (see below) for the nesting component may be more perceptive or intuitive.

The third model version may be further revised to incorporate geometric mean computations for both foraging and nesting components instead of arithmetic means and is referred to as version 4 . As expected, there are decreases in the values of components and indices in version 4 compared to version 3 throughout almost all settings. For short-legged birds, there is a 5 percent decrease in suitability values for the nesting component of the first setting, generating a 3 percent drop in the final index values. There are no changes, however, in component or index values for the long-legged birds. In the second setting for long-legged birds, the foraging component $\left(\mathrm{C}_{\mathrm{F}}\right)$ using the geometric mean of version 4 is 10-15 percent lower than $\left(\mathrm{C}_{\mathrm{F}}\right)$ using the arithmetic mean in version 3 , but the nesting component $\left(\mathrm{C}_{\mathrm{N}}\right)$ remains the same (0.95), so that the final index value declines only by 7 percent in version 4 . The foraging 
component $\left(\mathrm{C}_{\mathrm{F}}\right)$ of version 4 is 17 percent lower in shallow waters and goes to zero in deep waters for short-legged birds. The nesting component value also decreases by 4 percent. Thus, the final index value of version 4 for the short-legged birds is reduced by 10 percent for water depths of $10 \mathrm{~cm}$; however, it subsequently produces a zero value for $35 \mathrm{~cm}$ because of the foraging component. The road disturbance of the third setting forces the value to zero in the nesting component (geometric mean) for both bird groups, resulting in a zero value for the entire final index (geometric mean) in version 4. For short-legged birds, this is also coupled with the zero value of the foraging component in deep waters.

In conclusion, it appears that the third or fourth model version with three components combined as a geometric mean in the final index formula may be the better choice, where the habitat type characterization plays a more important role. In other words, the habitat (V1c and/or V1f) must be acceptable initially before any other factor considerations. Although none of the hypothetical settings were designed for unsuitable habitat choices in (V1c) or (V1f), the final index value is expected to decrease more dramatically or reach zero when the habitat is unfavorable. Furthermore, throughout all model versions, the option of the arithmetic or geometric mean formula in the foraging and nesting components depends on personal preference, reflecting the desire for retention of any nonzero value in the event of unfavorable conditions or for an instantaneous elimination of potential sites. 
Table 23. Comparison of general habitat suitability index (HSI) models for wading birds with the proposed LCA study models, separated by short- and long-legged groups. Setting 1 (versions 3 (v. 3) and 4 (v. 4)). Wading birds include: great blue heron (Ardea herodias), great egret (Ardea alba), and white ibis (Eudocimus albus). General HSI models are denoted as HSI (G) and the proposed model as HSI (new L). Final index computations include component calculations.

Dataset parameters of setting 1 :

$60 \%$ of feeding site with water depth of $10 \mathrm{~cm}$ and firm substrate ( $40 \%$ land), $75 \%$ emergent vegetation in water depths of $10 \mathrm{~cm}$

Feeding site is $2 \mathrm{~km}$ from colony, in estuarine intertidal emergent wetland (E2EM), and is $500 \mathrm{~m}$ from disturbances (roads, structures, and human)

Colony is in estuarine intertidal forested wetland (nonisland) (E2FO)

Colony is on 25 ha of tree grove within $150 \mathrm{~m}$ of water, proximity of next colony is $10 \mathrm{~km}$

Mean woody vegetation height of $5 \mathrm{~m}$, mean water depth in colony site is $0.5 \mathrm{~m}$ ( $60 \%$ flooded during nesting)

Distance from colony to road/structure and human activity disturbances are both $750 \mathrm{~m}$

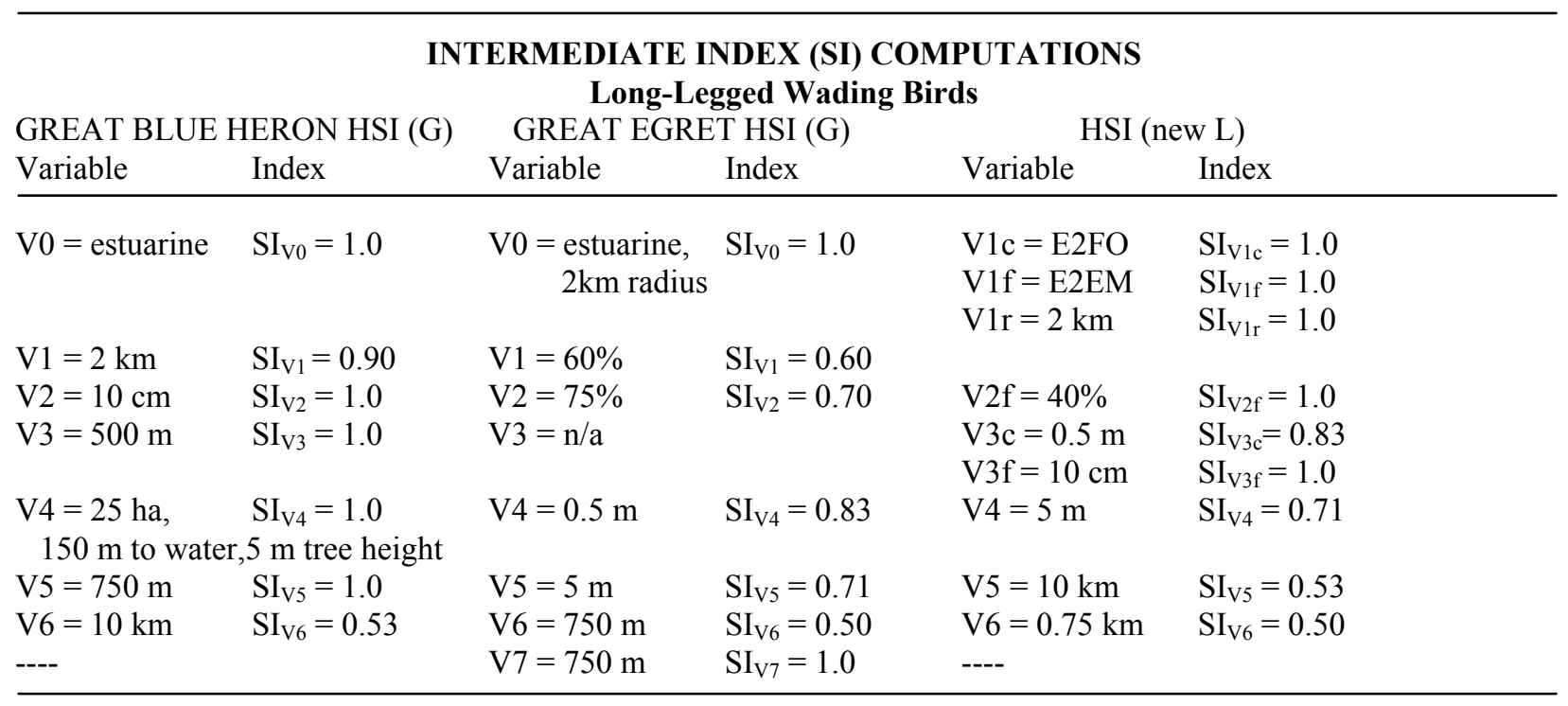

GREAT BLUE HERON HSI (G)

FINAL INDEX COMPUTATION

GREAT EGRET HSI (G)

HSI (new L)

\begin{tabular}{|c|c|c|}
\hline $\begin{aligned} \mathrm{FI} & =\left(\mathrm{SI}_{\mathrm{V} 0} * \mathrm{SI}_{\mathrm{V} 1} * \mathrm{SI}_{\mathrm{V} 2} * \mathrm{SI}_{\mathrm{V} 3}\right) \\
& =\mathbf{0 . 9 0}\end{aligned}$ & $\begin{array}{l}\mathrm{FI}=\left(\mathrm{SI}_{\mathrm{V} 1}+\mathrm{SI}_{\mathrm{V} 2}\right) / 2 \\
\quad=\mathbf{0 . 6 5} \\
\left(\mathrm{SI}_{\mathrm{V} 0}=1, \text { food radius } \leq 4 \mathrm{~km}\right)\end{array}$ & $\begin{aligned} \mathrm{C}_{\mathrm{V} 1} & =\left(\mathrm{SI}_{\mathrm{V} 1 \mathrm{c}} * \mathrm{SI}_{\mathrm{V} 1 \mathrm{f}}\right) \\
& =(1 * 1)=\mathbf{1 . 0} \\
\mathrm{C}_{\mathrm{F}} & =\left(\mathrm{SI}_{\mathrm{V} 1 \mathrm{r}}+\mathrm{SI}_{\mathrm{V} 2 \mathrm{f}}+\mathrm{SI}_{\mathrm{V} 3 \mathrm{f}}\right) / 3 \\
& =(1+1+1) / 3=\mathbf{1 . 0} \\
\text { or } & =\left(\mathrm{SI}_{\mathrm{V} 1 \mathrm{r}} * \mathrm{SI}_{\mathrm{V} 2 \mathrm{f}} * \mathrm{SI}_{\mathrm{V} 3 \mathrm{f}}\right)^{1 / 3}=\mathbf{1 . 0}\end{aligned}$ \\
\hline $\begin{aligned} \mathrm{RI} & =\left(\mathrm{SI}_{\mathrm{V} 0} * \mathrm{SI}_{\mathrm{V} 1} * \mathrm{SI}_{\mathrm{V} 4} * \mathrm{SI}_{\mathrm{V} 5} * \mathrm{SI}_{\mathrm{V} 6}\right)^{1 / 2} \\
& =\mathbf{0 . 6 9}\end{aligned}$ & $\begin{aligned} \mathrm{C}_{\mathrm{n}} & =\left(\mathrm{SI}_{\mathrm{V} 0} * \mathrm{SI}_{\mathrm{V} 4} * \mathrm{SI}_{\mathrm{V} 5}\right)^{1 / 2} \\
& =0.77 \\
\mathrm{D} & =\left(\mathrm{SI}_{\mathrm{V} 6} * \mathrm{SI}_{\mathrm{V} 7}\right)^{1 / 2} \\
& =0.71\end{aligned}$ & $\begin{aligned} \mathrm{C}_{\mathrm{N}} & =\left(\mathrm{SI}_{\mathrm{V} 3 \mathrm{c}}+\mathrm{SI}_{\mathrm{V} 4}+\mathrm{SI}_{\mathrm{V} 5}+\mathrm{SI}_{\mathrm{V} 6}\right) / 4 \\
& =(.83+.71+.53+.50) / 4=\mathbf{0 . 6 4} \\
\text { or } & =\left(\mathrm{SI}_{\mathrm{V} 3 \mathrm{c}} * \mathrm{SI}_{\mathrm{V} 4} * \mathrm{SI}_{\mathrm{V} 5} * \mathrm{SI}_{\mathrm{V} 6}\right)^{1 / 4}=\mathbf{0 . 6 3}\end{aligned}$ \\
\hline $\begin{aligned} \mathrm{HSI}_{\text {overall }} & =\left(\prod_{\mathrm{Vi}=0} \mathrm{SI}_{\mathrm{Vi}}\right)^{1 / 2} \\
& =\mathbf{0 . 6 9}\end{aligned}$ & $\begin{array}{l}\mathrm{HSI}_{\text {nest-nonisland }}=\min \left(\mathrm{C}_{\mathrm{n}}, \mathrm{D}\right) \\
\quad=\mathbf{0 . 7 1} \\
\text { (nesting only) }\end{array}$ & $\begin{aligned} \mathrm{HSI}_{\text {new }_{-} \mathrm{L}} & =\left(\mathrm{C}_{\mathrm{V} 1} * \mathrm{C}_{\mathrm{F}} * \mathrm{C}_{\mathrm{N}}\right)^{1 / 2} \\
& =(1 * 1 * .64)^{1 / 2}=\mathbf{0 . 8 0}(\mathrm{v} .3) \\
\text { or } \quad & =(1 * 1 * .63)^{1 / 2}=\mathbf{0 . 7 9}(\mathrm{v} .4)\end{aligned}$ \\
\hline $\begin{array}{l}\text { (min } 0.4 \text { ha tree grove, } \\
\text { within } 250 \text { m of water) }\end{array}$ & & $\begin{aligned} \text { Alt HSI }_{\text {new }_{-} \mathrm{L}} & =\left(\mathrm{C}_{\mathrm{V} 1}+\mathrm{C}_{\mathrm{F}}+\mathrm{C}_{\mathrm{N}}\right) / 3 \\
& =(1+1+.64) / 3=\mathbf{0 . 8 8}(\mathrm{v} .3) \\
\text { or } & =(1+1+.63) / 3=\mathbf{0 . 8 8}(\mathrm{v} .4)\end{aligned}$ \\
\hline
\end{tabular}


Table 23. Continued.

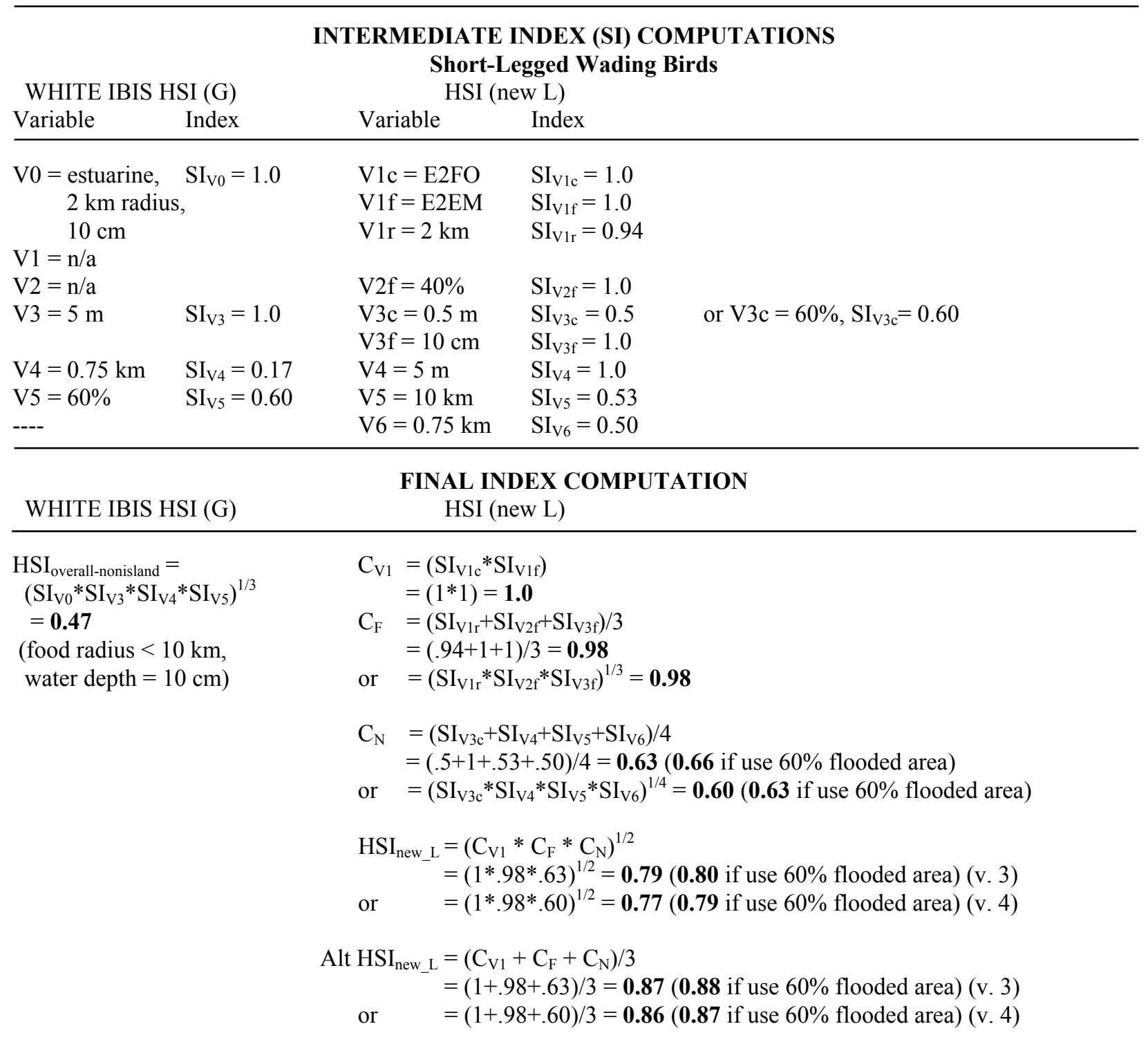


Table 24. Comparison of general habitat suitability index (HSI) models for wading birds with the proposed LCA study models, separated by short- and long-legged groups. Setting 2 (versions 3 (v. 3) and 4 (v. 4)). Wading birds include: great blue heron (Ardea herodias), great egret (Ardea alba), and white ibis (Eudocimus albus). General HSI models are denoted as HSI (G) and the proposed model as HSI (new L). Final index computations include component calculations.

Dataset parameters of setting 2 :

$30 \%$ of feeding site with water depth of $10 \mathrm{~cm}$ and firm substrate, $60 \%$ of feeding site with water depth of $35 \mathrm{~cm}, 1-90 \%=10 \%$ land $30 \%$ emergent vegetation in water depths of $10 \mathrm{~cm}$

Feeding site is $7 \mathrm{~km}$ from colony, in estuarine intertidal emergent wetland (E2EM), and is $200 \mathrm{~m}$ from disturbances (roads, structures, and human) Colony is in estuarine intertidal forested wetland (non-island) (E2FO)

Colony is on 25 ha of tree grove within $200 \mathrm{~m}$ of water, proximity of next colony is $1 \mathrm{~km}$

Mean woody vegetation height of $10 \mathrm{~m}$, mean water depth in colony site is $0.5 \mathrm{~m}$ ( $80 \%$ flooded during nesting)

Distance from colony to road and human activity disturbance are both $1 \mathrm{~km}$

\begin{tabular}{|c|c|c|c|c|c|c|}
\hline \multicolumn{7}{|c|}{$\begin{array}{l}\text { INTERMEDIATE INDEX (SI) COMPUTATIONS } \\
\text { Long-Legged Wading Birds }\end{array}$} \\
\hline \multicolumn{2}{|c|}{ GREAT BLUE HERON HSI (G) } & \multicolumn{2}{|c|}{ GREAT EGRET HSI (G) } & \multicolumn{3}{|c|}{ HSI (new L) } \\
\hline Variable & Index & Variable & Index & & Variable & Index \\
\hline $\mathrm{V} 0=$ estuarine & $\mathrm{SI}_{\mathrm{V} 0}=1.0$ & $\begin{aligned} \mathrm{V} 0= & \text { estuarine, } \\
& 7 \mathrm{~km} \text { radius }\end{aligned}$ & $\mathrm{SI}_{\mathrm{V} 0}=0.0$ & & $\begin{aligned} \mathrm{V} 1 \mathrm{c} & =\mathrm{E} 2 \mathrm{FO} \\
\mathrm{V} 1 \mathrm{f} & =\mathrm{E} 2 \mathrm{EM} \\
\mathrm{V} 1 \mathrm{r} & =7 \mathrm{~km}\end{aligned}$ & $\begin{array}{l}\mathrm{SI}_{\mathrm{V} 1 \mathrm{c}}=1.0 \\
\mathrm{SI}_{\mathrm{V} 1 \mathrm{f}}=1.0 \\
\mathrm{SI}_{\mathrm{V} 1 \mathrm{r}}=0.43\end{array}$ \\
\hline $\mathrm{V} 1=7 \mathrm{~km}$ & $\mathrm{SI}_{\mathrm{V} 1}=0.40$ & $\mathrm{~V} 1=30 \%$ & $\mathrm{SI}_{\mathrm{V} 1}=0.30$ & & & \\
\hline $\mathrm{V} 2=35 \mathrm{~cm}$ & $\mathrm{SI}_{\mathrm{V} 2}=1.0$ & $\mathrm{~V} 2=30 \%$ & $\mathrm{SI}_{\mathrm{V} 2}=0.75$ & & $\mathrm{~V} 2 \mathrm{f}=10 \%$ & $\mathrm{SI}_{\mathrm{V} 2 \mathrm{f}}=0.25$ \\
\hline $\mathrm{V} 3=200 \mathrm{~m}$ & $\mathrm{SI}_{\mathrm{V} 3}=1.0$ & $\mathrm{~V} 3=\mathrm{n} / \mathrm{a}$ & & or & $\begin{array}{l}\mathrm{V} 3 \mathrm{c}=0.5 \mathrm{~m} \\
\mathrm{~V} 3 \mathrm{f}=10 \mathrm{~cm} \\
\mathrm{~V} 3 \mathrm{f}=35 \mathrm{~cm}\end{array}$ & $\begin{array}{l}\mathrm{SI}_{\mathrm{V} 3 \mathrm{c}}=0.83 \\
\mathrm{SI}_{\mathrm{V} 3 \mathrm{f}}=1.0 \\
\mathrm{SI}_{\mathrm{V} 3 \mathrm{f}}=0.75\end{array}$ \\
\hline $\begin{array}{l}\mathrm{V} 4=25 \text { ha, } \\
200 \text { m to wate }\end{array}$ & $\begin{array}{l}\mathrm{SI}_{\mathrm{V} 4}=1.0 \\
, 10 \mathrm{~m} \text { tree height }\end{array}$ & $\mathrm{V} 4=0.5 \mathrm{~m}$ & $\mathrm{SI}_{\mathrm{V} 4}=0.83$ & & $\mathrm{~V} 4=10 \mathrm{~m}$ & $\mathrm{SI}_{\mathrm{V} 4}=1.0$ \\
\hline $\mathrm{V} 5=1 \mathrm{~km}$ & $\mathrm{SI}_{\mathrm{V} 5}=1.0$ & $\mathrm{~V} 5=10 \mathrm{~m}$ & $\mathrm{SI}_{\mathrm{V} 5}=1.0$ & & $\mathrm{~V} 5=1 \mathrm{~km}$ & $\mathrm{SI}_{\mathrm{V} 5}=1.0$ \\
\hline $\mathrm{V} 6=1 \mathrm{~km}$ & $\mathrm{SI}_{\mathrm{V} 6}=1.0$ & $\mathrm{~V} 6=1 \mathrm{~km}$ & $\mathrm{SI}_{\mathrm{V} 6}=1.0$ & & $\mathrm{~V} 6=1 \mathrm{~km}$ & $\mathrm{SI}_{\mathrm{V} 6}=1.0$ \\
\hline---- & & $\mathrm{V} 7=1 \mathrm{~km}$ & $\mathrm{SI}_{\mathrm{V} 7}=1.0$ & & ---- & \\
\hline
\end{tabular}

GREAT BLUE HERON HSI (G)

FINAL INDEX COMPUTATION GREAT EGRET HSI (G)

$\mathrm{FI}=\left(\mathrm{SI}_{\mathrm{V} 1}+\mathrm{SI}_{\mathrm{V} 2}\right) / 2$

$=\mathbf{0 . 0}$

$\left(\mathrm{SI}_{\mathrm{V} 0}=0\right.$, food radius $\left.\leq 4 \mathrm{~km}\right)$

$$
=\mathbf{0 . 5 2 5}
$$

(if radius up to $35 \mathrm{~km}$ )

$$
\begin{aligned}
& \mathrm{RI}=\left(\mathrm{SI}_{\mathrm{V} 0} * \mathrm{SI}_{\mathrm{V} 1} * \mathrm{SI}_{\mathrm{V} 4} * \mathrm{SI}_{\mathrm{V} 5} * \mathrm{SI}_{\mathrm{V} 6}\right)^{1 / 2} \mathrm{C}_{\mathrm{n}}=\left(\mathrm{SI}_{\mathrm{V} 0} * \mathrm{SI}_{\mathrm{V} 4} * \mathrm{SI}_{\mathrm{V} 5}\right)^{1 / 2} \\
& =\mathbf{0 . 6 3} \\
& \mathrm{HSI}_{\text {overall }}=\left(\prod_{\mathrm{Vi}=0}^{6} \mathrm{SI}_{\mathrm{Vi}}\right)^{1 / 2} \\
& =0.63 \\
& \mathrm{D}=\left(\mathrm{SI}_{\mathrm{V} 6} * \mathrm{SI}_{\mathrm{V} 7}\right)^{1 / 2} \\
& =1.0 \\
& \mathrm{HSI}_{\text {nest-nonisland }}=\min \left(\mathrm{C}_{\mathrm{n}}, \mathrm{D}\right) \\
& =\mathbf{0 . 0} \\
& \text { (nesting only) }
\end{aligned}
$$

\section{HSI (new L)}

$$
\begin{aligned}
& \mathrm{C}_{\mathrm{V} 1}=\left(\mathrm{SI}_{\mathrm{V} 1 \mathrm{c}} * \mathrm{SI}_{\mathrm{V} 1 \mathrm{f}}\right) \\
&=(1 * 1)=\mathbf{1 . 0} \\
& \mathrm{C}_{\mathrm{F}}=\left(\mathrm{SI}_{\mathrm{V} 1 \mathrm{r}}+\mathrm{SI}_{\mathrm{V} 2 \mathrm{f}}+\mathrm{SI}_{\mathrm{V} 3 \mathrm{f}}\right) / 3 \\
&=(.43+.25+1) / 3=\mathbf{0 . 5 6} \quad(10 \mathrm{~cm}) \\
&=(.43+.25+.75) / 3=\mathbf{0 . 4 8}(35 \mathrm{~cm}) \\
& \text { or } \quad=\left(\mathrm{SI}_{\mathrm{V} 1 \mathrm{r}} * \mathrm{SI}_{\mathrm{V} 2 \mathrm{f}} * \mathrm{SI}_{\mathrm{V} 3 \mathrm{f}}\right)^{1 / 3}=\mathbf{0 . 4 8}(10 \mathrm{~cm}) \\
&=\mathbf{0 . 4 3}(35 \mathrm{~cm}) \\
& \mathrm{C}_{\mathrm{N}}=\left(\mathrm{SI}_{\mathrm{V} 3 \mathrm{c}}+\mathrm{SI}_{\mathrm{V} 4}+\mathrm{SI}_{\mathrm{V} 5}+\mathrm{SI}_{\mathrm{V} 6}\right) / 4 \\
&=(.83+1+1+1) / 4=\mathbf{0 . 9 6} \\
& \text { or } \quad=\left(\mathrm{SI}_{\mathrm{V} 3 \mathrm{c}} * \mathrm{SI}_{\mathrm{V} 4} * \mathrm{SI}_{\mathrm{V} 5} * \mathrm{SI}_{\mathrm{V} 6}\right)^{1 / 4}=\mathbf{0 . 9 5} \\
& \mathrm{HSI}_{\mathrm{new}-\mathrm{L}}=\left(\mathrm{C}_{\mathrm{V} 1} * \mathrm{C}_{\mathrm{F}} * \mathrm{C}_{\mathrm{N}}\right)^{1 / 2} \\
&=\left(1 * .56^{*} .96\right)^{1 / 2}=\mathbf{0 . 7 3}(10 \mathrm{~cm})(\mathrm{v} .3) \\
&=\left(1 * .48^{*} .96\right)^{1 / 2}=\mathbf{0 . 6 8}(35 \mathrm{~cm})(\mathrm{v} .3) \\
& \text { or }=\left(1 * .48^{*} .95\right)^{1 / 2}=\mathbf{0 . 6 8}(10 \mathrm{~cm})(\mathrm{v} .4) \\
&=(1 * .43 * .95)^{1 / 2}=\mathbf{0 . 6 4}(35 \mathrm{~cm})(\mathrm{v} .4)
\end{aligned}
$$


Table 24. Continued

$$
\begin{aligned}
\text { Alt HSI }_{\text {new } \_\mathrm{L}}=\left(\mathrm{C}_{\mathrm{V} 1}+\mathrm{C}_{\mathrm{F}}+\mathrm{C}_{\mathrm{N}}\right) / 3 \\
=(1+.56+.96) / 3=\mathbf{0 . 8 4}(10 \mathrm{~cm})(\mathrm{v} .3) \\
=(1+.48+.96) / 3=\mathbf{0 . 8 1}(35 \mathrm{~cm})(\mathrm{v} .3) \\
\text { or } \quad=(1+.48+.95) / 3=\mathbf{0 . 8 1}(10 \mathrm{~cm})(\mathrm{v} .4) \\
=(1+.43+.95) / 3=\mathbf{0 . 7 9}(35 \mathrm{~cm})(\mathrm{v} .4)
\end{aligned}
$$

\begin{tabular}{|c|c|c|c|c|}
\hline \multirow{2}{*}{\multicolumn{5}{|c|}{$\begin{array}{l}\text { INTERMEDIATE INDEX (SI) COMPUTATIONS } \\
\text { Short-Legged Wading Birds } \\
\text { HSI (new L) } \\
\text { Variable } \quad \text { Index }\end{array}$}} \\
\hline & & & & \\
\hline $\begin{aligned} \mathrm{V} 0= & \text { estuarine } \\
& 7 \mathrm{~km} \text { radiu } \\
& 10 \mathrm{~cm} \text { and } \\
\mathrm{V} 1= & \mathrm{n} / \mathrm{a}\end{aligned}$ & $\begin{array}{l}\mathrm{SI}_{\mathrm{V} 0}=1.0 \\
\mathrm{~s} \\
35 \mathrm{~cm}\end{array}$ & $\begin{array}{l}\mathrm{V} 1 \mathrm{c}=\mathrm{E} 2 \mathrm{FO} \\
\mathrm{V} 1 \mathrm{f}=\mathrm{E} 2 \mathrm{EM} \\
\mathrm{V} 1 \mathrm{r}=7 \mathrm{~km}\end{array}$ & $\begin{array}{l}\mathrm{SI}_{\mathrm{V} 1 \mathrm{c}}=1.0 \\
\mathrm{SI}_{\mathrm{V} 1 \mathrm{f}}=1.0 \\
\mathrm{SI}_{\mathrm{V} 1 \mathrm{r}}=0.35\end{array}$ & \\
\hline $\begin{aligned} \mathrm{V} 1 & =\mathrm{n} / \mathrm{a} \\
\mathrm{V} 2 & =\mathrm{n} / \mathrm{a}\end{aligned}$ & & $V 2 f=10 \%$ & $\mathrm{SI}_{\mathrm{V} 2 \mathrm{f}}=0.25$ & \\
\hline $\mathrm{V} 3=10 \mathrm{~m}$ & $\mathrm{SI}_{\mathrm{V} 3}=1.0$ & $\begin{array}{l}\mathrm{V} 3 \mathrm{c}=0.5 \mathrm{~m} \\
\mathrm{~V} 3 \mathrm{f}=10 \mathrm{~cm} \\
\mathrm{~V} 3 \mathrm{f}=35 \mathrm{~cm}\end{array}$ & $\begin{array}{l}\mathrm{SI}_{\mathrm{V} 3 \mathrm{c}}=0.5 \\
\mathrm{SI}_{\mathrm{V} 3 \mathrm{f}}=1.0 \\
\mathrm{SI}_{\mathrm{V} 3 \mathrm{f}}=0.0\end{array}$ & or $\mathrm{V} 3 \mathrm{c}=80 \%, \mathrm{SI}_{\mathrm{V} 3 \mathrm{c}}=0.80$ \\
\hline $\begin{aligned} \mathrm{V} 4 & =1 \mathrm{~km} \\
\mathrm{~V} 5 & =80 \%\end{aligned}$ & $\begin{array}{l}\mathrm{SI}_{\mathrm{V} 4}=0.33 \\
\mathrm{SI}_{\mathrm{V} 5}=0.80\end{array}$ & $\begin{aligned} \mathrm{V} 4 & =10 \mathrm{~m} \\
\mathrm{~V} 5 & =1 \mathrm{~km} \\
\mathrm{~V} 6 & =1 \mathrm{~km}\end{aligned}$ & $\begin{array}{l}\mathrm{SI}_{\mathrm{V} 4}=1.0 \\
\mathrm{SI}_{\mathrm{V} 5}=1.0 \\
\mathrm{SI}_{\mathrm{V} 6}=1.0\end{array}$ & \\
\hline
\end{tabular}

\section{WHITE IBIS HSI (G)}

$$
\begin{aligned}
& \mathrm{HSI}_{\text {overall-nonisland }}= \\
& \left(\mathrm{SI}_{\mathrm{V} 0} * \mathrm{SI}_{\mathrm{V} 3} * \mathrm{SI}_{\mathrm{V} 4} * \mathrm{SI}_{\mathrm{V} 5}\right)^{1 / 3} \\
& =\mathbf{0 . 6 4} \\
& (\text { food radius }<10 \mathrm{~km}, \\
& \text { water depth }=10 \mathrm{~cm}) \\
& \quad=\mathbf{0 . 0} \\
& (\text { water depth }=35 \mathrm{~cm})
\end{aligned}
$$

\section{FINAL INDEX COMPUTATION} HSI (new L)

$$
\begin{aligned}
& \mathrm{C}_{\mathrm{V} 1}=\left(\mathrm{SI}_{\mathrm{V} 1 \mathrm{c}} * \mathrm{SI}_{\mathrm{V} 1 \mathrm{f}}\right) \\
& =(1 * 1)=\mathbf{1 . 0} \\
& \mathrm{C}_{\mathrm{F}}=\left(\mathrm{C}_{\mathrm{V} 1 \mathrm{r}}+\mathrm{SI}_{\mathrm{V} 2 \mathrm{f}}+\mathrm{SI}_{\mathrm{V} 3 \mathrm{f}}\right) / 3 \\
& =(.35+.25+1) / 3=\mathbf{0 . 5 3}(10 \mathrm{~cm}) \\
& =(.35+.25+0) / 3=\mathbf{0 . 2 0}(35 \mathrm{~cm}) \\
& \text { or }=\left(\mathrm{C}_{\mathrm{V} 1 \mathrm{r}} * \mathrm{SI}_{\mathrm{V} 2 \mathrm{f}} * \mathrm{SI}_{\mathrm{V} 3 \mathrm{f}}\right)^{1 / 3}=\mathbf{0 . 4 4}(10 \mathrm{~cm}) \\
& =\mathbf{0 . 0}(35 \mathrm{~cm}) \\
& \mathrm{C}_{\mathrm{N}}=\left(\mathrm{SI}_{\mathrm{V} 3 \mathrm{c}}+\mathrm{SI}_{\mathrm{V} 4}+\mathrm{SI}_{\mathrm{V} 5}+\mathrm{SI}_{\mathrm{V} 6}\right) / 4 \\
& =(.5+1+1+1) / 4=\mathbf{0 . 8 8}(\mathbf{0 . 9 5} \text { if use } 80 \% \text { flooded area }) \\
& \text { or }=\left(\mathrm{SI}_{\mathrm{V} 3 \mathrm{c}} * \mathrm{SI}_{\mathrm{V} 4} * \mathrm{SI}_{\mathrm{V} 5} * \mathrm{SI}_{\mathrm{V} 6}\right)^{1 / 4}=\mathbf{0 . 8 4}(\mathbf{0 . 9 5} \text { if use } 80 \% \text { flooded area }) \\
& \mathrm{HSI}_{\text {new_L }}=\left(\mathrm{C}_{\mathrm{V} 1} * \mathrm{C}_{\mathrm{F}} * \mathrm{C}_{\mathrm{N}}\right)^{1 / 2} \\
& =(1 * .53 * .88)^{1 / 2}=\mathbf{0 . 6 8}(10 \mathrm{~cm})(\mathbf{0 . 7 1} \text { if use } 80 \% \text { flooded area })(\mathrm{v} .3) \\
& =(1 * .20 * .88)^{1 / 2}=\mathbf{0 . 4 2}(35 \mathrm{~cm})(\mathbf{0 . 4 4} \text { if use } 80 \% \text { flooded area })(\mathrm{v} .3) \\
& =(1 * .44 * .84)^{1 / 2}=\mathbf{0 . 6 1}(10 \mathrm{~cm})(\mathbf{0 . 6 5} \text { if use } 80 \% \text { flooded area })(\mathrm{v} .4) \\
& =(1 * 0 * 84)^{1 / 2}=\mathbf{0 . 0} \quad(35 \mathrm{~cm})(\mathbf{0 . 0} \text { if use } 80 \% \text { flooded area })(\mathrm{v} .4) \\
& \text { Alt } \mathrm{HSI}_{\text {new_L }}=\left(\mathrm{C}_{\mathrm{V} 1}+\mathrm{C}_{\mathrm{F}}+\mathrm{C}_{\mathrm{N}}\right) / 3 \\
& =(1+.53+.88) / 3=\mathbf{0 . 8 0}(10 \mathrm{~cm})(\mathbf{0 . 8 3} \text { if use } 80 \% \text { flooded area) (v. 3) } \\
& =(1+.20+.88) / 3=\mathbf{0 . 6 9}(35 \mathrm{~cm})(\mathbf{0 . 7 2} \text { if use } 80 \% \text { flooded area })(\mathrm{v} .3) \\
& =(1+.44+.84) / 3=\mathbf{0 . 7 6}(10 \mathrm{~cm})(\mathbf{0 . 8 0} \text { if use } 80 \% \text { flooded area })(\mathrm{v} .4) \\
& =(1+0+.84) / 3=\mathbf{0 . 6 1} \quad(35 \mathrm{~cm})(\mathbf{0 . 6 5} \text { if use } 80 \% \text { flooded area })(\mathrm{v} .4)
\end{aligned}
$$


Table 25. Comparison of general habitat suitability index (HSI) models for wading birds with the proposed LCA study models, separated by short- and long-legged groups. Setting 3 (versions 3 (v. 3 ) and 4 (v. 4)). Wading birds include great blue heron (Ardea herodias), great egret (Ardea alba), and white ibis (Eudocimus albus). General HSI models are denoted as HSI (G) and the proposed model as HSI (new L). Final index computations include component calculations.

Dataset parameters in setting 3:

$30 \%$ of feeding site with water depth of $10 \mathrm{~cm}$ and firm substrate; $60 \%$ of feeding site with water depth of $35 \mathrm{~cm}, 1-90 \%=10 \%$ land.

$30 \%$ emergent vegetation in water depths of $10 \mathrm{~cm}$.

Feeding site is $7 \mathrm{~km}$ from colony, in estuarine intertidal emergent wetland (E2EM), and is $200 \mathrm{~m}$ from disturbances (roads, structures, and human). Colony is in estuarine intertidal forested wetland (non-island) (E2FO).

Colony is on 25 ha of tree grove within $200 \mathrm{~m}$ of water; proximity of next colony is $10 \mathrm{~km}$.

Mean woody vegetation height of $10 \mathrm{~m}$; mean water depth in colony site is $0.5 \mathrm{~m}$ ( $80 \%$ flooded during nesting).

Distance from colony to road is $200 \mathrm{~m}$; human activity disturbance is $1 \mathrm{~km}$.

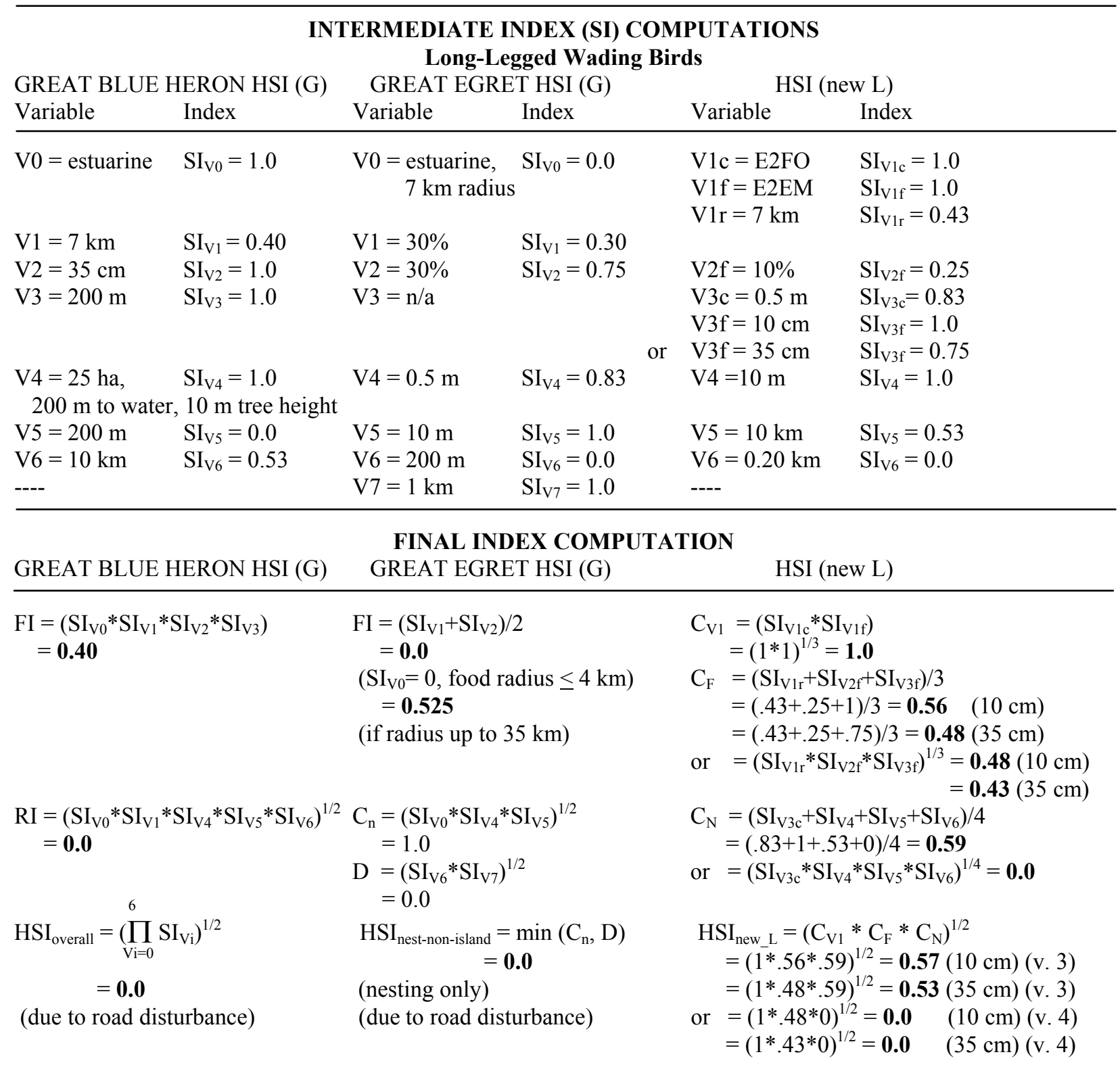


Table 25. Continued

$$
\begin{aligned}
& \text { Alt } \mathrm{HSI}_{\text {new } \_}=\left(\mathrm{C}_{\mathrm{V} 1}+\mathrm{C}_{\mathrm{F}}+\mathrm{C}_{\mathrm{N}}\right) / 3 \\
& =(1+.56+.59) / 3=\mathbf{0 . 7 2}(10 \mathrm{~cm})(\mathrm{v} .3) \\
& =(1+.48+.59) / 3=\mathbf{0 . 6 9}(35 \mathrm{~cm})(\mathrm{v} .3) \\
& \text { or }=(1+.48+0) / 3=\mathbf{0 . 4 9} \quad(10 \mathrm{~cm})(\mathrm{v} .4) \\
& =(1+.43+0) / 3=\mathbf{0 . 4 8} \quad(35 \mathrm{~cm})(\mathrm{v} .4)
\end{aligned}
$$

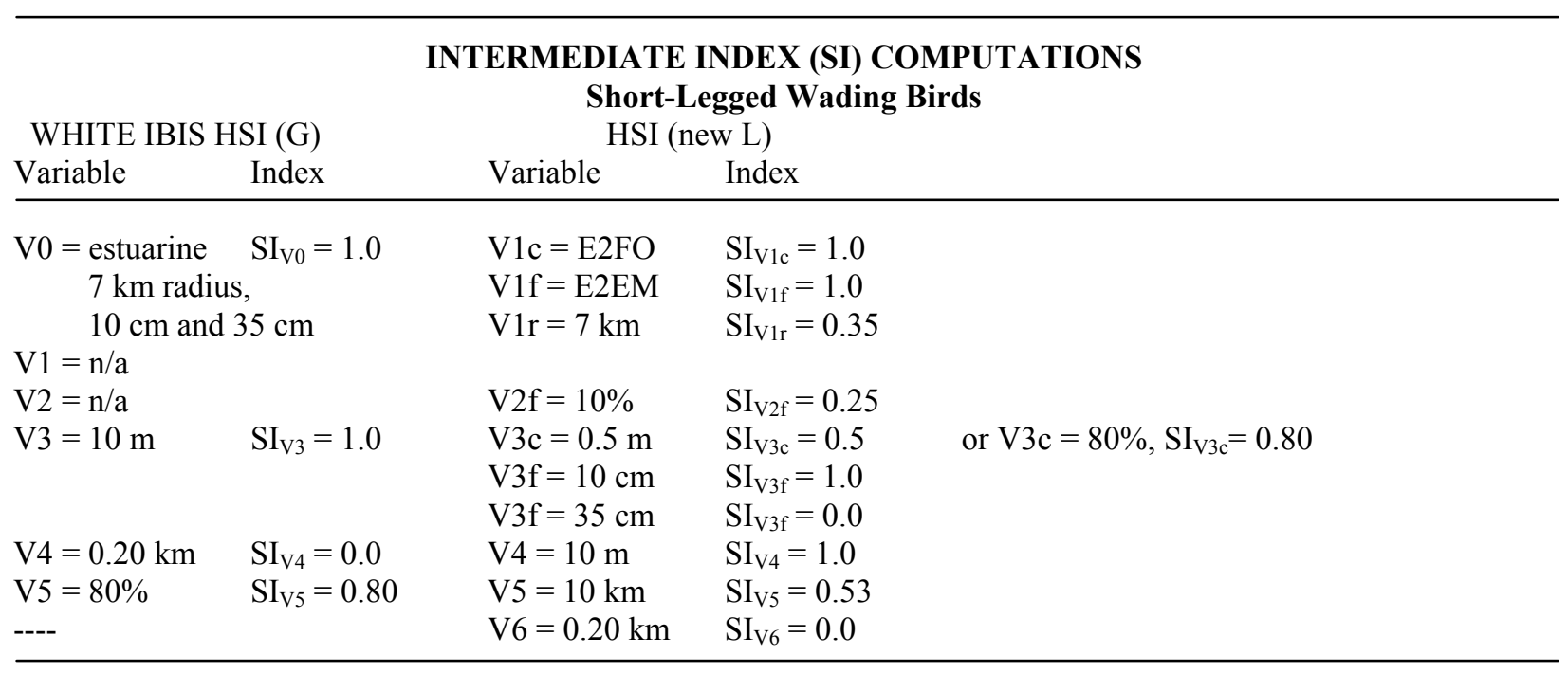

\section{WHITE IBIS HSI (G)}

$$
\begin{aligned}
& \mathrm{HSI}_{\text {overall-non-island }}= \\
& \left(\mathrm{SI}_{\mathrm{V} 0} * \mathrm{SI}_{\mathrm{V} 3} * \mathrm{SI}_{\mathrm{V} 4} * \mathrm{SI}_{\mathrm{V} 5}\right)^{1 / 3} \\
& =\mathbf{0 . 0} \\
& (\text { food radius }<10 \mathrm{~km}, \\
& (\text { water depth }=10 \mathrm{~cm}) \\
& \quad=\mathbf{0 . 0} \\
& (\text { water depth }=35 \mathrm{~cm})
\end{aligned}
$$

\section{FINAL INDEX COMPUTATION} HSI (new L)

$$
\begin{aligned}
& \mathrm{C}_{\mathrm{V} 1}=\left(\mathrm{SI}_{\mathrm{V} 1 \mathrm{c}} * \mathrm{SI}_{\mathrm{V} 1 \mathrm{f}}\right) \\
& =(1 * 1)=\mathbf{1 . 0} \\
& \mathrm{C}_{\mathrm{F}}=\left(\mathrm{C}_{\mathrm{V} 1 \mathrm{r}}+\mathrm{SI}_{\mathrm{V} 2 \mathrm{f}}+\mathrm{SI}_{\mathrm{V} 3 \mathrm{f}}\right) / 3 \\
& =(.35+.25+1) / 3=\mathbf{0 . 5 3}(10 \mathrm{~cm}) \\
& =(.35+.25+0) / 3=\mathbf{0 . 2 0}(35 \mathrm{~cm}) \\
& \text { or }=\left(\mathrm{C}_{\mathrm{V} 1 \mathrm{r}} * \mathrm{SI}_{\mathrm{V} 2 \mathrm{f}} * \mathrm{SI}_{\mathrm{V} 3 \mathrm{f}}\right)^{1 / 3}=\mathbf{0 . 4 4}(10 \mathrm{~cm}) \\
& =\mathbf{0 . 0}(35 \mathrm{~cm}) \\
& \mathrm{C}_{\mathrm{N}}=\left(\mathrm{SI}_{\mathrm{V} 3 \mathrm{c}}+\mathrm{SI}_{\mathrm{V} 4}+\mathrm{SI}_{\mathrm{V} 5}+\mathrm{SI}_{\mathrm{V} 6}\right) / 4 \\
& =(.5+1+.53+0) / 4=\mathbf{0 . 5 1}(\mathbf{0 . 5 8} \text { if use } 80 \% \text { flooded area }) \\
& \text { or }=\left(\mathrm{SI}_{\mathrm{V} 3 \mathrm{c}} * \mathrm{SI}_{\mathrm{V} 4} * \mathrm{SI}_{\mathrm{V} 5} * \mathrm{SI}_{\mathrm{V} 6}\right)^{1 / 4}=\mathbf{0 . 0}(\mathbf{0 . 0} \text { if use } 80 \% \text { flooded area }) \\
& \mathrm{HSI}_{\text {new_L }}=\left(\mathrm{C}_{\mathrm{V} 1} * \mathrm{C}_{\mathrm{F}} * \mathrm{C}_{\mathrm{N}}\right)^{1 / 2} \\
& =(1 * .53 * .51)^{1 / 2}=\mathbf{0 . 5 2}(10 \mathrm{~cm})(\mathbf{0 . 5 5} \text { if use } 80 \% \text { flooded area })(\mathrm{v} .3) \\
& =(1 * .20 * .51)^{1 / 2}=\mathbf{0 . 3 2}(35 \mathrm{~cm})(\mathbf{0 . 3 4} \text { if use } 80 \% \text { flooded area })(\mathrm{v} .3) \\
& \text { or }=(1 * .44 * 0)^{1 / 2}=\mathbf{0 . 0} \quad(10 \mathrm{~cm})(\mathbf{0 . 0} \text { if use } 80 \% \text { flooded area })(\mathrm{v} .4) \\
& =(1 * 0 * 0)^{1 / 2}=\mathbf{0 . 0} \quad(35 \mathrm{~cm})(\mathbf{0 . 0} \text { if use } 80 \% \text { flooded area })(\mathrm{v} .4)
\end{aligned}
$$




\section{Conclusion}

The critical review in appendix C (volume 4) of the Louisiana Coastal Area (LCA) Comprehensive Ecosystem Restoration Plan project (USACE, 2004) has suggested low-rated parameter quality and oversimplification of habitat suitability index (HSI) models for all wildlife. The success of the HSI models from the South Florida Water Management District for The Everglades restoration project and from the Spatially Explicit Species Index Models (SESI) from the Across Trophic Level System Simulation (ATLSS) Program of Florida warranted investigation with possible application of all or part of modeling theory to the current LCA study. Theoretical formulae examinations and model comparisons using diverse hypothetical settings of hydrological or biological ecosystems were used to highlight weaknesses as well as strengths among all of the models. The different models were assessed, and recommendations were made for the LCA study.

An enhanced HSI model is proposed for American alligators in the LCA study. A new HSI model for wading birds, separated for long- and short-legged groups, is introduced for the LCA study. Both HSI models presented here are compatible with the current structure of the models used in the LCA study and are based on data from the LCA study, the Florida models (HSI and SESI), and the general HSI models developed by the U.S. Fish and Wildlife Service (USFWS). Performance comparisons of the proposed models with other suitability models are made by using various hypothetical settings (tables 14-18 and 20-25).

Inasmuch as the Florida SESI and HSI models may be well suited for the particular nontidal environments of The Everglades, albeit with limitations as previously discussed, they introduce certain features that cannot be implemented in the current LCA study model framework. These include the number of nonbreeding dry days as well as body condition and survival for alligators. For wading birds, the concepts of foraging cycles or shifting landscape introduced in the Florida models are not applicable to the LCA study. On the other hand, the general HSI models are more broadly defined for all coastal wetlands throughout United States and consider additional features, such as percentage of area and pond interspersion for alligators, as well as island characteristics (distances, surface area, and vegetation) for wading birds. Thus, a scoring system is employed to measure the effectiveness of all features across the models (see "Scoring All Models by Factor Categories" sections in chapters 4 and 5), from which a subset of factors is selected that represent the best applicable features for the current design of the LCA study models. The intention of the subset selection is to simplify or eliminate the need for extensive data measurements of some models, while retaining important basic information that uses more accessible data.

The development process for the HSI models proposed for the LCA study involves synchronization of the selected features across all relevant models. A compromise is usually reached for optimal suitability ranges, often by averaging several limit values and tapering to extended limits. Thus, wider ranges are frequently defined. Furthermore, the proposed models conglomerate more features from all models and contain more information than the individual 
HSI models. Also, different formula options are considered, where the arithmetic mean versions of the formulae generally produce higher suitability values than geometric mean versions. Consequently, the final suitability index values of the proposed model are usually higher than other models. This may be biologically inferred as an increase of acceptable sites, since wildlife could instinctively adapt to hydrological or biological ecosystem variations and be found in uncommon sites throughout the coastal regions.

The proposed HSI models for the LCA study have not been field tested and are subject to variable definition modifications and calibrations of specific limit values. The wading bird models especially may benefit from more information, in particular on additional species. It is recommended (J. A. Nyman, oral commun., 2006) that field testing should be conducted in marshes between Sabine Lake and Calcasieu Lake in extreme southwestern Louisiana.

\section{Acknowledgments}

A deep appreciation is expressed for the time, effort, and cooperation concerning the discussions of the various models with the developers and associated project managers: Louis Gross, Mark Palmer, Kenneth Rice, Ronnie Best, Donald DeAngelis, and John Andrew Nyman. A special gratitude is given to John McCoy for his technical assistance in the preparation of graphics. This report was supported under Project Number 2080B6I, "ER-FISC-Across Trophic Level Simulation (ATLSS) for the wetland ecosystems of South Florida," FISC-Development of selected model components of an Across-Trophic-Level Simulation for the wetland ecosystems of South Florida (Task 4); A Spatial Explicit Decision Support System for Everglades Ecological Risk Assessment and Restoration (SubTask 4.4). 


\section{References}

Barr, B., 1997, Food habits of the American alligator, Alligator mississippiensis, in the southern Everglades: Miami, Fla., University of Miami, Ph.D. dissertation, 243 p.

Boesch, D.F., Josselyn, M.N., Mehta, A.J., Morris, J.T., Nuttle, W.K., Simenstad, C.A. and Swift, D.J.P., 1994, Scientific assessment of coastal wetland loss, restoration and management in Louisiana: Journal of Coastal Restoration, Special Issue No. 20, 103 p.

Carter, M.R., and Burns, L.A., 1973, Ecosystems analysis of the Big Cypress Swamp and estuaries: Washington, D.C., U.S. Environmental Protection Agency, Ecological Report Number DI-SFEP-74-51, v. p.

Chabreck, R.H., 1970, Marsh zones and vegetative types in the Louisiana coastal marshes: Baton Rouge, La., Louisiana State University, Ph.D. dissertation, 112 p.

Chabreck, R.H., 1972, Vegetation, water and soil characteristics of the Louisiana Coastal region: Louisiana Agricultural Experiment Station Bulletin 664, 72 p.

Chapman, B.R., and Howard, R.J., 1984, Habitat suitability index models - great egret: U.S. Fish and Wildlife Service FWS/OBS-82/10.78, 23 p.

Conner, W.H., and Day, J.W., 1987, The ecology of Barataria basin, Louisiana - an estuarine profile: U.S. Fish and Wildlife Service Biological Report 85(7.13), 165 p.

Cowardin, L.M., Carter, V., Golet, F.C., and LaRoe, E.T., 1979, Classification of wetlands and deepwater habitats of the United States: U.S. Fish and Wildlife Service FWS/OBS79/31, $103 \mathrm{p}$.

Craig, J.J., Turner, R.E., and Day, J.W., 1979, Land loss in coastal Louisiana (U.S.A.): Environmental Management, v. 3, p. 133-144.

Costanza, R., and Daly, H.E., 1991, Natural capital and sustainable development: Conservation Biology, v. 6, no. 1, p. 37-46.

Curnutt, J.L., Comiskey, E. J., Nott, M.P., and Gross, L.J., 2000, Landscape-based spatiallyexplicit species index models for Everglades restoration: Ecological Applications, v. 10, p. 1,849-1,860.

Day, J.W., Martin, J.F., Cardoch, L., and Templet, P.H., 1997, System functioning as a basis for sustainable management of deltaic ecosystems: Coastal Management, v. 25, p. 115-153.

Delany, M.F., and Abercrombie, C.L., 1986, American alligator food habitats in north central Florida: Journal of Wildlife Management, v. 50, p. 348-353.

Erwin, R.M., 1983, Feeding habitats of nesting wading birds - spatial use and social influences: The Auk, v. 100, p. 960-970.

Fisk, H.N., Kolb, C.R., McFarlan, E., and Wilbert, L.J., 1954, Sedimentary framework of the modern Mississippi Delta: Journal of Sedimentary Petrology, v. 24, no. 2, p. 76-99.

Gawlik, D., Crozier, G., and Tarboton, K.C., 2004, Wading bird habitat suitability index, in Tarboton, K.C., Irizarry-Ortiz, M.M., Loucks, D.P., Davis, S.M., and Obeysekera, J.T., eds., Habitat suitability indices for evaluating water management alternatives: West Palm Beach, Fla., South Florida Water Management District Office of Modeling Technical Report, p. 111-127.

Gould, H.R., and McFarlan, E., 1959, Geological history of the chenier plain, southwestern Louisiana transactions: Gulf Coast Association of Geological Societies, v. 9, p. 261-270. 
Gunther, G., 1961, Some relationships of esturaries to the fisheries of the Gulf of Mexico, in Lauff, G.H., ed., Estuaries: Washington, D.C., AAAS Publ. 83, p. 621-638.

Hingtgen, T.M., Mulholland, R., and Repenning, R.W., 1985, Habitat suitability index models white ibis: U.S. Fish and Wildlife Service Biological Report 82(10.93), 18 p.

Houghton, R.A., 1994, The worldwide extent of land-use change: Bioscience, v. 44, p. 305-313.

Howard, K.S., Loftus, W.F., and Trexler, J.C., 1995, Seasonal dynamics of fishes in artificial Culvert Pools in the C-111 Basin, Dade County, Florida: Miami, Fla., Florida International University and National Biological Service, $48 \mathrm{p}$.

Inhaber, H., 1976, Environmental indices: New York, John Wiley and Sons, 178 p.

The Institute for Environmental Modeling (TIEM), 2004a, Descriptions, flowcharts, and presentations related to ATLSS Spatially Explicit Species Index (SESI) Models: University of Tennessee at Knoxville, The Institute for Environmental Modeling, accessed Oct. 25, 2007, at http://atlss.org/cerp_runs/mod info/.

- - 2004b, American alligator version 1.1 - CERP target sheet, textual description, flowcharts, and presentation: University of Tennessee at Knoxville, The Institute for Environmental Modeling, accessed Oct. 25, 2007, at http://atlss.org/cerp_runs/mod info/.

- - 2004c, Wading bird version 1.2 - CERP target sheet, textual description, flowchart, and presentation: University of Tennessee at Knoxville, The Institute for Environmental Modeling, accessed Oct. 25, 2007, at http://atlss.org/cerp runs/mod info/.

- 2005, Initial performance measures and information related to the ATLSS vegetation succession model: University of Tennessee at Knoxville, The Institute for Environmental Modeling, accessed Oct. 25, 2007, at http://atlss.org/VSMod/.

Jacobsen, T., and Kushlan, J.A., 1989, Growth dynamics in the American alligator (Alligator mississippiensis): London, Journal of Zoology, v. 219, no. 2, p. 309-328.

Kesel, R., 1988, The decline in the suspended load of the Lower Mississippi River and its influence on adjacent wetlands: Enviromental Geology and Water Science, v. 11, p. 271281.

Kushlan, J.A., 1976, Wading bird predation in a seasonally fluctuating pond: The Auk, v. 93, p. 464-476.

Kushlan, J.A., 1981, Resource use strategies of wading birds: Wilson Bulletin, v. 93, p. 145-163.

Kushlan, J.A., and Jacobsen, T., 1990, Environmental variability and the reproductive success of Everglades alligators: Journal of Herpetology, v. 24, no. 2, p. 176-184.

Loftus, W.F., and Eklund, A.M., 1994, Long-term dynamics of an Everglades small fish assemblage, in Davis, S.M. and Ogden, J.C., eds., Everglades - the ecosystem and its restoration: Delray Beach, Fla., St. Lucie Press, p. 461-483.

Mitchell, W.A., 1999, Species profile - wood stork (Mycteria americana) on military installations in the southeastern United States: Vicksburg, Miss., U.S. Army Corps of Engineers Research and Development Center Technical Report SERDP-99-2, 36 p.

Michot, T.C., Jeske, C.W., Mazourek, J.C., Vermillion, W.G., and Kemmerer, R.S., 2003, Atlas and census of wading bird and seabird nesting colonies in south Louisiana, 2001: Thibodaux, La., Bataria-Terrebonne National Estuary Program Preport No. 32, 76 p. 
Newsom, J.D., Joanen, T., and Howard, R., 1987, Habitat suitability index model - American alligator: Washington, D.C., U.S. Fish and Wildlife Service Biological Report 82(10.136), $14 \mathrm{p}$.

Nyman, J.A., 2001, Water level and salinity data used for coastal management: Baton Rouge, La., Louisiana State University Final Report CFMS \# 568573, 29 p.

Penfound, W.T., and Hathaway, E.S., 1938, Plant communities in the marshland of southeastern Louisiana: Ecological Monographs, v. 8, p. 1-56.

Penland, S., and Suter, J.R., 1989, The geomorphology of the Mississippi chenier plain: Marine Geology, v. 90, p. 231-258.

Portnoy, J.W., 1977, Nesting colonies of seabirds and wading birds - coastal Lousiana, Mississippi, and Alabama: U.S. Fish and Wildlife Service Biological Service Program FWS/OBS-77/07, 126 p.

Reed, D.J., and Fuller, D.A., 1995, Status and trends of hydrologic modification, reduction in sediment availability, and habitat loss/modification in the Barataria-Terrebonne estuarine system: Thibodeaux, La., Barataria-Terrebonne National Estuary Program Publication No. 20, 338 p.

Rice, K.G., Mazzotti, F.J., Brandt, L.A., and Tarboton, K.C., 2004, Alligator habitat suitability index, in Tarboton, K.C., Irizarry-Ortiz, M.M., Loucks, D.P., Davis, S.M., and Obeysekera, J.T., eds., Habitat suitability indices for evaluating water management alternatives: West Palm Beach, Fla., South Florida Water Management District Office of Modeling Technical Report, p. 93-110.

Roberts, H.H., 1977, Dynamic changes of the Holocene Mississippi River Delta Plain - the delta cycle: Journal of Coastal Restoration, v. 13, p. 605-627.

Rootes, W.L., Chabreck, R.H., Wright, V.L., Brown, B.W., and Hess, T.J., 1991, Growth rates of American alligators in estuarine and palustrine wetlands in Louisiana: Estuaries, v. 14, p. 489-494.

Schelske, C.L., and Odum, E.P., 1961, Mechanisms maintaining high productivity in Georgia estuaries, in Proceedings of Gulf and Caribbean Fisheries Institute, v. 14: Coral Gables, Fla., Gulf and Carribean Fisheries Institute, p. 75-80.

Short, H.L., and Cooper, R.J., 1985, Habitat suitability index models - great blue heron: U.S. Fish and Wildlife Service Biological Report 82(10.99), 23 p.

Smith, J.P., and Collopy, M.W., 1995, Colony turnover, nest success and productivity, and causes of nest failure among wading birds (Ciconiiformes) at Lake Okeechobee, Florida (1989-1992): Advances in Limnology, v. 45, p. 287-316.

Steyer, G.D., Sasser, C.E., Visser, J.M., Swenson, E.M., Nyman, J.A., and Raynie, R.C., 2003, A proposed coast-wide reference monitoring system for evaluating wetland restoration trajectories in Louisiana: Environmental Monitoring and Assessment, v. 81, p. 107-117.

Swenson, E.M., and Turner, R.E., 1987, Spoil banks - effects on a coastal marsh water-level regime: Estuarine, Coastal and Shelf Science, v. 24, p. 599-609.

Tarboton, K.C., Irizarry-Ortiz, M.M., Loucks, D.P., Davis, S.M., and Obeysekera, J.T., eds., 2004, Habitat suitability indices for evaluating water management alternatives: West Palm Beach, Fla., South Florida Water Management District Office of Modeling Technical Report, 148 p. 
Templet, P.H., and Meyer-Arendt, K., 1988, Louisiana wetland loss - regional water management approach to the problem: Environmental Management, v. 12, p. 181-192.

Turner, R.E., and Cahoon, D.R., eds., 1987, Causes of wetland loss in the coastal central Gulf of Mexico, v. 2 - technical narrative: New Orleans, La., Minerals Management Service, OCS Study/MMS 87-0120, 400 p.

U.S. Army Corps of Engineers (USACE), 2004, Appendix C - Hydrodynamic and ecological modeling, in Louisiana Coastal Area (LCA), Louisiana - ecosystem restoration study: New Orleans, La., U.S. Army Corps of Engineers - New Orleans District, 276 p.

U.S. Fish and Wildlife Service, 1980, Standards for the development of habitat suitability index models: Washington, D.C., U.S. Fish and Wildlife Service 103 ESM, 71 p. 


\section{Appendix 1}

Proposed American Alligator (Alligator mississippiensis) Model for the Louisiana Coastal Area (LCA) Study

Habitat:

$$
\begin{aligned}
& \mathrm{SI}_{\mathrm{V} 1}=0.0 \\
& \mathrm{SI}_{\mathrm{V} 1}=0.26 \\
& \mathrm{SI}_{\mathrm{V} 1}=0.55 \\
& \mathrm{SI}_{\mathrm{V} 1}=1.0
\end{aligned}
$$

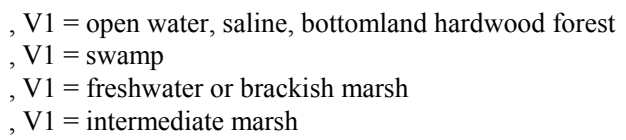

Percentage of Area:

$$
\begin{array}{ll}
\mathrm{SI}_{\mathrm{V} 2}=\mathrm{V} 2 * 0.0167 & , 0 \% \leq \mathrm{V} 2<60 \% \\
\mathrm{SI}_{\mathrm{V} 2}=1.0 & , 60 \% \leq \mathrm{V} 2 \leq 80 \% \\
\mathrm{SI}_{\mathrm{V} 2}=5-(\mathrm{V} 2 * 0.05) & , 80 \%<\mathrm{V} 2 \leq 100 \%
\end{array}
$$

Nonbreeding Water Depth (Sept. 1 of previous year to Apr. 15):

$$
\begin{array}{ll}
\mathrm{SI}_{\mathrm{V} 3}=0.0 & , \mathrm{~V} 3 \leq-0.5 \mathrm{~m} \\
\mathrm{SI}_{\mathrm{V} 3}=2.5+(\mathrm{V} 3 * 5) & ,-0.5<\mathrm{V} 3 \leq-0.3 \mathrm{~m} \\
\mathrm{SI}_{\mathrm{V} 3}=1.0 & ,-0.3<\mathrm{V} 3 \leq 0.0 \mathrm{~m} \\
\mathrm{SI}_{\mathrm{V} 3}=1-(\mathrm{V} 3 * 3.33) & , 0.0<\mathrm{V} 3 \leq 0.3 \mathrm{~m} \\
\mathrm{SI}_{\mathrm{V} 3}=0.0 & , \mathrm{~V} 3>0.3 \mathrm{~m}
\end{array}
$$

Breeding/Nesting Water Depth (Apr. 16-May 15):

$$
\begin{aligned}
& \mathrm{SI}_{\mathrm{V} 4}=0.0 \quad, \mathrm{~V} 4 \leq 0.0 \mathrm{~m} \\
& \mathrm{SI}_{\mathrm{V} 4}=\mathrm{V} 4 / 0.4 \\
& =\mathrm{V} 4 * 2.5 \quad, 0.0<\mathrm{V} 4 \leq 0.40 \mathrm{~m} \\
& \mathrm{SI}_{\mathrm{V} 4}=1.0 \quad, 0.40<\mathrm{V} 4 \leq 0.49 \mathrm{~m} \\
& \mathrm{SI}_{\mathrm{V} 4}=(0.61-\mathrm{V} 4) / 0.12 \\
& =5.09-(\mathrm{V} 4 * 8.33) \quad, 0.49<\mathrm{V} 4 \leq 0.61 \mathrm{~m} \\
& \mathrm{SI}_{\mathrm{V} 4}=0.0 \quad, \mathrm{~V} 4>0.61 \mathrm{~m}
\end{aligned}
$$

Nonflooding Factor $\left(\mathrm{d}_{3}=\right.$ mean water depth June 15 - June 30$)$ :

$$
\begin{aligned}
& \mathrm{SI}_{\mathrm{V} 5}=1.0 \quad, \Delta_{\max }<0.15 \mathrm{~m} \text { and } \mathrm{d}_{3}<0.61 \mathrm{~m} \\
& \mathrm{SI}_{\mathrm{V} 5}=1.48-\left(\Delta_{\max } * 3.22\right) \quad, 0.15<\Delta_{\max } \leq 0.46 \mathrm{~m} \text { and } \mathrm{d}_{3}<0.61 \mathrm{~m} \\
& \mathrm{SI}_{\mathrm{V} 5}=0.0 \quad, \Delta_{\max }>0.46 \mathrm{~m} \text { or } \mathrm{d}_{3} \geq 0.61 \mathrm{~m}
\end{aligned}
$$

Water Depth Component - arithmetic average of V3, V4, and V5:

$$
\mathbf{C}_{\mathrm{water}}=\left(\mathbf{S I}_{\mathrm{v} 3}+\mathbf{S I}_{\mathrm{v} 4}+\mathbf{S I}_{\mathrm{v} 5}\right) / 3
$$

Final HSI - geometric mean of three components:

$$
\text { HSI }=\left(\mathrm{SI}_{\mathrm{V} 1} * \mathrm{SI}_{\mathrm{V} 2} * \mathrm{C}_{\text {water }}\right)^{1 / 3}
$$




\section{Appendix 2}

The following, proposed wading bird model for the Louisiana Coastal Area (LCA) study is based on specific species that are separated into two groups: great blue heron (Ardea herodias), great egret (Ardea alba), snowy egret (Egretta thula), and wood stork (Mycteria americana) as long-legged birds; white ibis (Eudocimus albus) and little blue heron (Egretta caerulea) as short-legged birds. The models present two options for the habitat, as a two-classed variable or a multiclassed variable. Both formula options are presented, where the use of the multiclassed variable changes the power in the geometric mean formula. The multiclassed variable formula is denoted with a superscript symbol " 1 " that refers to the corresponding footnote explanation.

There are four versions of the models. All versions implement the following: (1) the habitat factor for both foraging (V1f) and colony site (V1c) may use the two-classed U.S. Fish and Wildlife Service's wetland classification system for habitat or the multiclassed habitat definition from the current LCA study (see above), and (2) the percentage of land (substituting V2f for V2) of the current LCA study.

Version 1: The first version specifically utilizes the following: (1) the arithmetic means for both foraging and nesting components $\left(\mathrm{C}_{\mathrm{F}}\right.$ and $\left.\mathrm{C}_{\mathrm{N}}\right)$ and $(2)$ the geometric means for the habitat component ( $\mathrm{C}_{\mathrm{V} 1 \mathrm{f}}$ ) (using V1f and V1r) and the final HSI.

Version 2: The second version modifies the first version by instead calculating the geometric means for both foraging and nesting components $\left(\mathrm{C}_{\mathrm{F}}\right.$ and $\left.\mathrm{C}_{\mathrm{N}}\right)$.

Version 3: The third version applies the alternative approach of isolating the habitat component as $\mathrm{C}_{\mathrm{V} 1}$ (using V1c and V1f) that is to be included as a separate component in the final HSI computation. The arithmetic means are used for the intermediate foraging and nesting components $\left(\mathrm{C}_{\mathrm{F}}\right.$ and $\left.\mathrm{C}_{\mathrm{N}}\right)$ as in version 1 .

Version 4: The fourth version likewise applies the alternative approach of version 3 by defining the habitat component $\left(\mathrm{C}_{\mathrm{V} 1}\right)$ as a separate component in the final HSI computation. The geometric means are used for the intermediate foraging and nesting components $\left(\mathrm{C}_{\mathrm{F}}\right.$ and $\left.\mathrm{C}_{\mathrm{N}}\right)$ as in version 2 . 


\title{
Proposed Wading Bird Model for the Louisiana Coastal Area (LCA) Study
}

Foraging Habitat:

$\mathrm{SI}_{\mathrm{V} 1 \mathrm{f}}=1.0$

Long-Legged Wading Bird Group

\author{
, $\mathrm{V} 1 \mathrm{f}=$ one of suitable feeding habitats within foraging radius \\ Estuarine - Intertidal - (E2AB,E2EM,E2FO,E2SB,E2SS,E2US) \\ Riverine - Tidal - (R1AB,R1EM,R1UB,R1US) \\ - Lower Perennial - (R2AB,R2EM,R2UB,R2US) \\ - Intermittent - Stream bed (R4SB) \\ Lacustrine - Littoral - (L2AB,L2EM,L2UB,L2US) \\ Palustrine - (PAB,PFO,PEM,PSS,PUB,PUS) \\ , V1f $=$ otherwise
}

or $\quad \mathrm{SI}_{\mathrm{Vlf}}=($ density of category $\mathrm{k}) /($ max density $), \mathrm{V} 1 \mathrm{f}=$ category $\mathrm{k}$ habitat in current LCA study (multiclassed variable changes power)

Foraging Radius:

$$
\begin{array}{ll}
\mathrm{SI}_{\mathrm{Vlr}}=1.0 & , \mathrm{~V} 1 \mathrm{r} \leq 3 \mathrm{~km} \\
\mathrm{SI}_{\mathrm{V} 1 \mathrm{r}}=(10-\mathrm{V} 1 \mathrm{r}) / 7 & , 3<\mathrm{V} 1 \mathrm{r} \leq 10 \mathrm{~km} \\
\mathrm{SI}_{\mathrm{V} l \mathrm{r}}=0.0 & , 10 \mathrm{~km}<\mathrm{V} 1 \mathrm{r}
\end{array}
$$

Percentage of Land Area:

$$
\begin{array}{ll}
\mathrm{SI}_{\mathrm{V} 2 \mathrm{f}}=\mathrm{V} 2 \mathrm{f} * 0.025 & , 0 \% \leq \mathrm{V} 2 \mathrm{f}<40 \% \\
\mathrm{SI}_{\mathrm{V} 2 \mathrm{f}}=1.0 & , 40 \% \leq \mathrm{V} 2 \mathrm{f} \leq 60 \% \\
\mathrm{SI}_{\mathrm{V} 2 \mathrm{f}}=2.5-(\mathrm{V} 2 \mathrm{f} * 0.025) & , 60 \%<\mathrm{V} 2 \mathrm{f} \leq 100 \%
\end{array}
$$

Foraging Water Depth:

$$
\begin{array}{ll}
\mathrm{SI}_{\mathrm{V} 3 \mathrm{f}}=0.0 & , \mathrm{~V} 3 \mathrm{f} \leq 0 \mathrm{~cm} \\
\mathrm{SI}_{\mathrm{V} 3 \mathrm{f}}=\mathrm{V} 3 \mathrm{f} / 4 & , 0 \mathrm{~cm}<\mathrm{V} 3 \mathrm{f} \leq 4 \mathrm{~cm} \\
\mathrm{SI}_{\mathrm{V} 3 \mathrm{f}}=1.0 & , 4<\mathrm{V} 3 \mathrm{f} \leq 30 \mathrm{~cm} \\
\mathrm{SI}_{\mathrm{V} 3 \mathrm{f}}=(50-\mathrm{V} 3 \mathrm{f}) / 20 & , 30<\mathrm{V} 3 \mathrm{f} \leq 50 \mathrm{~cm} \\
\mathrm{SI}_{\mathrm{V} 3 \mathrm{f}}=0.0 & , 50 \mathrm{~cm}<\mathrm{V} 3 \mathrm{f}
\end{array}
$$

Colony Habitat:

$$
\mathrm{SI}_{\mathrm{Vlc}}=1.0 \quad, \mathrm{~V} 1 \mathrm{c}=\text { one of suitable nesting habitats for colony site }
$$

Estuarine - Intertidal - Scrub-shrub (E2SS) and Forested (E2FO)

Palustrine - Scrub-shrub (PSS) and Forested (PFO)

$$
\mathrm{SI}_{\mathrm{V} 1 \mathrm{c}}=0.0 \quad, \mathrm{~V} 1 \mathrm{c}=\text { otherwise }
$$

or $\quad \mathrm{SI}_{\mathrm{V} 1 \mathrm{c}}=($ density of category $\mathrm{k}) /(\max$ density $) \quad, \mathrm{V} 1=$ category $\mathrm{k}$ habitat in current LCA study (multiclassed variable changes power)

Nesting Water Depth:

$\begin{array}{ll}\mathrm{SI}_{\mathrm{V} 3 \mathrm{c}}=0.0 & , \mathrm{~V} 3 \mathrm{c} \leq 0.0 \mathrm{~m} \\ \mathrm{SI}_{\mathrm{V} 3 \mathrm{c}}=\mathrm{V} 3 \mathrm{c} / 0.6 & , 0.0<\mathrm{V} 3 \mathrm{c}<0.6 \mathrm{~m} \\ \mathrm{SI}_{\mathrm{V} 3 \mathrm{c}}=1.0 & , 0.6 \mathrm{~m} \leq \mathrm{V} 3 \mathrm{c}\end{array}$

Woody Vegetation Height:

$$
\begin{array}{ll}
\mathrm{SI}_{\mathrm{V} 4}=0.0 & , \mathrm{~V} 4 \leq 0.0 \mathrm{~m} \\
\mathrm{SI}_{\mathrm{V} 4}=\mathrm{V} 4 / 7.0 & , 0.0<\mathrm{V} 4<7.0 \mathrm{~m} \\
\mathrm{SI}_{\mathrm{V} 4}=1.0 & , 7.0 \mathrm{~m} \leq \mathrm{V} 4 \\
& \\
\text { roximity: } & , \mathrm{V} 5 \leq 1 \mathrm{~km} \\
\mathrm{SI}_{\mathrm{V} 5}=1.0 & , 1<\mathrm{V} 5 \leq 20 \mathrm{~km} \\
\mathrm{SI}_{\mathrm{V} 5}=(20-\mathrm{V} 5) / 19 & , 20 \mathrm{~km}<\mathrm{V} 5 \\
\mathrm{SI}_{\mathrm{V} 5}=0.0 &
\end{array}
$$

Colony Proximity:

Disturbance Factor (Distance):

$$
\begin{array}{ll}
\mathrm{SI}_{\mathrm{V} 6}=0.0 & , 0.0 \leq \mathrm{V} 6 \leq 0.5 \mathrm{~km} \\
\mathrm{SI}_{\mathrm{V} 6}=(\mathrm{V} 6-0.5) / 0.5 & , 0.5<\mathrm{V} 6 \leq 1.0 \mathrm{~km} \\
\mathrm{SI}_{\mathrm{V} 6}=1.0 & , 1.0 \mathrm{~km}<\mathrm{V} 6
\end{array}
$$

Foraging Component:

Habitat $\mathrm{C}_{\mathrm{Vlf}}$ - geometric mean of V1f and V1r (versions 1 \& 2): $\mathrm{C}_{\mathrm{V} 1 \mathrm{f}}=\left(\mathrm{SI}_{\mathrm{V} 1 \mathrm{f}} * \mathrm{SI}_{\mathrm{V} 1 \mathrm{r}}\right)$ or $\mathrm{C}_{\mathrm{V} 1 \mathrm{f}}{ }^{1}=\left(\mathrm{SI}_{\mathrm{V} 1 \mathrm{f}} * \mathrm{SI}_{\mathrm{V} 1 \mathrm{r}}\right)^{1 / 2}$

Habitat $\mathrm{C}_{\mathrm{V} 1}$ - geometric mean of V1c and V1f (versions $\left.3 \& 4\right)$ :

$$
\mathbf{C}_{\mathrm{V} 1}=\left(\mathrm{SI}_{\mathrm{V} 1 \mathrm{c}} * \mathrm{SI}_{\mathrm{V} 1 \mathrm{f}}\right) \text { or } \mathbf{C}_{\mathrm{V} 1}{ }^{1}=\left(\mathrm{SI}_{\mathrm{V} 1 \mathrm{c}} * \mathrm{SI}_{\mathrm{V} 1 \mathrm{f}}\right)^{1 / 2}
$$

Foraging component $\mathrm{C}_{\mathrm{F}}$ - arithmetic mean (version 1):

$$
\mathbf{C}_{\mathbf{F}}=\left(\mathbf{C}_{V_{1 f}}+\mathbf{S I}_{\mathrm{V}_{2 \mathrm{f}}}+\mathbf{S I}_{\mathrm{V} 3 \mathrm{f}}\right) / \mathbf{3}
$$

Foraging component $\mathrm{C}_{\mathrm{F}}$ - geometic mean (version 2):

$$
\mathrm{C}_{\mathrm{F}}=\left(\mathrm{C}_{\mathrm{V} 1 \mathrm{f}} * \mathrm{SI}_{\mathrm{V} 2 \mathrm{f}} * \mathrm{SI}_{\mathrm{V} 3 \mathrm{f}}\right)^{1 / 3}
$$

Foraging component $\mathrm{C}_{\mathrm{F}}$ - arithmetic mean (version 3 )

$$
\mathbf{C}_{\mathrm{F}}=\left(\mathrm{SI}_{\mathrm{V} 1 \mathrm{f}}+\mathbf{S I}_{\mathrm{V} 2 \mathrm{r}}+\mathrm{SI}_{\mathrm{V} 3 \mathrm{f}}\right) / \mathbf{3}
$$

Foraging component $\mathrm{C}_{\mathrm{F}}$ - geometic mean (version 4):

$$
\mathrm{C}_{\mathrm{F}}=\left(\mathrm{SI}_{\mathrm{V} 1 \mathrm{f}} * \mathrm{SI}_{\mathrm{V} 2 \mathrm{r}} * \mathrm{SI}_{\mathrm{V} 3 \mathrm{f}}\right)^{1 / 3}
$$

Final HSI - geometric mean of foraging and nesting components (versions 1 \& 2):

$\mathrm{HSI}=\left(\mathrm{C}_{\mathrm{F}} * \mathrm{C}_{\mathrm{N}}\right)^{1 / 2}$

Final HSI - geometric mean of habitat, foraging and nesting components (versions $3 \& 4$ ):

$$
\text { HSI }=\left(C_{V 1} * C_{F} * C_{N}\right)^{1 / 2} \text { or } \text { HSI }^{1}=\left(C_{V 1} * C_{F} * C_{N}\right)^{1 / 3}
$$

1 - Multiclassed habitat variables change the power in the geometric mean formula. 
Foraging Habitat:

$\mathrm{SI}_{\mathrm{V} 1 \mathrm{f}}=1.0$

$\mathrm{SI}_{\mathrm{V} 1 \mathrm{f}}=0.0$

or

Foraging Radius:

$\mathrm{SI}_{\mathrm{V} 1 \mathrm{r}}=1.0$

$\mathrm{SI}_{\mathrm{V} 1 \mathrm{r}}=(10-\mathrm{V} 1 \mathrm{r}) / 8$

$\mathrm{SI}_{\mathrm{V} 1 \mathrm{r}}=0.0$

, $\mathrm{V} 1 \mathrm{r} \leq 2.0 \mathrm{~km}$

, $2.0 \mathrm{~km}<\mathrm{V} 1 \mathrm{r} \leq 10 \mathrm{~km}$

, $10 \mathrm{~km}<\mathrm{V} 1 \mathrm{r}$

Percentage of Land Area:

$\mathrm{SI}_{\mathrm{V} 2 \mathrm{f}}=\mathrm{V} 2 \mathrm{f} * 0.025$

$\mathrm{SI}_{\mathrm{V} 2 \mathrm{f}}=1.0$

$0 \% \leq \mathrm{V} 2 \mathrm{f}<40 \%$

, $40 \% \leq \mathrm{V} 2 \mathrm{f} \leq 60 \%$

$\mathrm{SI}_{\mathrm{V} 2 \mathrm{f}}=2.5-(\mathrm{V} 2 \mathrm{f} * 0.025) \quad, 60 \%<\mathrm{V} 2 \mathrm{f} \leq 100 \%$

Foraging Water Depth:

$\begin{array}{ll}\mathrm{SI}_{\mathrm{V} 3 \mathrm{f}}=0.0 & , \mathrm{~V} 3 \mathrm{f} \leq 0 \mathrm{~cm} \\ \mathrm{SI}_{\mathrm{V} 3 \mathrm{f}}=\mathrm{V} 3 \mathrm{f} / 2 & , 0 \mathrm{~cm}<\mathrm{V} 3 \mathrm{f} \leq 2 \mathrm{~cm} \\ \mathrm{SI}_{\mathrm{V} 3 \mathrm{f}}=1.0 & , 2<\mathrm{V} 3 \mathrm{f} \leq 15 \mathrm{~cm} \\ \mathrm{SI}_{\mathrm{V} 3 \mathrm{f}}=(25-\mathrm{V} 3 \mathrm{f}) / 10 & , 15<\mathrm{V} 3 \mathrm{f} \leq 25 \mathrm{~cm} \\ \mathrm{SI}_{\mathrm{V} 3 \mathrm{f}}=0.0 & , 25 \mathrm{~cm}<\mathrm{V} 3 \mathrm{f}\end{array}$

Colony Habitat:

$\mathrm{SI}_{\mathrm{V} 1 \mathrm{c}}=1.0$

$\mathrm{SI}_{\mathrm{V} 1 \mathrm{c}}=0.0$

, $\mathrm{V} 1 \mathrm{c}=$ one of suitable nesting habitats for colony site

Estuarine - Intertidal - Scrub-shrub (E2SS) and Forested (E2FO)

Palustrine - Scrub-shrub (PSS) and Forested (PFO)

, $\mathrm{V} 1 \mathrm{c}=$ otherwise

or $\quad \mathrm{SI}_{\mathrm{V} l \mathrm{c}}=($ density of category $\mathrm{k}) /(\max$ density $) \quad, \mathrm{V} 1$ = category $\mathrm{k}$ habitat in current LCA study (multiclassed variable changes power)

Nesting Water Depth (preferred):

$$
\begin{array}{ll}
\mathrm{SI}_{\mathrm{V} 3 \mathrm{c}}=0.0 & , \mathrm{~V} 3 \mathrm{c} \leq 0.0 \mathrm{~m} \\
\mathrm{SI}_{\mathrm{V} 3 \mathrm{c}}=\mathrm{V} 3 \mathrm{c} / 1.0 & , 0.0<\mathrm{V} 3 \mathrm{c} \leq 1.0 \mathrm{~m} \\
\mathrm{SI}_{\mathrm{V} 3 \mathrm{c}}=1.0 & , 1.0 \mathrm{~m}<\mathrm{V} 3 \mathrm{c}
\end{array}
$$

Woody Vegetation Height:

$\begin{array}{ll}\mathrm{SI}_{\mathrm{V} 4}=0.6 & , 0 \leq \mathrm{V} 4<1.0 \mathrm{~m} \\ \mathrm{SI}_{\mathrm{V} 4}=0.8 & , 1.0 \leq \mathrm{V} 4<2.0 \mathrm{~m} \\ \mathrm{SI}_{\mathrm{V} 4}=0.9 & , 2.0 \leq \mathrm{V} 4 \leq 4.0 \mathrm{~m} \\ \mathrm{SI}_{\mathrm{V} 4}=1.0 & , 4 \mathrm{~m}<\mathrm{V} 4\end{array}$

Colony Proximity:

$$
\begin{aligned}
& \mathrm{SI}_{\mathrm{V} 5}=1.0 \quad, \mathrm{~V} 5 \leq 1 \mathrm{~km} \\
& \mathrm{SI}_{\mathrm{V} 5}=(20-\mathrm{V} 5) / 19 \quad, 1<\mathrm{V} 5 \leq 20 \mathrm{~km} \\
& \mathrm{SI}_{\mathrm{V} 5}=0.0 \quad, 20 \mathrm{~km}<\mathrm{V} 5
\end{aligned}
$$

Disturbance Factor (Distance):

$$
\begin{aligned}
& \mathrm{SI}_{\mathrm{V} 6}=0.0 \\
& \mathrm{SI}_{\mathrm{V} 6}=(\mathrm{V} 6-0.5) / 0.5 \\
& \mathrm{SI}_{\mathrm{V} 6}=1.0
\end{aligned}
$$

(Alternate - Percent Colony Area Flooded:

$$
\left.\mathrm{SI}_{\mathrm{V} 3 \mathrm{c}}=\mathrm{V} 3 \mathrm{c} / 100 \quad, 0 \% \leq \mathrm{V} 3 \mathrm{c} \leq 100 \%\right)
$$

\section{Nesting Component:}

Nesting Component - arithmetic mean (version 1): $\mathbf{C}_{\mathrm{N}}=\left(\mathbf{S I}_{\mathrm{V} 1 \mathrm{c}}+\mathbf{S I}_{\mathrm{V} 3 \mathrm{c}}+\mathbf{S I}_{\mathrm{V} 4}+\mathbf{S I}_{\mathrm{V} 5}+\mathbf{S I}_{\mathrm{V} 6}\right) / \mathbf{5}$

Nesting Component - geometic mean: (version 2):

$$
\begin{array}{ll} 
& \mathrm{C}_{\mathrm{N}}=\left(\mathrm{SI}_{\mathrm{V} 1 \mathrm{c}} * \mathrm{SI}_{\mathrm{V} 3 \mathrm{c}} * \mathrm{SI}_{\mathrm{V} 4} * \mathrm{SI}_{\mathrm{V} 5} * \mathrm{SI}_{\mathrm{V} 6}\right)^{1 / 4} \\
\text { or } & \mathrm{C}_{\mathrm{N}}{ }^{1}=\left(\mathrm{SI}_{\mathrm{V} 1 \mathrm{c}} * \mathrm{SI}_{\mathrm{V} 3 \mathrm{c}} * \mathrm{SI}_{\mathrm{V} 4} * \mathrm{SI}_{\mathrm{V} 5} * \mathrm{SI}_{\mathrm{V} 6}\right)^{1 / 5}
\end{array}
$$

Nesting Component - arithmetic mean: (version 3):

$$
\mathrm{C}_{\mathrm{N}}=\left(\mathrm{SI}_{\mathrm{V} 3 \mathrm{c}}+\mathrm{SI}_{\mathrm{V} \mathbf{4}}+\mathrm{SI}_{\mathrm{V} 5}+\mathrm{SI}_{\mathbf{V} 6}\right) / \mathbf{4}
$$

Nesting Component - geometic mean (version 4 )

$$
\mathrm{C}_{\mathrm{N}}=\left(\mathrm{SI}_{\mathrm{V} 3 \mathrm{c}} * \mathrm{SI}_{\mathrm{V} 4} * \mathrm{SI}_{\mathrm{V} 5} * \mathrm{SI}_{\mathrm{V} 6}\right)^{1 / 4}
$$

Final HSI - geometric mean of foraging and nesting components (versions $1 \& 2$ ):

HSI $=\left(C_{\mathrm{F}} * \mathrm{C}_{\mathrm{N}}\right)^{1 / 2}$

Final HSI - geometric mean of habitat, foraging and nesting components (versions $3 \& 4$ ): HSI $=\left(C_{V 1} * C_{F} * C_{N}\right)^{1 / 2}$ or HSI $^{1}=\left(C_{V 1} * C_{F} * C_{N}\right)^{1 / 3}$

1 - Multiclassed habitat variables change the power in the geometric mean formula. 